


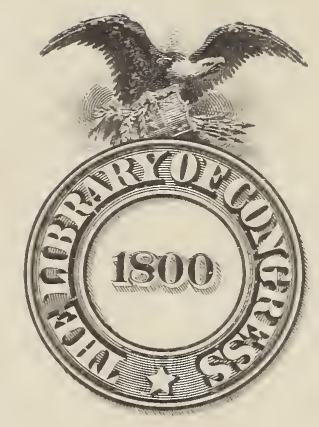










\section{A M E R I C A N}

\section{FLOWER-GARDEN DIRECTORY:}

CONTAINING

PRACTICAL DIRECTIONS FOR THE CULTURE OF PLANTS

IN THE

FLOWER-GARDEN, HOT-HOUSE, GREEN-HOUSE, ROOMS, OR PARLOR WINDOWS,

FOR EVERY MONTH IN THE YEAR.

W1TH

A DESCRIPTION OF THE PLANTS MOST DESIRABLE IN EACH, THE NATURE OF THE SOIL, AND SITUATION BEST ADAPTED TO THEIR GROWTH, THE PROPER SEASON FOR TRANSPLANTING, ETC.

WITH INSTRUCTIONS FOR ERECTING A

HOT-HOUSE, GREEN-HOUSE, AND LAYING OUT A FLOWERGARDEN.

THE WHOLE ADAP IED TO EITHER LARGE OR SMALL GARDENS.

WITH INSTRUCTIONS FOR PREPARING THE SOIL, PROPAGATING, PLANTING, PRUNiNG, TRAINING AND FRUITING THE

\section{G R A P E V I N E.}

WITH DESCRIPTIONS OF THE BESİ SÚR'AS FOR CULTIVATING IN THE OPEN AIR.

FOURTH EDITION, WITE NOMEROUS ADDITIONS.

BY ROBERT'BUIST,

NURSERYMAN AND SEED-GROWER.

PHILA DEL P H A:

A. HART, LATE CAREY AND HART.

1851. 
Entered according to the act of Congress, in the year 1851, by

A. HART, LATE CAREY AND HART,

in the Clerk's Office of the District Court for the Eastern District of Pennsylvania.

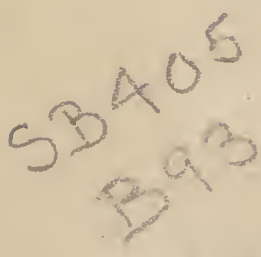

PHILADELPHIA :

T. K. AND P. G. COLLINS, PRINTERS. 


\section{PREFACE}

\section{TO THE FIRST EDITION.}

THIS volume owes its existence principally to the repeated requests of a number of our fair patrons and amateur supporters, whose inquiries and wishes for a practical manual on Floriculture at last induced us to prepare a work on the subject. That now offered is given unaffectedly and simply as a plain and easy treatise on this increasingly interesting: subject. It will at once- be perceived that there are no pretensions to literary claims-the directions are given in the simplest manner-the arrangement made as lucidly as was in our power-and the whole is presented with the single wish of its being practically useful. How far our object has been attained, of course our readers must judge. Nothing has been intentionally concealed; and all that is asserted is the result of minute observation, close application, and an extended continuous experience from childhood. We pretend not to infallibility, and are not so sanguine as to declare our views the most perfect that can be attained. But we can so far say that the practice here recommended has been found very successful.

Some, very probably, may be disappointed in not having the means of propagating as clearly delineated as those of culture; but to have entered into all the minutix connected 
therewith would have formed materials for two volumes larger than the present. We might have described that branch, as it has already been done in works published both on this continent and in Europe. In one of the former, it is said, "You may now propagate many kinds (Exotic Plants) by suckers, cuttings and layers, which should be duly attended to, particularly such as are scarce and difficult to be obtained." And the directions given in one of the most extensive works in Europe on the propagation of an extensive genus varied in character and constitution, run thus: "Cuttings of most kinds will strike root. From the strongestgrowing kinds, take off large cuttings at a joint, and plunge them in a pot of sand under a hand-glass in the bark bed. Of the smaller kinds, take younger kinds and put them under a bell-glass, also plunged in heat. The sooner the plants are potted off after they are rooted the better."

Such instructions to the inexperienced are imperfect and unavailing, which, we flatter ourselves, is not the character that will attach to the present work. We are well aware that there are persons who, to show their own superior abilities, may cavil and say that there is nothing new. To such critics it may be answered, if arranging, simplifying, digesting and rendering Floriculture attainable by the humblest capacity, with useful lists and tables on a plan quite novel, as we believe, offer nothing new, it may at least be called an improvement. However, we submit all to a generous public, to whom we are already under many obligations.

HIBBERT \& BUIST.

Philadelphia, Aprit 18th, 1832. 


\section{INTRODUCTION.}

WE are again called upon to present to the public the fourth edition of this popular work on the Culture of Flowers-a taste that is now widely disseminating itself; in fact, a knowledge of which is requisite before a refined education is completed. We boldly and fearlessly say that no country has made such rapid advancement in the art and science of Horticulture in so short a period as the United States. Wherever the taste prevails, it diffuses a peace and harmony among its participants without either symbol or mystery. In this edition, a feast of new materials has been served up; entire lists have been canceled and replaced with those of newer and finer forms and habits; extraneous matter and plants of indifferent character are dropped. The great and successful adaptation of Hot water to Horticultural purposes is explicitly described, and to those who wish to examine the results, we say "Come and see." A new and distinct list of hardy Evergreens has been added, and a new chapter on the ever-to-be-admired ROSE, and every improvement in the art up to this present time introduced.

True, we have not dilated on the wonderful effects of electricity upon vegetation, nor have we been extravagant in the results of guano in the growth of plants. With regard to the former, the capability of its reduction to general practice has yet to be proven - and the latter has to be 
cautiously used, and even then its beneficial effects are not universal. However, it can in a liquid state be used to advantage on almost any plant, especially those of strong habits, such as the Rose, Geranium, Fuchsia, Heliotrope, Chrysanthemum, \&c. To such, the following proportions will be rery beneficial: $1 \mathrm{lb}$. of guano to 5 galls. of water; after standing 12 or more hours, can be used in the routine of watering once a-week or even once in two weeks; but to plants that have more delicate and silky rootlets, such as Epacris, Erica, Azalea, \&c., the liquid must be reduced onehalf.

Our descriptions of plants have been conveyed more with the view of giving an idea of their character to the general reader than an accurate botanical synopsis, which would have been known to the botanist alone. All that we have described and recommended have, with a few exceptions, passed under our own observation, and are such as are worthy of cultivation, either for beauty of flower, foliage or habit, together with those celebrated in arts and medicine. Many may, possibly, have passed unobserved, either from their being very generally known or difficult to obtain; but in no case has there been suppression from business prejudices. Where the words "our collections" occur, they are meant for those of the country generally.

All our observations have been guided by dint of practice; and, although others may differ, this is designedly and professedly given as the result of our own experience. The plan laid down is our own routine of culture; the soils are those which we adopt; but, at the same time, conceding that every art and profession is subject to improvement, and none more so than American horticulture. The table of soils was originally constructed at the expense of much investigation and labor, and has, also, in this edition, undergone considerable improvement. To every one that has but a single plant 
it will be found invaluable. Although the publications in Europe on Gardening and Floriculture are profuse, yet many of their directions, when practiced in the United States, prove almost a dead letter. Not so with their architectural and horticultural designs. The estates of the wealthy are susceptible of great improvement; they want more of the picturesque, and (to use the words of the veteran pioneer of horticulture) gardenesque effect, to relieve their premises from the monotonous erections and improvements which seem to govern all. On culture, a work adapted to the climate must (and no other can) be the guide in this country: on this account, a work like the present has been a desideratum to aid the very rapid advancement of the culture of flowers among the intelligent of our flourishing republic.

ROBERT BUIST.

Philadelphia, October, 1850. 



\section{TABLE OF CONTENTS.}

FLOWER-GARDEN, LAYING OUT A . . . . . 13

\section{JANUARY。}

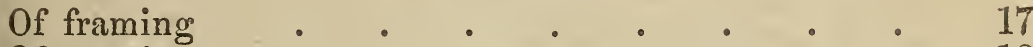

Of pruning . . . . . . . . . 18

FEBRUARY.

Of pruning $\quad . \quad$. $\quad$. . . . . . 19

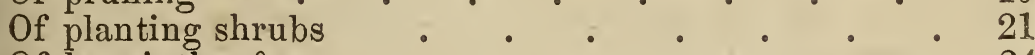

Of hyacinths, \&c. . . . . . . . 24

MARCH.

Of framing . . . . . . . . 25

List of choice annuals for hot-bed . . . . 26

List of choice hardy annuals . • . . . . 29

Box-edgings . . . . . . . . 31

Grass and other edgings . . . . . . 32

List of hardy biennials . . . . . . 33

List of hardy perennials . . . . . . 35

Bulbous roots . . . . . . . 47

Carnations, pinks, primroses, \&c. . . . . . 47

Auriculas . . . . . . . 48

Ranunculus and anemone . . . . . . 49

Roses. . . . . . . . . . 49

Roses, climbing . . . . . . . . 53

Deciduous, ornamental flowering shrubs . . . 53

Grass-plats and walks . . . . . . 54

Gravel-walks • . . . . . . 56

Of grafting . . . . . . . 56 
APRIL.

Annuals

Biennials and perennials . . . . . 58

Roses. . . . . . . . . . . 59

Hybrid Chinese roses . • . . . . 59

Select list of Chinese roses . . . . . 59

Hybrid roses, striped, spotted, or marbled . . . 61

Perpetual roses . . . . . . . . 61

Hybrid perpetual roses . . . . . . . . 63

Grafting roses . . . . . . . . 64

Bourbon roses . . . . . . . . 65

Bengal roses . . . . . . . . . . . 66

Tea rose . . . . . . . . . . . 69

Noisette roses . . . . . . . . . . 72

Musk roses . . . . . . . . 74

Climbing roses . . . . . . . . . 75

Microphylla roses . . . . . . . . 78

Climbing plants . . . . . . . . . 80

Deciduous shrubs . . . . . . . . . 83

Of planting evergreen shrubs . . . . . 84

Care of choice bulbs . . . . . . . . 85

Anemones and ranunculus . . . . . 87

Character of a fine ranunculus . . . . . 87

Auriculas . • . . . . . . . . 88

Character of a fine auricula . . . . . . 88

Carnations, pinks, \&c. . . . . . . . 88

Character of a polyanthus . . . . . . . 89

IIeart's-ease or pansy . . . . . . . 90

Gladiolus or sword lily . . . . . . . . . 92

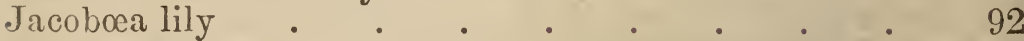

Tiger flower . . . . . . . . . . . . 93

Walks . • . . . . . . . . . 93

Evergreen hedges . . . . . . . . . 94

Box-edgings . • • • • . . . . 95

General care of plants coming into flower . • • • 96

$\mathrm{MAY}$.

Dahlia, propagation of, by cuttings . • . . 97

Dahlias, list of . •

Dahlia, character of . . . . . . 103

Annuals, hardy and tender . . . . . 104

Care of hyacinths and tulip . . . . . . . 105

Anemones and ranunculus . . . . . 105

Tuberose and amaryllis . . . . . $\quad . \quad 105$ 


\section{DECEMBER .}

General observations

\section{HOT-HOUSE.}

Constrection of a hot-house

JANUARY.

Of firing and fuel . $\quad$. . . . . . 134

Of watering the plants . . . . . . . . 135

Of insects-their destruction . . . . . 136

Of cleansing plants, house, \&c. . . . . . . 139

FEBRUARY.

Of insects, \&c. . . . . . . . . . 141

Of repotting plants $\quad . \quad . \quad . \quad . \quad . \quad . \quad .142$

Of cleansing plants, house, \&c. . . . . . 143

MARCH.

Of repotting plants

\section{APRIL.}

Repotting cacti, \&c. . . - . . . . 145

MAY.

Of repotting plants, \&c. . . . . . . 146 Of bringing out the hot-house plants . . . 174 Succulent plants, as cacti, \&c. . . . . . 175

JUNE AND JULY.

General observations . . . . . . . 176

AUGUST.

Repotting . . . . . . . . 177 Of painting, repairing, and cleansing the house $\quad \cdot \quad 177$ SEPTEMBER.

Dressing the plants . . . . . . . 177 Of taking in the plants . . . . . . 178 General observations . . . . . . 178 
OCTOBER.

General observations .

NOVEMBER.

Of air and water . . . . . . . . . . 180 General observations . . . . . . . . 181

DECEMBER.

Of shutters . $\quad . \quad . \quad . \quad . \quad . \quad . \quad . \quad .181$

Of bulbous roots . . . . . . . . . 182

General observations . . . . . . . 182

Epiphyte, or air plants . . . . . . 183

GREEN-HOUSE.

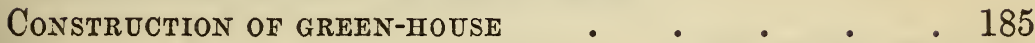

JANUARY.

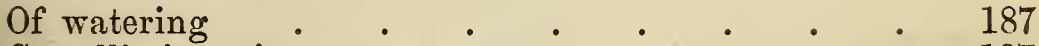

Camellia japonica . $. \quad . \quad . \quad . \quad . \quad . \quad . \quad 187$

Of oranges, lemons, \&c. $\quad . \quad$ • . . . . . 188

Of cape bulbs . . . . . . . . . 188

Of hyacinths and other bulbs . . . . . . 189

FEBRUARY.

Of oranges and lemons . . . . . . . . 190

Of cape bulbs . . . . . . . . . 190

Camellia japonica . . . . . . . . . . 191

Of shifting . . . . . . . . . . 192

Of cleansing, \&c. . . . . . . . . . . 193

MARCH.

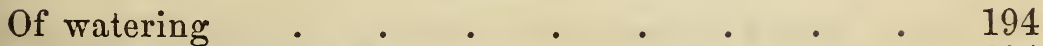

Of oranges, lemons, \&c. • . • . . . . . 194

Myrtles, oleanders, \&c. . . . . . . . 195

Geraniums • • . • . . . . 195

Herbaceous plants . . . . . . . 196

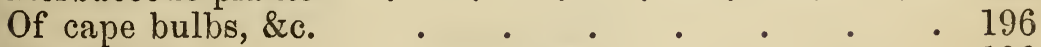

Repotting . • . . . . . . . 196

Of enarching, or grafting by approach . . . . 259 
APRIL.

Watering • • • • • • • • • 261

Oranges and lemons . . . . . . . . 262

Myrtles and oleanders . . . . . . 263

Geraniums . . . . . . . • . 263

Flowering plants . . . . . . . 264

Insects . . . . . . . . . 264

Flowering stocks . . . . . . . . 265

MAY.

Watering.$\quad \cdot \quad \cdot \quad \cdot \quad \cdot \quad \cdot 266$ Of bringing out the green-house plants . . . 266 Repotting plants . . . . . . . . 267 Camellias . . . . . . . . . . 269

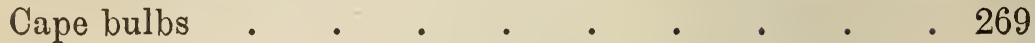

JUNE AND JULY.

General observations . • . . . . • . 269

AUGUST.

Geraniums . . . . . . . . . . 270

Oranges and lemons . . . . . . . . 271

Pruning oranges and lemons . . . . . . 272

Repotting plants . . . . . . . 273

General observations . $\quad . \quad$. $\quad . \quad$. $\quad 275$

SEPTEMBER .

Of watering . . . . . . . . 276

Preparing for taking in the plants . . . . 276

Stocks and wallflowers . . . . . . 276

Chrysanthemums . . . . . . • . 277

Cape and Holland bulbs . . . . . . 277

OCTOBER.

Of taking in and arranging the plants . . . . 280

Of repotting . . . . . . . . . 281

Camellias . . . . . . . . . 283

Sowing camellia seed $\quad . \quad$. $\quad$ • . . 284

NOVEMBER.

Of air and water . . . . . . . . . 284

Of tender bulbs . . . . . . . . . 285

General observations . . . . . . . . 285 
DECEMBER .

PAGE

Bulbous roots • • • • • • • • • 286

\section{ROOMS.}

Treatment of Plants in ROOMS $\quad . \quad \ldots \quad . \quad . \quad 287$

JANUARY .

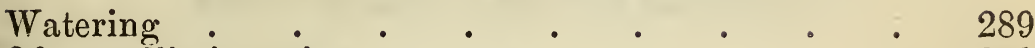

Of camellia japonica . . . . . . . 290

Of insects, \&c. . . . . . . . . . 290

Of bulbous roots in general . . . . . . . 291

FEBRUARY.

General observations . • • . . . . . 292

MARCH.

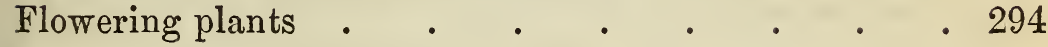

APRIL.

Directions for plants brought from the green-house . 295 Flowering plants . . . • • • . 296 Bringing plants out of the cellar . . . . . 296 MAY.

Cape bulbs . . . . . . . . . . 298

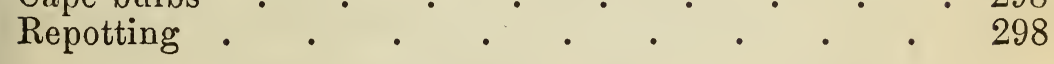

\section{JUNE AND JULY.}

General observations

\section{AUGUST.}

General observations

\section{SEPTEMBER.}

General observations

OCTOBER.

Of bulbous roots General observations 
NOVEMBER.

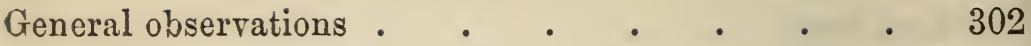

DECEMBER.

Roses . . . . . . . . . . . . 303

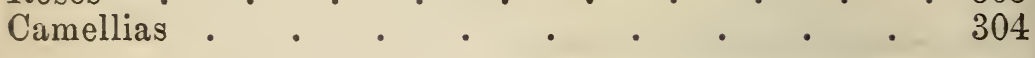

\section{CULTURE OF THE GRAPE VINE}

Aspect . . . . . . . . . . . 308

On soil . . . . . . . . . 308

On the propagation of vines . . . . . . 311

On erections for the support and protection of the vines in out-door culture . . . . . . 314

Of transplanting the vine . . . . . . 316

On pruning $. \quad . \quad . \quad . \quad . \quad . \quad . \quad 318$

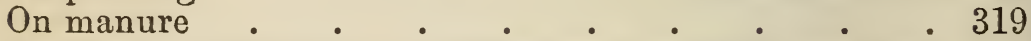

Descriptire catalogue of grapes most suitable for open air culture . . . . . . 320

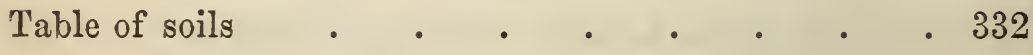

LISTS.

Hardy evergreens • • . • . • • 325 deciduous trees and shrubs . . . . 328 


\section{THE}

\section{AMERICAN FLOWER GARDEN DIRECTORY.}

\section{ON LAYING OUT A FLOWER GARDEN.}

The Flower Garden is chiefly devoted to the cultivation of showy flowering plants, shrubs, and trees, either natives of this country or those of a foreign clime: it is a refined ap. pendage to a country seat, "suburban" villa, or city residence; every age has had its principles of taste, and every country its system of gardening. Our limits do not permit us to enter minutely into the details of any of these sys. tems; but a few hints may not be out of place to those whose design is the laying out or improvement of the garden. The Italian style is characterized by broad terraces and paratlèle walks, having the delightful shade and agreeable fragrance of the orange and the myrtle. Terraces may be advantageously adopted to surmount steep declivities; and, if judiciously laid out, would convert a sterile bank into a beautiful promenade, or choice flower garden.

The French partially adopt the above system, interspersing it with parterres and figures of statuary work of every character and description. When such is well designed and neatly executed, it has a lively and interesting effect; but now the refined taste says these vagaries are too fantastic, and entirely out of place. A late writer says of Dutch gardening, that it "is rectangular formality :" they take great pride in trimming their trees of yew, holly, and other ever- 
greens, into every variety of form, such as mops, moons, halberds, chairs, \&c. In such a system, it is indispensable to order that the compartments correspond in formality, nothing being more offensive to the eye than incongruous mixtures of character.

The beauty of English gardening consists in an artful imitation of nature, and is consequently much dependent on aspect and locality. It is a desideratum, where wood and water can be combined with the flower garden, and the practical eye can dispose of an object to adrantage by interspersing shrubbery and walks, that the combined objects form an agreeable whole. They are not to be disposed with a view to their appearance in a picture, but to the use and enjoyment of them in real life.

We will now endeavor to give an explicit exposition of a system adapted to our variable climate of extreme heat and excessive cold. Where choice of aspects can be obtained, preference should be given to a south-east or east; but, if not, south or south-west, and, if possible, sheltered by rising ground or full grown woods from the north-west and north. But to lay down directions for a flower garden is not a little difficult, seeing that there cannot be any given area or any description of local circumstances applicable to all situations. A good soil is the sure foundation on which to rear the grand floral superstructure, and the most genial is a sandy loam: I mean by sandy loam a soil which contains from one-sixth to one-tenth of sand; and if on a gravelly or sandy bottom, so much the better. Where the general surface is gently undulating, it will greatly add to the beauty of arrangement; if access to a spring can be obtained, it will prove a desideratum in completing the whole: it can be arailable for a fish-pond or an aquarium, or can be converted into a swamp for the cultivation of many of our most beautiful and interesting native plants, such as Habanaria, Lilium, Sarracenia, Dionea, \&c., and on the margin of which (if partially shaded) can be planted the beautiful varieties of Azaleas, and the splendid flowering Rhododendron, which, by the by, are almost entirely neglected in all our floral decorations. With many, the arrangement of a flower garden is rather a matter for the exercise of fancy, than one calling for the application of refined taste: true, it may be said there is no mathematical law to guide the designer, so that 
if he avoid incongruity of arrangement the end is accomplished. But, in commencing these operations, a design should be kept in view that will tend to expand, improve, and beautify the situation; not, as we too frequently see it, the parterre and borders with narrow walks up to the very household entrance: such is decidedly bad taste, unless compelled for want of room. For perspicuity, admit that the area to be enclosed should be from one to three acres, a circumambient walk should be traced at some distance within the fence, by which the whole is enclosed; the inferior walks should partly circumscribe and intersect the general surface in an easy, serpentine, and sweeping manner, and at such distances as would allow an agreeable view of the flowers when walking for exercise. Walks may be in breadth from three to twenty feet, although from four to ten feet is generally adopted; and, to have these dry and permanent, those that are to be much used should have six to eight inches of the bottom soil dug out in a coneave manner, and in the centre of the concave dig out a trench of about nine inches square to form a drain, which may be made with brick or filled with rough stone, and the concave may be filled with refuse of buildings or broken stone within three inches of the desired height, which should be covered with gravel, and then firmly rolled with a heavy roller. Where the gravel cannot be obtained, sand may be used, mixed with a few small stones to bind it, but such needs very repeated rolling. Walks, such as described, when completely finished, will last for ages; but many will not be disposed to go to such expense; to those we say use tanner's bark, which is rery cheap, and accessible to all. The outer margin of the garden should be planted with the largest trees and shrubs; the interior arrangement may be in detached groups of shrubbery and parterres. In order that the whole should not partake of a uniform and graduated character, it should be broken and diversified by single trees planted in the turf, or arising in scattered groups from a base of shrubs. In some secluded spot, rock-work or a fountain, or both, may be erected; the foundation of the former should consist of mounds of earth, which will answer the purpose of more solid erections, and will make the stones go farther: rocks of the same kind and color should be placed together, and the greatest possible variety of character, size, and form 
should be studied, the whole showing an evident and welldefined connection. These erections generally are stiff, artificial, disjointed masses, and often decorated with plants having no affinity to their arid location. The undertaking, when well completed, will present a field of raried and interesting study, and more than compensate for the labour and expense bestowed upon it. If it is desired that the flower garden should be a botanical study, there should be some botanical arrangement adopted.

The Linnean system is the most easily acquired. A small compartment, laid out in beds, might contain plants of all the twenty-four classes, and a few of all the hardy orders, which do not exceed one hundred. Or, to have their natural characters more assimilated, the Jussievean system could be carried into effect by laying down a grass plat to any extent above one quarter of an acre, and cut therein small figures to contain the natural families, which, of harly plants, we do not suppose would exceed one hundred and fifty. The difficulties of this arrangement are, that many of the characters are imperfectly known, even to the most scientific. (See Professor Lindley's Introduction to Botany.) All the large divisions should be intersected by small alleys, or paths, about one and a half or two feet wide. When there is not a green-house attached to the flower garden, there should be, at least, a few sashes of framing or a forcing pit, to bring forward early annuals, \&c., for early blooming. These should be situate in some spot detached from the garden by a fence of Roses, trained to trellises, Chinese Arbor vitæ, Privet, or even Maclura, makes excellent fences; and, when properly trimmed, are very ornamental: they require to be neatly and carefully clipped with shears every September. In the Southern States, Noisette, Bourbon, and China Roses, with a profusion of Sweetbriar, would make the most beautiful of all fences, and could be very easily obtained: a fence three hundred feet long would only cost about one hundred and twenty dollars. Frames for forcing should be made of plank two inches thick, and well put together; the sash should be from five to seven feet long, and from three to four feet wide, and filled with six by eight glass. In the framing ground should be kept the various soils required for plants, and also various characters of manure at all times -ready for use, the whole in regular heaps, and kept free from 
weeds. Having given these brief outlines of a flower garden, we now proceed to give monthly directions for planting and keeping the same in order.

\section{JANUARY.}

IF the covering of the beds of choice bulbs, herbaceous plants, or tender shrubs, has been neglected last month, let it be done forthwith. The season is now precarious, and delays are dangerous. For particular directions, see December. Any bulbous roots that have been kept out of the ground, should be planted immediately, according to directions in October. Some writers have recommended keeping some of the bulbs until this month, in order to have a continued succession. Experience will prove the inefficacy of the plan, and will satisfactorily show that the difference is almost imperceptible, while the flowers are very inferior, and much degenerated; and, in place of having "a long-continued succession of bloom," there appear, along with your finest specimens, very imperfect flowers, calculated to discourage the admirers of these "gaudy" decoratives of our flower gardens. Whereas, every art employed should be to the advancement and perfection of nature.

\section{OF FRAMING, \&c.}

The plants and roots that are in frames, should be protected with straw, mats, and boards, and the frame surrounded with litter, or leaves, or, what is more advisable, banked with turf-the former being a harbor for mice and other vermin. For full directions, see December. Under this head, the plants, such as Auriculas, Polyanthus, Daisies, Carnations, Pinks, Pentstemons, Campanula pyramidalis, Double rocket, Double stock, or Stockgillys, Double Wallflower, Anemone, Ranunculus, \&c., as previously enumerated as frame plants, will require very little water, and be sure to give none while they are in a frozen state. If snow 
should cover them, the plants will keep in a fine state under it; so never remove snow from covering cold frames, even suppose it should lie for weeks-nature will operate here herself. But when framing cannot be obtained, they will, in this latitude, keep tolerably, if gently covered with leaves or litter, using means to secure them from being blown over the garden.

\section{OF PRUNING.}

It is not advisable to carry on a general system of pruning in this month, in whatever state the weather may be. The severest frosts, generally, are yet to come, and too frequently what is done now in this operation has to be repeated in the spring, causing, at that time, work to a disadvantage ; because, if pruning, when done just now, is accomplished judiciously, whatever more is requisite to be done in the spring on the same bush will be injudicious. Hence, it is far preferable to delay it till the frost is nearly over, when all can be done to advantage. There are, undoubtedly, hardy trees and some shrubs, that may be pruned and thinned out at any time from the first of November to the first of March; such as Cratægus, Sorbus, Spirea, and even Althea, in the Middle States; (the Double white Althea is very tender, and requires to be covered.) The tying together the loose branches of Juniper, Cedar, and Arbor vitæ should be particularly attended to, as heavy snow frequently destroys the shape of those handsome shrubs by breaking down the branches, \&c.-When the snow is heary, the precaution of shaking it off should be resorted to. In many seasons, the beginning of this month is open, and admits of the operation of digging in open quarters, which if not done, as advised last month, ought not to be delayed. The fruits of it will appear in the mellowed state of your soil in spring.

If there is any spare time, tallies, straight sticks, or stakes, may be prepared for summer use. Tie them up in neat bundles, which will be of great service during the hurried period of the year. An opportunity of this kind should always be laid hold of ; the beneficial results will, in season, be displayed. 


\section{FEBRUARY.}

WHEN the borders and various compartments were dug in the autumn, and compost, or a thin coating of well decomposed manure given, the advantage will now, in part, be experienced. If the weather is open about the end of the month, the pruning should be done with the utmost dispatch, that all may be prepared for a general dressing next month, and let nothing be delayed which can now properly be accomplished, under the idea that there is time enough.

\section{OF PRUNING, \&c.}

Generally, about the end of the month, the very severe frosts are over, and when none need be apprehended that would materially injure hardy shrubs, they may be freely pruned, and the points cut of such shoots as may have been damaged by the winter. Most of shrubs require nothing more than to be thinned of straggling, irregular, and injured branches, or of suckers that rise round the root, observing that they do not intermingle with each other. Never trim them up in a formal manner; regular shearing of shrubs, and topiary work, have been expelled as unworthy a taste the least improved by reflections on beauty, simplicity, and grandeur of nature.

In fact, the pruning of deciduous, hardy shrubs should be done in such a manner as not to be observable when the plants are covered with verdure. It may frequently be observed in flower gardens, that roses and shrubs of every description are indiscriminately cut with the shears, the Amórphas, Viburnums, and Altheas sharing the same fate.

Robinias, Colùteas, Cytisus, Rhuis, Genistas, with several of the Viburnums, and many others, bear their flowers on the wood of last year, and, when thus sheared, afford no gratification in flowering. And those shrubs that thus flower on the shoots of last year are perhaps worse to keep in regular order than those to which the knife can be freely applied; but good management, while young,.will ensure handsome, free, flowering plants. 
Climbing shrubs, and others that are trained against outbuildings, walls, or such as are sheltered thereby, and not now in danger of suffering by frost, may be pruned and dressed. These should be neatly trimmed, and the branches moderately thinned out, tying in all the shoots straight and regular. Avoid, at all times, the crossing of any shoots.

There is not a shrub in the garden that agrees so well with close cutting as the Althè a, and all its varieties. These can be made either bushes or trees, and kept at any desired height. Where the wood of last year is cut to about two or three inches from the wood of the former year, the young shoots of the coming season will produce the largest and finest flowers, and likewise more profusely. When they have attained the desired height, let them be kept in the most natural and handsome shape that the taste of the operator can suggest. They will bear cutting to any degree.

Honeysuckles, of every description, may, with all freedom, be trimmed, providing the frost is not very severe. These are very frequently allowed to become too crowded with wood, and then superficially sheared or cut. The flowers would be much finer, and the bush handsomer, if they were regularly thinned out, divesting them of all naked and superfluous shoots. Of those that remain, shorten the shoots of last year. Where any of the honeysuckle kind has become naked at the bottom, and flowering only at the top of the trellis, or extremities of the shoots, one-half of the bush should be cut to within four inches of the ground. It will throw out plenty of fine, young wood, which give room for, and train them straight, and to the full extent, during summer. These shoots will flower profusely the following season, and in like manner, when thought proper, the other half can be cut.

Roses of the hardy kinds (termed garden roses) that were not attended to in November, should, if the weather permit, be dressed and pruned forthwith. In small gardens, where these are generally attached to the walls and fences, neatness should be a very particular object. If any of such bushes have got strong and irregular, the most proper method to bring them to order will be to cut down each alternate shoot of the bush to within a few inches of the surface, thereby renovating it, and, in part, preserving the flowers. Those that are cut down will put out sereral luxuriant shoots, 
which must be regularly tacked in, spreading them in a fan shape. These, in another year, will flower well, when the others may go through the same operation. Thus, in two or three years, the bushes will have resumed'a different and more agreeable aspect. By the above treatment, these ornaments of the garden will always have a neat and healthful appearance, and the roses will be much finer. Where they are intended for the borders, they should never be allowed to get too high. In a border from four to six feet, they ought never to exeeed four feet at the back of the border, and in front one foot, after being pruned; they can be kept down by the above method. It is not advisable to cut down rose bushes all at once, unless no regard is paid to flowering. The roses that are in grass plats, and interspersed through the garden, would have a superior appearance in every respect, if they were kept and trimmed like small trees. They may be of different sizes and heights, according to the distance they are from the walk. A single stem may arise from six inches to six feet, with a head in proportion to the height of the stem. Where it is necessary to have them above two feet, and likewise to carry a good head, inoculation must be resorted to, which, in the months of July and August, will be fully treated of. All under two feet (except the weak growing kinds) will do on their own stems, taking care not to allow shoots to arise from the bottom during the summer. For directions for pruning climbing roses, see March and April.

\section{OF PLANTING SHRUBS, \&c.}

As soon as the frost is out of the ground, these should be planted, if the soil is not too wet. Where soil is binding, upon no consideration plant it while wet; rather defer it until the end of March.

Trees and shrubs, if they are well arranged, are the chief ornaments, give the most pleasure, and afford the greatest delight that we enjoy in our gardens. Although they give no sort of nourishment, nor produce any edible fruits, yet they are particularly grateful, and conducive to our enjoyments. Our walks in summer would be oppressive, but for their agreeable shade; in the fall and winter, we would be 
left exposed to the chilling winds, but for the shelter they afford.

Likewise, they produce a great variety of flowers, a varied foliage, and are standing ornaments that give no great trouble. In the character of screens, they are particularly useful, whether to hide disagreeable objects, or as a guard against the weather; or, if they are planted in masses at a distance; they soon become agreeable objects, frequently very much improve the scenery of the place, become objects of utility as well as ornament, and, in such case, afford the highest satisfaction. When formed so as to exclude offices from the view of the house, or for sheltering the latter, or for connecting the house with the garden, orchard, or any similar purpose, shrubs are both useful and interesting.

Where many shrubs are to be planted, the disposing of them properly is a matter of considerable importance to the future welfare of the whole; and, whether deciduous or evergreens be mixed or grouped, that is, indiscriminately planted together, or the evergreens planted by themselves, as is frequently done, a regular and natural arrangement is indispensable for establishing ornament.

Arranging, no doubt, depends very much on fancy; still, there ought always to be plenty of evergreens planted, that the whole may be more cheerful in winter.

If shrubberies were made to a great extent, the scencry would be much more varied and characteristic by grouping judiciously than by indiscriminately planting.

However, in small flower gardens and shrubberies, the latter has to be adopted. In such places, tall growing kinds should never be introduced, unless merely as a screen from some disagreeable object, for they crowd and confuse the whole. The dwarf and more bushy sorts should be placed nearest to the eye, in order that they may conceal the naked stems of the others. Generally, when shrubs are planted, they are small; therefore, to have a good effect from the beginning, they should be planted closer than they are intended to stand. When they have grown a few years, and interfere with each other, they can be lifted, and such as have died, or become sickly, replaced, and the remainder can be planted in some other direction. Keep them always distinct, one from another, in order that they may be the better shown off. But, if it is not desired that they should be more 
thickly planted than it is intended to let them remain, the small growing kinds may be six or eight feet apart ; the larger, or taller sorts, ten to twenty feet, according to the condition of the soil.

Thick masses of shrubbery, called thickets, are sometimes wanted. In these, there should be plenty of evergreens. A mass of deciduous shrubs has no imposing effect during winter; and, as this is not the proper season for planting evergreens (April, and the end of September, or first of October being best), small stakes can be placed in the destined spot. Planting in rows, or in any plan of a formal character, should, at all times, be avoided.

In planting at this season, observe that the roots are not much exposed to the air, especially if the wind be high and sharp ; but it is always better, if possible, to defer the business until good, mild weather. According to directions in November, the ground will be well prepared, and only requires a hole dug for the reception of the roots, which must be considerably larger, that the roots may not be in the least confined. Break the earth well at bottom, put in as much as will receive the plant from one to two inches (according to its size) lower than it has previously been in the Nursery. If any of the roots are bruised or broken, cut them off; then place the plant in the centre of the hole, breaking fine all the soil that is put in, at the same time shaking the stem a little; that the earth may mix with the roots; when full up, press all the soil down with the foot, that it may, in some degree, consolidate about the roots, and support the plant. Tall plants should have a good stake for support, and place a small bandage between the stake and stem of the shrub or tree, where the tie is made, to prevent the bark from suffering by friction. Observe, always, before planting, if the soil is not suitable, to supply that which is congenial to the nature of the intended plant. When shrubs or trees are to be carried to any distance, the roots should be carefully kept from air, by tying damp moss, straw, or mats about them, as circumstances will admit: the success, in part, depends on due attention being paid, to prevent the roots drying before planting. Although we have given the above directions for planting in this month, it will frequently occur that they can only be put into practice during the next, as this month is often the severest of the scason. 


\section{OF HYACINTH AND OTHER BULBS.}

Towards the end of the month, if the weather proves favorable, the covering should be partially taken off from the Hyacinths, Tulips, and other bulbous roots. It sometimes occurs that, by careless planting in the autumn, they are thrown above ground by the frost, especially if the ground is inclined to moisture, and they not being deep enough planted: if such is the case, cover them with decayed leaves, old tan, or soil, whichever is most convenient; if not done, the sun and air will overpower the bulbs, and although the fibres have hold of the ground, the flowers will be miserably weak.

\section{MARCH.}

As soon as the frost is entirely gone, uncover all plants O: shrubs that have been protected, preserving carefully such of the materials as will answer the same purpose next season. Cut off all decayed shoots, or such as have been hurt by the frost. The Lagerstrœmias will flower in greater perfection, if they are pruned closely; that is, cut the shoots of last year to within two or three eyes of the wood of the previous year, at the same time having regard to the regular and natural shape of the bush. Cut off the injured foliage of any of the erergreens that have suffered by the severity of the winter, but leave erery green part which is essential to the support of this kind of plants. It is expected that all pruning of the shrubbery is finished; if not, get all expeditiously done according to directions given in the preceding months. All work that can be done in this month should not be delayed, such as hoeing, digging, raking, and clearing away all leaves and litter of every description that have been brought or blown into the garden during autumn or winter. 


\section{OF FRAMING.}

Where it is desired to have the more showy annuals early in bloom, it is necessary to prepare a hot-bed frame, for the purpose of bringing them forward. It is time, about the first of the month, to collect and prepare manure for the desired hot-bed; and, as that operation, in many instances, is very imperfectly performed, a few observations on the subject may be useful.

Take three parts of fresh, hot stable manure, with one part of fresh oak leaves. Have a sufficient quantity to make the intended bed, or beds, from three to four feet high. Shake and mix up both together in a compact, conical heap, in order to encourage fermentation. If the weather is cold and windy, cover it with straw or leaves and boards, which is necessary to produce the desired effect. If fermentation soon takes place, it will need to be thoroughly turned over in eight or ten days. If any of it has become dry and musty from excessive heat, as you proceed, water the affected parts, pile all up neatly, and leave it protected in part as before. In five or six days more, it will have to be turned again, repeating it until the first extreme heat has been over. In neglect of this, the heat, after making up the bed, will be vehement for a week or two, frequently destroying the vegetative purity of the soil, and proving destructive to the seeds.

Allowing the manure to come to a lively heat, having no unpleasant, rancid smell, proceed to mark off your intended bed, running it east and west, as nearly as possible, measure your frame, and allow the site of the bed eight inches, each way, larger than the frame: at the corners, place a stick or rod perpendicularly. The ground ought to be higher than that around it, to prevent water from getting into the bed, which, if low, must be filled up; or, if supposed that water may lodge there, a little brushwood might be put under the manure, which would keep it from being inundated. The manure must be built up square and level, shaking, mixing and beating it regularly with the back of the fork. When you have it to the desired height (from two to three feet will be sufficient for annuals), leave the centre of the bed a little higher than the sides, thus allowing it more to subside. When finished, put on the frame and sash, or sashes, keep 
them close until the heat arises, covering them at night with mats or shutters. As soon as you feel the heat increased, give air by tilting the sashes a few inches, to let off the steam and stagnated air, observing to close in the afternoon, and cover at night. If the heat is violent, about half an inch of air might be left during the night. In about three days, if all has been properly attended to, the bed will be what is termed sweet. Then put in about six inches of fine garden soil; if heavy, mix a little sand with it. Spread it level, and, when the soil is heated through, sow in small drills, from one-eighth to an inch deep, according to the size of the seeds; cover with very fine, sifted soil. Some very small kinds do best when sown upon the surface. When sown, give gentle sprinklings of water until they come up, when it will be necessary to give air freely during the day, to prevent them from being weak, or damping off, which many of them will do if they have not air regularly admitted.

\section{A LIST OF CHOICE FLOWERING ANNUALS ADAPTED FOR SOWING ON A HOT.BED.}

Alyssum calycina, white, fragrant.

Argeratum Mexicanum, blue-flowered Argeratum.

Asclepias curassavica, swallow wort, orange and red-flowered. Aster Chinensis, China Aster, or Queen IIargarets, in great variety. The late imported German and Italian Asters are of extraordinary beauty.

Balsamina hortensis, Balsam, commonly called Ladies' Slipper.

Browallia alata, upright blue and white Browallia.

Cacalia coccinea, scarlet Cacalia, or Venus' Paint Brush. sonchifolia, orange Cacalia.

Calandrinia discolor, rosy purple, very pretty.

Celosia cristata, Coxcomb, two varieties, red and yellow. Centaurea Americana, American Sultan.

Clarkia elegans, elegant rose-colored Clarkia. pulchella, showy purple Clarkia. alba, white flowered Clarkia.

Cleome grandiflora, large lilac flowering spider plant. Clintonia elegans, elegant blue Clintonia. 
Collinsia bicolor, two-colored Collinsia. heterophylla, lilac and white.

Commelina colestis, blue flowering Commelina.

Dianthus Chinensis, China pink, many fine double varieties. Gomphrena globosa, red and white globe Amaranthus.

Hibiscus manihot, large yellow Hibiscus.

Africanus major, buff with black centre.

Helichrysum bracteatum $\}$ Xeranthemum lucidum $\}$ Yellow everlasting.

Lophospermum erubescens, $\left\{\begin{array}{l}\text { Pose-colored flowers like the } \\ \text { Digitalis, a fine climber for } \\ \text { arbors. }\end{array}\right.$

Loasa lateritia, $\left\{\begin{array}{c}\text { Orange red, an interesting, climbing plant, } \\ \text { blo }\end{array}\right.$ Malope alba, white flowering Malope.

__ grandiflora, large red flowering Malope.

Mathiola annua, all the varieties of ten week stocks should be industriously cultivated, and seed sown also in April and May for autumn blooming.

Maurandia Barclayana, blue flowering, $\int$ Climbing plants

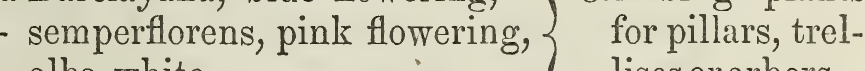
alba white,

Mesembryanthemum.

lises or arbors.

$\left.\begin{array}{l}\text { Mimosa pudica, Sensitive plant, } \\ \text { Mimulus Wheelerii, Monkey flower, yel- }\end{array}\right\}$ Will grow best crystallinum, Ice plant. low and crimson, Smithii, Smith's yellow and red, $\}$ in wet places.

- roseus, rose-colored,

Petunias of variety, a beautiful genus of plants, of cvery variety of color, from deep purple to pure white, blooming from June till frost; the seeds are small and require to be very lightly covered.

Phlox Drummondii and its varieties of crimson, rose, lilac, and white.

Portulaca splendens, splendid purple-flowered Purslane.

- Thorburnii, yellow.

alba, white:

- elegans, crimson.

Salpiglossis picta, atropurpurea, \&c., delight in a cool situation. 
Schizanthus retusus, orange-colored) Schizanthus, thus,

And a few other varieties,

Like a rich soil, and a cool and partially shaded situation.

Shortia Californica, yellow Shortia, very profuse flowering. Tagetes, Marigold, the new varieties of the French are very pretty-they like rich soil and plenty of moisture.

Tropæolum aduncum, Canary bird flower, a beautiful climber. tium.

Thunbergia alata, buff with black centre. atrosanguineum, crimson Nastur$\left\{\begin{array}{l}\text { Climbing } \\ \text { plants. }\end{array}\right.$ alba, white-flowered. aurantiaca, fine orange.

Verbena Defiance, Robertson's, bright scarlet.

Queen, pure white.

Beauty, supreme bright rose.

Perfection, pale-blue with white.

- Polkii, dark crimson purple.

Triumphant, crimson.

A lovely family of pretty and profuse flowering plants, generally of a procumbent habit.

Seeds may be obtained from the above, although they cannot be relied upon to produce the same colors.

Vinca rosea, Madagascar Periwinkle, ) Thrive best in a warm, alba, white flowered $\mathrm{Pe}$ riwinkle,

Zinnia elegans, splendid Zinnia. ) Very showy plants, and dry situation, with rich soil.

$\left.\begin{array}{l}\text { alba, white. } \\ \text { pauciflora jellow. }\end{array}\right\} \begin{aligned} & \text { are well supplied } \\ & \text { with water. }\end{aligned}$

Though the above will bloow much earlier by being sown on a hot-bed, yet where that convenience cannot be obtained, they will all succeed treated as hardy annuals.

After sowing, if the weather be clear, the sun acting on the glass will produce a too rapid evaporation of the moisture of the soil, and may otherwise affect seeds but thinly covered, which must be guarded against by shading with mats for a few hours during bright sunshine. In giving water, it ought always to be about mills-warm, and passed 
through a fine rose, to prevent the stems being broken or bruised. Weeds must be drawn out as soon as they appear.

\section{HARDY ANNUALS.}

Many annual plants, though of short duration, are pos-. sessed of much beauty of hue and elegance of form: they are farther valuable from their adaptation in filling up vacant spots through the flower garden or parterre. They are, besides, of easy culture, many requiring nothing more than to have the seeds sown in the spot where they are to grow. The first sowing may take place about the end of the month, when the ground is prepared and the weather fine; but avoid it at all times when the ground will not pulverize properly. The neatest and most expeditious method is to take a rod about one foot long and one inch in diameter, rounding at the end, with which draw a circle from four to nine inches in diameter, and from one-eighth of an inch to an inch deep, according to the size of the seeds. Many very small seeds will grow best, if sown on the surface of fine mould. When sown, cover with fine mould, placing a small twig or tally, with the name, in the centre of the circle to prevent mistakes, either in sowing, planting, or hoeing. When they have grown from one to two inches, the first moist day should be taken to remove such as are too crowded, which can be generally transplanted to some other situation; taking care to shade them a few days, with flower-pots, or some other substitute. A ferw kinds do best with removing, such as Balsams, China Asters, Marigold, ten week stocks, Hibiscus, Zinnias, and several others of a free-growing and strong-wooded nature. Annuals are such plants as grow from seed, flower and perfect their productions, and then die within one year. The following sorts are well deserving of culture:-

Adonis miniata, Flos Adonis or Pheasant's eye, red. Amaranthus caudatus, Love lies Bleeding, red and yellow variety.

hypochondriacus, Prince's Feather, red. 
Amaranthus tricolor; three-colored Amaranthus should be sown on rather poor soil-zon rich soil it has little beauty.

Brachycome iberidifolia, fine dark blue.

Brugmansia Waymeria, double-flowered, large and showy.

Centaurea moschata, purple sweet Sultan.

cretica, white sweet Sultan.

- suaveolens, yellow sweet Sultan.

Collinsia grandiflora, blue Collins' flower.

Convolvulus, minor, dwarf blue Bindweed.

Calliopsis bicolor, formerly Coreopsis tinctoria, or Fair Eye;

a very gay plant, and flowers best when sown in October.

Crepis rubra, red Hawkweed.

Drummondii, yellow calliopsis.

- aurea, golden Hawkweed.

Delphinium ajacis, Rocket Larkspur, many varieties, all staperb, and do best to be sown in rich ground in October.

consolida, branching Larkspur, various colors.

Euphorbia variegata, variegated Euphorbia.

Eschscholtzia crocea, Orange. (Now chryseis.) Californica, yellow.

Erysimum Perowffskyanum, bright orange.

Gilia tricolor, three-colored Gilia, )

_ capitata, blue-colored, $\left.{ }_{\text {Achillæfolia, large blue, }}\right\}$ Bloom all summer.

Heliophila Araboides, blue sun love, very pretty.

Hieracium meutabilis, changeable Hawkweed.

Helianthus Californicus, superb double dwarf sunflower.

Iberis amara, white Candytuft.

- umbellata, purple Candytuft.

violacea, violet Candytuft.

odorata, white sweet-scented Candytuft.

Ipomoea quamoclit, Cypress vine, the seed will grow freely, if soaked two or three hours in hot water. alba, white.

Lathyrus odoratus, sweet Pea, of many varieties.

Leptosiphon densiforus, dense-florrered Leptosiphon.

Ioasa lateritia, orange-colored Loasa, a climbing plant.

Lupinus, many varieties; they require to be partially shaded from hot suns. 
Malope grandifiora, scarlet Malope.

- alba, white.

Mirabilis jalapa, marvel of Peru, many varieties. If the roots of this plant are lifted in October, and placed in a dry cellar, free from frost, and planted out next April, they will bloom much finer.

Nemophila insignis, or blue Grove Love, a pretty dwarf plant, requiring rich soil and a half-shaded situation.

atomaria, white with black spots. maculata, spotted, beautiful.

Nigella Damacene, Love in a mist.

Hispanica, Spanish, blue and brown.

Enothera, or tree Primrose; many varieties of the annual

species produce their flowers in much greater perfection, if planted or sown in poor soil. To this, ansiloba, sinuata, and tetraptera are exceptions, as they flower the finest in a rich, light loam.

Papaver Marseillii, double white poppy, edged with red.

gigantea, large Dutch poppy.

Phlox Drummondii, many colors; a superb article, and blooms from May till October. In dry situations, it is apt to die off unless partially shaded.

Reseda odorata, Mignonette; to have it in perfection the whole season, there should be a sowing in May and July. It delights in a rich, loamy soil.

Tournefortia heliotropoides, summer Heliotrope.

Viscaria oculata, violet viscaria.

Viola tricolor, Pansy or Heart's-ease, require very rich soil, and should be shaded from hot sun; if sown early in the season, they will flower profusely in the autumn.

For other varieties of Annuals, see list adapted for hot-bed sowing. We have omitted many not agreeing with our climate, or those very common; for such, we refer our readers to the lists published annually by respectable seedsmen.

\section{BOX EDGINGS}

Niay be planted any time this month, or beginning of next, which in most seasons will be preferable. We will 
give a few simple directions how to accomplish the work. In the first place, dig over the ground deeply where the edging is intended to be planted, breaking the soil fine, and keeping it to a proper height, namely, about one inch higher than the side of the walk; but the taste of the operator will best decide, according to the situation. Rake the surface even, and tread it down with the feet, or beat it with the spade. Where it gives most, continue to add, keeping the surface at the desired height. If the edging is to be in a direct line, either on a level or inclined plane, you may be correctly and simply regulated by making the desired level at each end of the line. Take three rods, about four feet long each, having a piece of one foot to cross at one end, two of these pieces painted black, the other white. Have a black one at each end of the line on the level; take the white one for the centre, going along the line, and, about every twenty feet, level a spot to the exact height, which will be seen by looking over the top of the rods from one end. Having found the level, drive in a peg to it, so that no mistake may occur; beat and level between them, leaving a smooth surface. This being done, strain the line, and with the spade proceed to cut out the trench perpendicularly on the side next the walk, six, eight, ten, or twelve inches deep, according to the length of the plants. Afterwards take the plants, and cut the tops even, with the knife or shears, at the same time shortening the roots. Then with the left hand next the line, plant forward, Jeeping the tops of the plants level, and from one to two inches above ground, keeping the plants close, according to the required thickness. Put in the earth as you proceed, and tread it firm, then rake the surface eren, and with the spade beat it smooth. If the weather sets in very dry, the box will be the better of a few waterings. Sometimes boxwood is planted without roots, but it seldom gives satisfaction; not growing equally.

\section{GRASS AND OTHER EDGINGS.}

Grass verges for walks and borders, although frequently used, are by no means desirable, except where variety is required; they are the most laborious to keep in order, and at best are inelegant, and the only object in their favor is 
their being everywhere accessible. Tris humilis, Viola tricolor, thyme, Sea Pink (Stattice Armeria), Mignonette, Phlox subulata, and Phlox procumbens, all make tolerable edgings. In the Southern States, Euonymus Japonica, kept closely sheared, will make a very handsome green edging.

\section{HARDY BIENNIALS.}

Biennial plants are such as are of two years' duration. Being sown this year, they flower, seed, or fruit next year, and soon after decay: the seeds should be sown about the end of this month or beginning of next, either in the spot where they are to remain or a compartment by themselves, regularly marked, and to be transplanted in May or September. When they appear above ground, thin them out distinctly, that, when they are to be removed, a little earth may adhere to them: and, if sown where they are to stand, leave only three or four plants in each patch. The following list are a few of the free-blooming and more elegant sorts :-

Agrostemma coronaria, Rose Campion, blooms all summer. Althea rosea, Hollyhock, and all its varieties, very showy in July and August. When any very desirable variety is procured, it can be multiplied by dividing the root. Antirrhinum majus, Snap-dragon, and its varieties, require

to be protected during winter with a few leaves or litter.

Cantua coronopifolia, flowers in August and September, beautiful scarlet, delights in dry, gravelly soil.

Ipomopsis elegans.

Campanula media, dark blue Canterbury bell,

Campanula media, semi-pleno, half double

Canterbury bell,

Campanula media, alba, white Canterbury

bell,

Campanula thyrsoides.

Bloom in June and July.

Cheiranthus cheiri, Wall-flower, should be protected by leaves or boards during winter.

Digitalis purpurea, purple Foxglove.

alba, white Foxglove. 
Digitalis guttata, spotted Foxglove.

Dianthus barbatus, Sweet William pink.

- coccineus, crimson pink.

fl. pl. double-flowered; the double surts can be propagated by laying, same as carnations.

Gerardia purpurea, purple Gerardia, - quercifolia, spotted flowered Gerardia, $\left\{\begin{array}{l}\text { this } \\ \text { try. }\end{array}\right.$

Hedysarium coronarium, red-flowered French Honeysuckle. Humea elegans, scarlet Humea, flowers in June and September.

Lunaria biennis, Honesty, various colors; not beautiful, but curious in sced.

Anothera corymbosa, dwarf Evening Primrose.

Papaver nudicaule, naked-stemmed yellow Poppy.

Scabiosa atropurpurea, musk-scented Scabious.

Silene multiflora, many-flowered Catch-fly.

There might be many other beautiful biennial plants enumerated, which are justly considered worthy of attention; but most of them do not withstand the severity of our winters, although very much prized in England.

\section{PERENNIALS.}

In every flower garden, there ought to be a good selection of these plants. They are lasting ornaments; and, when judiciously selected, will give yearly gratification. In making a choice, a view should be to have those that flower abundantly, are of free growth, beauty, and continuation of bloom. It would go beyond our limits to give an extensive description of any, but a few remarks on some of the fuest, with their names, are indispensable.

Adònis vernátis is a fine border flower, and will grow in any common soil; flowers large, yellow-rayed, having in the rays about trvelve petals; leaves much divided; blooms in April and May.

Anemóne, Wind-flower. Several fine species, with flowers from one to three inches in diameter, very celebrated in Europe, though succeeding poorly with us except in cool lati- 
tudes. A. alpina, large white. A. japonica, rosy purple. A. palmàta fiòre-plèno, yellow; A. stellàta versícolor, various colored; A. pavonina fiòre-plèno, scarlet; A. narcissi-fiòra, white. Any of these are very desirable.

Antirrhinums, Snap-dragon. All the varieties of $A$. màjus are esteemed in the flower borders; the pure white, bright red. rich crimson, and variegated are very showy. A few of the species, $A$. málle and $A$. siculum, where there is variety required, deserve a situation. The flowers are all large, and similar to the snout of an animal.

Anthèricum liliástrum, St. Burnos Lily, is an excellent liliaceous plant, with orange-yellow flowers, blooming in June, July and August, and will grow in any common garden soil.

Asclèpias. The finest of this genius are native plants, and are highly esteemed in Europe, but frequently rejected with us, because "they are wild plants." A. tuberòsa has beautiful orange flowers, and delights in dry situations. $A$. rùbra, $A$. nevía, $A$. purpuráscens; and $A$. incarnàta are the finest of the family. It is best to plant $A$. tuberòsa in October.

Aconitums, Wolfsbane, one hundred and twenty-eight distinct species, with several varieties. Many of them are of consequence and beauty; the flower-stems rise from one and a half to six feet upright, and strong, furnished with many palmate and digitate leaves, terminated by spikes of blue, yellow, or white flowers, similar to a hood; hence the name of Monk's Hood is often applied to them. They are scarce in collections; but, in a few years, we have no doubt but many of them will be plentiful. The finest species are $A$. speciòsum, $A$, sieboldii, large dark blue, $A$. pyrenaiacum, branching blue, $A$. napèllus, A. venústum, $A$. pyramidàle, A. lycótonum, A. versícolor, or variegatum, and A. grandiforum. They flower from May to September, and will grow in any common garden soil. The roots of $A$. napéllus are like small turneps, and are poisonous. They like a little shade and rich soil.

Béllis perénnis horténsis, Daisy. We might almost say with another, "Every one knows the Daisy." It is named from being pretty, and is perfectly hardy, though generally kept under cover. They delight to have a shaded situation during summer, to protect them from the sun, which, as it 
were, scorches the roots. There are many double varieties in the gardens, which flower early. The one called Crown or Camation Daisy is twice the size of the common varieties, and has white and red petals alternately and very double. Loamy soil; inclined to moisture, is best adapted to their growth.

Campánula. This genus affords very many ornamental plants for the Flower garden and Shrubbery, and they flower superbly during the summer, agreeing better with our climate than with that of Europe. Many have two successions of flowers, C. persicifòtia álba pléna; C. persicifòtia coerùlea pleno; C. urticifolia, white. Of this last, there is also a double variety. C. speciòsa; 'C.' glomerata; C. versicolor, with several others, are worthy of a situation in every garden. Their roots are strong, fleshy and fibrous. They are easy of culture, and will retain their situation in the severest of our winters. C. grandiflòra is now Wahlenbérgia grandiflòra. It has superb large blue flowers, stems are slender, and should be supported as soon as they grow.

Cheirainthus Chérivi vulgàris is the common garden Wallflower. There are about ten rarieties of it, all admired for their rarious colors and agreeable odor. The common variety survires the mildest of our winters. The most esteemed rariety is hocmánthus, Double bloody. They should all be protected by a frame. C. mutátilis is a beautiful species; it has many shades of color, from lilac to dark purple. The flowers are on extending racemose spikes; blooming from April to June; it requires a light rich soil ; is a half-shrubby evergreen plant.

Chélone. This genus belong's entirely to this continent, and possesses many fine species. It is a matter of astonishment that they are not more cultivated and sought for in our collections. C. glábra; C. obliqua; C. barbàta; $C$. atropurpùrea; C. pulchélla; and C. speciòsa; are all handsome, and flower from May to September ; corolla large, ringent, ventricose; flowers in spikes or panicles.

Chrysinthemums. There are few of this genus of any consequence as herbaceous plants, except the varieties of C. sinense, of which there are about ninety, all desirable; but in small gardens, where there is a deficiency in room, the following are select in color and quality: Admiration, yellow; Celestial, pale blush; Coronet, white; Defiance, 
lemon yellow; King, pale rose; Perfection, lilac; Queen, blush; Triumphant, buff and white; Wm. Penn, large creamy white, yellow and red; Indica rubra, very dwarf early red; Angelina, rose; Beauty, lilac; Empress, pink; Napoteon, crimson; Mrs. Cope, crimson purple; Mrs. Camerson, bronze. To grow these in perfection, they require rich light soil; and about the end of this month the roots should be lifted, divided, and planted into fresh soil, either by giving them a new situation, or changing the earth they were in. Two or three stems together are quite sufficient. The flowers, by the above treatment, will be much larger, more double, and finer in color; where they are wanted to grow low and bushy, top them in June, but not later than the first of July. Where the soil is rich, and the plant having only one stem, by topping it, makes a beautiful bush. They are in flower from the first of October until severe frost; thus beautifying our gardens at a season when they would be destitute of one single attraction. If the season be dry, to water them with liquid manure will add to their vigor. They are all natives of China, and greatly esteemed by the Chinese, who only allow a few blooms to come out on the top of each stem, thereby having the flowers much finer.

Within these few years, hundreds of varieties of this winter flower have been produced from seed in Europe; many of them very superb, having more luxuriant foliage and greater diversity of color.

Clématis, Virgin's-bower. A few species are good herbaceous plants, of upright growth and blue flowers, C. integrifólia; C. angustifolia; and C. erécta; they grow best in light soil.

Coréopsis, chiefly native plants, and free-flowering; color principally yellow; flowers rayed. C. tenuifolia, C. verticilláta, C. díscolor, and C. tripteris, are the finest of the genus, and will grow in any common garden soil.

-Delphiniums. There are some showy border flowers of these, of strong growth. The leaves are much divided; the flowers in terminal spikes; color blue, purple, pink, white and yellow, with various shades. D. grandiflorum, and its varieties, are the best of the genus. D. intermedium, and its varieties, D. elitum, Bee Larkspur, from the ringent part of the flower being very like a bee, and $D$. montínum, are good varicties, and easily cultivated. When the 
plants become large, they ought to be divided, and planted in fresh soil. They are in bloom from May to September.

Dianthus. Some of the species of this genus are the most prominent of the flower garden, not only for their beauty, but also their fragrance, which is peculiarly grateful, especially in the well-known and celebrated Pink and Carnation, with the Sweet William, which was esteemed in the days of old "for its beauty to deck up the bosoms of the beautiful, and garlands and crowns for pleasure." The finest species are $D$. barbàtus and $D$. barbàtus plèno, Sweet William; $D$. discolor; $D$. chinènsis; $D$. alpinus; $D$. supérbus; $D$. caryophyllus, from which have originated the Picotee and the Carnation; D. plumàrius, from which originated the Double Pink. Several of these, although they will stand the severest cold, have to be protected in frames during winter, to have them in the perfection of beauty. For the character of a Pink and Carnation, see May.

Dictámnus. Two species of this genus, D. fraxinélia and $D$. álbus, have been cultivated and esteemed upwards of two hundred and forty years. A plant of the first of these species, when gently rubbed, emits an odor like that of lemonpeel; and when bruised emits a balsamic scent, which is strongest in the pedicles of the flowers. They have glands of a rusty color, that exude a viscid juice, or resin, which exhales in vapor, and in a dark place may be seen to take fire. Its flowers are red, those of the other white, in loose terminal spikes; the flower has five petals, clawed and unequal, with glandular dots; in bloom from May to July; delights in sandy loam.

Dodecatheon. This is a native genus, and commonly called American cowslip. The generic term, a name of the Romans, signifying twelve gods or divinities, is applied with great absurdity to a plant, a native of a world the Romans never saw nor bad any idea of ; neither resembling in any particular the poetical fancy of their writers. The nost admired species is $D$. mèdia; the flowers are in umbels, on a pedicle, from six to twelve inches high; the corolla is rotata reflexa, color light purple, bottom of petals lake and yellow; blooming in May. The white variety is very much esteemed, and surpasses the preceding. The ground is pure white, the bottom of the petals the same as the other. 'There is also a spotted variety found on the banks of the Missouri. They 
delight in brown loam, a half shady situation, inclining to moisture. The foliage soon decays after flowering.

Dracocéphalum, Dragon's Head, about twenty species, mostly ornamental. $D$. virginicum is a profuse blooming plant, with bluish-pink flowers, and grows about four feet high. D. argunénse is a superb dwarf, with large dark blue flowers.

Eupatóriums. These generally are native plants, not worthy of notice here, except for two species. $E$. coclestinum has syngenesious flowers in flattened panicles, color fine light blue, blooming from September to November, desirable for its beauty at that season. E. aromàticum may be cultivated for its spicy odor; flowers white, in loose terminal panicles ; blooming from August to October. Either of them will grow in common soil.

Funteia, Japan Day Lily, three species, all beautiful. $F$. coerùtéa, with blue flowers. $F$. japónica, pure white, and $F$. variegata, with striped leaves and flowers. $F$. laurifolia, early blue. This genus has been separated from Hemerocállis.

Gentiánas, a genus of very showy plants, and flower in great abundance. The flowers are tubular and inflated; color generally blue. A few species are yellow, and some white; flowers in whorls, terminal or solitary. They grow best in a light rich soil. G. luitea, G. purpurea, $G$. septémfida. G. acaúlis is a pretty dwarf growing species, the flower dark and light blue; interior of the corolla spotted; has a succession of flowers from April to June. These are fine exotics, but may give place to our native species, such as G. Catesbær; G. ochrolenca; G. incarnata; with several others, and G. crinàta, which is a biennial, and finely fringed; color light blue.

Gevm. There are only four species that are worth cultivation, namely, G. quéllyon, once G. coccíncum ; G. splendens, G. Wicea, and G. hybridum. G. urbannum is sometimes cultivated for its roots, which, when chewed, sweeten the breath. They are all of easy culture. G. quellyon and splendens flower from May to October, and are very desirable plants for the borders, and much esteemed in Europe.

Hemerocállis, Day Lily; three species, H. fúlva, H. graminea, and H. Sieboldii, flower well, and are remarkable among the border flowers for their large yellow or copper- 
colored corollas, some of them about six inches in diameter; bloom from May to July, and will grow in almost any soil. There is a plant known in our gardens as H. coerillea, which is Funkia coeritlea, and has a campanulate corolla, with a cylindrical tube; flowers in spikes; leaves ovate, acuminate.

Hibiscus. There are several herbaceous species very showy and handsome, $H$. palústris ; $H$. ròseus; $H$. milititàris ; H. speciòsus; H. grandiflòrus; and H. puingens. They grow best in moist situations, and where these are not to be had, give them plenty of water, and plant in sandy soil enriched with decayed leaves. The flowers are about six inches in diameter, flowering up the stem, either solitary or in small bunches. H. speciòsus is the most splendid, and deserves a situation in every garden. The roots in winter ought to be covered with litter, tan, or saw-dust; but a better method is to lift them, and put them in the cellar, covered with dry earth, and kept from the frost. All the above-mentioned species are improved by being protected during winter.

Iris, Flower-de-lis, has many fine species of various shades and colors, I. subiflora, I. nepalénsis, I. Pallàsii, I. pállida, I. cristàta, I. arenària, I. furcàta, I. germánica, I. florentìna, I. verna, and I. susiàna. The last is the finest of the herbaceous species; the flowers are very large and curiously spotted with brown; it stands the severest of our winters unprotected. The root of $I$. florentina is the orris root of the druggists, They are all of easy culture in any loamy soil inclining to moisture. The bulbous species will be treated of in September or October. Corolla six-petaled, three crect and three reclined alternately; proceeding from spathes or sheaths with flowers in succession.

Liatris is a genus of native plants, containing several fine species, L. squarròsa, large purple heads of beautiful flowers; L. élegans; L. paniculàta. L. macróstachya, now L. spicàta, is a fine large growing species. They have syngenesious purple flowers in long close spikes, differing from other spiked flowering genera by blooming first at the extremity. 'They grow best in strong heary soil.

Lychnis. Three species are very desirable in the flower borders. L. chalcedónica has bright scarlet crowned flowers; the double scarlet variety is splendid; there is also a double 
white variety; $L$. fúlgens and $L$. flós-jòvis. They ought to be frequently lifted and planted afresh, or they will dwindle to nothing. The best time is when they begin to grow. There is a plant known in our collections as Lychnis flóscuiculti, ragged Robbin or French Pink, which is now Agrostémma flós-cucùli; it is a fine and showy border plant with double red flowers; a double white variety of it has been recently introduced of the same character, with the additional quality of blooming the whole season. They delight in a light rich soil.

Lythrums. A few species flower well, and have small pink blossoms in great profusion, $L$. alàtum, $L$. virgàtum, $L$. diffusum, L. roseum, and L. lanceolàtum. They will grow in any common garden soil if not too much shaded; and flower from June to September.

Mimuilus, Monkey-flower. A few species may be cultivated. They will grow in any soil or situation. M. lìteus and M. rivulàris are the best. M." moschátus has a very strong musk scent, to many agreeable. The former two have large gaping flowers, of a golden yellow, and beautifully spotted with purple in the interior; they all grow in moist situations.

Monárdas, a fine native genus, and showy. The foliage of several of the species is aromatic, and resembles mint. $M$. didyma has long scarlet ringlet flowers, in headed whorls; M. Talmiana, flowers very long, and a beautiful crimson, with fragrant leaves. M. Russelliana has red and white flowers; curious and handsome. M. punctata has yellow and red flowers; they grow in any common soil.

Mathiola is the generic of the Stock-gilly. None of them will survive severe winters in this latitude; yet many of them are indispensable in the flower garden. MI. simplicáulis, Brompton-stock and its varieties, with M. incána, Queen-stock, and its varieties, require the protection of a good frame in winter; and about the end of this month, or beginning of next, plant them in good, light, rich soil to flower, which they will do all summer, if attended to with frequent supplies of water. M. ánnua has about forty varieties, valuable for flowering the first year from seed, and are all annuals. They ought to be sown on a gentle hot-bed about the first of this month, and carefully pricked out so as they may be ready to transplant about the end of $A$ pril or 
the first of May. Plant them in light, rich soil, and they will flower profusely through the season; if it is very dry, they must be watered to keep them growing. The scarlet, white, and purple varieties are the finest; but there are many intermediate sorts, all handsome. M. glábra is the Wallflower leared stock, and requires the same treatment as the former two. There are about twenty varieties of this, all various in color. In planting any of these into the open ground, choose cloudy weather, except they hare been in pots; in such case, plant at any time in beds, or detached groups, through the borders, keeping each kind separate.

Qinotheras. The most of them are indigenous, and in Europe they afford a continual ornament to the flower garden from April to November; but in our gardens they are entirely neglected. By rejecting these and many others, our

- flower gardens are deprived both of much beauty and interest they might easily possess. The herbaceous sorts delight in light, rich soil. $\quad E$. odorcita, sweet-scented; $C$. mucrocárpa; E. media; E. latifiora; E. Frazèri; QE. speciòsa; $E$ : missouriensis, and $E$. pállita; are all fine, native, herbaceous plants, mostly with large yellow, fourpetaled corollas; in bloom from May to September.

Phlox, another American genus, and one of the most handsome in cultivation. It consists of elegant border flowers, valuable for flowering early, and during the whole sea- son, eren till frost. While the majority of plants blooming late in the season are generally syngenesious, with yellow flowers, these delight us with their lively colors of purple, red, white, and striped. A collection of them, properly attended to, would of themselves constitute a beautiful flower garden. It will be difficult to state which are the finest; but the following are select rarieties: $P$. alba kermosine, white rose-eye; Llanc de Neuilly, pure white; captivation, dark rose; Charles, blush ; divaricàta, blue; longiftora, white; odorita, fragrant red; prostrita, creeping; P'rincess Marianne, striped; speciòsa, dark crimson; speciosissima, rosy lilac; subulita, dwarf pink; Tan Houttii, striped. In the spring of 1831, an eminent British collector* exclaimed, on seeing a patch of $P$. subulita in one of the pine barrens of New Jersey, "The beauty of that alone is worth coming to

* Mr. Drummond. 
Anterica to see ; it is so splendid." Most of the species delight in a rich, light, sandy loam. When the plants become large, they ought to be divided, and planted in fresh ground.

Primulas, Primrose. To this genus belong the celebrated Cowslip, Oxslip, Primrose, and the esteemed Auricula. The double varieties of Primrose have originated from $P$. vulgàris. These are such as carry their flowers on separate pedicles, rising from the root on a small stem. The double varieties are desirable for their beauty, but require the protection of a frame during winter. They are in color red, white, yellow, lilac, purple, and crimson. $P$. elatior is the Oxslip, from which all the Polyánthuses have been grown. They are in variety innumerable, and are those whose flowers are in umbels, on a scape or flower-stalk, rising from three to nine inches. The rules for judging of their merits are wholly artificial, agreed on from time to time by florists. The one that is the leading beauty this year would, in a few years, be far in the rear. The principal character is that the corolla is not notched or fringed; the colors pure and distinct, not running into one another; the tube small; the eye round, and a little prominent. Being surrounded with white, and the ground purple, is a fine character. $P$. auricula. From this the highly esteemed varieties have originated. The cultizated auricula has many admirers, both for its exquisite beauty and fragrance. For the criterion of a fine flower, see April. There are several other species worthy of a situation, such as $P$. cortusordes, $P$. dentiflora, $P$. suavèolens, $P$. decòra, with $P$. scótica and $P$. farinòsa, both small, neat species. A shady situation agrees best with them; and they require loamy soil, free from any kind of manure, except it be fully decomposed. The leaves of $P$. vèris have been recommended for feeding silk-worms.

Plumbago Larpantea, Lady Larpants, Lead-wort, darkblue, flowering from July till frost; a very great acquisition to the flower garden; will require to be covered in winter in the Eastern and Northern States.

Potentillas are similar to the strawberry in habit and appearance. P. nepalénsis, or formòsa, has rose-colored flowęrs; P. atropurpuirea ; P. Russelliìna, scarlet; P. Hopwoodiàna, buff and scarlet; and P. spléndens, yellow, with superb leaves. These are the finest of the genus, and flower from May to September. It will be well to protect them with a 
few leaves or litter during the severity of winter; they delight in light soil.

Saponciria officinàtis, and S. o. plèna, are fine free flowering, dwarf plants; the color is pink in both double and single varieties. The roots run under ground, and care should be taken to keep them within bounds; they flower from June to October. S. ccespitòsa is a neat growing species, of a rose color. They will grow in any soil.

Silène. Several of this genus are popular annuals, but the herbaceous species are very indifferent. S. viscósa and S. viscósa flòre plèna are frequently cultivated for their beauty; they will grow well if not too much shaded.

Saxifraga, above one hundred species. Many of them are beautiful plants for rock-work. They are regardless of cold, but will not generally withstand much moisture. A few of them are highly deserving a situation in any garden. S. hirsìtum and S. crassifòtia are used in some countries for tanning. S. granulàta multipléx has fine, double, white flowers, and is desirable. S. umbròsa, London-pride, makes a beautiful edging for a flower border; the flowers are small, but, on close examination, its colors are unrivaled. It is sometimes called "none so pretty." S. sarmentòsa is kept in the green-house, but is perfectly hardy, and makes a fine plant in a shaded situation, and will grow where grass and other plants generally die. We have no doubt that it would make a good fancy edging. S. pulchélla and S. pyramidàtis require protection; these are easily cultivated, and flower in spikes from May to July.

Spiræas. A few species are showy plants, and continue flowering from May to September. S. ulmària múltiplex, Meadow-sweet, has sweet-scented, white flowers, in long dense spikes. S. filipéndula múltiplex, Drop-wort, double white. S. lobcita is a native, and has fine rose-colored flowers, and blooms in June and July ; S. japónica, beautiful dwarf white; these are the finest of the herbaceous species, and will grow in any common garden soil.

Státice, Thrift. A genus containing many fine herbaceous plants; only a few of them are common in collections. The finest of them are scarce, and said to be "bad to cultivate." S. vulgàris, once Armèria vulgàris, is a valuable plant for an edging, and does well in our climate, flowering in great profusion from May to July. When done flower- 
ing, the stems should be cut off. The foliage is an agreeable evergreen; the plant increases rapidly, and in a few years may be planted to a great extent. S. speciòsa has red flowers, crowded in spreading panicles. S. tartàrica has also very showy flowers, and is now given to the genus Taxinthema. S. latifolia and S. maritima are the finest. $T$. latifolia and T. conspicua deserve attention. They should be lifted every alternate year, and sunk deeper into the soil, because they incline to grow out, and are sometimes during summer killed by the drought. Hence they are said to be "bad to cultivate."

Véronica, Speed-well. This genus consists of about one hundred and twenty species of herbaceous plants, besides several varieties. The flowers are in long, close spikes, white, flesh-colored, or blue; they are generally of the latter color. Above sixty species are equally fine, and, being generally of the same character, the catalogue at the end of this work will contain the best selection that we can make. Very few of them are in the collections of the country, although they are very showy, and flower from May to August. They will grow in any soil, but will not flourish where they are much shaded. $V$. officinális has been used in Germany and Sweden as a substitute for tea. Some prefer V.chamæedrys for the same purpose.

Valerianas. Several species are showy border plants, with small flowers in large close flattened panicles. V. dioica is remarkable for having the stamens and pistils in separate flowers, situated on different plants; the flowers are of a blush color. V.phì, a large growing species with white flowers, and V. rivbra, with its varieties which bloom all the season, are the finest of the genus. They are now given to Centranthus. They are all easy of culture in common garden earth, but preferring moist shady situations. In flower from May to September.

Viola, a genus consisting of upwards of eighty species of low pretty plants, of great diversity of color and foliage. Many of them are natives, and well worth a situation in our gardens. They mostly delight in sandy loam, and a little shade. A few of the species grow in moist situations. The most esteemed varieties for fragrance are, $V$. odoratc purpuirea plèna, double purple, V.odoràta alba plèna, doublo white, the double Neapolitan and the monthly Double purples 
They flower very early. and make good edgings, where they are kept in order ; flowering profusely from April to June, and again in autumn.

Yúcca, Adam's needle. This is a very showy and ornamental genus ; their character forming a picturesque contrast in the flower garden; foliage long, narrow, lanceolate, and stiff; with white campanulate flowers, about two inches in diameter, in conical spikes from two to four feet long, arising from the centre of the plant, containing frequently from two to four hundred florets. They are principally native plants. $Y$. stricta, $Y$. supérba, $Y$. aloifòlia, $Y$. angustifòlia, $Y$.gloriosa, $Y$. recurvifòlia, and $Y$. filamentòsa, are all fine species, and will grow in any common soil. When in flower, if protected from the sun by an awning, they will be of considerable duration. There are variegated varieties of stricta and aloifolia, which look very handsome in foliage, but are at present very rare, and it will be a number of years before they are plentiful. There ought, at least, to be one specimen of each in every garden.

We have given the names and characters of a few herbaceous plants, all or most of them easily obtained, many of them extremely handsome, and such as agree best with transplanting at this season of the year; for several others, such as Pæònias, or any other strong tuberous or bulbous sorts, see October. Where they are in pots, they can be planted at any time, the weather permitting, provided the ball of earth is not broken. But where they are only to be removed, the best time is in October or November, or just as regetation commences in the spring. That herbaceous plants may look to the best advantage, and flower well, they must not be allowed to get into large stools; but, as soon as they are above one foot in diameter, they should be divided.

Very frequently, those who perform this operation take the spade, and cut a piece off all round, which, to a degree, improves the look of the plant; but this is only half justice. It should be lifted entirely, fresh soil giren, or removed a few feet, and planted a little deeper than it was before, as the plant tends apparently to grow out of the soil when allowed to stand long. If the weather becomes dry shortly after transplanting, give them a few waterings, until they have taken fresh roots, which will be within two weeks. 
Color should be diversified through the garden as much as practicable, and the highest growing sorts planted farthest from the walk, so as all may appear in view. At all times, avoid crowding plants together.

\section{BULBOUS ROOTS.}

About the middle of this month, let the covering of tan, sawdust, or decayed leaves be cleared from the beds of such as were directed to be corered in November; afterwards carefully stirring the surface among them with a kind of wooden spatula, or wedge, breaking the surface fine; then dress all the alleys smooth and neat with the hoe and rake, clearing away every particle of litter. When the leaves of Tulips are expanding, they frequently become entangled so much that the force of growth breaks the foliage; if there are any appearances of this at any time, they should be set right with the hand. In early seasons, these roots will be far advanced, and perhaps one night of frost, unexpectedly, might materially injure them. When there is any suspicion of cold weather, hoops should be spanned across the beds, so that the necessary mats or canvas could in a few minutes be placed over them, to ward off danger. Protect the finest sorts from heavy drenching rains, and give them small neat rods for support as they grow up. If the rods and tyings are painted green, the effect will be improved. These directions equally apply to Narcissus, Jonquils, Iris, and all Holland Bulbs.

CARNATIONS, PINKS, PRIMROSES, \&c.,

Which have been protected by frames through the winter, must have, at all favorable opportunities, plenty of air admitted to them by lifting the sashes, and in fine mild days and nights, the sashes may be taken entirely off. Divest them of all decayed leaves, and stir up the earth on the surface of the pots; those that are intended to be planted in the garden may be set to one side, while those that are to be kept in pots must be more strictly attended to. Of these the Pinks and Carnations should be repotted about the first 
of the month. Those that have been kept in fuur inch pots should be put into pots of seven inches, and those that are in five inch pots may be put into eight inch. Give a gentle watering after repotting. Pinks do not require the pots so large, but the same treatment in every other respect. Where the extremities of the leaves are decayed, cut them off, with any other decayed leaves: the pots must be well drained with shivers or fine gravel. Give them plenty of air, otherwise they will be weak in growth.

Primroses and Daisies may be planted out in shady situations: the sun destroys them during summer if exposed.

\section{AURICULAS.}

These beautiful and highly interesting plants are, to a great degree, neglected in our collections. It cannot be from want of beauty or fragrance that they have not attracted our attention, for they are exquisite in both. We are rather inclined to think that those who have them do not give them the treatment they require yearly to perfect their bloom. They should now have the surface earth taken off about half an inch down, and fresh soil added, which will cause them to put on fresh fibres about the upper part of the roots, and greatly increase their growth. The frame in which they are placed should now face the east, as the sun will be too strong for them; and about the end of the month turn it to the north. The glass of the frame may be white-washed, which will partially shade them from the sun, that being their delight. Give them water sparingly until they begin to grow, and never water them over the foliage previous to flowering, as water injures that fine mealy-like substance found on many of the sorts, and which so greatly improves their beauty. Defend them, therefore, from rain and high winds. To have them flower strongly, only one flower stem should be allowed to grow. The first one that shows is generally the best. At all events, leave the strongest, and cut off all the others, or only nip off the flower pips, which answers the same end. Never kecp the sash off during the night, in case it rain before morning. 


\section{RANUNCULUS AND ANEMONE.}

The frames of Ranuculus and Anemone must have plenty of air, and give frequent sprinklings of water. The sashes or shutters should be taken entirely off every mild day, and in fine nights leave them exposed to the dew. Stir the earth among them, breaking it fine, and making all neat and clean. They require liberal supplies of water after they begin to grow.

\section{ROSES.}

This is the most favorable month for planting all kinds of garden roses, which must be done as soon as the weather opens, and the ground in a proper state. The earlier they are planted the more perfect they will flower. Never delay planting when there is an opportunity; for, if delayed until the leaves are expanded, the bloom will be much weakened, and the probability is there will be no flowers, and the plants meet with a premature death. It has been said, "There is a particular advantage in planting some every ten days, even to the middle of May; for the flowering of them may be retarded in this way, and the bloom of these delightful shrubs continue for a much longer period." One moment's reflection will convince us that nature, while in her own element, will not be retarded, suppose there was no danger of instantaneous death to the plants. The artificial means that might be judiciously adopted, with which we are acquainted, to keep back the blooming of hardy plants, is to lift them as soon in spring as is practicable, put them in boxes of earth, and then place them in the dryest part of an ice-house, until the desired time of planting, which may be delayed as long as the required time of flowering. This will be found a true method of retarding the flowering of roses especially, and not going counter to the rules and principles of nature. There are many beautiful varieties of the garden rose in cultivation, the names of the finest of which we will give in the following catalogue:-

African black, very dark crimson, compact and ver̀y double. Belle amabile, fine dark red, large and double. 
Baron de Stael, bright cherry color, globular, large ${ }^{\circ}$ and double.

Bellc Hebe, large purplish red, cupped, double and fine.

- rouennaise, a very supcrb rose, with red centre and blush edge.

Belgic or Dutch Provins, red, with very large flowers, cupped and extra double.

Bouquet de Lisle, spotted.

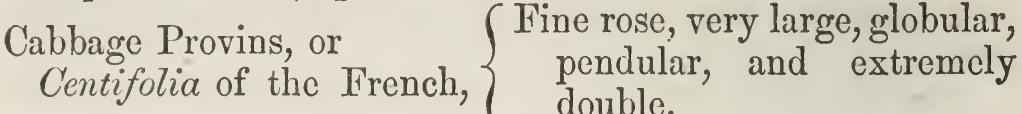

Deuble.

Delicious, rosy color, large compact and double.

Don Solo, shaded and spotted.

Edinberger, violet purple, very compact and most perfectly double.

Grandis royal, deep pink, large, expanded and double.

Harrisoni,* bright yellow, cupped, small and semi-double.

Helen, light pink, very large cupped.and fine.

Imperial blush, delicate blush, expanded, 'large and double.'

Isabella, blush pink, very profuse, cupped and double.

King of Rome, deep red, very large, compact and exquisitcly double.

La Belle Augusta, shaded blush and white, expanded and double.

- ville de Bruxelles, bright rose.

Leonore, purplish red, very compact, imbricated, and double.

Madam Hardy, pure white, large, globular and exquisitely double.

Plantier, pure white, very profuse.

Moss rose, $\nmid$ delicate rose, globular and perfectly double.

- Compte di Montmorency, pale blush.

white, old white, expanded and double.

white bath, or Clifton, white moss, fine white cupped and double.

* This Rose, with a "Florist's privilege," has been sold for the yellow sweetbrier. It is also called Hogg's Yellow Rose.

f It has long been questioned whether the Moss Rose was a dis. tinct species, or merely a seminal variety of the Provins Rose. I perfectly agree with the latter opinion--for in June, 1836, I saw in my nursery a plant of the Moss rose with a large shoot that had sported back to the Provins Rose, and entirely destitute of moss on either shoots or buds. We have no faith in black and yellow Moss Roses; all we have seen for such have proved false to.their character. 
Moss crimson or Damask, very bright rose, expanded and double, and very mossy.

— crested moss or $\quad$ crested Provins, $\left\{\begin{array}{l}\text { This is not properly a moss rose, } \\ \text { but has a curiously mossy calyx } \\ \text { that envelops the bud-pink, } \\ \text { globular, and double. }\end{array}\right.$ Luxemburg, bright red, compact and double.

panache, frequently striped.

_ perpetual red.

- white, blooming in clusters.

unique de Provence, white.

Negritina, pink, very compact, imbricated and double.

Nonpareil, rosy red, compact and perfectly double.

Oillet parfait, striped like a carnation.

Perlet des panaches, striped rose and white.

\section{red, see red Provins.}

white, see white Provins.

Prince de Joinville, bright rose, large, expanded and finely double.

Prolific blush, changeable blush, expanded and double.

Provins cabbage, see Cabbage Provins.

Queen of violets, violet color, compact, cupped and very double.

of Roses, beautiful rosy purple, imbricated and double. Caroline, fine changeable red, cupped and double.

Sweetbrier, single pink.

celestial, blush, fine double flowered.

Swiss Rose, large pink, expanded, and profusely double.

Unique or white Provins, pure white, very large, globular, and double, superb.

Unique striped, often is perfectly white, and merely a sport from the former.

Vandál carmine, compact, imbricated, and double.

Village Maid, or Belle Rubine, striped.

Violatum, violet purple, expanded and double.

Yellow Persian, the finest yellow rose grown.

We mention these as fine; but, among several thousand cultivated varieties of the garden rose, there must be many of equal, if not surpassing beauty; of Rosa spinosissima, there are about five hundred varieties; Rosa gallica, two hundred; R. centifòlia, one hundred and fifty; $R$. damas- 
cène, above one hundred; $R$. alba, fifty ; R. mubiginòsa, thirty; and of various sorts abore eleven hundred. In sereral individual collections of Europe, there are cultivated above fifteen hundred species, sub-species, and rarieties.

When planted, they are too frequently crowded indiscriminately among other shrubs, which prevents them having the effect they would have if planted singly or grouped. They vary in size, in different sorts, from one to ten feet. When planted in the latter method, they should be assimilated in size of leaves and manner of growth, with the greatest rariation of flower; or, if planted in small patches, each distinct in color, will havę a very picturesque effect. Another desirable and fanciful method is to plant them in figures, with edgings of wire, willow, or any other substitute, in imitation of basket-work, which is called "baskets of roses;" the ground enclosed in the basket margin to be made convex, which will present a greater surface to the eye; the strong shoots to be layered, or kept down by pegs in the ground, baring the points of the shoots only to appear above the soil, which should be corered with moss. With this treatment, in a few years the whole surface of the basket will be covered with rose buds and leares, of one or various sorts. If tro or three of the larger growing sorts are taken, such as Moss or Provins, they may be trained so as to cover a surface of several square yards.

A modern invention in the cultivation of the rose is to grow them in shape of trees, by budding on strong growing kinds at different heights from the ground, according to taste, and the purposes intended. If budded on Rosa cánina, or Dog Rose, they are much more raluable : it is a lasting and strong growing stock; and the worst of all stocks is the Boursalt rose, and it is too frequently resorted to, being casy of propagation. They will form in a fer year's handsome round heads, which will flewer more freely than by layers, or trained on their own stalk. They are particularly desirable anong low shrubs. When planted, they should be well supported by strong rods, to prevent the wind from destroying them. If any of the roots have been bruised in lifting, cut off the bruised part with the knife, and likewise shorten the young shoots; breaking the earth well about their roots when planting. The rose has been an esteemed shrub among all civilized nations. The flowers are double, 
semi-double, and single; the colors are pink, red, purple, white, yellow, and striped, with almost every shade and mixture; the odor universally grateful. This plant is cultivated in every garden, from the humblest cottager to the loftiest prince, and by commercial gardeners in Europe extensively, for distilling rose water, and making the essential oil of roses. They delight in a rich loamy soil, and require plenty of moisture while in a growing state. Those sorts which throw up numerous suckers should be lifted every three or four years, reduced, and then transplanted. When thus removing them, avoid, as much as possible, exposing their roots; and when nerrly planted, mulching is of considerable advantage; that is, putting half rotten stable-manure on the surface of the ground round their roots, which prevents evaporation, and keeps up a constant moisture. If this were done in general to our roses in dry seasons, it would greatly improve their flowering. For Chinese and other roses, see next month.

\section{CLIMBING ROSES.}

This is the best time to prune ever-blooming climbing roses, such as Champney, Noisette, \&c. Many of these, when allowed to grow year after year without pruning, become unsightly: they never bear flowers on the old wood, that is, wood of three or four years. Having a tendency to throw out young shoots from the bottom of the stem, the old wood should be cut out, thus encouraging the young wood, which the second year bears the most and finest flowers. In severe winters, the extremities of the shoots are frequently killed, and we have often seen all the wood black or brown, and apparently dead. When that is the case, it is best to leare it until they begin to grow, which will show what is dead or alive, when they can be pruned to better advantage.

\section{DECIDUOUS ORNAMENTAL FLOWERING SHRUBS.}

The earlier the planting of these shrubs is attended to in this month, the more will their growth and flowering be promoted, having all finished before the buds begin to expand. 
(For kinds recommended, see list, end of the volume.) They should never be planted too thick; but leave space for them to grow as they respectively require, and according as they are designed for open or close shrubberies, clumps, or thickets. Have all in readiness, that it may be done with as much expedition as possible, to prevent their roots from being dried by the sun and wind in time of planting. Make the holes intended for their reception round, capacious, and deep enough to hold their roots, without confining them in the least, and loosen well the bottom, putting new and fresh soil under their roots, breaking and pulverizing it during the operation, and frequently shaking the plant as you progress in filling up. When done, make all firm with the foot, leaving a circular cavity to hold the water they will require during dry weather. Give rods, and tie with bands all that need that support before they are left, lest they should be neglected. Cut off any of the bruised roots or irregular growths of the branches.

\section{GRASS PLATS AND WALKS.}

A most wonderful renovator of grass plats may be found in Guano. Take at the rate of one pound to twelve square yards, mix it with double the quantity of sand, and before rain in April or May, sow the mixture over the grass; in a few days, its effects will be seen. Where grass lawns are poor, and of a pale yellow color, about four hundred weight to the acre, mixed with sand, plaster, or dry earth, will effectually restore them to a luxuriant verdure.

Riake and sweep off from these all litter, and worm-cast earth, and give an occasional rolling to settle the ground, and render the surface smooth, where the scythe is to be used. The grass will likewise grow better by rolling it where the frost has partially thrown it out, and add greatly to its beauty. Cut the edgings with an edging iron or spade, so that the whole will have a finished appearance. If any new turf is required to be laid down, this is a very good time to do it, before vegetation is strong; as the turf that is now laid will have taken root before the dry season commences. Where a great extent is to be done, sowing might be adopted; but it will not have the effect of turf under three years, and dur- 
ing that time must be-carefully cut, after the first season, every three weeks, while growing; nor must it be too frequently walked upon. White clover and true perennial ryegrass are the seeds most proper for sowing. The ground must, in the first place, be all equally made up, and leveled with the spade and rake; not "cart-loads of soil laid down and leveled," which would finally become very uneven, and would need to be lifted and re-laid next year. The best turf is that of a close-growing pasture or common, free from all kinds of weeds or strong roots, and the grass short. To cut it expeditiously, be provided with a turfing-iron; but if that cannot be conveniently had, a spade may do very well. Strain a line tight, cutting the turf lengthwise, at equal distances, from twelve to eighteen inches. Next draw the line across, cutting from one and a half to two feet; then cut them up with the spade, about one and a half inch thick. In laying, join them close and alternately; when done, beat them firm with a level wooden beater, and roll with a heavy roller.

Grass walks, in the last century, were very popular; but time having put them to the test, they are found unfit for walking upon or using in any manner, almost for one-half of the year; therefore, not answering the purposes intended. They require great attention to keep them in order; and if not always neat and clean, they are a disagreeable object in a garden ; but, when they are well dressed, their effect is very enlivening. Where they are desired, prepare the ground as above directed; making the walk a little higher than the adjoining borders, to prevent the earth from being washed on it by the rain. Allowing the walks to be six feet wide, make the centre five inches higher than the sides, or about seven-eighths of an inch to the foot whatever the breadth may be, which will form a gentle declivity to throw off the rain. When laid, beat and roll it well; cutting the edge neat and even. Water frequently if the weather sets in dry. To keep grass walks or plats in order, they should be mown once every three or four weeks from May to September, and the grass each time swept clean off. When the grass is allowed to get long before being cut, the roots become tender, and die when exposed to the sun ; at last the grass is all in spots, and in another year requires to be re-laid. 


\section{GRAVEL WALKS.}

A practice once existed of turning these into heaps, or ridges during winter, to destroy weeds, \&c. But this has almost been given up as unnecessary, unsightly, inconvenient, and not doing any material service.

Where the surface of these has become foul, irregular, or mossy, they had better be turned over four or five inches deep where the gravel will admit of it; but if not, hoe and rake them perfectly clean, give a new coat of gravel, and pick up any stones that you think too large; then give them a good rolling, applying it frequently after showers of rain. When they are well attended to just now, they will look well all the season; but if neglected, they take more labor, and are never in such good condition.

Fancy-edgings of Thyme, Thrift, Lavender, and Violets(Daisies may be used if the situation is shaded). 'The whole of these may be planted by the line with the dibber except Thyme, which lay as directed for Box. See this month, under that head. Any time in this or beginning of next month will answer to make edgings of these; and if dry weather occurs before they begin to grow after planting, they must have frequent waterings until they have taken fresh root. Thyme requires to be dressed twice during the season to keep it in order.

\section{OF GRAFTING.}

There are four methods of grafting. It can be applied to all kinds of shrubbery, choosing a common species from the same genus that the sort belongs to, which is intended to be multiplied. The one we will describe is whip or tongue grafting, which is the preferable and most expeditious plan with all deciduous shrubs or trees. The stock upon which it is performed must be slender, from two-thirds of an inch to any diameter suitable to the thickness of the graft. Having headed the stock at a clear smooth part, slope it on one side with a sharp knife at a very acute angle, make a slit on the lower side of the slope about an inch downward, to receive the tongue or wedge of the graft or scion. Secondly, having 
the prepared scions cut into lengths of three, four or five eyes, take one which matches the stock in size, and slope the bottom of it so as to fit the stock, that the rinds of both may correspond exactly, especially on one side and at bottom ; make also a slit upward in the graft, like that in the slope of the stock, so that the one may be inserted in the other as evenly and completely as possible. Let the graft be carefully held in its due position, while a bandage is applied. Take strands of Russian mat, and bind them in a neat manner several times round the stock and graft. Lastly, cover the joint with well-worked clay; coat from half an inch below the bottom of the graft to an inch above the top of the stock, and to the thickness of half an inch all round; finish it in an oblong globular form, taking care to work it close, that no air may penetrate. If the clay is covered with moss, it will partially prevent it from cracking.

The grafts will have taken when they begin to grow freely: then the clay may be broken off, and the bandage loosened, and put on again, but not so tight as formerly; give the drafts a stake for support, tying them thereto to prevent accidents from the wind. Allow no shoots to arise from the stock.

\section{APRIL.}

The ambition of every amateur and gardener, during this month, is to be at the head of every department, and over every spot. The operator's activity, in this month, almost regulates the whole season. Every weed ought to be cut down as soon as it appears, and the proverbial saying will be realized, "A garden that is well kept is easily kept;" one hour of laborious industry now will save two in the heat of summer. A wet day need cause no loss of time: prepare rods, bands, and tallies, to be in readiness when required. Many, in the height of bustle, never finish properly as they proceed, which is the worst of practices. Every operation ought to be completely and properly finished before another 
is taken in hand, which will ultimately prove the quickest and best method to work upon.

Let digging, hoeing, and raking be done as expeditiously as strength will allow, that the time may be devoted, for a few weeks, to the beautifying of the garden and parterre, by sowing and planting.

\section{ANNUALS.}

Those that are tender and were sown last month, according to directions, will be ready to prick out into another glass frame. Keep them a few inches apart to let the air circulate. Give them frequent sprinklings with water, and shade them with a mat for a few days, until they have taken fresh root; then give them plenty of air, and by the first of next month, expose them, night and day, to harden the plants for the open ground. A few of the annual seeds, of every description, and of every country and climate, may be sown any time after the middle of the month. If the season prove favorable, they will do well; but reserving a part to sow about the 15th of May, will guard against every extreme.

\section{BIENNIALS AND PERENNIALS.}

Any biennials that are intended to be removed, and not done last month, must not be delayed longer. The roots of many of them will be rery strong, and, if possible, a cloudy day should be chosen for the operation. Give one or two copious waterings, and, if necessary, shade them from the sun till they begin to grow.

Perennials.-For a limited description of sereral genera and species, see last month. Where dividing the root or replanting is required, let it be done forthwith. If the weather is dry, they must be carefully watered and shaded for a few days. 
ROSES.

The subject of garden roses was touched upon last month, as far as our limits would ađmit. We will now give short descriptions of the other varieties of Roses that are of more delicate character-and, for distinction and perspicuity, we will give them under the various divisions to which they belong.

\section{HYBRID CHINESE ROSES.}

All the varieties of this fine division of Roses owe their origin to the Chinese tea-scented, Noisette and Bourbon Roses impregnated with the French Provins, and other garden Roses. The seeds of such fertilized flowers produce hybrid Chinese Roses. These have, in many instances, resulted from accident; but latterly, from the regular impregnating process. The superb varieties of this fine division give a combination of all that is grand and beautiful in roses. Their flowers are of the most elegant forms and richest colors; their foliage of great luxuriance, and their branches flexile and vigorous. Many of them are of first rate importance for covering pillars and trellises, their shoots frequently growing from six to ten feet in one season; these shoots may be thinned out year after year, but never shortened. They require very rich soil, and do best on their own bottom, except elegans, Bizarre de la Chine, Wellington, and other dwarf growing sorts, which do well as standards. If they only possessed the property of ever blooming, they would be decidedly the finest division of the tribe; however, their general beauty and richness of color greatly make up for the deficiency. Many of them are also delightfully fragrant. The following are select sorts :-

Belle Marie, bright pink, a fine dwarf.

parabère, shaded crimson, a strong grower.

Theresa, very dark crimson.

Blanchefleur, white, a free grower.

Bon Ginneure, bright red, very early.

Bouquet blanc, white expanded, large and very double. 
Brennus or Brutus, of some French collections, vivid red or nearly scarlet, and, as a pillar rose, is one of the finest objects I have ever witnessed ; flowers extremely large, and of the most exquisite form, cupped, and perfectly double.

Catel, dark crimson, globular shape and very double. Coup de Hebe, delicate pink.

Dandigne, violet purple.

Duke of Devonshire, rosy lilac faintly striped with white, imbricated and perfect in its shape.

Egerie, brilliant red, a free grower.

Fabvier, very large changeable pink and red.

Fulgens or Malton, unique in brilliancy, approaiching bright scarlet, with large globular flowers, and of vigorous growth, and foliage finely tinted with red.

General Lamarque, very dark crimson, of luxuriant growth, and very distinct.

George the Fourth (Rivers'), most beautiful crimson, very large and exquisitely double, and of globular form. If in good rich soil, the shoots will grow eight feet in one season; foliage of a shining dark reddish green, and is unquestionably one of the finest of the family.

Georgiana, deep pink, cupped, large and finely double.

Grillony, slaty rose color.

L'ingenue, shaded riolet crimson.

Lady Stuart, flesh color, the form of the flowers before expansion is perfectly spherical, and of exceeding beauty. Louis Philippe, very splendid dark rose, a strong grower, superb.

Parny or La tourterelle, lilac or dove color, cupped and very double, requires to grow to a large bush before its beauty of form and profusion of bloom can be seen.

Princess, delicate rose, globular and perfectly double, and makes an excellent standard of itself, not being very subject to make shoots from the root.

Prolifère, dark rosy crimson, changing to violet, very perfect form, a dwarf.

Triomphe de Laffay, rosy white, large and very beautiful. Victor Hugo, changeable rosy violet. 
Violet de Belgique, dark violet crimson, very profuse and perfect.

Watts' Celestial, Celestial Wells' Cabbage China, Flora perfecta, \&c. (it is known under all these names), delicate rose, petals finely cupped, flower rather flat, is a frée grower, and very profuse of bloom.

Wellington (Lee's), rich purple crimson, flower beautifully formed; globular and very double. The first view of it is similar to Bizzare de la Chine; but it is very distinct in growth, and the color fades much sooner than in the latter rose, and, indeed, is never so bright. William the Fourth, blush red, extremely large, very perfect form, and is unquestionably a hybrid from the Cabbage Provins, and makes an excellent standard or tea rose.

HYBRID ROSES THAT ARE STRIPED, SPOTTED, OR MARBLED.

Abbe Berlèse, beautiful crimson, spotted with violet, and of the most perfect form.

Camaieu, delicate rose, with lilac stripes, large and double. Prince de Chimay, entirely now, crimson purple, beautifully marbled with rose, large, and very perfect.

Sandeur, Sandeur Panachee, of the French, and King of Hybrids of the English, bright rose color, beautifully spotted and striped with white, very double, and of perfect form-luxuriant in growth, and the shoots must never be shortened-we have seen it several years in perfect bloom.

\section{PERPETUAL ROSES.}

This once admired division of the Rose is now nearly superseded by the Hybrid Perpetual, a tribe that originated between it and the Bourbon. It was not known in Europe till about 1817, except in the red and white four seasons, roses, which have, no doubt, contributed a large portion of their "Sweet assistance;" for in many of them the powerful and agreeable fragrance of these two old roses is very 
evident. Unfortunately, there are two-thirds of these roses received both from France and England under the head of Perpetuals, which only bloom once in our arid and hot climate; of course, they will not make a second or third blooming, unless they, at the same time, grow freely and make strong shoots; consequently, they require very rich and deep soil, strongly manured, and repeated manurings given every year; also, very frequent waterings during the summer season, with liquid manure. Without such nourishment, the best of perpetual rosęs will only flower but once a-year. It is a peculiar feature in this tribe of roses, that they are nearly all reluctant in rooting from layers; therefore, it will be difficult to procure them on their own bottoms. However, they grow admirably, grafted on, or budded into, any of our stronggrowing native roses; although the French Eglantine and Marietta are most generally preferred. When grown in a luxuriant and well-cultivated state, they require twice pruning. First, in November, when the beds are dressed, cut off every shoot of the preceding summer's growth about two-thirds, and if they are crowded, displace some of them entirely. If this autumnal pruning be properly attended to, they will, early in the following June, throw out a great number of luxuriant shoots, each having one or more flowers. When a little sacrifice must be made to have a fine autumnal bloom, therefore, leave only about half the number of shoots to bring forth flowers, the remainder shorten to less than half their lengths. Each shortened branch will soon put forth buds, and in July and August the plants will again be covered with flowers. Our fine-growing fall months will greatly assist the plants without farther aid in bringing forth their third blooming, which will be in September and October; and Rose du Roi will even continue in mild seasons to bloom till November. It is necessary, at all times, as soon as the flower begins to fade, to cut it off, which greatly assists the vigor of the plants. Although in color many of them approximate each other, yet the following sorts will prove sufficiently distinct:-

Antinous, light crimson, beautifully formed, and perfectly double.

Billiard, rose color, very neat form, exceedingly sweet, and perfectly double. 
D'Angers, delicate rose, large size, compact and double. Du Roi, or Lee's crimson perpetual, bright red, cupped shape, perfectly double, and exquisitely scented : in warm dry weather, this rose is apt to become much lighter in color.

Grande et Belle, or Monstreuse rose, very large, cupped and perfectly double.

Jean Hachette (of the English), delicate pink, extremely large, cupped, and extra double.

Magadore, very dark crimson, perfect form.

Oliver de Serres, dark rose with a blush edge, very distinct. Palmyra, rosy pink.

Queen of Perpetuals, or Palotte picotée, pale blush, cupped and perfectly double.

Scotch Perpetual, pale blush, a profuse and constant bloomer. Stanwell, perpetual blush, expanded and very double; it has much the habit of a Scotch Rose: when budded, it is a constant and free bloomer.

Four seasons, pale rose, cupped and doukle.

White four seasons, nearly white, expanded and double; but rarely blooms oftener than once in the season

Perpetual white moss, white, blooms in large clusters, and when in bud is rery handsome; but the flower of itself is miserably indifferent, and, moreover, it is not a true perpetual. It is one of those floricultural misnomers expressing what the public would wish it to be, and not what it actually is.

\section{HYBRID PERPETUAL ROSES.}

It is but, comparatively, yesterday since this tribe was brought into existence; it is now the leading family of hardy Roses, and will continue to be for ages to come. We may expect in it every variety of color, from pure white to velvet crimson, and with a mixture of spotted, striped, and, may be, a touch of yellow. What we have said on the culture of Perpetual Roses will equally apply here, this tribe having the advantage of rapidity of growth-more diversity of color-a greater profusion of bloom, and is propagated with considerable facility by layers, or cuttings, or the com- 
mon process of budding and grafting. The following sorts are all perfectly distinct:-

Aubernon, dark rosy red, cupped and very double. Baron Prevost, dark rose, very large, strong growing. Blanche, pure white, cupped, rery profuse.

Comtesse Duchatel, dark rosy red, large and perfect. Duchess de Nemours, pale rose color, rery double. Duchess of Praslin, pale blush, very profuse.

Duc d'Aumale, rosy crimson, perfect form.

Edward Jesse, pale red, a very constant bloomer.

Geveral Taylor, bright crimson scarlet, fine.

Lane, bright carmine, fine form, and a constant bloomer.

La Reine, rosy lilac, very large.

Narquis Boccella, pale pink, a profuse bloomer.

Prince Albert, rich crimson, large and very double.

Youlande d'Arragon, pale rose, large and rery constant in bloom; one of the best light-colored sorts.

There are fifty other sorts could be added to the abore, without decidedly varying the color.

\section{GRAFTING ROSES.}

The operation of grafting, from the pithy nature of the stems of the rose, is more troublesome, and seldom succeeds so well as budding, though when the buds inserted the previous summer fail, it is worth while to have recourse to grafting, which may succeed, and thus make up for the failure. The cleft-grafting is much practiced, especially on the continent of Europe, and is the most successful method. It is necessary that the scion (or young shoot that is intended to be multiplied) should be cut from the bush before regetation commences, and placed in some shaded situation till the time of operation, which will be after the buds begin to swell on the stock, when the head of the stock may be cut horizontally to its desired height, and a slit made in its crown downward one and a half or two inches. The scion should be cut into lengths of trro and a half or three inches, and then, cutting its lower end into a wedge-like shape, inserting it into the slit of the stock, keeping the back of the stock and 
scion in contact, which must be held firmly and bound with ligatures of soft bast-mat or worsted, and, in order to render it water-proof, cover it with a paste made of pitch and beeswax, or clay mixed with old slaked lime; if the latter is used, it will sometimes crack, which must be carefully filled up. In August or September, the ligatures may be cut on one side, allowing the clay or wax to be displaced with the natural growth of the plant. Should the graft fail, you bave still the resource of budding in August on the young shoots that will grow from the stock. It must be observed that grafting leares a worse wound to heal over than budding, unless the stock and scion be nearly of the same size. Every bud which appears below the graft should be carefully rubbed off, except one or two nearest the crown, to encourage the sap upward to the grafts; and as soon as the latter begin to throw out leaves, the shoots from the stock should be shortened, and in one or two weeks more entirely taken off, if the scion has fairly grown. For whip-grafting, see page 59

\section{L'ISLE DE BOURBON ROSES.}

This group of Roses is one of the finest in the whole family of the "Queen of Flowers." They are generally perfectly hardy, of luxuriant growth, and will grow almost in any soil. They are profuse in blooming from June to October, and many of them delightful in fragrance. They are flowering ornaments of the garden, either as standards, climbers, or bushes; their foliage is large, exuberant and agreeable, and when the plants are established and well nurtured, they produce their flowers in immense clusters. There are now many varieties; the talent and ingenuity of the French in rose culture and reproduction will soon give the floral world a farther supply of some fine varieties, and many finer names. I can cheerfully recommend the following sorts, which require pruning similar to hybrid Roses :-

Acidalie, rose white, large and perfect.

Anne Beluze, waxy blush, rery perfect in form.

Bouquet de Flore, bright rose, large flower, and a profuse bloomer.

Desgaches, pale waxy rose, flat form, very distinct. 
Doctor Roques, dark crimson.

Duc de Chartres, large, rosy pink.

Duval, bright scarlet crimson, changeable.

Dupetit Thouars, bright crimson.

Desfosses, waxy pink, very double.

Enfant d'Ajaccio, very bright scarlet; makes an excellent pillar rose.

Henry Clay (Boll), carmine, very large.

Hermosa, bright rose, most perfect cupped form, a profuse bloomer, and highly esteemed. During the summer months it loses much of its color; but in autumn it is truly charming.

Leveson Gower, dark rosy red, large cupped, flower profuse and distinct.

Madam Angelina, creamy waxy white, cupped flower. Nerard, waxy pink, expanded and very double. Nerangot, dark rosy red, in clusters.

- Neuman, or Monthly cabbage, bright rose, very large and fragrant.

- Desprez, dark rose, globular, and perfectly double, blooms in large clusters, and approaches more the Noisette tribe than any other of the Bourbon Roses. Paul Joseph, brilliant crimson, very double and perfect, though not so large a flower as many others.

Queen of the Bourbons, beautiful waxy blush, perfect in form, profuse of flower.

Souvenir de la Malmaison, pale blush, very large, the Prince of Bourbons.

Triomph de la Duchere, rosy blush, a rapid grower, and makes an excellent pillar plant.

There might be several others added to the above, though we consider these the best and most distinct in color and character.

ROSA INDICA OR (BENGAL OF THE FRENCH) CHINESE EVER-BLOOMING ROSES.

Perhaps no Rose has been so universally distributed and industriously cultivated as Rosa indica (common Chinese or daily Rose), and Rosa Semperflorens (crimson or sanguinea 
Rose). It has been a favorite from the cottage to the mansion, and is truly a floral pioneer. They will almost withstand every vicissitude of treatment; but will not well survive the winters in the open air, north of this latitude, and even here they require some simple protection with straw, mats, litter, or other dry material during winter.

They require a very rich, loamy soil, well pulverized, and from fifteen to twenty inches in depth.

The best season of the year for pruning them is about the first of this month. In doing so, it is not adrisable to shorten any of the young şhoots, except in cutting off the injured parts, that being the rood most productive of bloom; but where there is old stinted wood, it should be cut out as close to the surface of the ground as the other parts of the bush will permit, with any other of the oldest wood that is too crowded. Dig every season in among their roots a good supply of well decomposed manure, and stir and hoe them frequently during the summer. The following are very desirable:-

Abbe Mioland, cupped, dark rosy crimson.

Agrippina, or Cramoisi Superieur, brilliant crimson, cup form, large and finely double.

Bengal Triomphant, La Superbe, Grande et Belle. This, like many fine roses, has its several names, but the former is the name under which I first knew it. It is a strong grower, with very large well-formed flowers of a rich purple crimson, which are extremely double, and always open well.

Beau carmine, dark crimson, of a very distinct habit and. color, is an excellent bloomer and finely formed.

Belle Isidore is also a changeable rose; it will open a light pink color, and before evening will be a rich crimson; is a regular and very double large rose, of strong growth and easy culture, and when known will be generally cultivated.

Cels, or Bengal Cels, flesh color, of the most perfect form, extremelydouble and always opens perfect; is a very profuse bloomer, and of a strong growing habit; it has much the appearance of a superb tea rose.

Comble de Gloir, rich reddish crimson, a free bloomer, and possesses considerable fragrance. 
Gros Charles, shaded rose, extremely large and fine. IIortensia, flesh color, very double, and an excellent rose. Indica, or common daily, dark blush or rose color-it is the prototype of the family, and is a free-growing and profuse blooming plant, and can withstand every variety of treatment. The flower is about three inches in diameter, and in our descriptions, where the word large is used, it signifies that the flower is larger than the present variety, and very large means still larger, say four inches; extremely large, between four and five inches. We have even seen roses in favorable soils and cloudy weather six inches in diameter, and would not be alarmed to see a HYBRID Rose twentyone inches in circumference.

alba, white daily or sarmeteuse of some, pure white, perfectly double, free-growing, and profuse in flowering; it is much more tender than the former, but does tolerably well when protected during winter. In the Southern States, it is a great and growing favorite. Thousands of this rose have been grown and sold in Philadelphia within these five years.

- minor var, Lawrencia flore pleno, delicate rose, a perfect rose in perfect miniature.

Jacksonia, * hundred leaved daily, or crimson daily, bright red, large and most perfectly double, of luxuriant growth, and more prickly (spines) than any other rose of the sort we have seen.

Jacques Plantier, shaded crimson, expanded.

L'Etna, bright light crimson, very double, globular, and very distinct, is of a strong-growing habit.

Lady Warrender, pure white, large cup form, very double, and a great bloomer.

La Cæmens, rosy shaded crimson, very perfect form.

Louis Philippe, dark crimson, very compact, globular, and extremely double.

Madam Breon, large bright rose.

Hersant, bright rose, very large, showy and double.

MIarjolin, large, dark crimson, a very strong grower-fine.

Mrs. Bosanquet, beautiful creamy blush, very large, perfectly formed-quite distinct.

* In compliment to the late President Jackson. 


\section{April.]}

Prince Eugène, very bright red, perfectly double cup form, and a profuse bloomer.

Roi de Cramoisis or Eugene Beauharnais, bright crimson, fine cup form-fragrant.

Rubens, dark rosy riolet.

Vesuvius, very dark crimson, perfectly double, and quite sweet scented.

Qucen of Lombardy, Reine de Lombardie, brilliant cherry red, cupped, perfectly double, a strong grower, and will be a great farorite-superb.

Semperforens, Crimson Chinese or Sanguinea, the type of all the scarlet and crimson varieties of this division; it is perfectly double, of a rich crimson color, and is everywhere cultivated, and will not be easily displaced from the window of the cottage, or the veranda of the palace.

Virginal, pale waxy blush, very distinct.

\section{ROSA ODORATA OR TEA ROSE.}

The original Rosa odorata or tea rose has been and will be a lasting favorite. It is supposed to have been imported from China so late as 1810, and is the leading parent of all the fine varieties we now possess. As this very popular and interesting group of Roses require more care in their culture than any yet described, I will endeavor to give the most explicit directions I am ąble, so as to insure, at least, a great chance of success. They delight to grow in a rich soil with a dry bottcm, and in rather an elevated situation, and a southern aspect. Select a spot of the dimensions requisite for a quantity of plants to be planted, and dig therefrom soil to the depth of at least eighteen inches; six inches of the bottom may be filled with pieces of bricks, stone, or limerubbish of any sort; on this, place a layer of compost (at least fifteen inches thick, to allow for its settling), half turf, or good garden mould, and half well-rotted manure, with about an eighth of sand, all completely mixed together. A ferw weeks after the bed is thus prepared-say about the first of May - the roses may be planted about two feet apart. In this latitude, during the severity of winter, they should be protected by a temporary frame: if covered with glass, so 
much the better; but boards will serve where glass frames are not at hand. With this treatment, they will never receive the least injury from our severest winters, and they will bloom in the greatest perfection the whole season. The only pruning they require is merely to remove any old shoots to give room for those of younger growth, and to occasionally shorten any of extra length. However, where there are only solitary plants, they will do very well covered with branches of cedar, or a box or barrel perforated in several places to allow the moisture to evaporate. Those that are grafted or budded will not generally stand the winters of our Eastern or Middle States, and should be lifted and put in a back shed, or tied close to the ground and covered with earth. About the first of the month, they can be raised up and pruned of any dead or superfluous wood, when they will bloom nearly as perfect as those that have received finer treatment. In the Southern States they enjoy the great luxury of this rose in its utmost perfection; there they grow in "wild luxuriance," displaying their varied beauties, and perfuming the air with their delightful fragrance. Every flower-garden in mild latitudes should have a full and perfect collection of such "pleasing flowers." Among the many distinct varieties known to be worth culture, are

Adam, very large, bright pink, cupped form.

Apricote, pale apricot color.

Antherose, pale pinkish white, large and compact.

Jurbot, deep pink inclining to creamy blush, very large.

Bougere, rosy lilac, extremely large, a strong grower, cupshaped.

Belle Marguerite, pale rose, changing to dark pink in the centre, large and extremely double.

Caroline, bright rosy pink, very large, beautifully formedpendulous and highly esteened.

Clara Sylvain, pure white, most perfectly double, a strong grower, and abundant in bloom, very sweet and highIy esteemed.

Devoniensis or Magnolia rose, yellowish white with pink centre, very large, always perfect, finely cupped-delightfully fragrant. If I were confined to cultivate only twelve roses, this magnificent variety would be one of the number. 
Elisa Saurage, Canary yellow, fading to creamy white, very large and double.

Etienie, pure white, cupped form.

Elvira, ereamy blush tinted with rose.

Fragoletta, large, rosy blush shaded with pink.

Flavescens, lutea or yellow tea, pale straw color, cupped petals, very large, and though only semi-double, has not a rival of its color; it was introduced to England from China by Mr. Parkes in 18.24; is a strong grower, but more tender than any other tea rose of its habit.

Floralie, beautiful blush, bloomy in clusters, very fragrant, and as yet quite rare.

Goubault, rosy blush with yellow eentre, very large.

Hippolyte, yellowish white, large and double, a strong grower and profuse bloomer.

Hyménée, white, with cream ecntre, globular, large, and very double.

Julia Mansais, yellowish white.

La Sylphide, rosy buff changing to creamy white, very perfect, and always beautiful.

Lyonnais, very large, pale pink inclining to deep blush.

Madame Desprez, or Bengal Madame Desprez, pure white, cupped, large and finely double; is a beautiful rose, and is rarely excelled in delicacy of fragrance.

Mansais, buff, very large, fincly double, and highly fragrant. Marechal Bugeaud, bright waxy rose.

Melville, flesh color, a strong grower.

Moirc, rose and blush, beautifully cup formed, very perfect, and proves to be a fine grower.

Nephitos, pure white, very large, quite distinct.

Odorata, or common tea rose, fine blush, very large cupped petals, delightfully scented, and everywhere anmired, and is the foundation of this sweet-scented family.

Princess Marie, flesh color, a most superb rose of first rate merit, perfectly double, and finely scented ; when well grown, will have flowers about five inches in diameter. Safrano, when the bud first opens it is of a fine saffron color, very pretty.

Strombio, creamy white, perfectly double, large and globular. Triomphe du Luxembourg, yellow flesh or copper color, ex- 
tremely large and perfectly double; is a rampant grower, has a most splendid bud.

Victorie modesta, blush, cupped, very large and double.

\section{NOISETTE ROSES.}

It is a remarkable fact, that the original of this famous group of roses originated in Charleston, South Carolina, with Mr. Noisette, about 1815, who sent it to his brother, the well-known nurseryman, at Parị (France). It was supposed to be produced between the white musk, cluster, and the common China rose, and created a very great excitement among the Parisian florists and amateurs; but since its introduction to France, thousands of seedlings have been raised from it, and so many of these are evidently hybrids, of the tea-scented and other roses, that some of the roses called "Noisettes" have almost lost every character of the division. They are generally hardy plants, requiring rich soil and a routine of treatment similar to the "Isle de Bourbon Roses." They will amply repay for extra attention to their culture. The great profusion and perpetual succession of flowers from June till November, of immense clusters, frequently from fifty to one hundred in each, make them truly ornamental objects, and are well calculated for covering fences, pillars, or trellis-work. Although they are hardy, they will be benefitted by a light covering of mats or litter: south of this, nothing of the kind is required. It must be kept in mind that pillar roses can scarcely have too much manure when planting, and they also require a regular annual dressing of some enriching material. We consider the annexed list indispensable to a flower garden. The flower of a Noisette Rose raries from one to four inches in diameter in the following descriptions; we take two inches as our standard:-

Alba, white, a beautiful dwarf with small flowers; but in the greatest profusion, and the whole bush is frequently like one bouquet.

Aimée Vibert, unique or Rosa nevia, showy white, very compact and perfectly double, and, if well treated, is one of the finest white dwarf Noisette Roses, and is a profuse autumnal bloomer. 
Bologne, dark crimson, compact form, dwarf habit.

Bengal Lee, Noisette Lee, Blush perpetual China, coelestis, grandifiora, monstrosa, and Triomphe des Noisettes, are all one and the same rose, blush or creamy white, very double, of strong growth, and flowers in large clusters; it is a good old rose, and fortunate in new names.

Conque de Venus, creamy white, with darker centre, very compact and double; blooms in large clusters, and is delightfully scented, a regular good article.

- Champneyana or Champney's pink cluster, light pink, a rampant grower, profuse bloomer, and universally cultirated.

Charles the Tenth, rosy purple, very double, and in dry weather blooms well, but in moist weather its buds do not open; is an excellent rose in a southern latitude.

Courjaune and Coeur suffre are alike yellowish white, a hardy rose of strong growth, and profusion of flowers.

Cloth of Gold, or chromatella-deep sulphur yellow, very large flower, cupped and fine-fragrant.

Cora I. Barton, fine rosy pink, very large flower, a profuse bloomer, fragrant.

Euphrosine, rosy buff, inclining to yellow, very fragrant-a very profuse blooming variety of medium growth. Fellenberg, bright crimson, double, a strong grower, profuse in bloom, and a decided, distinct, and excellent rose. Jaune Desprez, or French yellow Noisette, rosy buff, large, and perfectly double, flowers in large clusters; is a strong grower and delightfully fragrant, very hardy, and well calculated for a pillar rose.

Jeane de Arc, yellowish-white, of strong growth.

La Nymphe, delicate pink, blooms profusely, dwarf habit. Lamarque, greenish-white, extremely large, profuse in bloom, perfectly double, and agreeably scented-closely approaches the tea rose in its size and fragrance; it makes a splendid pillar rose, frequently growing ten feet in one season.

Lady Byron, pink, very compact, and perfectly double, and is a good pillar rose.

Lutea or Smithii, pale yellow, large double flowers, but does not open well in moist weather; it is a superb article 
when perfect, and is quite a dwarf, having very little of the Noisette character, but delightfully scented.

Luxembourg, fine rosy purple, very perfect, a free grower and fragrant.

Maria, dark rose, perfect form, rapid grower.

Ophire, orange yellow tinged with red, very double, a free grower, fragrant, very distinct.

Orloff, bright pink, large and showy, though not very double - a profuse bloomer when well established - is a very strong grower, and excellent for covering arbors or trellises.

Phaloe, rosy pink, large, fully cupped flower.

Solfatare, sulphur yellow, large and perfectly double, a strong grower, very fragrant, when well established blooming profusely.

Superba, delicate pink, an old rose; perfectly double, blooms in large clusters; is of strong habit, and flowers profusely. This, with Noisette Lee, are our two best old Noisette Roses.

Vitellina, pure white, cupped form, very double. Washington, pure white, a strong grower.

\section{MUSK-SCENTED ROSES (ROSA MOSCHATA).}

The white musk-scented cluster rose is one of the oldest inhabitants of the rose garden, and is known all over the earth, where the rose has been cultivated, or its name been heard. It is supposed that it is the famed rose of the Persian poets. Although there are several varieties under this head, very few of them, indeed, have that peculiar fragrance which the genuine old species possesses. They require similar treatment to the Bourbon and Noisette Roses, and, in fact, fanciers have been, if possible, too minute to separate this group from the Noisette Roses, merely because they are, in some degree, musk-scented.

Old musk 'cluster, yellowish white, expanded and semi-double, blooms in immense clusters and finely scented. Herbemonte, pure white, very large flower in fine clusters. Princesse de Nassau, creamy white, perfectly double, very fragrant, and blooms in large clusters. 
Ranunculus, musk cluster, pure white, very double; flowers in very large clusters.

\section{CLIMBING ROSES THAT BLOOM ONLY ONCE IN THE SEASON.}

Under this head, we will have to place several roses from very different countries, but all agreeing in habit and flowering disposition. Our readers will now be fully impressed with the knowledge that all roses of luxuriant growth require copious nourishment. Such is the case with many of those we are now about to describe; but others of them will grow and bloom most beautifully perfect even on the poorest of soil, and are very capable of covering rock-work, a sterile bank, or naked wall, or any disagreeable object, where it is not convenient to excavate for the purpose of introducing nutritious soils; and several of them are of such a hardy nature that they will withstand the utmost severity of our Northern States; others are more delicate, and can only bear the mild winters of a southern climate, where they richly display both flowers and foliage, and even retain their foliage during winter, and are evergreens for screening disagreeable objects or covering arbors. The best of the united groups are

(r)* Ayrshire tea-scented, or Rosa Ruga, delicate blush, flowers very compact and perfectly double; it is a freegrower and an excellent pillar rose, with a delightful fragrance. There are several others of the Ayrshire Rose, under very tempting names, such as Double Crimson, Mottled, Eclipse, Ayrshire Queen, Elegans, $\&$. These may do for those who wish a multiplicity of names; but will not take with our floral public, who wish every plant to have some merit as well as a name to recommend it.

Boursalt, white, Rose de Lisle, Boursalt Florida, Calypso, Pompone Florida, and Bengal Florida, \&c., for it is known by all these names, and I have imported it four times, under different names; it is a blush white,

- Those marked thus ( $r$ ) will do admirably for rock.work. 
and frequently exceedingly large and handsome, and is a pillar rose : its very double delicate flowers have a fine effect.

Boursalt elegans, Purple Boursalt, Purple Noisette, \&c., flowers of a virid purple crimson, with an occasional stripe of white, nearly double, and an early and profuse bloomer; is an excellent rose for an arbor.

- Inermis, very large, bright pink, a little fragrant, grows and blooms freely.

Banksia alba, white, with pink centre, very small, but perfectly double; has an agreeable violet perfume, and is a profuse bloomer, but is entirely too delicate to withstand our winters. This and the following are natives of China:-

- lutea, yellow inclining to buff, in erery other character similar to the former. They are elegant evergreens in the gardens of our Southern States, and are very highly esteemed; frequently known under the name of White Evergreen Multiflora, and Yellow Evergreen Ifultiflora.

(r) Felicite de perpetua, Noisette floralunda, Abelard sempervirens, Noisette compacta, Mactemoiselle Euphrasic, and perhaps many other high-sounding names; it is a beautiful cream-white, with perfect shaped flowers, and makes a lovely rock-work or pillar rose; but is rather delicate for our severe winters.

Graulhie, pure white, cup form in large clusters, very double, a strong grower and free bloomer.

Grevillia, or seven sisters, is a very curious rose, flowered the first time with us in June, 1830. It is of the Multiflora variety, and is a native of China; growth free and luxuriant; leares large and deeply nerved; flowers in large clusters, almost every eye of the wood of last year producing one cluster, having on it from eight to twenty roses, according to the state of the plant, each rose expanding differently in color or shade. Many suppose that they expand all of the same color, and change afterward. This is not the case. We have seen them white, pink, red, purple, and various other shades when the bloom expanded; and on two clusters we have observed twenty-two distinct shades of color. In fact, it is a complete non- 
descript, having roses single, semi-double, and double, large and small, and every color between white and purple, forming, in every garden where it is planted, a wonder of the regetable world.

Multiflora, beautiful pink, very compact and double; it is rather tender for this latitude. Celebrated as being the first climbing rose that was planted in or about Philadelphia, and was so much admired that twenty dollars were frequently given for a single plant.

alba, similar to the former, but lighter in color, though not a pure white.

Laure de Voust, changeable pale blush, pink or white, very compact, of the most perfect form, and a profuse bloomer, of rampant growth, and more hardy than the two preceding; it is one of the most beautiful and elegant of climbing roses, with rather large flowers and luxuriant foliage.

Prairie Rose; a few elegant sorts have been grown from this single flowered native rose : all are of rapid growth and partaking of the parent in blooming later than roses generally that flower only once in the season; they are admirably adapted for covering arbors, rockwork, or out-buildings of any kind, being of the most hardy nature, and standing the severest of our winters even in the most Northern States.

Beauty of Prairies, or Queen of Prairies, dark rose, cup form, very large, and frequently striped with white; it is highly esteemed, and a strong grower.

Prairie Baltimore Belle, nearly white, very perfect form, quite double, blooming in clusters.

Superba, blush, a very profuse bloomer in rich clusters, perfectly double.

Purpurea, rosy purple, imbricated, very double; said to bloom again in the autumn.

Anne Maria, pale rose, large and double. Mrs. Hovey, blush white.

Mrs. Pierce, fine pink, perfect form.

Pride of Washington, rosy violet, beautiful.

Russelliana, Cottage Rose, and Scarlet Grevillia: this is a distinct article in-growth from any other of this group; it is perfectly hardy, and does not climb 
freely; still it makes a lovely pillar rose with large clusters of bright crimson shaded flowers.

Triumphant, bright cherry red, very distinct and perfectly double.

\section{ROSA MICROPHYLLA (OR SMALL-LEAVED ROSE).}

This pretty little rose was originally from China, and since it has been introduced, several additions have been made by cultivation; although we have not yet seen any to excel the original Rose microphylla. They delight in light rich dry soils, and form very fine bushes for grass plats or small lawns, and generally flower the whole summer, producing their blooms from short young shoots produced from the wood of two or three years' growth. The plants should all have a little protection the first winter after planting, and in pruning the shoots should only be thinned out, or any dead piece cut off; we have had several roses under very enticing names added to this group, such as striped microplyylla, crim, son microphylla, scarlet microphylla, all deceptive; and even the first plant that came out as double white proved to be entirely single; but there is now a genuine double white, though not properly a microphylla. The following few are all we have seen worth cultivating:-

Microphylla. This rose is unique in every character. The foliage is very small and neat, and the calyx thick and bristly. The flowers are produced at the extremity of the young shoots in twos or threes, according to the strength of the plant; they are large and double; the exterior petals large and full ; those of the interior are very short and thici-set; the color in the centre is dark, shading lighter toward the exterior; the spines are in pairs on each side of the compound leares. It is perfectly hardy, and greatly esteemed, and not so subject to be attacked by insects as other roses.

rubra, dark red, having every character of the preceding. They are frequently called "The Burr Rose," from the appearance of the bud.

violacé, reddish violet; in habit very similar to 
the former, but much darker in color, and is a true microphylla.

Microphylla odorata alba, yellowish white, perfectly double, and finely scented; is a strong grower and very constant bloomer.

Maria Leonida, white, centre tinged with pinls; is very sweet-scented-blooms all the season-but has more the habit of a Macartney than Microphylla Rose.

We have now concluded our fer descriptions of the beautiful family of Roses; informing our readers, if they should think it brief, we can assure them it is candid, and, as far as we know, in every respect impartial. No doubt we could have given many beautiful details of "things" we never saw and probably never will; and we also promise that a few of our descriptions will, in some situations and peculiar seasons, "come short," or perhaps "overshoot the mark;" for it is well known to the cultivator that double roses will occasionally come single, and red roses become blush, and blush roses frequently bloom entirely white, and vice versa. We have also seen a moss rose bush have roses and shoots entirely without their "mossy conat." We have also avoided a few of high standing in character; but not being entirely known to us in their intrinsic worth, a description of them would have been too hazardous, knowing that much exaggeration exists.

The Roses and all their allies, described in this month, should be planted from the first to the middle of the month; and we would again enforce upon our rose arnateurs the actual necessity of giving soil of enriching qualities to all their roses; they will be amply repaid for their trouble. Nearly all the failures of roses giving a grateful and even universal satisfaction, can be traced to bad and shallow soils, more especially in our city gardens, where cheapness of workmanship is the best recommendation; consequently, there are a few inches of tolerable-looking clay thrown over brickbats and lime rubbish, and, when finished, is considered a "fine job," because it is done cheap ; the result is, that often the very next season the whole has to be gone orer and done in a permanent manner; not less than sixteen or eighteen inches of the best dark loam should be in every garden, and 'that well incorporated with manure at lêast one year old, 
and also have a portion of sand or fine rotten rock thoroughly mixed with it; and then, and not till then, the proprietor may expect satisfaction.

\section{CLIMBING PLANTS.}

As shade is much required in this country, and plants suitable for covering arbors, \&c., eagerly sought for, we will make a few remarks on those which are preferred for their beauty, growth, hardiness, \&c.

Aristolochia sipho Birthwort, or Dutchman'spipe, is a very curious blooming plant, "with extraordinary large foliage, and makes an excellent arbor-twiner, affording a dense and cooling shade.

Calystegia pubescens, flower double, of a blush white color, of rather free growth ; dies down in winter and grows up again in spring; blooms from June to August.

C'lématis viticella pulchélla, or double virgin's bower, is an esteemed climbing plant, of rapid growth, with large flowers in great profusion from June to September. There are several rarieties of the above, two of them single, and it is said that there is likewise a double red.

corìlea, C. corulea grandiflora, and C. azurea granciflora. This beautiful and entirely new climber is already distinguished by three distinct, names, and has been several times figured, each time with more or less flattery. I must confess the first representation I saw of it, truly enchanted me; the brilliancy of its blue surpassing every flower I had ever beheld; and named $C$. azurea grandiflora. The flowers are frequently four or five inches in diameter, of a fine bluish violet color, blooming freely, and perfectly hardy, the most magnificent of the family.

C. Sietóldii, or bicolor. This is another of Dr. Van Siebold's Japan additions, and is nearly, related to $\mathrm{C}$. florida. The leaves and branches, however, are rather more downy, and the petals suffused with violet spots; the anthers are also of a violet color, which has given it the name of bicolor; it is of graceful 
habit, and the size and beauty of its blossoms render it an attractive inhabitant of the flower garden.

C. flámmula, sweet-scented virgin's bower, is of very rapid growth. Established plants will grow from twenty to forty feet in one season, producing at the axils of the young shoots, large panicles of small white flowers of exquisite fragrance ; the leaves are compound pinnate; in bloom-from July to Norember, but in August, September and October, the flowers are in great profusion, perfuming the whole garden. This is one of the best slimbing hardy plants, and ought to have - a situation in every garden.

C. montana, mountain virgin-bower, flowers in large clusters, rery pure white, a strong and rapid grower.

C. Virginiana is of rapid growth, and well adapted for arbors; flowers small white in axillary panicles, dioecious, leaves ternate, segmẹnts cordate, acute, coarsely toothed and lobed, in bloom from June to August. A native, and a little fragrant.

C. crispa, or Bell Clematis, is a native plant of free growth; flowers of a pink color, in clusters, bell-shaped, the points of the petals folding backwards-a little fragrant. There is also a variety having purple flowers.

C. flòrida plenò is a fine free flowering plant; though generally considered a shrub, is more herbaceous than shrubby; the flowers are large double white; in growth will not exceed ten feet in one season.

Glycine frutéscens, a beautiful natire climbing shrub, known in our gardens under that name, but is properly Wistèria frutéscens. It has large pendulous branches of blue leguminose (pea-like) flowers, blooming from Nay to August; pinnated leaves with nine ovate downy leaflets; grows freely.

chinénsis is given to Wistèria, and is the finest climbing shrub of the phaseolius tribe. The flowers are light blue, in long nodding many-flowered racemose spikes, blooming from Nay to August, profusely; leares pinnated, with eleven orate lanceolate silky leaflets, and is of a rery rapid growth. It is perfectly hardy, withstanding the severity of our winters without protection.

Bignònia crucigera is an evergreen which is very desirable in 
many situations, being likewise of luxuriant growth. It will cover in a few years an area of fifty feet; flowers of an orange scarlet color, blooming from Nay to August.

B. grandiflòra, now given to Tecòma, has large orangecolored flowers, blooming from June to August, and grows very fast. It is perfectly hardy, and a most magnificent plant.

B. rádicans is likewise giren to Tecòma, and is a native plant. When in flower it is highly ornamental, but it requires great attention to keep it in regular order, being of a strong rough nature; in bloom frow June to August.

Periplica graca, silk vine, is a climber of-extraordinary growth. Well established plants grow thirty or forty feet in one season; flowers in clusters from May to July, of a brownish-yellow color, and hairy inside; leaves smooth, ovate, lanceolate, wood slender, twining and elastic.

Hedera Hélix, Irish Ivy, is a valuable evergreen for covering naked walls, or any other unsightly object. The foliage is of a lively green, leaves from three to five angled. There are several varieties of it, all valuable for growing in confined shady situations where no other plant will thrive.

Ampetopsis hedercicea. This plant is commonly employed for covering walls, for which the rapidity of its growth and the largeness of the leaves render it extremely appropriate. There are several species of the genus, all resembling the Vine in habit and in flower.

Jasminum officinále, garden Jasmine. This delightful climbing shrub has been in common use all over Europe for covering arbors from time immemorial; its white, delicate, and lovely fragrant flowers render it a great acquisition. Unfortunately, with us, it is rather delicate for our winters, unless well protected by a south wall or other building, and even then, when in a joung state, must be protected: but, in the south, this plant and also the yellow Jasminum revolitum grow luxuriantly and bloom profusely, and eren $J$. grandiflórum is a hardy shrub in South Carolina and Georgia. 
Lonicera, or more properly Caprifolium. The Itoneysuckle. This genus of flowering odoriferous climbing shrubs are principally natives of this country: they are all equally beautiful; but. where there is not space in our city gardens to cultivate the whole family, it is indispensable to have C. Alexuósum, the Chinese sweetscented or evergreen; it blooms in May and September, and is a very rapid grower. C. Belgíca is also a charming species; it blooms the whole summer, and is very odorous. Our native C. sempervirens, or Coral Honeysuckle, is not easily surpassed; its profuse and brilliant scarlet flowers render it the most attractive object in all our country gardens. C. Japònicum is also an excellent Chinese species, with delicate orange-colored flowers of aigreẻable sweetness; but will not bear our winters north of the southern part of Virginia.

Passifiora, or Passion vine. There are several hardȳ species for this latitude; but the only very beautiful one is $P$. incarnàta, which, although it dies to the ground every winter, yet will, during the summer, put forth shoots from twenty to forty feet long, all covered with a profusion of beautiful purple flowers.

There are several other climbing plants, both curious and ornamental; but our limits will not admit of farther detail.

\section{DECIDUOUS SHRUBS.}

Finish planting all deciduous shrubs in the early part of the month. These plants are generally delayed too long; the leaves in many instances are beginning to expand, thereby giving a check to the ascending sap, which we may safely assert causes the death of one-third of the plants, when perhaps the operator or some individual more distantly concerned is blamed.

These shrubs, if properly removed and planted at the exact starting of vegetation, pressing the earth close to their roots when planting (previously taking care that the small fibres have not become dry, by exposure,) there will not one out of fifty fail by these simple attentions. Those that are late planted should have frequent waterings, and, if large, 
firmly supported, that the wind may have no effect in disturbing the young and tender fibrous roots.

\section{OF PLANTING EVERGREEN SHRUBS.}

Now is the season to plant all kinds of evergreen trees and shrubs. In most seasons, the middle of the month is the most proper time, the meather then being mild and moist; or if a late season, defer it to the end of the month. When planted earlier, they will remain dormant until this time, and their tender fibrous roots in that case frequently perish from their liability to injury from frost or frosty winds, being more susceptible of such injury than fibres of deciduous plants. They now begin to vegetate, which is the grand ciriterion for transplanting any plant. The buds begin to swell, the roots to push, and if they can be quickly lifted and replanted, they will hardly receive a check. At all erents, care must be taken that they are not long out of the ground and exposed to the air, which greatly assists the success in planting. It may be observed that evergreens in general succeed the better the smaller they are, although we have seen plants, trees and evergreens successfully lifted upward of thirteen feet high, and fifteen in diameter, and carried sereral miles.*. By the second year there was no appearance that such operation had taken place. In preparing a liole for the reception of these plants, make it larger than the roots, breaking the bottom thereof fine, and putting in some fresh soil. Place the plant upright in the centre,

- putting in the earth and breaking it fine, and give the plant a few gentle shakes. When the roots are more, than half covered, put in a pot or pailful of water, allowing it to subside; then cover all the roots, gire a second or third pailful, and when subsided, the earth will be close to all the roots. Corer with more earth, pressing all firm with the foot. Put more soil loosely on, which will give it a finished appearance, and prevent it from becoming dry, and not require mulching, which has an unsightly appearance. All that the wind will have any hurtful effect upon must be firmly supported espe-

* See Mr. IINal's rich pamplilet treatise on removing evergreens, \&c. 
cially large plants. If the weather sets in dry and hot, they should be watered as often as necessity shall direct.

Those that are established, it will be necessary to go over them (if not already done) to cut off all wood killed in winter, and also to thin them if too thick and crowded.

When the above is done, let every part of the shrubbery be dressed off as directed in March. Shrubs of all kinds will now begin to look gay and lively, which may be very much. heightened or depreciated, according to the state in which the ground and contiguous walks are kept. Always keep in view that weeds are no objects of beauty.

\section{CARE OF CHOICE BULBS.}

Hyacinths of the earliest sorts will begin to expand and show their colors; of which we can boast of a few as fine sorts in the vicinity of Philadelphia as in any garden of Europe; but even these very superior sorts, when in bloom, are too frequently neglected, being allowed to stand without rods, stakes, or any means of support, likewise equally exposed to drenching rains and scorching suns; and the finest collections may be seen after heavy rains prostrate on the ground, whereas a few hours' trouble would give them the requisite support, thereby preserving their beauty much longer, and giving more gratification. As soon as the stems advance to any height, they should be supported by wires, rods, \&c., and tied slightly thereto with threads of matting, or any other substitute; repeat the tying as they advance, avoid tying among the florets, because they grow by extension, and are liable to be broken off by so doing. The sun deteriorates the colors very much, especially the red, blue, and yellow sorts; whereas, if they were simply protected from the sun by an awning of thin canvas, the colors would be preserved and the beauty protracted. If there are stakes drove into the ground on each side of the beds, about three feet high, with others in the centre about eight feet, having laths or hoops from the side to the centre, formed similar to the roof of a house, so that people may walk or sit under it, the canvas or awning being thin to admit of the light freely, the effect in the time of sunshine, from the brilliancy of the colors, is peculiarly gratifying. Where an awning is thus 
erected, it requires to be kept on only from nine to three o'clock in sunshine days, and during nights or time of rain, allowing the awning on the most northern side to come close to the ground, when necessary, to shelter them from cold cutting winds.

The properties of a good Hyacinth are, namely-the stem strong and erect, the florets or bells occupying one-half of the stem, each floret suspended by a short strong footstalk, longest at the bottom; the uppermost floret quite erect, so that the whole may form a pyramid. Each floret well filled with petals rising toward the centre, that it may appear to the eye a little convex. Regarding color, fancy does not agree, and the most scrupulous cultivators differ materially. Howerer, the more pure and bright the finer, or a white with a pink centre, or the centre of the petals with a paler or deeper color appearing striped, which is considered to have a good effect.

Tulips in every respect should have the same care and protection, never neglecting to have the beds with a smooth clean surface, and the stems neatly tied up, although they are not in so much danger as Hyacintbs.

The characters of a good Tulip are-the stem strong, elastic, and erect, about two feet high; the flower large and composed of six petals, proceeding a little horizontally at first, and then turning upward, forming a flat-bottomed cup, rather widest at the top; the three exterior petals should be larger than the three interior ones, and broader at their base; the edges of the petals entire, free from notch or ruggedness; the top of each well rounded. The color of the flower at the bottom of the cup ought to be pure white, or yellow, and the rich-colored stripes, which are the principal ornament, should be pure, bold, regular, and distinct on the margin, and terminate in fine points elegantly penciled. The centre of each petal should have one bold stripe, or blotch, of rich coloring. The ground colors that are most esteemed are white, the purer the finer; or, on the other hand, the dark grounds, and of course the darker the better; but these vary in estimation, according to the prevailing taste of amateurs. 


\section{ANEMONES AND RANUNCULUS.}

Moist weather and frequent showers are highly essential to the perfecting of these flowers; and if these should fail at this season of the year, artificial means must be used to supply the deficiency. Take a watering-pot without the rose, and run the water (river or rain water is best) gently between the rows, taking care not to make holes in the ground. When they have got a good watering at root, take the syringe and give them a gentle sprinkling in fine evenings, observing not to use force for fear of breaking the flower stems. In dry weather, the result of a deficiency of water would be, that the stems and flowers of the strongest roots will be weak and make no progress, and many of them will not bloom; the foliage of a sickly, yellow appearance, from which they would not recover; and the roots, when taken up, are of little use for farther transplanting.

A good plan in dry seasons is to cover the ground between the rows with cow manure, which will prevent the moisture from evaporating; and the rain or water passing through it greatly enriches the soil and strengthens the roots.

\section{CHARACTER OF A FINE RANUNCULUS.}

"It is indispensable for a good ranunculus to have a stem about eight or twelve inches high, strong enough to support the flower, and quite upright. The form of the flower should be hemispherical, not less than two inches in diameter, consisting of numerous petals, gradually diminishing in size to the centre, lying over each other, so as neither to be too close nor too much separated, but having more of a perpendicular than a horizontal direction, in order to display the colors with better effect. The petals should be broad, with entire well-rounded edges, their colors dark, clear, rich, or brilliant, either of one color or variously diversified, on a ground of cinerous white, primrose, yellow, or flame color, or diversified with elegant stripes, spots, or mottlings." 


\section{AURICULAS.}

Having under this head last month given ample directions for the treatment of these plants previous to flowering, we refer to that head to avoid repetition.

\section{CHARACTER OF A FINE AURICULA.}

The pips should be large, flat, and round, with ground color equal on every side of the eye, which should be quite circular, as well as the edge. The tube a bright lemon yellow, perfectly round, well filled with the anthers or thrum, the eye round and large, the body color black or violet, the meal fine; the color, in green-edged flowers, should be a whole one, not a shaded green. The stem strong, and sufficiently long to bear the truss above the foliage-the truss to consist of not less than five full-blown pips; only one stem allowed.

\section{CARNATIONS, PINKS, \&c.}

If any of these were omitted to be shifted last month, or planted out according to directions therein given, let it be done forthwith. Where they are still protected with frames, give them plenty of air, keeping the sashes entirely off during the day, keep the pots perfectly free from weeds, and gire the foliage frequent sprinklings with water.

Polyanthus and Primroses will be exhibiting their beautiful flowers. They require the same treatment, and delight in moisture and a shaded situation. Do not sprinkle them while in flower, and keep them clear of weeds or decayed leares, never exposing them to the sun. They are very hardy, and, where required, may be planted in very shady situations, for they will suffer more from the influence of the sun's rays than from frost. Those plants in pots in general that have been protected in frames, and are destined for the borders, should now as soon as possible be planted in their destined situations, having nothing to fear from chilling winds or frosts after the middle of this month, except in un- 
common seasons. Those that are to be kept in pots, if not repotted, do it immediately, and give regular supplies of water.

\section{CHARACTER OF A POLYANTHUS.}

The pips large, flat, and round, with small indentures between each division of the limb, dividing the pip into heart-like segments edged with bright yellow; the edge and the eye ought to be of the same color, the truss to consist of not less than five full-blown pips, supported on a strong stem, standing well above the foliage.

\section{POLIANTHES TUBEROSA FLORE PLENO.}

This very popular bulb, generally known as Tuberose, has been cultivated in England upwards of two centuries, whence we no doubt have received it, and now can return those of our production to supply their demand. The flowers are many and highly odoriferous, and of the purest white, and on a flower stem from three to five feet high. To have them in the greatest perfection, they should be planted in a lively hot-bed, about the first of this month, in six inch pots filled with light rich earth, giving very little water until they begin to grow, when they ought to be liberally supplied with plenty of air, and about the end of next month they may be planted in the borders, providing a spot for them that is or has been well worked, and enriched with well-decomposed manure. Secure their flower stems to proper rods. Previous to planting the roots, all the off-sets should be taken off and planted separately; keep the crown of the bulb level with the surface of the pot, and when they are replanted in the open ground, put them two inches deeper.

But when the convenience of a hot-bed cannot be obtained, they will succeed very well if planted about the end of this month or first of next in the garden, in a bed of earth prepared for their reception. Let it be dug deep, and make the soil light and rich, by giving it a good supply of manure two years old, well broken and incorporated with the earth, adding a little sand where the soil is heavy. The black earth from the woods produced from decayed leaves is equally as 
good without sand. Having the ground in proper order, draw drills about four inches deep and eighteen inches apart; plant the bulbs (after divesting them of their off-sets) nine inches apart in the row, covering the crown of the bulb about an inch and a half. When done, carefully rake and finish off the beds. When they shoot up their flower stems, give them neat rods for their support. Plant the off-sets in closer rows to produce flowering roots for next year, because they seldom flower the second time.

\section{ON THE CULTURE OF THE HEARTSEASE OR PANSY (VIOLA TRICOLOR).}

The simplicity and striking beauty of this lovely little flower have attracted notice from the earliest floral times, but it is only within these few years that it has come into high estimation as a florist's flower. Indeed, when the figures and descriptive characters of these "little gems" came first from England to this country, we were almost induced to believe they were exaggerated "pictures of fancy," till we actually cultivated within these last two years in our own parterre upwards of two inches in diameter.

They delight in a situation partially shaded from the hot rays of the sun, either fully exposed to the morning rays till ten o'clock, or the afternoon sun from three o'clock; a soil composed of four parts good loam and one part thoroughly rotted manure, or three parts loam and one part decayed leaves, not less than one foot deep: the soil must not be more elerated than the surrounding surface, as they like a good supply of moisture. If they are to be cultivated from seeds, they should be thinly sown about the first of the month, or about the end of August or first of September, and very lightly covered with fine soil, giving them very frequent waterings in dry weather. Those sown now will bloom in July, and very profusely in the autumn; but those sown in the latter period will not bloom till early the following spring. When any very esteemed variety is raised, it should be propagated, which is very easily done, either by layers or cuttings, and sometimes by division of the root, but the two former methods are preferable. The best time for laying is about the first of September: an inch or two of the soil may 
be removed all round the plant, the shoots laid down in the hollow, and covered over with light rich compost. The shoots will root more freely if they get a gentle twist when laying them down. The best period-for propagating by cuttings is about the middle of this month or September. Cuttings should be chosen from young shoots about two or three inches long; for when shoots are woody or hollow they will either not strike at all or produce unhealthy plants. A shaded but airy situation is preferable, and if the soil is of a light sandy nature, the better success will attend the operation: the cuttings should be firmly inserted from one to two inches deep in the ground, and corered with a glass, or where that convenience is not at hand, they may be shaded during the day with oiled paper, or any similar substitutes. In preparing the cuttings, care ought to be taken to cut close to a joint, a rule which should be strictly attended to in making cuttings of every description. When they have fairly rooted and taken a growth, they can be remored in cloudy, moist weather, to their proper allotments. Seeds ought to be carefully collected from the finer sorts, and sown as soon thereafter as convenience will allow, as they deteriorate by long keeping. Many hundreds of named varieties are carefully cultivated in England. A select list sent contains only three hundred and serenty-four names. To attempt a general or even brief description of them in this work would be considered by many of our friends prolix and unnecessary; but the following criteria of a fine Pansy has just passed a select committee of the Pennsylvania Horticultural Society:-

"The chief object to be desired is symmetry of the flower. The petals should be large, broad and flat, lying upon each other so as to form a circle, and prevent anything like angles or intersections of this circular outline. The petals should be as nearly of a size as possible, the two top ones being the largest, but so covered with the two side ones as not to appear disproportioned. The top petals should not wave or bend back. The bottom petal should be broad and two-lobed, flat, and not curving inward; above an inch in breadth is a good size; the colors should be clear, brilliant, and not changing. The eye should not be too large, and it is accounted finest when the penciling is so arranged as to form a dark angular spot.

"The flower stalk should be long and stiff, rather than slender." 


\section{GLADIOLUS OR SWORD LILY.}

It is now a well-ascertained fact that the whole of this beautiful family will suceed well with a treatment similar to the tube rose, requiring to be two or three weeks earlier planted: indeed, $G$. comminis and its varieties are perfectly hardy; but the splendid $C$. psittacinus, with large yellow, red, and green flowers; G. cardinalis, scarlet and white; $G$. blandus, rose and white; G. florabundus, shaded rose, G. formosissimus, magnificent scarlet; G. Gandavensis, large and superb orange scarlet and yellow; $G$. ramosus, delicate waxy pink, of strong growth; G. Buistii, bright scarlet shaded with orange and yellow, splendid; and several others are worthy of the greatest care and attention. Their large spikes of showy flowers will well compensate for an extra degree of care in preparation of soil, \&c.

\section{AMARYLLIS FORMOSISSIMA, OR JACOBEA LILY.}

About the end of this or beginning of next month is the most proper time for planting out these bulbs. 'This flower is of tho most beautiful and rich crimson velvet color. 'The bulb generally produces two stems, the one after the other, about the end of May or first of June. The stem is from nine inches to one foot high, surmounted by a single flower, composed of six petals, three hanging down, three ereet and recurved; the stamens droop on the centre of the under petals. The flower thus appears nodding on one side of the stem, and has a most graceful and charming appearance. If planted in a bed, prepare the ground as before directed for Tuberoses. Keep the rows one foot asunder, and the bulbs six inches apart in the rows, eovering them two inches over their crowns. This plant is now ealled Spreiticlia formosissima, and we think properly, too, for its character and habit differ from Amaryllis.

We have not the smallest doubt that, in a few years, not only this superb South American bulb will adorn our flower gardens, but many of the rich bulbs of Brazil and South America generally will yearly exhibit to us the beaty of their colors, and the beautiful construction of their flowers 
and foliage, of which we are now generally deprived, perhaps because we have not the conveniency of a proper hot-house for their protection during winter. But it will be found, in many instances, that these bulbs will do perfectly well to be kept dry in a warm room from October to May, when the heat of our summer is sufficient for the perfection of their flowers, and many species will ripen their seeds. 'The bulb that is known as Amaryllis Belladónna, now called Belladónna purpuráscens, is hardy.

\section{TIGER FLOWER.}

Trigriflia, a genus of Mexican bulbs belonging to Monadelphia 'Triandria, producing the most beautiful flowers of the natural order of Iridea. 'T' pavomia is of the brightest scarlet, tinged and spotted with pure yellow. 'T'. conchiflore, color rich yellow, tinged and spotted with bright crimson; flower larger than the former. The colors are very rich, and purely contrasted. The corolla is about four inches in diameter, composed of six petals; the outer are reflexed. 'The flower, though splendid in beauty, exists only one day; but, to compensate for that, a plant will produce flowers for several weeks; and where a bed of them can be collected, they will bloom in profusion from July to September. 'They like a light, rich, free soil, from twelve to eighteen inches deep. Lift the bulbs in October, and preserve them as directed in that month for I'uberoses. Be sure that they be kept dry and secure from frost. A bed of these should be in every garden. A writer says, "It is the most beautiful flower that is cultivated." Plant them about the end of this or first of next month; if in beds, keep them six inches apart in the row, and one foot apart from row to row.

\section{WALKS.}

The walks in general should be put in the neatest order during this month. Little requires to be added to the ob"servations of last month; but if these have not been executed, fail not to have it done the first opportunity, choosing dry weather for the operation of turning the old or adding new 
gravel to them, leveling, raking, and rolling neatly as you proceed. Always after rain give the whole of the gravel walks a good rolling. This being frequently done during the early part of the season, will be a saving of much labor and time through the summer. The walks having a firm surface, the growth of weeds will be retarded, and the heavy rains will not be so apt to injure them. Where there are any pretensions to keeping these in order, they ought to be picked of weeds and litter once a-week, and gone over with the roller at least once every two weeks during the season.

Sweep and divest the grass walks or plats of all wormcasts, litter, \&c., cutting the edgings neatly. Mow the grass every two or three weeks from this time to October, sweeping off the grass clean each time, and give frequent rollings to keep the surface smooth. If any require to be laid with turf, delay it no longer. For direction, see last month. The above observations on walks in general will apply through the season; therefore, we will not repeat this subject until October.

\section{EVERGREEN HEDGES.}

We have previously observed, under the head Evergreens, that this is the best season for their replanting. We cannot pass over the obserrations of this month without having reference to evergreen hedges, so much neglected among us, and yet so important to the diversity of aspect, and especially to soften a little the gloomy appearance of our winters. There are three indigenous shrubs, and at least three exotics, that are well adapted for the purpose, viz., Pinus Canadénsis, Hemlock-spruce; Thùja occidentàlis, American arborvitæ; Thùja orientàlis, Chinese arborvitæ; and Juniperis Virginiàna, Red-cedar. Where there is to be a hedge of any of these planted, select plants about two feet high; lift them carefully, preserving the roots as much as possible. Dig a trench from one and a half to two feet wide, and from one to one foot and a half deep. This will admit the soil to be well broken about the roots, which must be done in planting. Keep the plants in the centre of the trench, mixing the shortest and the tallest, that it may be of one height, putting the earth close about their roots as you proceed, and make it 
firm with the foot; fill up, and water as directed for evergreens in this month. If the season is very dry, give it frequent copious waterings.

None of them should be topped for a few seasons, except such as are much above the others in height, keeping the sides regular and even by clipping or shearing once a-year, either in this month or at the end of August. It is better to keep the top (when they have got to the desired height) pointed than broad. The latter method retains a heavy weight of snow, which frequently breaks down, or otherwise deforms, that which has cost much labor to put into shape.

Euonymus japonica, bright green foliage of free growth and quite hardy. There is also the variegated variety, very excellent for hedges south of this latitude.

\section{BOX EDGINGS.}

Where these have not been laid, this month is the proper time. Do not delay the planting of such any later. For ample directions, see March, under this head. Clipping of these should be done about the middle of this month. There will then be no danger of frosts to brown the leaves, and the young foliage will not be expanded. To keep these edgings in order, they must be cut once a-year, and never be. allowed to get above four inches high and two inches wide. What we consider the neatest edging is three inches high, two inches wide at the bottom, tapering to a thin edge at the top. It is very unsightly to see large bushy edgings, especially to narrow walks.

The use of edgings is to keep the soil from the gravel, and the larger they are allowed to grow, the more ineffectual they become; growing more open below as they advance in height. The operation may be done very expeditiously by clipping the tops level, going longitudinally along with shears for the purpose, called "box shears." Strain a line along the centre of the edgings, cutting perpendicularly from the line to the bottom on each side, leaving only the breadth of the line at top. Edgings cut in this manner, every spring, will always look well, and the trouble, comparatively, is a mere trifle. 


\section{GENERAL CARE OF PLANTS COMING INTO FLOWER.}

Every part of the flower ground should be put into neat order, giving such plants about the borders as are shooting up their flower stems, and are tender, and in danger of being hurt or broken by the wind, proper sticks or rods for their support. In doing this, endeavor to conceal the rods, \&c., as much as possible, by dressing the stems and leaves in a natural-looking manner over them. Let the stakes be in proportion to the height and growth of the plants. It looks very unsightly to see strong stakes to short and weak-growing plants. The tyings likewise should be proportionate.

Examine all the beds and patches of seedling flowers now coming up, and let them be refreshed with water as it may be necessary, and pick out the weeds as they appear.

We cannot leave this department at this season of the year without enforcing the benefit and beauty that will result from keeping the weeds down during this and the next month. Therefore strictly observe that there are none running to seed in any part of the garden; in fact, they ought not to be allowed to rear their heads one day in sight.

\section{MAY.}

As the season for planting out the Dahlia is now approaching, we will endeavor to give our readers the whole subject of their management, so as to insure a good bloom of this the most fashionable and popular ornamental plant of the present day. As very many are entirely unacquainted with the nature and even the habits of the plant, a brief synopsis of its history will assist in giving a key to its culture. The plant was first discovered by Humboldt, in Mexico, growing in sandy plains, three thousand feet above the level of the sea. The date is not precisely known, but supposed to be about 1785-6. Indisputable authority, however, speaks of its being introduced into England in 1789; but was lost and again introduced in 1803, from Madrid, by 
Lady Holland; from which period till 1830 it had but little notice in cultivation. Indeed, it seems to have been reserved for the intelligent growers of the last few years to bring it into general notice; and if we take a retrospective view of the rapid progress of Dahlia culture within these last five years, we will be led to exclaim, "Where will all this terminate?" But time alone can solve the question; at present it is impossible to come to any satisfactory conclusions. Only a few years ago, and who would have conceived the idea of having tipped, striped, and spotted Dahlias of almost every hue and color; and although historical writers on the genus alluded to the improbability of a blue flower ever being produced, yet it is not unreasonable to imagine that ere long we will have flowers beautifully and distinctly striped with black and white, and even combining the gaudy colors of the tulip, or the choicest hues of the carnation; perhaps the criteria of character may change to those of huge globular forms or balls-nay, even the odor of the Rose or the Jasmine may be imparted, and what then? Only let amateurs and cultivators perserere with the spirit they have done during the last few years, and we think all we have adranced will be realized.

Propagation. This operation may be performed in various ways, either by division of the root, by cutting off the young shoots, or by grafting. For general planting, division of the root will be sufficient; about the first of the month the old root, entire, should be planted in some warm and sheltered spot of the garden, covering it with sand, vegetable mould, or any light soil; in about two weeks the eyes or young shoots will have sprouted: then it will be properly seen how they can be most carefully divided; the root should be carefully cut into as many pieces as there are eyes or sprouts, leaving only one tuber to each, when they can be planted into the situation appropriated for their blooming.

Propagation by Cuttings. Prepare a hot-bed in March, as therein described, and place a frame and lights of the required size upon it; scatter over the surface of the bed four or five inches of sand, old bark, or any light soil; after four or five days, the fresh steam will have subsided, when the roots may be laid thereon, covering them (but not over the crowns) with light sandy soil; but where large pots can be obtained, I prefer planting them in the pots; by this means 
the plants are kept distinct, and can be taken out at any time and examined. They should be frequently sprinkled with water that is partially warm; and if, after they are thus placed in the bed, a rank and dense steam should arise, the lights should be slightly raised both night and day, till it subsides; and if the nights are cold, cover the lights with mats or shutters. This gentle bottom heat will speedily induce the eyes to grow, and when the shoots have attained the height of three or four inches, they should be cut off close to the base, which makes the best plant. After the cuttings are taken off, pot them singly into very small pots filled with light sandy loam, containing a good portion of black earth from the woods, and placed in another moderate hot-bed and give a gentle supply of water. Particular care must be paid to shading them from the violent rays of the sun, for if they are once exposed, they seldom recover: in this state they should continue till they have formed their roots, which, in a temperature of from sixty to seventy degrees, will be in from two to three weeks. Where a great stock of any particular sort is wanted, the cuttings should be taken off just below a joint, learing two or three eyes at the base of the shoot, which will again speedily produce new shoots, that can be again removed in a similar manner.

When the plants are rooted, they may then be considered established, and all that is necessary is, to shift them into larger pots as they require; and gradually inure them to a lower temperature, till they can endure the open air, which will not be before the middle of May.

Propagation by Grafting. Where only a few plants are wanted, this is a very successful method, as an operation can be conducted in the office or parlor window. The cutting intended for the graft should have about three joints; when obtained, select a good tuber without eyes from any common sort, and with a sharp knife cut a slice from the upper part of the root downward about two inches in length, and about half an inch in depth, and then cut it off horizontally, learing a ledge whereon to rest the graft; next cut the graft sloping to fit, and cut it so that an eyc or joint may be at the bottom of it to rest on the aforesaid ledge. After the graft has been firmly tied, a picce of clay should be put round it; pot the root in fine soil, in a pot that will bury the graft half way in the mould, and corer it with a glass (a 
large tumbler will do), and in two weeks it will have taken root; the glass may then be removed, and the plant gradually inured to the open air.

Soil. As far as my obserrations enable me to judge, the soil best adapted for the Dahlia is a sandy loam, not retentive of moisture, and not too rich, as they will grow to leares and branches, producing few flowers, and even then imperfect: not too poor, as in such they will be very indifferent, meagre in size and general appearance. Where soils are rich and heary, a portion of sand or gravel should be mixed in the soil where they are planted: but if poor, incorporate with the sand well decomposed manure; and when the plants are planted, a stick in proportion to the plant should be put with it, and at least eighteen inches in the ground, and not less than two inches in diameter, to which they must be carefully tied as they grow, never allowing more than one stem to each plant; and the side branches should be cut off from one to three feet from the ground, according to the height of the plant. Emperor de Maroc, the most favorite crimson Dahlia, tipped with white, comes invariably true to its character in sandy soil, whereas, in rich heary soil, it is frequently only crimson. The worst of all soils for the Dahlia is a rich loam retentive of moisture; in such they grow to wood and foliage, producing few and very imperfect flowers.

The best disposition or arrangement in planting the Dahlia, I think, is in groups; each group should be composed of a different section of color: this affords a close comparison, and gives greater diversity of landscape than combining the colors; the tallest growing sorts should be carefully planted in the centre or at the back of each group. The roots should be planted from three to four feet from each other every way. But where they are planted in rows along walks or avenues, two or three feet will be a sufficient distance from plant to plant. Individual plants look extremely well if they are of a dwarf habit. To have a continued succession of bloom, there should be two plantings; the first about the fifteenth of the month, and the latest about the end of June; it is the June planting that generally produces the finest flowers; this fact (though lately discovered) is now well understood by some cultivators, and is easily accounted for. When plants are forced and planted early, they are in a flowering state much earlier, to be sure, 
but they are orertaken with, perhaps, a hot dry summer, which "blights" the buds, and are more subject to the disease called "curl;" the young leares, as they expand, are perforated with numerous holes; the margins become brownish, as if burnt; they then become curled, placid, and the whole plant unhealthy and dwarfish. The principal stem ceases to grow, and numerous suckers and stems arise from below, forming a dense bush. The flowers of such plant, as might be expected, are small and irregular; and however excellent the variety may be, they yield nothing but disappointment to the anxiously expectant cultivator. This disease is caused by an insect, Cymix Chloroterus, or green bug. It inhabits the extremities of the Dahlia, and grows and feeds on the under surface of the young leaves, and in its destruction is aided by our frequently hot and arid months of July and August. Hence, the reason that the late planting gives most satisfaction, they are in these months in a rapid growing state, and if attacked outgrow the effects, and push at once into bloom in the more moist and cooling month of September. The only remedy that is known for the above evil is, to look over the plants cautiously in the morning when the first attacks are perceptible, and pick off the insect; it has to be approached with caution, as it instinctively throws itself down among the leares if disturbed; and if it escapes, it again climbs up, and commences its depredations. It is admitted that there are exceeding one thousand distinet named varieties now in cultivation, and it may be desirable to some that a select list of the choicest named sorts now in cultivation should be given: but such is the almost endless multiplicity of kinds, and such the numerous additions every year made, that in a few years those I may mention now as being fine will then most probably be considered wholly useless. However, for immediate profit and benefit, I recommend the following :-

\section{PURE WHITE.}

Antagonist, Cheltenham Queen, Nount Blanc,
Indispensable, Miss Perciral, Princess Alice. 
WHITE OR BLUSH, SHADED OR EDGED WITH PINK OR RED.

Acantha,

Mrs. Rushton,

Miss Vyse,

Lady of the Lake,

Princess Radzivill,

LILAC.

Princess Royal,

Victorina,
Gem, Favorite, Bridal Ring, Star.

ROSE OR PINK.

Hero of Tippecanoe, Joshua Longstreth, Madam Dresser,
Helen, Queen (Widnall's), Dowager Lady Cowper.

PURE YELLOW.

Apollo,

Yellow Victory,

Croceus,
Argo,

California,

Florence Dombey.

YELLOW OR BUFF, STRIPED OR TIPPED WITH RED

Desdemona,

Madam Zahler,

Victor,
Unique,

Pactolus,

Nell Gwynne.

ORANGE.

Tison d'Or, Orange Superb. 


\section{RED OR ROSY RED.}

Perfection (McKenzie's), Cardinal Ferettii,
War Eagle,

Glory of Altenberg.

\section{SCARLET.}

Bloomsbury (Lee's),

Fire Column,

Scarlet Gem,
Fire King,

Fulwood,

Scarlet Perfection.

ROSY CRIMSON.

Caleb Cope,

Victory of Sussex,

Thomas Clarkson.

\section{CRIMISON.}

Compactum, Richard Cobden,

Warrior,
Louis Philippe,

Orb,

Westbury Rival.

DARK MAROON AND VERY DARK.

Admiral Stopford, Ifero of Stonehenge, Standard of Perfection, Othello, .
Vesurius, Col. Baker, Essex Triumph, Rio des Pontille.

CRIMISON PERMANENTLY TIPPED WITH WHITE.

Oakley's Surprise, Josephine, Emperor of Morocco,
Miss Shaw Leferre, Miss Blackmore. 
May.] Character of a Fine dahlia.

\section{STRIPED.}

Striata formosissima,

Multicolor.

\section{YELLOW TIPPED WITH WHITE.}

Mimosa, Andromeda,

The Baron.

The above are the choicest in cultivation at the present time, and for farther description in regard to color, height and price, we beg to refer our readers to the-periodical catalogues of our respectable nurserymen that are issued every spring, and contain many other sorts of eminence; and not a few equally desirable with the above, though the descriptions of some that are annually received from England are more tempting than the article. Whether there are some sorts that do produce more perfect and beautiful flowers in their humid climate than they do when transferred to ours, we cannot practically decide, but presume that it is the fact, for we are confident, and every season does more fully confirm it, that the seedlings grown in this country from seed sowed here do grow better, and flower finer, than the generality of those imported; and, to prevent us adopting inferior sorts, and giving them dashing names, we subjoin the following rules for judging:-

\section{CHARACTER OF A FINE DAHLIA.}

"The best judges distinguish Dahlias by the three criteria of form, color and size.

"1. Form.-The front view of the blossom should be perfectly circular, without notches or inequalities, caused by the petals being pointed, and not, as they should be, rounded; smooth at the edges, and slightly concave, but not so much as to show any of the back. One of the most perfect flowers, in this respect, is the Springfield Rival. When the petals are pointed, notched, fringed, piped, quilled, concave, convex, or flat, the perfectness of the circle is broken, and one indispensable beauty in the eye of the florist is deficient. 
"When the eye or dise is shown in the full-blown flower, it is also a striking defect.

"The side view of a first rate flower should be that of a perfect hemisphere.

"There is, perhaps, no example of this perfection of form without some slight deficiency. The Countess of Liverpool is one of the nearest to a perfect flower in this respect.

"2. Color.-This is looked upon by florists as an inferior consideration to form, though it is usually the first to attract the notice of common observers.

"In flowers of one color, or selfs, the color ought to be bright and distinct, without any breaking or blotching. When there are stripes, mottlings, shadings, or edgings, these should be clear and uniformly marked, the colors distinct without clouding or running.

"3. Size.-Although large flowers with superior form and clear distinct colors are esteemed superior to small flowers with the same properties, yet size alone is looked upon by flcrists as nothing when form and color are defective."

Particular care should be taken with seeds, especially such as are sared from fine sorts. If they are sown about the first of April, on a gentle hot-bed, or in a green-house in plots, filled with light rich earth, covering the seeds about three-eighths of an inch, and when they have made leares, pot them off singly into small pots, till time for planting out, or where a quantity is grown, three plants may be put into one pot, and thus planted, and when they bloom the bad can be pulled up, leaving those of good character to stand for farther trial: none should be kept but such as come up to the above rules; and if they do not do so the first year, there is little hope of their being more perfect the second.

\section{ANNUALS, HARDY AND TENDER.}

By the first of the month, finish sowing all hardy Annuals and Biennials; and about the middle of the month all those that are tropical. The weather being now warm, they will vegetate in a few days or weeks. Attend to thinning of those that are too thick, giving gentle waterings to such as are weak in dry weather. Those that have been protected in 
frames should be fully exposed therein night and day; take the first opportunity of damp cloudy days to have them transplanted into the borders or beds, lifting them out of the frame with as much earth as will adhere to their roots.

\section{CARE OF HYACINTHS, TULIPS, \&c.}

For the treatment of these, while in bloom, see last month. The best time to take them out of the ground is about five weeks after they are done flowering, or when the stem appears what may be termed half-decayed. The best method to dry them is to place the roots in rows, with bulb to bulb, the stems lying north and south, or east and west. Give the bulbs a very thin covering of earth, merely to exclude the sun, so that they may not dry too rapidly, being thereby liable to become soft. When they have thoroughly dried in this situation, which will be in eight or ten days in dry weather (and if it rains cover them with boards), take them to an airy dry loft or shade, clearing off the fibres or stems, and in a few weeks put them in close drawers, or cover them with sand perfectly dry, until the time of planting, for which see October.

It is not advisable to allow any of the bulbs of either Hyacinths or Tulips to seed, as it retards their ripening and weakens the root, except where there are a few desired for new varieties. The small off-sets must be carefully kept in dry sand, or immediately planted.

\section{ANEMONES AND RANUNCULUS}

These, while in bloom, should be carefully shaded from the sun by hoops and thin canvas, or an erect temporary awning; and as soon as they are done flowering, they must be fully exposed and the waterings given up.

\section{TUBEROSES AND AMARYLLIS,}

That are not planted, should now be done. For full directions, see last month. In many seasons, any time before the twelfth is quite soon enough; but nothing ought to be 
delayed when the season will permit it to be done. It is necessary to have them properly labeled.

\section{AURICULAS, POLYANTHUS, AND PRIMROSES}

Will now be done flowering, but still must be carefully kept in a cool, shady situation, and all decayed leares cut off as soon as they appear. Examine them carefully and frequently, in case slugs of any description be preying upon them. A dusting of hot lime will kill them, or they may be otherwise destroyed. Some have recommended to repot and slip those plants when done flowering, "or they will contract a destructive disease;" which disease is a loss of verdure, and is induced by too much heat and drought, and a few other causes from inattention; but if attended to as above, until September, when they should be fresh-potted, they will have time to be sufficiently established before winter, which is the most judicious time to take off slips, for two reasons, namely, they do not want so much nursing through the most precarious season of the year (summer) for these plants, and they begin to grow, and will root afresh sooner.

\section{. DOUBLE WALL-FLOWERS.}

As these are very seldom grown from seed, and are semibiennials, art has to be used to preserve or renew them. About the end of this month, take shoots of this year about three inches long, cutting them carefully off, and smoothing the cut end with a sharp knife: from this, cut the lower leaves off about one inch and a half, and then put it in the ground; choose a very shady spot, mixing the soil with a little sand and earth, or decayed leaves. Sprinkle them three times a-day until they have taken root, which will be in a few weeks. Keep the cuttings about four inches apart.

\section{GENERAL OBSERVATIONS.}

We do not consider that it is essential every month to repeat the necessity of tying up plants, cutting down weeds, 
raking \&c., with many other similar observations. We have already been full on these subjects, and expect these to be remembered through the season. Particular care, however, is required to carnations, pinks, or any plants that have heavy heads and slender stems. If carnations are desired to flower strongly, cut off all the buds except three, leaving the uppermost and any other two of the largest. All climbing plants should have timely support, and tied securely every week while they are growing.

\section{JUNE AND JULY.}

\section{HOLLAND BULBS.}

THe lifting of these will be general in June. For directions, see May. It is not advisable to take up Jonquils, Fritillària, Crocus, and Iris, oftener than every alternate year. Jonquils may stand three years. Anemones and Ranunculus should be carefully lifted after their leaves begin to fade. Do not expose them to the sun, but cover slightly with earth or sand until they are perfectly dry, when they may be sifted out of the earth, and put into drawers carefully labeled. Some recommend to soak these roots in soap-suds, to destroy a worm with which they are frequently attacked. We know not how far this may be carried, nor the good or bad effects, never having practiced it.

\section{AUTUMN FLOWERING BULBS.}

These are Amaryllis lùtea, now called Sternbérgia Th̀tea; A. Belladónna, now Belladónna purpuráscens; C'ròcus satìvus, C. Pallàsii, C. serotinus, and C. nudiflorus, and all the species of Cólchicum, with species of several other genera not introduced into the country. They should all be lifted as soon as the foliage is decayed, and kept only a few weeks out of the ground, and then again replanted in fresh soil. The economy of the genus Cólchicum in regard to its bulbs, 
flowers, and seeds, is altogether singular, and may be termed an anomaly of nature. In producing the new bulbs or offsets, in a very curious manner the old one perishes. The flowers, which arise with long slender tubes from the root, die off in October, without leaving any external appearance of seeds. These lie buried all the winter within the bulb; in spring they throw up a fruit stalk, and are ripe about the first of June. How beautiful and admirable is this provision! The plant blooming so late in the year would not have time to mature its seeds before winter; and is, therefore, so contrived that it may be performed out of the reach of the usual effects of frost, and they are brought above the surface when perfected, and at a proper season for sowing.

\section{CARNATIONS AND PINKS.}

In order to make the former flower well, if the weather is dry, give them frequent waterings at the root, and tie them up neatly to their rods. The criterion of a fine Carnation is-The stem strong and straight, from thirty to forty inches high; the corolla three inches in diameter, consisting of large, round, well-formed petals, but not so many as to crowd it, nor so few as to make it appear thin or empty; the outside petals should rise above the calyx about half an inch, and then turn off in a horizontal direction, to support the interior petals, they forming nearly a hemispherical corolla. The interior petals should decrease in size toward the centre, all regularly disposed on every side; they should have a small degree of concavity at the lamina or broad end, the edges perfectly entire. The calyx abore one inch in length, with strong broad points in a close and circular body. The colors must be perfectly distinct, disposed in regular long stripes, broadest at the edge of the lamina, and gradually becoming narrower as they approach the unguis or base of the petal, there terminating in a fine point. Those that contain two colors upon a white ground are esteemed the finest.

The criterion of a doulle pink. - The stem about twelve inches, the calyx smaller, but similar to a carnation; the flower two inches and a half in diameter; petals rose edges; color white and pure purple, or rich crimson; the nearer it approaches to black the more is it esteemed; proportions 
equal as in carnation. Those that are very tasteful with these flowers are attentive to the manner of their opening. Where the calyx is deficient in regular expansion, to display the petals; that is, where there is a tendency to burst open on one side more than on the other, the opposite side in two or three different indentations should be slit a little at several times with the point of a small sharp knife, taking care not to cut the petals, and about the centre of the calyx tie a thread three or four times round to prevent any further irregularity. Some florists and connoisseurs place cards on them. This is done when the calyx is small. Take a piece of thin pasteboard, about the size of a dollar, cut a small aperture in its centre to admit the bud to pass through. When on, tie it tight to the rod, to prevent the wind from blowing it about; and when the flower is expanded, draw up the card to about the middle of the calyx, and spread the petals one over the other regularly upon it. When these plants are in flower, their beauty may be prolonged by giving them a little shade from the mid-day sun by an awning of any simple description. Where they are in pots, they can be removed to a cool shady situation (but not directly under trees).

\section{OF LAYING CARNATIONS AND PINKS.}

This is a necessary and yearly operation to keep a supply of plants, and likewise to have them always in perfection. As the process of laying, though simple, may not be known to all who are desirous of cultivating these plants, we will give an outline of the mode of operation. Provide first a quantity of small hooked twigs (pieces of Asparagus stems are very suitable), about three inches long, for pegging the layers down in the earth. Select the outward, strongest and lowest shoots that are round the plant; trim off a few of the under leaves, and shorten the top ones even with the knife, and then applying it at a joint about the middle of the under side of the shoot, cut about half through in a slanting direction, making an upward slit toward the next joint, near an inch in extent; and loosening the earth, make a small oblong cavity one or two inches deep, putting a little fresh light earth therein. Lay the stem part where the slit is made 
into the earth, keeping the cut part open, and the head of the layer upright one or two inches out of the earth; and in that position peg down the layer with one of the hooked twigs, and cover the inserted part to the depth of one inch with some of the fresh earth, pressing it gently down. In this manner proceed to lay all the proper shoots of each plant. Keep the earth a little full around the plant, to retain longer the water that may be applied. Gire immediately a moderate watering, with a rose watering-pot, and in dry weather give light waterings every evening. Choose a cloudy day for the above operation. In about two months they will be well rooted.

\section{OF BUDDING OR INOCULATION OF ROSES.}

According to what we have previously hinted in regard to having roses as standards, where such are desired, the month of July or August is a proper time for the operation of budding. The kinds to be taken for stocks should be of a strong free growth: such as Manitta, Maiden's blush, $R$. canina, and frequently the French Eylantine are taken. Be provided with a proper budding knife, which has a sharp, thin blade, adapted to prepare the bud, with a tapering ivory haft, made thin at the end, for raising the bark of the stock. For tyings, use bass strings from Russia mats, which should be soaked in water to make them more pliable. The height of the stock or stem at which the bud is to be inserted, is to be determined by the intended destination of the tree (as it may be properly called). Choose a smooth part of the stem, from one to three years old. Having marked the place, prune away all the lateral shoots about and underneath it. With the knife directed horizontally, make an incision about half an inch long in the bark of the stock, cutting to the wood, but not deeper; then applying the point of the knife to the middle of this line, make a perpendicular incision under the first, extending from it between one and two inches. Having a healthy shoot of the growth of this year provided of the kind that is desired, begin at the lower end of this shoot, cut away all the leaves, leaving the footstalk of each. lieing fixed on a promising bud, insert the knife about half an inch above the eye, slanting it downward, and about half 
through the shoot. Draw it out about an inch below the eye, so as to bring away the bud unimpaired with the bark, and part of the wood adhering to it; the wood now must be carefully detached from the bark. To do this, insert the point of the knife between the bark and wood at one cnd, and, holding the bark tenderly, strip off the woody part, which will readily part from the bark, if the shoot from which the piece is taken has been properly imbued with sap.* Look at the inner rind of the separated bark, to see if that be entire: if there be a hole in it, the eye of the bud has been pulled away with the wood, rendering the bud useless, which throw away; if there be no hole, return to the stock, and with the haft of the knife gently raise the bark on each side of the perpendicular incision, opening the lips wide enough to admit the prepared slip with the eye. If the slip is longer than the upright incision in the stock, reduce the largest end. Stock and bud being ready, keep the latter in its natural position; introduce it between the bark and wood of the stock, pushing it gently downward until it reaches the bottom of the perpendicular incision. I et the eye of the bud project through the centre of the lips; lay the slip with the bud as smooth as possible, and press down the raised bark of the stock. The bud being deposited, bind that part of the stock moderately tight with bass, beginning a little below the incision, proceeding upward so as to keep the eye uncovered, finishing above the incision. In a month after the operation, examine whether the bud has united with the stock. If it has succeeded, the bud will be full and fresh; if not, it will be brown and contracted. When -it has taken, untie the bandage, that the bud may swell, and in a few days afterwards cut the head of the stock off about six inches above the inoculation, and prevent all shoots from growing by pinching them off. This will forward the bud, which will push and ripen wood this season; but it must be carefully tied as it grows to the remaining head of the stock. Some do not head down the stock until the following spring,

* We once budded three eyes of the white moss rose, after they had, by mistake, been carried in the pocket of a coat three days. The shoot was soaked six hours in water, and two of the buds grew. From this we infer that shoots, if properly wrapped up, may be carried very great distances, and grow successfully. 
thereby not encouraging the bud to grow, which, if winter sets in early, is the safest method.

\section{OF WATERING.}

If the season be dry, look over the lately planted shrubs, and give them frequent copious waterings; and a few of the finest annuals that are wanted to flower perfectly should be attended to. We do confess that we used to be advocates for giving plenty of water to the Dahlia, but the serere drought of 1838 put our science to the test, and the result was, that of about one hundred plants of our most choice kinds, which we regularly watered three times a-week, for nine weeks, during which period we had not a drop of rain, the plants grew luxuriantly, but many of them never produced a perfect bloom; and those that had no attention whaterer paid to them, except a little manure or litter laid on the surface over the roots, flowered almost as well as in our more moist seasons. Hence we infer that an occasional watering may be of service, but continued and repeated artificial waterings are injurious.

\section{AUGUST.}

\section{EVERGREEN HEDGES.}

THese always make two growths in the season, and the best time to perform the operation of clipping or dressing them is before the plants begin their second growth. Choose, if possible, dull and cloudy days, as in such weather they will not be so liable to get brown or bruised by shearing. The general practice in forming these is to have the sides eren and the top level, forming a right angle on each side. However neat in appearance this may be considered, it certainly is stiff and formal. We never approve of clipping where it can be avoided, and, when adopted, nature ought to 
be imitated. Therefore, have all hedges and edgings tapering toward the top.

\section{CARNATIONS AND PINKS,}

If laid about the end of June, and have been properly attended, will, by the end of this month, be well rotted and fit for transplanting. Clear away the earth lightly, and cut them clean off from the parent plant, nearer the stool than the original slit. Raise them neatly out of the earth, with as many of the root-fibres as possible; cut off the naked part of the stem close to the fibrous roots, and trim away the strangling leaves. Plant the finest sorts in four-inch pots, and those more common, three plants in five-inch pots, in the form of a triangle, which can be separated in spring to plant in the garden. Any of the principal stools should be (if in the ground) lifted and put into seven-inch pots to be preserved: the others may be allowed to stand through the winter, covering them with a few dry leaves. Keep them in the shade a few weeks, when they may be fully exposed. Give gentle and frequent sprinklings of water until they have taken fresh root; or, if in want of pots, mark out a bed that can be covered with a frame, preparing the soil therein properly. Plant them from four to six inches apart. Shade them from the sun until they begin to grow, gixing sprinklings of water over the foliage every evening.

\section{BULBOUS ROOTS.}

Look over the bulbs that are out of the ground, and examine those that require planting. Of Fritillaria there are about twenty species, but few of them generally cultivated, except $F$. imperiàlis, Crown Imperial, and $F$. pérsica. Of the former there are many very splendid varieties, such as Crown upon crown, Lutea Maxima, Striped leaved, Double flowered, \&c. These will require planting, and ought not to be lifted oftener than every third year. They require a deep, rich, loamy soil, and, if in beds, plant them from five to seven inches deep, and one foot apart. They will grow under the shade of trees, or in any situation where the soil 
is adapted for them. No imbricated or scaly bulb ought to be retained long out of the ground. When any of these are lifted, and the young bulbs taken off, they should be planted at once. See particularly, on bulbous roots in general, next month.

\section{SOWING SEEDS OF BULBOUS ROOTS.}

Where any seeds of these are saved, with the intention of sowing, let it be done this month. Procure boxes about seven inches deep, and, in size, proportioned to the quantity to be sown. Put five inches of light sandy soil in the box, level it smoothly, and sow the seeds separately and thickly; cover with half an inch of light sandy loam, with a portion of earth from the woods. Keep the box or boxes in a sheltered situation, giving frequent sprinklings of water, to keep the earth damp, which must be protected with a frame, or covered with leaves during winter. The plants will appear in the spring, and must be watered and lept in the shade. When the leares decay in June, put one inch more soil upon them, and the second year they can be planted with the small off-sets in the garden, and treated as other bulbs. They must be carefully marked every year. Tulips require several years of trial before their qualities are known; and a poor soil is best suited to produce their characters after the first bloom.

\section{SEPTEMBER.}

\section{OF DAHLIAS.}

SEe that all these plants are supported with proper stakes, rods, \&c., that the wind may have no effect in breaking down or otherwise destroying the flower stems. Strictly observe their respective heights and colors, that they may be duly disposed and interspersed next year, if not done so this. Attend particularly to the merits of those grown from seed. 


\section{GENERAL CARE OF PLANTS IN POTS.}

All the flowers that are in pots, and intended to be kept in frames during winter, should have a top-dressing and a general preparation for their winter quarters, by tying up, \&c. The carnation and pink layers that were lifted and potted last month must be brought from the shade as soon as they begin to grow; and those that are not lifted, have them done forthwith, that they may be rooted afresh before the frost sets in. All Wall-flowers and Stocks should be lifted about the end of this month, and planted in five to seven inch pots, and treated as directed for carnation layers last month, until they begin to grow, when they must be fully exposed.

\section{PREPARE BEDS AND BORDERS FOR BULBOUS ROOTS.}

Bulbous roots of every character delight in deep free soil ; consequently, wherever they are desired to be planted, due attention must be paid to put the soil in proper order, to have them in perfection. Where there is a quantity intended to be planted, to have them in beds is the general and preferable method. These ought to be dug from eighteen inches to two feet deep, at the bottom of which place three or four inches of decayed manure. Where the soil is poor, it should be enriched with well-decomposed manure and earth from the woods, incorporating both well with the soil, breaking it all fine. This being done, allow it to stand until the middle of next month, which see for farther directions.

\section{GENERAL OBSERVATIONS.}

Tie up carefully all the Chrysánthemums, Tuberoses, \&c. Clear away the stems or haulm of any decayed annuals or herbaceous plants, that nothing unsightly may appear. Propagate the Pansy by layers, \&c. See page 94 . 


\section{SOWING AND SAVING SEEDS.}

About the end of this month or beginning of next is an advisable period to sow seed of Delphinium Ajácis flòre plèno, or Double Rocket Larkspur. This plant does not flower in perfection unless sown in autumn, and grown a little above ground before winter; when a few leaves can be lightly thrown among them, but not to cover them entirely, or a few branches thickly laid on will answer as well. There are several other annuals that bloom more early and much finer by being sown about this period: such as Erysimum, Gília, Coreópsis, Centaurèa, Clárkia, Collínsia, \&c. Be attentive in collecting and saving all kinds of seeds, and have them correctly named, with the year in which they were grown.

The finer kinds of Pansy seeds that may have been collected during the season, should now be sown in a rich, free, loamy soil, and in a situation where they can be covered during winter with a temporary frame of boards; although they are perfectly hardy, yet they will bloom earlier and more superb in the spring by having a slight protection.

\section{OCTOBER.}

OF PLANTING VARIOUS BULBOUS AND TUBEROUS ROOTS.

Frow the first of October to the middle of November is the best period for a general planting of bulbs, corns, and tubers, which, if the ground has been prepared, as formerly directed, will now be in readiness. We will give the names and descriptions of a few of the leading sorts.

Anemòne horténsis. The cultivation of this tuber has been attended with less satisfaction than any other floral plant that has been introduced into this country. The general failure may, in part, be attributed to the very inferior roots annually sent from Holland, which rarely arrive in good order; and those that do grow are very discouraging, 
never making a tuber sufficient for another year's planting. Several hundred varieties are cultivated in England with great care and complete success. They are planted in a deep rich soil, using a considerable portion of cow manure and decomposed leaves; covering the crowns of the roots about two inches. The tubes are flat, but the eye from whence the flower stem arises is apparent on one of the sides, which must be laid uppermost. During the severity of winter, they should be protected by a frame, and have a sprinkling of very dry leaves strewn among them.

Cròcus. There are upwards of one hundred varieties of this vernal flower in cultivation, attended with universal success. They delight in rich soils, and may either be planted in beds or rows, at least two inches deep, and six inches from row to row-they seldom require removal; every three or four years will be sufficient. They can be purchased at from seventy-five cents to two dollars per hundred, according to quality. When they are done blooming, the foliage should not be removed till perfectly decayed.

Fritillária, or Crown Imperial. See last month.

Hyacinths. The ground that was prepared for these last month should all be divided into beds four feet wide, leaving between each alleys of twenty inches. Skim off four or five inches of the surface of the former into the latter, level the bed smoothly with the rake, and mark it off in rows eight inches apart. Plant the roots in the row eight inches asunder. Thus they will be in squares, and by planting the different colors, alternately, the bed will be beautifully diversified. Cover each bulb with sand, when it can be procured. Put about four inches of earth over the crowns, which will make the beds from two to three inches higher than the alleys. The beds before and after planting should be gently rounded from the middle to each side, to let the rain pass off. Finish all by raking evenly, straighten the edgings with the line, and clear out the alleys or pathways.

We have grown Hyacinths in great perfection, when, in addition to the above, we covered them with two to three inches of cow manure. The Dutch florists name nearly two thousand varieties of this flower, and have large fields devoted to their culture. When the double varieties were first brought into notice, they sold at from one to two thousand guilders a root (about from four to eight hundred dollars). 
The finer kinds ean be purchased at from two to four dollars per dozen.

Iris, or Fleur de luce. The English and Parisian irises are coming into repute as showy garden flowers. They will grow in any well-prepared soil, and require to be planted in the same manner as the tulip.

Jonquils. Double and single. Plant these in the same soil as Tulips, six inches apart, and cover three inches deep. They do not flower so well the first year as in the second and third, therefore should only be lifted every third year.

Lilium. The family of Lilies are all splendid, very interesting, and easy of culture, requiring merely a good deep loamy soil - nowise inclined to moisture. They are all hardy, except $L$. japònicum and $L$. longiflòrum, which we lift in November, and again plant them about the first of March, keeping them through the winter in dry sand, in a cellar free from frost. The hardy kinds, deserving most attention, are $L$. Candidum (the double variety of it is not worth growing), $L$. Chalcedónicum and its varieties, $L$. Tigrinum, L. C'óncolor and L. Mártagon; these, with the epecies indigenous to this country, are all very beautiful. They should be planted from three to five inches deep, according to the size of the bulb, and need not be taken up oftener than once in every three or four years. None of the species can be transplanted after they have grown, without injuring their flowering.

Nurcissus require treatment similar to the Lily, except the soil, which must be richer, and even then they do not bloom so finely in a few years as they do when first imported; but they are cheap, and can annually be procured.

Painias are all magnificent in flower, and, for display, are not surpassed by any spring-blooming plant; and we do cheerfully urge our readers to cultivate the choice sorts, which can scarcely be said to have a rival. Such are-

P. Moután Bánksii, common double blush tree Pæonia.

$P$. Moután papaveràcea, single white tree Pæonia, with purple centre.

P. Moután ròsea, large rose, scmi-double tree Pæonia.

P. Moután odoráta, sweet-scented, rose-colored tree Pronia.

P. Moután albida pleno, double white tree Pæonia. 
The following are Herbaceous Paenias:-

$P$. èdulis albiftòra, single white.

$P$. èdulis whitlèji, superb double white.

$P$. èdulis Hùmei, very large double rose.

$P$. èdulis fiágrans, double red, swect-scented.

$P$. èdulis Réevesiana, Chinese double purple crimson.

$P$. èdulis Pottsii double blush, very distinct.

$P$. odoràta, double lilac.

$P$. mutatilis, double rose changing to blush.

$P$. anemoneflora, double dark crimson, very distinct.

$P$. officinàtis rùbra, common double.

$P$. officinalitis atropurpùrea, very dark crimson.

$P$. officinàlis álbicans, changeable white rose, or blush.

There are several other splendid double varieties in our collections, which have not yet bloomed in this country. There are also a few very choice single kinds that are desirable for growing to raise new sorts from; for it is from the single species that the Chinese have been so successful in procuring the magnificent double varieties, which are so anxiously and perseveringly sought for. The seeds mature well in this country, and should be sown as soon as ripe; they will vegetate the following spring, and in three years may be expected to bloom. The Pæony will grow in any rich, loamy soil, which should be at least fifteen inches deep. An eastern situation or aspect is best adapted for them in this latitude; but in the more Southern States, they will display their flowers better on a northern aspect, or where they will be shaded from the sun, but not under the dripping of trees. The most suitable time for planting them is in September, October, or November. Spring-planted roots never succeed well the first year. Pæony moutan and its varieties are all of a shrubby nature, and will grow into large bushes, producing from fifty to one hundred blooms of not less than fifteen inches in circumference; they can be propagated by division of the root, or by layers.

Tulips. As this flower will soon be a decided favorite over this mighty country, we will give a minute description of the soil most genial to it, at the same time remarking that it will grow in almost any soil or situation, though less perfect. Nany of the kinds are of the most splendid colors and 
strong in growth, frequently growing over three feet in height, with cups sufficiently large to satisfy the greatest Bacchus. All writers agree that Tulip beds should be "four feet wide;" though I think three and a half will be found more convenient, and, in length, according to the number of roots to be planted. The soil should consist of good fresh loam, mixed with a small portion of well-rotted stable manure, at least two years old. The whole should be incorporated together four months previous to using. The common soil should be taken out sixteen inches deep, and filled with the above compost. Raise the beds not less than three inches above the paths at the outside, and about six or eight inches in the middle; this convexity will assist in throwing off the water in times of heavy and continued rains. The bed thus formed, plant the bulbs in rows, lengthwise on the bed, about six inches from bulb to bulb, and seven inches from row to row. The bed may be marked out by straining a line very tight, lengthwise on the bed, and beating it with the back of the spade, leaving a lined groove along the ground. Then, with a lath four feet long, let the bed be marked across at six inches distance, so as to leave distinct impressions at each crossing of the ground lines; for these will form the spots where the bulbs are to be planted, by means of a dibber, made larger than the largest bulb, and flattened at the end. The holes are to be made four inches deep, and about half an inch of sharp sand ought to be dropped in each. The centre line ought to be planted with the tallest kinds, and the outside of the bed with the lowest. In severe frosts they should be protected by boáds or branches. Tulips have ever been held in the highest estimation. As early as 1637 history records one hundred and twenty Tulips being sold at public auction for no less a sum than nine thousand gilders, equal to thirty-six hundred dollars; and, in England, at the present day, a good collection is valued at five thousand dollars. Florists generally divide them into three classes, viz., first, Bybloemens, such as have a white ground, variegated with purple, as Bienfait, or Wushington, \&c.; secondly, Bizarres, having a yellow ground, variegated with scarlet, purple, rose, or velvet, as Trafalgar, Duc de Savoie, \&c.; and, thirdly, Roses with white ground, variegated with rose, scarlet, or crimson, as La T'endresse, Rose mignonne, \&c. 
The superb kinds are often very expensive; even fifty pounds sterling is frequently given for a single bulb; and we doubt much if these high-priced kinds are finer than Washington, Milo, or Trafulgar, which, with many others, can be procured for less than one dollar each.

\section{PLANTING AND TRANSPLANTING.}

This is a very proper period to plant the beautiful and early flowering Pyrus japónica, now called Cydónia japónica. The blossoms are of a rich scarlet color. It is the earliest flowering shrub of the garden, and deciduous, though said by some to be "an evergreen." The plant is bushy, and well adapted for single plants in grass plats, or forming low ornamental hedges. There is likewise $C \cdot j$. álla, a fine blush variety of the same habit, and both are of the hardiest nature.

Doulle Primroses, Polyanthus, Daisies, \&c. Any of these that were planted in shaded situations in spring, and have been preserved through the summer, should have for their farther protection a bed well sheltered from the northwest, in which they should be planted four inches apart. Give them a few sprinklings of water in the morning, and have a temporary frame of rough boards put together to place over them during the severity of winter. The frame may be covered with the same in place of glass, which must be kept over them while they are in a frozen state.

Any other plants that are in the ground, which are intended to be protected with frames through the winter, ought to be immediately lifted and potted, and treated as directed for all now-potted plants.

\section{GRASS AND GRAVEL WALKS.}

The former should be trimly cut and well rolled this month, that they may appear neat all winter. Never allow decayed leares to lie any time upon them, as they are apt to rot out the grass. The latter should be divested of every weed, and receive a firm rolling. Clear them at all times of leaves and other litter. These, if on a declivity, and have 
not a firm substantial bottom, will be subject to be cut up with every heary rain. A break should be put in every twenty, forty, or eighty feet to throw off the water. A strong plank will answer perfectly well, but in such situations we would prefer grass walks.

\section{PLANTING EVERGREENS.}

This month is the best period in autumn to plant these shrubs; and where there is a great extent to be planted, it would be adrisable to do a part of it now; but we gire the preference to April, which see for directions.

\section{GENERAL OBSERVATIONS.}

When the plantings of bulbs, \&c., are finished, erery part of the garden should have a thorough cleaning. All annual flowers will have passed the season of their beauty; therefore, remove the decayed flower stems or haulm, and trim off the borders. Dig all racant ground, especially that intended to be planted with shrubs in the ensuing spring, which ought to be dug from one to two feet deep.

\section{NOVEYBER.}

\section{DAHLIAS.}

IT is not advisable to delay lifting the roots of the Dahlia after the first of the month, as frequently severe frosts set in about this period, and would totally destroy them. Choose a dry day for the purpose, and with a spade carefully lift every root, divesting it of any earth that may adhere thereto, but not to shake it off, as thereby the neck of the tubers would be bruised, and probably entirely destroy the vitality of the plant for the coming season. With us, the frost generally destroys the foliage and stems of the plants from about the 
middle of October to the beginning of the present month. The stems should then be cut to within a fer inches of the ground: when the roots should be lifted directly thereafter, and the labels properly secured to them with metallic wire. Many opinions are given for the best method of securing them during winter from the effects of frost, which is their certain destruction. In this country, a dry close cellar, that will retain a temperature of not less than thirty-five degrees, and not over forty-five, will be the most proper place: if the tubers are small, they should be covered with dry sand or earth. The method we have adopted with our finest kinds, which has resulted in complete success, is to lay dry boards on the cellar-floor, and place the roots closely thereon, covering them to the stem with dry sand, laying mats over all: in this manner they preserve till spring in the most perfect order. They can also be kept in a cool green-house; but must be protected from drippings of water falling upon them.

\section{TUBEROSES, TIGRIDIAS AND AMARYLLIS.}

These tubers and bulbs, as soon as the frost has partly injured the foliage, should be taken up, and dried thoroughly in the sun, taking care, at all times, to keep them clear from frost. When they are dry, divest them of their foliage and fibres, and pack them in boxes with dry sand or moss: Store these away for the winter, either in a room or a dry cellar, where they will at all times be exempt from frost, the least touch of which would destroy them. We have kept them completely secure in the cellar.

\section{ERYTHRINAS.}

Where there are any plants of $E$. herbàcea, E. laurifolia and $E$. crista-gálla, which are intended to be lifted, they should be carefully done and preserved in half dry earth, and kept beside the Dáhlias. They are magnificent ornaments in the flower garden. 


\section{PRIMROSES, POLYANTHUS AND DAISIES̀',}

That were planted in a sheltered spot, as directed last month, should have a frame placed over them, and their covering in readiness for the approach of winter; giving the plants a light covering of leaves, which will preserve their foliage from the effects of frost.

CHOICE CARNATIONS, PINKS, PANSIES AND AURICULAS,

That are in pots, should be placed in the frame intended for their abode during winter. If the pots are plunged to the rims in dry leaves or sawdust, it will greatly protect their roots from the severe effects of frost. Where glass is used for these frames, they should have besides a covering of boards or straw mats; those that are in beds may be covered as above directed for Primroses, \&c.

They ought not to be uncovered while in a frozen state. It is not aliogether the intensity of cold that destroys these plants so much as the alternate thawing and freezing.

All half hardy plants, such as Wall-flower, German stocks, Sweet-bay, tender roses, with several others, should be protected as above directed for Carnations. Earth or tan should be put round the outside of these frames, which will be a partial shelter from the changing state of the atmosphere. Oak leaves answer the purpose very well, but they are a harbor for all kinds of vermin, especially rats and mice, which would destroy ererything. It may be useful to say a few words on the nature of tan or tanner's bark. Many suppose that the smallest quantity will produce heat. If three or four cart loads of it are put into one heap, and protected from the rain, it will ferment; and when the first fermentation is abated, by mixing it with leaves, a substantial hot-bed may be made, or put it by itself into a pit; and when there is no pit, boards may be substituted to keep it together: either of these methods will produce a lasting heat. But in small quantities, and exposed to rain, \&c., no heat will be produced, but rather the contrary. It is excellent, when dry, in keeping out frost from any plants; being a body not easily penetrated, similar to dry sand, sawdust, 
November.] OF PLANTiNG, ETC.

or dry leaves. Frequently the same opinion is held in regard to stable manure, small portions of which will never produce heat.

\section{OF PROTECTING PLANTS IN THE GARDEN.}

During this or next month, according to the state of the season, protect all the plants that are in the ground, which are not completely hardy. The coverings may be straw, Russia mats, canvass, boxes or barrels. The two latter must be perforated in the top, to let the damp air pass off, or the plant would become musty and decay. Those covered with straw or mats should have small stakes placed round the plans, and covering tied thereto, and remain so until the month of March or first of April. Herbaceous plants that are tender may be covered with three or four inches of tan, sawdust, or half-decayed leaves, which will tend greatly to preserve their roots. These coverings must be carefully removed on the first opening of spring. The shrubs that are otherwise covered would be greatly benefited by having their roots protected in a similar manner, as directed for herbaceous plants.

\section{PROTEC'TION OF SEEDLING BULBS.}

If any seeds of Hyacinths, Tulips, or Fritillára, were sown in pots or boxes, let them be removed to a dry, sheltered situation, and plunged level with the ground; or fill the spaces between them with dry leaves or tanner's bark, and cover the whole with new-fallen leaves, laying over all a few boards to prevent the wind blowing them off. These form better coverings than straw or haulm, which is liable to become musty, and communicate the effect to the roots. The above covering is not required until the approach of severe frost.

\section{OF PLANTING DECIDUOUS TREES AND SHRUBS.}

It is not recommendable to make a general planting of these at this period of the year; the success entirely depend- 
ing on the nature of the season and the state of the soil. If any are planted, let them be those of the hardiest nature, and in light and absorbent soil, not subject to be stagnated or over-flooded during winter. When this and next month are mild, autumn plantings are very frequently as sure as those of the spring. But the precarious state of the season is not to be depended upon, therefore avoid large plantings of any kind, and more especially of delicate roses, the roots of which are apt to rot off, except they have been previously grown in pots. Nothing can be more injurious to a plant, at this season particularly, than to bed its roots in mortar, by which the tender fibres either perish or are cramped ever afterward. The soil at the time of planting should be so friable as not to adhere to the spade, which is a good rule in planting at any season, or in any soil.

\section{GENERAL OBSERVATIONS.}

Carry out of the garden all decayed leaves and litter of every description, cutting down any weeds that remain. Collect all the stakes and rods that have been supporting plants, tie them up in bundles for the use of next year, and put them under cover. Look over every part of the garden, and see that nothing has been omitted in the way of covering or other protection. The sashes that are to be used on the frames should be perfectly whole, every interstice in the glass puttied, and all ready for use when occasion may require. Attend to all plants in pots, and give them gentle waterings as they stand in need; but never during the time the soil is frozen about the roots.

\section{DECEMBER.}

\section{GENERAL OBSERVATIONS.}

Having in the preceding months under this head given details for the protection of plants of a delicate nature, and 
the forwarding of necessary work, only a few remarks remain to be added. If there is any part therein described omitted, have it done forthwith: every day increases the danger of severe weather. If there are doubts of any plants or shrubs not standing without some light covering, it is best to err on the side of safety. Valuable plants on walls, and in danger of being destroyed, it is advisable to be at the expense of having a frame made to surround them, and cover the same with oil-cloth. The frame thus covered should be taken off in mild weather, and replaced again when necessary, causing very little trouble; and, if properly taken care of; will last many years. Coverings of any construction, and of the same material, would answer for any part of the garden, and are the best in our opinion that could be adopted. 



\section{AMERICAN FLOWER GARDEN \\ DIRECTORY.}

\section{HOT-HOUSE.}

\section{ON THE CONSTRUCTION OF A HOT-HOUSE.}

THERE have been many plans devised and visionary projects offered to the public as the best for a well-regulated hot-house. . As we intend forming one for practical purposes, we shall adopt a convenient size, have flues for the conveyance of heat, and coal or wood for fuel.

Site and Aspect.-The house should stand on a situation naturally dry, and, if possible, sheltered from the northwest, and clear from all shade on the south, east, and west, so that the sun may at all times act effectually upon the house. The standard principle, as to aspect, is to set the front directly to the south. Any deviation from that point should incline to the east.

Dimensions. - The length may be from ten feet upward; but, if beyond forty feet, the number of fires and flues are multiplied. The medium width is from twelve to sixteen feet. Our directions will apply to the two extreme points, viz., forty feet by sixteen, and in height, at back, from twelve to eighteen feet; the height in front six feet, including about three feet in brick basement, to support the front glass, which will be two and a half feet, allowing six inches for framework. 
Furnace and Flues.-It is of great importance to have these erected in a such a manner as will effectually heat the house. The greatest difficulty is to have the furnace to draw well. As workmen are not generally conversant on the subject, nor yet understand the effect or distribution of heat in these departments, we will give minute details on their construction. The furnace should be outside of the house, either at back or end; the former is preferable, circumstances not always allowing it on the other plan. Dig out the furnace-hole, or what is termed stock-hole, about five feet deep. Let the door of the furnace be in the back wall of the house, thereby having all the heated building inside, that no heat may be lost. The brick-work round the furnace should be nine inches thick, laying the inside with fire-brick. Around the outside leare a vacuum two or three inches wide, to allow the heat to arise from around the furnace into the interior of the house, thereby saving the whole heat of the fuel. The furnace will require to be two and a half feet long, ten inches wide, and one foot high, before the spring of the arch and clear of the bars; leave one foot for an ash-pit, then lay the bars. They should be sixteen inches long, one inch broad on the upper side, two inches deep, and two-eighths broad on the lower side, and, with the door and frame, should be cast iron. Half an inch between each bar will be sufficient. The flue should rise from the furnace by a steep declivity of from twenty inches to two feet, and pass the door of the house (without a dip), when it must be elevated above the level of the floor of the house along the front, and at the opposite end of the house must dip to pass the door. The dip must not be lower than the bottom of the flue at the neck of the furnace. Lead it along the back to enter the wall over the furnace. When thus taken round the house, the heat will be expanded before it enters the chimney. The inside of the flues should be from six to ten inches wide, and eight inches deep; plaster the bottom of it, but no other part, as plaster is partially a non-conductor. The above description is for burning anthracite coal; but where wood is to be the fuel, the furnace must be one-half larger. We have been particular in the description of furnace bars, as those generally used are miserable substitutes. Circumstances may cause the furnace to be placed at the end or front of the house. In either case, the stock-hole will not require to be 
so deep; or where there is only one door in the house, a stock-hole three and a balf feet deep will be enough, which should be built like a ceellar, to keep out any under water. In all instances, pass the first flue to the front of the house, over which have a close table, covered with two inches of sand, and, by keeping it moist, will afford a very congenial heat to young and valuable plants. Likewise over the furnace have a frame in the same manner, which will be found useful for propagating. Any part of the furnace or flue that is under the floor of the house should have a vacuity on both sides to let the heat pass upward.

Furnaces and flues on the above construction are the most simple in arrangement, and the easiest to manage at all times. But where capital, taste, and practical science can be united, the more elegant disposition of heating by hot water is now universally adopted in extensive glass structures, and will soon be generally adopted in the dwellings of the better class. We have used it in every variety of form and structure for "the past twelve years, and have now five greenhouses, each over one hundred feet long, heated by it, using every variety of pipe and form of boiler; have also used wooden and cement tanks. Sand beds heated by it for propagating upon. It cannot be economically used in greenhouses under seventy-five feet long, and sixteen to thirty feet wide. In all erections for plant or grape culture, at, or over that extent, the best and cheapest method of applying artificial heat is by the diffusion of hot water through cast iron or copper pipes, of three or four inches in diameter. The boiler may be of any size, from five to fifteen gallons-of any shape, from a pancake to a puncheon; though best adapted to the exposing the greatest surface to the fire is to be preferred. We use what is termed the saddle boiler, and also the double cylinder boiler, preferring the latter, which holds about ten gallons, and will supply heat enough for two green-houses, each one hundred feet long, or will supply a green-house of one hundred feet in length, and a hot-house fifty feet, and from sixteen to twenty feet wide, using four inch pipe, at a cost of about $\$ 250$, including labor and materials. Its erection is perfectly simple, and can be done by any good bricklayer and handy laborer : build the boiler in the centre of the furnace, with its bottom about twelve or fourteen inches above the fire bars; allow the heat to have 
full play all round the boiler, carrying the flue about forty or fifty feet through the house, that no heat may be lost; attach two pipes to the surface or top of the boiler, if it is to heat right and left, but only one pipe if the heat is to be carried in one direction; distribute the pipe wherever required, giving it an ascent of not less than six inches to the fifty feet, more if it can be done-return the pipe, entering it into the lowest part of the boiler; the greater the ascent and descent the more rapid the circulation. The joints of the pipe are closed by soft hemp rope, firmly rammed up and closed by a mixture of white and red lead made to the consistency of putty. These joints are preferable to those of lead, which expand and contract by strong heat, requiring to be hammered up frequently during the season-they can also be very readily taken apart, when removal or alteration is required. It must be observed that air tubes have to be inserted into the highest part of the pipes at each extremity, and also one over, or near the boiler, for the conveniency of supplying water. If the pipes diverge from the boiler to two extremes, each extremity must be on a level, which otherwise will cause an unequal diffusion of heat.

EXAMPLE.-If a house to the right of the boiler one hundred feet long has the extreme end of the pipe elevated one foot above the level of the boiler, a house fifty feet long to the left must have the same elevation, otherwise the heat will be the greatest where the pipe is highest.

This we consider the most economical method of heating by hot water, and it is by far the most simple-simple indeed in every part, though volumes have been written on the subject.

Bark Pit.-We consider such an erection in the centre of a hot-house a nuisance, and prefer a stage, which may be constructed according to taste. It should be made of the best Carolina pine, leaving a passage all round, to cause a free circulation of air. The back and end paths may be about two feet wide, and the front three feet. The angle of the stage should be parallel with the glass, having the steps from six inches to one foot apart.

Where there are some large plants, they may stand on the floor behind the stage, or on tressels, according to their height. 
Angle of the glazed Ronf.-The pitch of the roof is usually varied to agree with the design of the house, and the size of the plants to be grown therein. Where pleasure and ornament are the principal objects, the angle should be about $33^{\circ}$ from the level line; but a few degrees of inclination either way is of minor importance.

Materials for glaziny Sashes.-Carolina pine is the best material for the wood-work, as it is not so subject to decay from moisture and heat as the other kinds of pine wood. The frames or sashes can be of any convenient length, not exceeding ten feet, and about three and a half or four feet wide, and made from plank two inches thick, divided so as they can be glazed with glass six inches wide.

Of Glazing.-The pieces of glass should not exceed six inches by eight, though six by six is preferable; the lappings about one quarter of an inch. The frames ought to have two coats of paint previous to glazing, and the glass bedded in putty. Some prefer the lappings to be puttied also. It is our opinion that in a hot-house these should not be puttied, but, in the green-house, the closer they can be made the better.

Of Shutters.-These should be made of three-quarters of an inch white pine, and bound on both ends and sides, having a cross piece in the middle of the same. They ought to be painted at least once in three years.

\section{HOT-HOUSE.}

\section{JANUARY.}

A $\mathrm{r}$ all times, be very careful of the temperature of this department, and more especially at this season of the year, as a few minutes' neglect might materially injure many of the delicate plants. The thermometer ought to range between $55^{\circ}$ and $65^{\circ}$. In fine sunshine days, admit a little air by having some of the top sashes let down one, 
two, or three inches, according to the weather, and let it always be done from eleven to one o'clock; but by no means in such a manner as to cause a draught in the interior of the house, which would be very prejudicial. Therefore, be always cautious during cold weather in administering that necessary element to regetation, which is so conducive to health.

\section{OF FIRING AND FUEI.}

The hot-house ought never to be left entirely to inexperiencel persons, because they are not aware of what might be the result of inattention even for an hour. Attention to the following observations will obviate every difficulty: A bout this season of the year, frost generally sets in very severe in the Middle States. Suppose the day may have all the clemency of spring, the night may be directly the reverse. Every precaution is necessary to guard against extremes. The shutters are put on every night at sundown, and, in severe weather, as soon as the sun goes off the glass. If the shutters are omitted till late in severe frost, it will so reduce the heat of the house that you can not overcome it by fire until near midnight; and, when done, the fire or fires have been made more powerful than they ought to be, proving ungenial to the plants that are near the flues. The air, as above directed, having been taken off the house at one o'clock, as soon as the mercury begins to fall in the thermometer, kindle the fire, and, supposing it is anthracite coal, in twenty minutes, with a good drawing furnace, the heat will operate in the house. If a coal fire, kindled about four o'clock, it will require an addition about six, and then may be made up again about nine or ten, which will suffice until morning. The quantity must be regulated by the weather. If the fuel is wood, it must be attended to three or four times during the evening; and, when the mornings are intensely cold, a fire may be requisite. When there are bad drawing furnaces, the fires must be made much earlier, perhaps by two or three o'clock, which will be easily observed by the time the fire takes effect upon the air of the house. The temperature ought never to be under fifty degrees of Fahrenheit. 


\section{OF WATERING THE PLANTS.}

To do this judiciously, is so necessary to vegetation, and so requisite to understand, and yet the knowledge so difficult to convey to others (being entirely acquired by practice), that if the power were in man to impart to his fellowmen, he would possess the power of perfecting a gardener by diction. However, the hints on this important point of floriculture will be as clear and expressive as can at present be elicited. All plants in this work that are aquatic shall be specified as such; and those that are arid shall be duly mentioned. All others will come in the medium.

All the plants must be looked over every day, and those watered that appear to be getting dry on the top. It must be strictly observed not to give water to any but such as strictly require it, and let it be given moderately at this season. There is not so much liability to err, at present, in giving too little, as in administering too much. Tegetation among the stove or hot-house plants will soon begin to show, and the soil will become sour if it is impregnated with stagnant moisture. Small plants should always be watered with a pot having what is termed a rose upon it. The surface of the rose, that is, where it is perforated with small apertures, ought to be level, or a little concave, which would convey the water more to a centre, and make ncater work, by preventing any water from being unnecessarily spilt in the house. The size of the pot will be regulated by the person to suit the conveniences of the place. Watcr, when applied either to the roots or foliage of the plants, should be about the medium temperature of the house. Where there are no cisterns, a tank or barrel might be in the house, in which the water could stand for one night or more, as is most suitable. When water is given without being thus aired, it chills the roots, prevents a luxuriant growth, injures the fresh and healthful appearance of the foliage, and too frequently gives to all the plants a sickly hue. 


\section{OF INSECTS, THEIR DESTRUCTION, \&c.}

In this department, insects begin to increase by hundreds, and too frequently their ravages are very obvious before their progress is arrested. We will treat of those which are most common, under their respective heads, with their nature and cure, as far as has come under our observation.

Aphis rosce, of the natural order of Hemiptera, or what is commonly known by Green Fly, Green Lice, \&c., infect plants in general, and are particularly destructive in the hot-house to Hiliscus ròsa-sinénsis, Asclépias, Crríssulu coccínea, Lantána, \&c., and many other plants of a free-growing nature. They attack the young and tender shoots at the point, leaving a dark filthy appearance on the foliage. Many remedies for their destruction have been offered to the public by various writers, each equally secure in his own opinion. Extensive practice alone can show the most easy and effectual cure. Fumigating with tobacco is decidedly the most efficacious, and in the power of any to perform. Take a small circular furnace, made of sheet iron, diameter at top twelve inches, and at bottom eight; depth one foot, having a grating in it to reach within three inches of the bottom, which will leare space for the air to pass, and where the ashes will fall and be kept in safety, having a handle like a pail to carry it with. This, or anything similar, being ready, put in it a few embers of charcoal, ignited to redness; take it into the centre of the house, and put therein a quantity of moist tobacco. If it attempts to blaze or flame, sprinkle a little water thereon; and, as it consumes, continue to add tobacco until the house is entirely full of smoke, observing always to do it in still, cloudy weather, or in the evening. If it is windy, the smoke is carried off without having half the effect, and requires more tobacco. The house must be closely shut up. There are several plants whose foliage is of a soft downy nature, such as Helitròpiums, Callacárpus, Sálvias, and many of the Lantànas, Vincas, with several others that cannot stand strong fumigation without danger. These should be put down in the house, or under the stage. These fumigations will have to be repeated frequently, the time for which will easily be perceived; and, when required, ought not to be delayed. 
Several species and varieties of the same genus, Aphis, can be destroyed in the like manner.

Acaris tellurius, or red spider, is caused by a dry atmosphere, and its havoc generally is obvious before it is arrested. With its proboscis it wounds the fine capillary vessels of the leaves. If they progress in their destructive work, the leaves will prematurely decay. On this appearance, turn up the leaf, and you will see them running about with incredible swiftness. Their body is of a blood color, and their feet light red. When very numerous, they work thick webs on the under side of the leaf, and frequently all over it, forming a mass of half dead plants, decayed leaves, and thousands of spiders. The most effectual remedy is a thorough syringing with water, and profusely under the foliage. This being done every evening, will subdue and eventually banish them. Had the house been syringed two or three times per week, these intruders would not have appeared. It is said by some writers that watering only reduces them to a temporary state of inaction, and will not destroy them. Laying aside the many prescribed nostrums, we assert that the pure element is the most effectual cure, as well as the most easy to be obtained.*

Thrips, order Hemiptera, are insects so minute as scarcely to be perceptible to the naked eye. They generally lurk close to the veins of the leaves of plants, and frequently attack esculents. When viewed through a glass, they are seen, when touched, to skip with great agility. The larva is of a high brown or reddish color. The thrip

- has four wings, and walks with its body turned upward. It frequently attacks the extremities of tender shoots or young leaves, which become shriveled, brown, and will rub to dust easily between the thumb and finger. When any leaves or shoots are perceived to be so, if you do not observe the green fly, expect the thrips. They may be destroyed by a fumigation of tobacco, in the same manner as the green fly. By the simple and expeditious method of fumigation, these insects and several others may be destroyed effectually at any time they appear.

Cocus hesperidus, or mealy bug, has appeared in the hot-

* Fumes of sulphur is instant death to them; but it lias to be used with great caution and experience. 
houses about Philadelphia within these few years, and, if not instantly destroyed, increases rapidly. It is of a white dusty color; when broken, of a brownish red, generally covered with down, under which it deposits its eggs; and they, in a few months, come forth in great numbers. The cocus generally is of a dormant nature, but in warm weather they may be seen moving rapidly up the stems of the plants. Fumigating has no observable effect on these insects; therefore, as soon as they appear, recourse must be had to other means. The liquid made from the following receipt is death to any of the Cocus tribe: Take two pounds of strong soap, one pound of flour of sulphur, one pound of leaf tobacco, one and a half ounce of nux vomica, with a tablespoonful of turpentine, which boil in four gallons of river water to three; then set aside to cool. When boiling, stir it well with a stick, continuing to do so until it is reduced as above. In this liquor immerse the whole plant, drawing it to and fro gently, that the liquor may penetrate everywhere. This done, lay the plant on its side, until it begins to dry, then syringe well with clean water, and put it in its respective station. Where a collection of plants is free from any insects of the kind, every plant that is introduced ought to be minutely scrutinized, that the unclean may be kept from the clean : the above insect will feed almost on any plant, but indulges on Crásilus, any of the bristly Cáctus, Gurdenias, and in fact whatever is in the way.

Cocus —- or brown scaly insect, is frequently found on many plants, but we never could perceive that it does any other material injury than soiling them. We have, always observed, that it is found in winter to abound in those situations which are most excluded from air; therefore is of less importance than the other species, which eat and corrode the leaves of tender plants. A washing with strong soapsuds will destroy them, or the above liquid will do it more effectually. Tie a.piece of sponge on the end of a small stick, and scrub every leaf, stem and crevice. Fumigating destroys the larva of this species.

Cocus _ - or small white scaly insect, which generally infests Cycas, Nèrium, Oleas, and Acacias, \&c., may be destroyed by washing as above with a sponge, and a strong decoction of tobacco, using the liquid about the warmth of $100^{\circ}$. Being thus heated, it irritates the insect, 
when, by easing itself from its bed, the fluid passes under it, and causes immediate death. If it is not thus irritated, it adheres so closely to the foliage that it will keep you at defiance. The under or dark side of the leaves is its residence ; and we have observed a plant in a house where there was only light on one side, with the dark side literally covered, while the light side was clean. So much for having houses with plenty of light. The effects of this insect are of a corroding nature, extracting all the juice from the leaf; and where they have got to the extremity, the foliage is completely yellow, and of a decayed appearance.

Cocus _ or turtle insect. We have never obserred this insect arrive to any extent. It is the largest of any known among us, and very like a turtle in miniature. On lifting it from the wood, to which it generally adheres, there appear to be hundreds of eggs under it, but fumigating completely destroys the larvæ. In our opinion, this turtle insect is no other than the old female of the brown scaly insect, which swells to a large size before depositing its eggs. We have frequently observed the insect dead in this enlarged state, and question if this be not the last stage of its transmigration. The male insect is winged, and very active in its movements.

Where bulbous roots, such as Hyacinths, Jonquils, Ixias, Lachencillas, \&c., are required to be early in flower, they may, during this month, be put in the front of the hothouse and watered freely till they bloom, when they may be taken to the green-house or parlor.

Azaleas, Rhododendron Roses, and some other plants, do admirably to force; and where there is a large stock, a few should be brought into early bloom with the heat of this department.

\section{OF CLEANSING PLANTS, HOUSE, \&c.}

This subject ought to be kept constantly in view. However correctly everything else may be executed, without that adorning beauty, cleanliness, all will appear only half done. Therefore let all the dead leaves be picked off every day, the dust and other litter swept out of the house, and, when necessary, the house washed, which will be at least 
once a-wcek. That the foliage of the plants may always appear fresh, syringe them every morning, when there is the appearance of sun. At present, this will in a great measure keep down the insects, and will prove a bane to the red spider.

Tie up neatly with stakes and threads of Russia mat all the straggling growing plants; let the stakes be proportionate to the plants, and never longer, except they are climbing: sorts. Do not tie the branches in bundles, but singly and neatly, imitating nature as much as possible. If any of the plants are affected with the Cocus insect, let them be cleansed according to the plan already mentioned, taking particular care also in washing the stakes to which they had been previously tied, and burning all the old tyings, which contain the larve of the insect in many instances, especially of Cocus hesperidus. It is premised, when any of these things are done, that they will be well done, and not half doing, and always doing. Cleanliness, in every respect, promotes a pure air, which is congenial to regetation, and will, with other attentions, always assume a healthful and vigorous appearance in the hcuse.

\section{FEBRUARY.}

In the early part of this month, the weather gencrally is very cold and changeable in the Middle States, and strict attention, with the greatest caution, will require to be paid to the management of the hot-house. Most of the tropical plants commence an active state of regetation; and, if checked by temperature or otherwise, they will not recorer until midsummer. The thermometer may be kept two or three degrees higher with fire heat than last month: the sun will be more powerful, and this will, in a great degree, increase the vigor of the plants. Air may be admitted when the thermometer rises to $75^{\circ}$ or $80^{\circ}$, not allowing it to rise higher than the latter. In giving air, let it be done by the top sashes. It is improper to give it in any way to cause a current, for the external air is yet very cold, although the 
sun is more powerful. An inch or two on a few of the sashes, as has been previously observed, will be effectual in keeping the temperature low enough.

With regard to firing, what was said last month may suffice for this. Always recollect that it is more preferable to keep out the cold than to put it out. It will frequently happen in the time of intense frost that the weather is dull. In such cases, fire in a small degree is requisite all day.

Heary snows ought never to be allowed to remain on the shutters while they are on the house. If the snow lies on the sashes one day, the internal heat will dissolve some of it; night coming on, will freeze it to the wood-work, when it will become a solid mass, and frequently cannot be separated without much damage. If allowed to remain on for two days, the plants are very much weakened and the foliage discolored. Therefore, let the snow be cleared off instantly, that no inconvenience may take place.

It will be observed that plants absorb more water this month than last. The quantity given will require to be increased, according to the increase of regetation and the advancement of the season; but never give it until the soil begins to dry, and then in such proportion as will reach the bottom of the pot. The best time to water is after the sun has got on the house in the morning, observing all the directions given in January.

\section{OF INSECTS, \&c.}

Perhaps sufficient observations were given under this head last month; but the importance of keeping these disagreeable visitors out of the house constrains us to make a few more remarks. Man cannot be too frequently guarded against his foes, more especially when they are summoning all their forces, and no profession has more than that of the Horticulturist. Let a strict examination be made about the end of the month for the red spider; they will be in operation some weeks before their depredations are observed on the foliage. The under side of the leaf is their resort in the first instance, and on such plants as have been already mentioned.

Observe daily the young shoots, in case the green fly be- 
comes numerous. They give the foliage a very disagreeable appearance, and it is too often intolerable, before their carcer is arrested. It also takes a stronger fumigation, which has frequently to be repeated the following day to the same degree, much to the injury of many of the plants, and adding to the disagrceableness of the continued vapor in the house.

\section{OF REPOTTING PLANTS.}

About the end of the month, some of the plants of Curcúma Amómum Kæmpféria, Alpína, Phrynium, Cánna, Zingiber, Hedychium, and others that are on the dry shelf, will be offering to grow. Let them be taken out of their pots, some of their weakest shoots or tubers taken off, and the strong ones repotted: give gentle waterings until they grow freely, then give in abundance. (Soil No. 17.)

Dionæea mucipula, or Venus fly-trap, grows best in the hot-house, and will, about the end of the month, stand in need of being repotted. This plant is very seldom grown in any degree of perfection, having been always considered a delicate plant in collections. Take it out of the pot just before beginning to grow afresh, and divested of all the soil, leaving only a few of the young roots (it is a bulb, and will reccive no injury by so doing), put it in new soil; when potted, place the pot in a saucer with one inch of water in it, giving a fresh supply every other day; this being repeated every year, it will grow, flower and seed in perfection. (Soil No. 5.)

Gesnérias, if in small pots, give larger as they advance in growth. This genus requires to have plenty of pot-room to make them flower well. $G$. oblongata, $G$. Zebrina and $G$. Seliowii ough't to have a situation in every hot-house. They are remarkable for their many brilliant crimson flowers, and continue in flower for a length of time. When the bulbs begin to push, shake them out of the earth, and repot them into smaller pots; and, as soon as the roots reach the side of the earth, which will be in about one month, put them in larger pots, and continue to do so until flowering, which will be about the first of June, observing always to keep the ball of earth entire. G. Douglásii, G. rìtilla, G. acaùtis, and some others, are all well worth attention. (Soil No. 11.) 
Gloriosas must be repotted in the beginning of this month; G. supérba is the most beautiful and curious. The crown of the roots ought to be planted one and a half inch deep, taking care not to break them. Do not water much until they begin to grow. The earth must not have much water. As the plants grow, they will require a more liberal supply; yet it is necessary, at all times, to be moderate in giving it. If well treated, the superb flowers will appear in June or July. (Soil No. 12.)

Gloxiniás are beautiful herbaceous plants, with large showy flowers, requiring soil and treatment similar to (Gesneria). $G$. speciósa dark blue, $G$. speciósa-pállida, pale lilac; $G$. càndida, pure' white, G. grandiflóra, very large light blue, rubra, red; Cerina, pink and white; maxima, lilac and white, Lennigii, rose and white; and Teuclerii, rose, white and violet, are the finest, although several of the other species are very interesting.

\section{OF CLEANSING PLANTS, HOUSE, \&c.}

With regard to cleaning the plants, sprinkling or syringing is at all tirnes, to a greater or less degree, necessary. The plants will, in this compartment, be in their first stage of growth, and, if dust or foulness be permitted to lodge on their foliage, the pores will be obstructed, the plants will become unhealthy, and the growth of insects increased.

Let all moss, litter, decayed leaves or weeds, be cleared out of the house, the earth in the pots stirred up with a round pointed stick, and fresh earth given where required, that the air may operate therein freely.

The house ought always to be sprinkled before being swept, to prevent the dust rising.

Attend to the bulbous roots as directed last month, such as Hyacinths, Narcissus, \&c. 


\section{MARCH.}

If this department has been regularly attended to, the plants will be in a fresh healthy state. Where there is any sickly appearance, heat has been deficient, or insects of a destructive character are preying upon the plants. Too much water at the root frequently causes the foliage to become yellow. Regular syringing must be continued in the morning, and it is highly necessary that the water that is used should be of the same temperature as the house; and at all times, whatever water is given to the roots, the same must be observed. For airing, see last month, observing, as the season advances, to increase the quantity.

Continue to fumigate when any of the Green-fly appears (see January for directions), and where there are any of the plants infected with the white scaly insect, clean them as there directed. If overlooked for a few months, they will be increased tenfold. Very frequently, where there are only a few, they are neglected until the plant is overrun with them, and then it may be said it is impossible to dislodge them entirely. Clear off all decayed leaves from the plants which will have made fresh shoots, for the decayed leaves very much disfigure the whole collection. We would not have repeated this observation if it was not an essential point; and one which is so frequently neglected.

\section{CF REPOTTING PLANTS.}

Nany of the young plants that are growing freely, and where they may be desired to grow to a large size, should be frequently repotted to encourage their growth. Gesnèria, Gloxinia, and others previously mentioned, must have larger pots, as they require it. Flowering bulbs of Amaryllis may be brought into the heat to make them bloom early; before they begin to grow, divest them of the old soil, and put them into fresh: this is particularly necessary, when the bulbs are already in large pots. By thus renewing the soil, the pots can be used much smaller: they require plenty of drainage in the pot, and agree best with soil No. 12 . 
Where plants of the dwarf Musas are intended to be grown for fruiting, they must have particular attention in repotting as they grow; about the first of the month will be a proper time to begin: copious waterings are daily required when they are in a growing state. Their soil is No. 12, with one portion more manure. For farther detail, see May.

\section{APRIL.}

WHERE the hot-house has been properly conducted, the plants generally will have a vigorous and healthful aspect. An error frequently arises in the conducting of these departments, by inexperienced operators, being ambitious of outstripping their competitors. They keep the house in a very high temperature, and admit little or no air. Where such a mode has been pursued, the plants will have got over their first growth, and the foilage looks yellow and decaying; thus throwing the plants into a state of inactivity, when nature herself commences her most active movements. The temperature should not be under $55^{\circ}$ in the night, nor much above $75^{\circ}$ during the day, without admitting a little air by the top lights. It will not do yet to give air by the front sashes, the wind being cool, and a current in the house would be hurtful. The sun is not so powerful, but the heat can be kept down by the air given from above.

Hot-house or tropical plants will not materially suffer with $100^{\circ}$ of sun-heat, provided they are not very near the glass; but such an extreme would be injurious to practice.

\section{REPOTTING.}

Where there is a general assortment of the Cactre tribe, and kept in this department, now is the proper period to give them a general repotting. Of all the tropical floral productions, there is not a family more curious, grotesque, interesting, and beautiful than this; and, what still more enhances their real value, they are in this country of the 13 
easiest culture; it is with pleasure that we recommend a few of the grand and the novel, which are faithfully described in the general list given next month. The bottom of every pot must be covered with an inch of pot-shreds, or rough gravel for drainage.

\section{MAY.}

VERY few directions for this department remain to be given; except for shifting plants, and a few observations on those that are most desirable for the hot-house; which we will do in this month, considering May and June the best months of the year for that operation.

The days and nights will be very mild by this time, and the sashes in every favorable day should be opened, both in front and top, so that the plants may be inured to the open air, which they will be exposed to by the end of the month. Leave in the beginning of the month the top sashes a little open every mild night, and gradually, as the heat increases, leave the front sashes and doors open. Continue to syringe them at least every alternate night, and, if possible, every night; and give them all, according to their respective wants, liberal supplies of water every day. Absorption among hothouse plants is as great during this month as in any period of the year.

\section{OF REPOTTING PLANTS, \&c.}

It is our candid opinion that this and next month are the best periods for shifting or repotting all or most of hot-house plants; the end of August being the time always adopted around Philadelphia for that operation (and then they are done indiscriminately). We will assign a few reasons for our practice.

First, that it is not congenial to the nature of these plants to have their roots surrounded with fresh soil when they are becoming inactive; secondly, that there is not a sufficiency 
of heat naturally to quicken them to an active state when they are encouraged; and, thirdly, being thus in new soil while dormant, they have a yellow and sickly aspect until they begin to grow; and the folitge thus deprived of its natural vigor, will not appear so healthful again: whereas, if they are shifted or repotted in this or next month, at which season they are between two stages of growth, they immediately, on receiving fresh assistance, and by the increasing heat of the summer, make new growths, are perfectly ripened before the approach of winter, and never lose that vernal appearance they have attained. These are our reasons, acquired from a close practice and obscrvation, and are not influenced by the doings of others which are so much aside. No practical operator especially, nor, in fict, any individual, ought to be governed by custom in regard to the treatment of plants, without having any idea as to why and wherefore, founded on the principles of nature, and governed by her unerring results.

As many are desirous of having a knowledge of plants before they order them, and likewise which are the finest flowerers and their general character, especially those who are at a great distance, and seldom have the privilege of seeing what is most desirable, our descriptions will be limited, but still will convey some accurate idea of the article describèd.

Acacias. Several of these are desirable in the hot-house for the grandeur of their foliage, beauty of flower, and a few of them as specimens of valuable medicinal plants. $A$. Houstóni, now Anneslèia Houstóni, is one of the most magnificent of the Mimòsa tribe, blooming from August to November in large terminal spikes of a crimson color, stamens very long and beautiful, leaves bipinnated in pairs. $A$. grandiforra, likewise given to Anneslèia, and similar to the former in color, has very large compound bipinnate leaves, with from twenty to forty pairs. A. Catèchu, flowers yellow, wood spiny, leares bipinnated, about ten pairs. The inner wood of this tree is of a brown color, from which the Catéchu used in medicine is prepared. It is disputed whether A. véra or A. arébica produces the gum Arabic. We are inclined to think it is the latter, which grows principally on the Atlas mountains. The gum exudes spontaneously from the bark of the tree in a soft half fluid state. There are 
many others of this genus belonging to the hot-house, but being shy in flowering, are not generally esteemed. Most of the flowers have the appearance of yellow balls of down, and are hermaphrodite. The pots should all be well drained. (Soil No. 1.)*

Aschynanthus, about four species, among which $E$. grandiflorus, $A$. Boscanus, dark velvet purple and bright scarlet, and $\mathbb{E}$. parasiticus are very deserving of culture; they have thick fleshy foliage, are of slender growth, producing orange-colored tubular flowers in clusters, and require treatment similar to the wax-plant.

Ardisias, about eighteen species. Plants highly esteemed for the beauty of their foliage, flowers, and berries. The most popular in our collections is $A$. crenulata. It has rosecolored star-like flowers, in terminal panicles, and produces beautiful small red berries, which continue until other berries are produced the following year; and frequently there may be seen on one plant the berries of three successive years, thus being a very ornamental plant and very desirable. It is vulgarly called the dwarf ever-bearing cherry. It will keep in a good green-house, but not grow freely. $A$. solanàcea has large oblong leaves, narrowed at each end, and bears purple berries; $A$. élegans has entire, oblong, shining leaves; $A$. umbellata, once $A$. littorális, is also a fine plant for an abundance of flower and beauty of foliage. The flowers are pink, in large decompound panicles.

Allamanda, a family of half climbing plants, a little assimilated to the oleander, with large chrome-yellow blossoms, requiring plenty of pot-room and good culture to flower well. A. cathùrtica and A. Schottii we consider the finest. (Use soil No. 13.)

Aphelanda cristata, a new plant with a brilliant spike of crested flowers about six inches long crowning the plant. (Use Soil No. 9.)

Arèca, Cabbage-tree, ten species. They are a kind of palms, with large pinnated leaves, or properly fronds. In their indigenous state they are from six to forty feet high, but in the hot-house they seldom exceed twenty feet. $A$. cátechu is used in medicine. A. olerácea is cultivated exten-

* These numbers refer to the table of soils at the end of the work. 
sively in the West Indies, and the tender part of the top is eaten by the natives. A. montand is most frequent in collections. There is no particular beauty in the flowers. They are all easily grown, if plenty of heat be given. (Soil No. 12.)

Aristolóchias, Birth-wort. There are several of these belonging to the hot-house, but none of them deserving particular observation, except A. labiòsa and A. brasiliénsis. The leaves are reniform, roundish, cordate, and amplexicaule; the flower or corolla is of a curious construction, being incurved, and at the base swelled or saccate, with a large lip, and all beautifully spotted; color greenish brown. They are climbing plants, and require a strong heat. (Soil No. 9.)

Astrapæas, three species. A. Wallichii is a celebrated plant in Europe, and is frequently met with in our collections. It has a profusion of scarlet umbellated flowers, with an involucre; has twenty-ive stamens united into a tube, bearing the corolla with five petals; leaves roundish, cordate, acuminate, very large, with persistent, ovate wavy stipules. The plant is of easy culture, and grows freely, wood very strong. (Soil No. 12.)

Bambrisas, Bamboo-cane, two species. Plants of very strong growth, and are used in the East Indies, where they are indigenous, for every purpose in the construction of huts, for furniture both domestic and rural, for fences, boats, boxes, paper, \&c. It is frequently used as pipes to convey water. The species thus useful is $B$. arundinácea, which grows to a great height. We do not mention it as interesting in beauty, but as a valuable plant for the many useful purposes to which it is applied. It requires to be kept wet. (Soil No. 15.)

Banistèrias, a genus of about fourteen climbing evergreen plants. Three of them are esteemed, $B$. fúlgens, yellow flowers in racemose spikes, leaves subovate and downy beneath. B. chrisophylla has beautiful foliage, as if covered with a shining gold-colored dust; leaves large, oblong, acute. B. splèndens, flowers in spikes of a yellow color; foliage large and silvery-like; the pots should be well drained. (Soil No. 9.)

Barringtònias, two species. B. speciòsa has produced a great excitement among cultivators, and is one of the handsomest plants produced within the tropics. The leaves are 
large, oblong, acute, shining, with fleshy nerves, tinged with red; the flowers are large, full of stamens with four petals, opens in the evening and fades at sunrise; color purple and white; grows freely in strong heat. (Soil No. 9.)

Beaumóntias are strong-growing climbing plants, with large foliage. B. grandiflora is said to have beautiful large white flowers approaching the Oleander. (Soil No. 12.)

Blétias, a genus of about eight species, all beautiful flowering plants. B. Tankervillize is most superb, a small plant, now (Jan.) in bloom, has upward of fifty full-blown flowers, besides many buds - they are brown, white, and purple, and about two inches in diameter. When out of flower, and the roots become dormant, place the pots in a shady situation; allow the soil to become dry, until the roots begin to grow : as soon as this is observed, repot the plants and expose them fully to the sun, giving plenty of water while growing. $B$. Shéppherdii is a fine pink, and requires similar treatment. (Soil No. 13.)

Bignonia, a very beautiful family of climbing plants, some of them gorgeously covered with bloom half of the year. $B$. venustà has large clusters of bright orange-colored flowers in great profusion from December to May. B. picta, violet and lilac-colored striped flowers. B. chamberlyana, yellow flowers with rich foliage.

They should be planted into large pots or tubs, or if practicable into the ground in the interior of the house, giving them plenty of space to climb, using Soil No. 9.

Brunfélsias, very fine, free flowering plants, with white, yellowish, or purple flowers. B. grandifiora blooms freely, and is finely scented - a plant before me now (28th of Jan.) only one foot high, has six full expanded flowers upon it, each fully two inches in diameter. (Soil No. 9.)

Buonapártec júncea, a very curious low growing plant, with long narrow, recurved, round leaves; with spikes of small green flowers. There does appear to be three distinct varieties in cultivation, but are rarely attainable. (Soil No. 12.)

Buiddlea madagascariensis blooms profusely during winter in spikes of orange-colored flowers, of a kind of honey fragrance-the plant is strong growing, and of the easiest culture. (Soil No. 11.)

Calathèa zebrina, frequently known as maránta zebrina ; 
it is a plant unique in appearance, having large elongated ovate leaves, beautifully striped with green and dark purple, and called the Zebra plant. It has light blue flowers in ovate spikes, about the size of large pine cones. It is an herbaceous plant; but in the warmest part of the hot house retains its splendid foliage; requires a very liberal supply of water, and ought to be in every collection. (Soil No. 11.)

Cánnas, about thirty species, several of them deserving cultivation both for flower and foliage: they are principally natives of the West Indies, and might all be easily obtained. The finest are $C$. gigántea, has large leaves and orange flowers; C.limbita, flowers scarlet and yellow ; C. discolor, has large cordate, acuminate leaves of a crimson color, the flowers are scarlet; C. iricliflòra, has large crimson nodding flowers, very different from any of the others, and the finest of the genus. They all, while in a growing state, require a liberal supply of water; and being herbaceous plants, watering ought to be given up about the first of November, and renewed in February, thus giving them a cessation which they require to flower freely; but when water is constantly given, which is the general plan in our collections, they continue to push weak shoots and few flowers. (Soil No. 12.)

Cáctus. This extensive genus is interesting, and varied in character and habit; it is now divided into seven distinct genera, according to their natural appearance and disposition. We will describe a few of each genus, none of which going under the name of Cactus, we will give them the six following, premising that the time is not far distant when this family will be successfully cultivated in every parlor window, and the whole tribe will be sought for with more avidity than any other class of plants that have ever been brought to notice, not even excepting the Rose. They require a dry heat, and will grow either in town or country, and are completely adapted for the denizen amateur, and will afford more beauty and interesting display than can be imagined until witnessed.

Mamillàrias, about serenty species, and are those which are covered with roundish bearded tubercles, and with small red and white flowers. M. coccinea, MI. simplex, M. pusilla, MI. cónica, M. stellata, and MI. acanthòphlegma, are good 
species, and will do well with water once a-week during summer. (Soil No. 15.)

Melocáctus, seven species, and are those that are roundish with deep and many angles, with spines in clusters on the top of the angle. M. comminis is the Turk's cap, named from having an ovate conate crown upon the top, from which proceed the small red flowers. MI. macránthus has large spines; $\boldsymbol{M}$. pyramidalis is a conical growing species. These require the same treatment as the last. (Soil No. 15.)

Echinocátus, a great number of species; are those that have many deep angles, and have a remarkable swelling with each parcel of spines; $E$. gibbósus, $E$. crispàtus, $E$. recrirvus, P. rodinthia, and E. scopa, are curious in appearance, with small white and purple flowers. - These three genera in most collections are not well known specifically, but it is easy to discriminate with which genus they are connected. (Soil No. 15.)

Cèreus. This is the most magnificent genus with regard to the magnitude and beauty of the flowers, but not so closely allied in character. It takes in all those of a trailing or erect growing habit, having spines in clusters, solitary, or spineless. $\quad C$. senilis is the celebrated monkey cactus. $\quad C$. peruviànus and C. heptagònus grow very erect, and to the height of thirty or forty feet in Peru and Mexico, where they plant them close together as fences, and they are in a few years impenetrable. C. flagellifórmis is a well-known creeping flowering species, has ten angles; will keep in a good green-house, and produce in May and June a great number of blooms. The petals are of a fine pink and red color; the tube of the flower is long, and will stand a few days in perfection, when others come out successively for the space of two months, and during their continuance make a brilliant appearance. C. grandiflòrus is the celebrated "Nightblooming Cereus." The flowers are very large, beautiful and sweet-scented. They begin to open about sundown, and are fully expanded about eleven o'clock. The corolla, or rather calyx, is from seven to ten inches in diameter, the outside of which is a brown, and the inside a fine straw yellow color; the petals are of the purest white, with the stamens surrounding the stile in the centre of the flower, which add to its lustre, and make it appear like a bright star. Its scent is agreeable, and perfumes the air to a considerable distance; 
but these beauties are of momentary duration. By sunrise they fade, and hang down quite decayed, and never open again.* One of these ought to be in every collection, and, if trained up a naked wall, will not occupy much room, and grow and flower profusely. C. Mállisoni and C. Scottii are nearly alike, and have beautiful scarlet flowers: it has been gratuitously (to say the least of it) called "The Scarlet Night-blooming Cereus." C. speciossíssimus has most beautiful large flowers, about six inches in diameter; the outside petals are a bright scarlet, those of the inside a fine light purple. One flower lasts a few days, and a large plant will produce every year from ten to fifty flowers, and blooming from May to August. C. Maynardii has very large orange scarlet flowers, about nine inches in diameter, blooming during the day. C. Fielderii is of a brilliant bluish violet color, even more of the peculiarly blue tints so greatly admired in speciossissimus. C. triangulàris has the largest flower of the Cactere family; the bloom is of a cream color, and about one foot in diameter. In its indigenous state it produces a fine fruit called "Strawberry Pear," and is much esteemed in the West Indies as being slightly acid, and, at the same time, sweet, pleasant and cooling.

Epiphyllums are those species of the Cacter family which have flat shoots, or leaves without spines; from the edges of those leaves the flowers are produced. They are extensively cultivated for their profusion of bloom, and are frequently grafted on Cèreus triangulìris and Perèskia, which greatly promotes their growth, and prevents them from so easily damping off by over-watering. The original species are E. speciossum, pink; E. phylanthoìcles or Hoôkerii, white; $E$. alàtum, white; $E$. truncàtum, scarlet; flowers tubular, from two to three inches in diameter. The plant is of a very dwarf growth, and much branched; when in bloom, it is quite a picture, and rendered more beautiful when grafted. There are three varieties of truncitum, differing from it in color, or rather shades of color: Altenstëinii, rosy red; violacea, very beautiful violet and white;

* 'They may be preserved if cut off when in perfection, and put in spirits of wine, in a glass vase, made air tight. A plant flowered in our collection in May, 1830, at 12 o'clock at noon-the only instance of the kind we ever heard of. 
mbens, bright red. E. Ackermania has a magnificent large crimson flower. Besides these, there are many superb hybrid varieties, vieing with any of the originals. Among them are the following: $E$. crinitum, large brilliant crimson, quite new, of fine habit; $E$. fulgens, large violet crimson firmly formed flowers, very desirable; $\boldsymbol{E}$. Grahamii, very distinct, of a brilliant rose color; $E$. speciòsa major, large delicate rose. E. Hibbèrtii, E. Hoòdii, E. Boydii, E. De váuxii, E. quillardittii, E. F'éastii, E. Vándesii, E. Mayfly, E. elegantissima, and E. Naiperii, and no doubt many other varieties and sub-varieties will be continually making their appearance. 'All the Epiphyllum tribe require a very rich open soil, not of too sandy a nature, as they thereby grow to wood, and bloom but sparingly-give plenty of drainage. (Soil No. 18.)

Oprintias, upwards of fifty species, and are those whose branches are in thick joints, flat, oblong, or ovate; spines solitary or in clusters. Some of the plants are very desirable for their singular appearance, and some of them, particularly 0 . cochinillifera, are valuable for feeding the Cochineal insect. O. microdâsys, O. feróx, O. lacte-spina, O. sericeá, and some others, are beautiful plants, and will grow in any kind of soil, but No. 2 will suit them best.

Peréstias. About four species, and those that are of a shrubby nature, producing leaves; $P$. aculeata bears a fruit called "Barbadoes-gooseberry." The flowers are very small and simple, spines about half an inch long, leaves fleshy and elliptical. (Soil No. 2.)

The whole of the plants in the family of Cacter require very little water in winter, and delight in a dry, warm situation. They do not agree with very frequent repotting; once a year to young plants, and in two or three to those that are established, with the exception of the large, free flowering species, which should be repotted once in two years, and never be allowed to shrink for want of moisture.

The operation of grafting is very simple, merely requiring an incision to be made, and fitting in it a fresh cutting of another kind, holding the cutting stationary in the incision half a minute, till the juices of the two adhere together, when it may be said the union is effected, and, in a few weeks, the new branches will grow freely. We have seen 
the Mammillaria tribe growing neatly upon the triangularis, and other species of the cereus.

Ceropergia elegàns is the only species of any merit: it is a thin-growing climbing plant, producing a great profusion of very curious flowers of a greenish color, spotted with brown; the interior and tips of the corolla are set with hairs - it is of very easy culture. (Soil No. 7.)

Caryota. A genus of palms. C. uirens is an admired species, produces flowers in long pendulous spikes, which are succeeded by strings of succulent globular berries. In its native state it produces a sweet liquor in large quantities, and no stronger than water. (Soil No. 12.)

Caryophyllus aromaticus is the clove tree of commerce. The whole plant is aromatic, and closely allied to Myrtus; the flowers are in loose panicles, the leaves oblong, acuminate, entire. It is a fine evergreen. Pots must be well drained. (Soil No. 9.)

Centradenia rosea. A unique-looking plant, with a fine reddish purple foliage, which in the winter season is profusely covered with delicate rosy pink flowers. The plant is of dwarf habit, and of the easiest culture. Use Soil No. 2.

Cérberas. About twelve species of strong-growing trees, full of poisonous juice. C. thevètia is an elegant plant, with acuminate leaves, and large, nodding, yellow, solitary fragrant flowers, proceeding from the axil ; C. ahoìai produces a nut which is deadly poison. $C$. odallam, once $C$. mànghas, has large star-like flowers, white, shaded with red. They are principally East India plants, and require great heat. (Soil No. 17.)

Clerodéndrum. This genus contains some very beautiful and fragrant plants. C. frágrans floré pléno has a very beautiful head of double white sweet-scented flowers, and does very well as a green-house plant. C. squamátum has very showy scarlet flowers. C. speciosissimum, the plant so glaringly figured in some of the English periodicals, is the same as C. squamátum, a plant which has been grown in this vicinity fifteen or twenty years. (Soil No. 2.)

Coffèa Arábica. It produces the celebrated coffee, and is a plant universally known in our collections, and of easy culture. The leaves are opposite, oblong, wavy and shin- 
ing, the flowers white, of a grateful odor, but of a short duration. (Soil No. 17.)

Combrètums. Nine species of beautiful flowering climbing plants, standing in very high estimation. The leaves of the principal part of them are ovate, acute, flowers small, but on large branches, the flowers all coming out on one side of the branch. They have a magnificent effect. $C$. èlegans, red; C. formòsum, red and yellow; C. pulchéllum, scarlet; C. comòsum, have crimson flowers in tufts; C. purpureum is the most splendid of the genus. It was first cultivated in 1818, and so much admired that the whole of the species, as soon as introduced, was extravagantly bought up; and none of them has retained their character, except C. purpireum, which is now called Poivrea coccinea. The flowers are bright scarlet, in large branches, blooming profusely from April to September, and flower best in a pot. When planted in the ground, it grows too much to wood, carrying a few flowers. This plant ought to be in every hothouse. (Soil No. 13.)

Córyphas (Large fan Palm), five species of the most noble and magnificent of palms. C. ambraculifera, the fronds or leaves are palmate. In Ceylon, where the tree is indigenous, they are frequently found fifteen feet wide and twenty feet long. Knox says they will cover from fifteen to twenty men, and, when dried, will fold up in the shape of a rod, and can be easily carried about, and serve to protect them from the scorching sun. C. taliera, now Taliera bengalensis, being stronger, is of great utility for covering houses. They do not grow to such immense extent in artificial cultivation, but require large houses to grow them. (Soil No. 12.)

Crìnums, about one hundred species, chiefly stove bulbs, many of them beautiful. Those that are of great celebrity are C. errubéscens, pink; C. scàbrum, crimson and white; C. amaibile, purple and white; the neck of the bulb of the latter is long, is easily distinguished by its purplish color, and is unquestionably the finest of the genus. Several specimens of it are in our collections. Their flowers are in umbels, on a stalk about three feet high; corolla funnelshaped; petals recurved; nearly fifty flowers on each stem, and a good plant will produce three stems in one year. They require large pots to make them flower well, and, 
when growing, should be liberally supplied with water. (Soil No. 12.)

Crôtons. About twenty-eight species, few of them deserving cultivation; but the genus is celebrated for its beautiful $C$. pictus, leaves oblong-lanceolate, variegated with yellow, and stained with red, flowers small green, or axillary spikes. C. variegattus, variety latifolia, is finer than the original variegàtus; the nerves in the leaves are yellow, and the leares lanceolate, entire, and smooth. To make them grow freely, give them the warmest part of the hot-house, and drain the pots well. (Soil No. 13.)

Cycas, four species, generally called Sago palm, as an English name. The plant from which Sago is extracted, belongs to another genus, (see Sàgus.) C. revolìta is a well-known palm, and will keep perfectly well in the greenhouse. We have seen a beautiful specimen of it which is kept every winter in the cellar; but those that are kept so cool in winter only grow every alternate year, while those that are kept in the hot-house grow every year, which shows that heat is their element. C. circinalis is a large-growing species; the fronds are much longer, but not so close and thick. C. glairca is a fine species; the foliage is slightly glaucous. They require plenty of pot room, are much infested with the small white scaly insect, and ought to be frequently examined and carefully washed as prescribed in January. (Soil No. 12.)

Cypripedium insigne is a very beautiful nepal species of this curious Ladies' Slipper plant. The flowers have a waxy appearance, and very much in shape of an Indian shoe; the colors are green and purple; it likes a moist, halfshaded situation. (Soil No. 16.)

Cyrtocercas reflexus, or Hoya coriacea, a new dwarf waxplant of magnificent appearance, either for foliage or bloom, which it produces in great profusion from the axils of almost. every leaf; it is a native of Manilla; it grows freely in Soil No. 13.

Draccenas, Dragon-tree, $s$ about twelve species of Asiatio plants, varied in character. D. Férrea is plentiful in our collections, and will keep in the green-house; but the foliage is not so well retained as when kept in the hot-house; the leaves are lanceolate, acute, of a dark crimson color. $D$. terminális, striped leaved; D. fràgrans, when in bloom, 
will scent the air for a considerable distance, leaves green and lanceolate. D. Margináta is rare, yet it is to be seen in a few of our collections. D. stricta is now Charlwoòdia* stricta, flowers blush, and in loose panicles. D. Dráco is admired, and the most conspicuous of the genus. (Soil No. 11.)

Eránthemums, about ten species. E. pulchéllum and E. bicolor are the finest of the genus; the former is in our collections. Plenty of heat is indispensable to make it flower in perfection; therefore it should have the warmest part of the house, and it will produce flowers of a fine blue color from December to April. The flowers of the latter are white and dark purple, with a few brown spots in the white: blooms from April to August. Drain the pots well, and give the plants little sun during summer. (Soil No. 11.)

Eugènias, about thirty species, esteemed for their handsome evergreen foliage. This genus once contained a few celebrated species, which have been divided. (See Jambòsa.) The Allspice tree, known as Myrtus Piménta, is now $E$. Pimenta; the leares are ovate, lanceolate, and, when broken, have an agreeable scent. There are several varieties, all of the same spicy fragrance. The plant is in very few of our collections. $E$. fragrans is sweet-scented; the flowers are on axillary penduncles; leaves ovate, obtuse. (Soil No. 11.)

Euphórbia (spurge), a genus of plants disseminated over every quarter of the globe; a few are beautiful, many grotesque, and several of the most worthless weeds on the earth. There are about two hundred species, and from all of them, when probed, a thick milky fluid exudes. Those of the tropics are the most curious, and very similar in appearance to Cáctus, but easily detected by the above perforation. There is a magnificent species in our collections, which was lately introduced from Mexico-(see Poinsettia). I. spléndens flowers freely from December to May, and is of easy culture. E. fúlgens, same as jaquiniiflòra, is a plant of a slender willow-looking habit, but produces a profusion of flowers from the axil of each leaf, which renders it very showy. The flowers of the whole genus are apetalous, and the beauty of those described is in a brilliant scarlet bractca,

* In honor of Mr. Charlwood, an extensive seedsman of London, who has made several botanical excurions on this continent. 
which is very persistent. They must have plenty of pot. room. (Soil No. 9).

Erythrinas (Coral tree), a genus containing about thirty species of leguminose, scarlet-flowering plants. Several species are greatly esteemed for their beauty and profusion of flowers, which, in well-established plants, are produced in long spikes. $E$. corallodéndrum blooms magnificently in the West Indies, but in our collections has never flowered. Perhaps if it were kept dry during its dormant season, which is from November to January, and when growing greatly encouraged, it might produce flowers. E. speciòsa is a splendid flowerer, leaves large, ternated, and prickly beneath; stem prickly. E. pubéscens is valued for its large peculiar brown pubescent leaves. E. princéps is quite a new species, and is represented as being the finest of all the Erythrinas, and exhibits its rich crimson flowers in great profusion; to make them grow well and bloom freely, they require plenty of pot-room; indeed, while in a growing state, they should be repotted every month. In regard to E. hierbicea, which is a native of the Carolinas, and frequently treated as a hothouse plant, it is our opinion that it would be more perfectly grown if planted about the first of the month in the garden; and, when growing, if well supplied with water, it would flower from July to September. About the first of November lift the roots and preserve them in half dry earth. $E$. laurifòlia and $E$. crístagálli are likewise often treated as hot-house plants, and in such situations they cast prematurely their first flowers by the confined state of the air. They will keep in perfect preservation during winter in a dry cellar, half covered with earth, or entirely covered with half dry earth; consequently, the best and easiest method of treatment is, to plant them in the garden about the first of May, and, when growing, if the ground becomes dry, give them frequent waterings. They will flower profusely three or four times in the course of the summer.

We freely recommend the last species to all our patrons, confident that it will give ample satisfaction, both in profusion of flower and beauty of color. The soil they are to be planted into should be rich and well pulverized; or, if they are kept in pots, they must be enlarged three or four times, when they are in a growing state, to make them flower perfectly; otherwise they will be diminutive.

(Soil No. 13.)

Ficus, Fig-tree, a genus containing about fifty hot-house 
species, besides several that belong to the green-house : greatly admired for the beauty of their foliage. A few of them are deciduous, and all of the easiest culture. We have seen plants of $F$. elástica hung in the back of the hot-house, without the smallest particle of earth, their only support being sprinklings of water every day. $F$. brássi and $F$. macro- phylla are the finest-looking species that have come under our observation; the leaves of both are very large and shading, occupying considerable space. In small collections, $F$. indìca and $F$. nitida are desirable; $F$. repèns is a climbing plant. (Soil No. 13.)

Franciscea, a new genus of plants from South America, containing about four species of profuse blooming plants. $F$. Hopeana and $F$. latifolia are generally known; the latter possesses all the combined fragrance of the jasmine and jonquil; the flowers are one inch in diameter, of a rich purple fading to pure white, and blooms the whole winter. (Soil No. 9.)

Gardènias, a genus containing about seventeen species, several of them very popular in our collections, going under the name of Cape Jasmine, which do well in the greenhouse (see May). The species requiring this department, and deserving attention, are G. campanulàta, of a soft woody nature, with ovate, acuminate leaves; flowers of a straw color, and solitary ; $G$. amæna, the flowers are white, tinged with crimson, terminal and solitary, but seldom bloom; $G$. costàta, admired for its beautiful ribbed foliage; $G$. lùcida has a handsome, ovate, acuminate, shining foliage, flowers white and solitary; G. Sherbournii has large spotted flowers. G. Stanleyana, flowers of a greenish white color, nine inches long, spotted with brown; they require to have the pots well drained. (Soil No. 13.)

Geissoméria longiflora. This is a new genus, and closely allied to Ruéllia. The species alluded to is a free flowerer, blooming from January to May, in close spikes of a scarlet color, leaves opposite, ovate, elongate, and shining; the plants must be well drained, and in summer kept from the direct influence of the sun. (Soil No. 2.)

Helicónia braziliénsis. This very splendid plant'is nearly related to Strelitzin, and in splendor surpasses it. The brilliant scarlet sheath that envelops the flowers contrasts most admirably with its rich green leaves. Give plenty of 
drainage to the pots, and, when the plants are growing, give a liberal supply of water. (Soil No. 17.)

Helitròpiums, about twelve species, of little merit, except $H$. peruvianum, $H$. intermedia, $H$. valitariana, pale bluish white; H. fleur de Liege, represented as yellow, but is only a very dull white, with a faint yellow eye; these are all very agreeably scented, especially the two former, which are universal favorites. (Soil No. 3.)

Hibiscus. This genus affords many fine species and varieties of plants for the hot-house, besides others for every department of the garden. The most popular in our collections of the hot-house is $H$. ròsa sinénsis, with its varieties, which are magnificent, and flower profusely from February to September. The single or original species is also beautiful; the varieties are $H$. ròsa sinénsis rùbro plénus, double red; H.r. s. cárnea plénus, double salmon; H.r.s. varicgattus, double striped; striped on the back of the outside petals; H. r. s. flava plènus, or carnea, double buff; H. $r$. s. lùtea plènus, double yellow, or rather sulphur. The plants grow freely, and produce their flowers three or four inches in diameter, from the young wood; the leaves are ovate, acuminate, smooth, entire at the base, and coarsely teethed at the end. All the varieties are of the same character, and highly deserving of a situation in every collection. There is said to be a double white variety, which we doubt. $H$. mutabilis flòre plèno is a splendid plant, of strong growth, and will, when well established, flower abundantly, if the wood of last year is cut to within a fer eyes of the wood of the previous year; the flowers are produced on the young wood, and come out a pale color, and change to bright red, and about the size of a garden Provins rose; leaves downy, cordate, angular, five-lobed, acuminate, and slightly indented. $H$. lillii-flòrus is a new highly esteemed species; the flowers are various in color, being pink, blush, red, and purple. The leaves vary in character, but are generally cordate, crenate, acuminate; the petioles are brown, and the whole slightly hirsute; is deciduous, and requires to be kept in the warmest part of the house. (Soil No. 9.)

Hóyas, wax-plant twelve species. All of them are climbing succulents, requiring plenty of heat and little water. $H$. carnòsa is a fine flowering species, and known in our collections as the wax-plant; the leaves are green and fleshy; $14 *$ 
the flowers are mellifluous, five-parted, and in pendulous bunches, slightly bearded, and have every appearance of a composition of the finest wax; of a blush color. H. crassifòtia, H. grandiflora, brown flowered, $H$. bella, variegated, H. Cunninghamii and $H$. imperialis are all well worthy of cultivation. (Soil No. 2.)

Ipomæas, a genus of tropical climbing plants, nearly allied to Convolvuilus, but of greater beauty. I. Jálapa is the true jalap of the druggists, but not worthy of any other remark. I. Horsfállia has brilliant rosy crimson flowers, which it is almost entirely covered with from December to May. I. mugosu has a profusion of large rosy lilac flowers. I. multifiòra, blush and lilac. I. Learii produces a profusion of large blue flowers; they are all very showy and beautiful ornaments for either the hot-house or the flower garden. (Soil No. 13.)

Ismène amáncaes, or Pancràtium amáncaes. This profuse yellow flowering bulb is richly deserving of cultivation, and should be kept in the house all summer, repotting it as often as the roots touch the interior side of the pot, giving it plenty of water when in a growing state; but when dormant, it must be kept dry till it offers to grow: when well treated it will bloom repeatedly during summer. (Soil No. 12.)

Ixòras, a genus of fine flowering plants, and does extremely well in our collections in comparison to the state they are grown in England. The genus specifically is much confused among us, either from error originating with those who packed them for this country, or after they have arrived. $I$. purpùrea, leaves oblong, ovate, blunt; flowers crimson; $I$. crocata, leaves oval, lanceolate, narrowing toward the stem, smooth underside of the leaf; the nerves are very perceptible; flowers saffron-colored, and very profuse. I. ròsea, leaves large, regular, oblong, a little acute, very distant on the wood, central nerve strong; flowers rose-colored in large corymbs, branching finely; I. bandhicca, leaves very close to the stem, ovate, acuminate; nerves straight, middle nerve stronger than any other of the genus; flowers scarlet. $I$. blánda, leaves small, lanceolate, ovate; flowers red, cymes branching in three. I. dichotima, leaves largest of the genus, ovate, acuminate, undulate footstalk three-eighths of an inch long; whereas, none of the leaves of the other species have footstalks of any length; it is now called 1 . undulata; 
flowers are white, leaves ovate, elongate, sessile; flowers scarlet, in crowded round corymbs; is called $I$. coccinea in the Botanical Magazine, by which it is known in our collections, and we think is the same as I. stricta. I. flimmea and I. speciòsa. I. Pavétta, the flowers are white and sweetscented, the leaves of all the species are opposite; there are a few other species that we are not thoroughly acquainted with, but have been thus explicit to prevent error as fur as possible in this beautiful genus. They are all evergreen, low growing shrubs; the plants grow best in Jersey black sandy earth, but flower most abundantly with Soil No. 10 .

Jambosas, about twelve species, which have been principally taken from Eugèria, and contains its finest plants, and is a splendid genus of evergreen shrubs. E. Jámbos is now Jambòsa vulgàris, which flowers and fruits freely in our hot-houses. The fruit is about an inch in diameter, eatable, and smelling like a rose, hence called "Rose Apple." The petals of all the species are simple, and may rather be considered the calyx; the beauty of the flowers is in the many erect spreading stamens, either straw, white, rose, or green color. J. maläccénsis, Malay Apple, is greatly esteemed for the delightful fragrance of its fruit. We frequently see $J$. purpuráscens, which is a native of the West Indies, going under $J$. $m$., which is an Asiatic species, with white flowers and entire oblong leaves; whereas, the leaves of $J . p$. are small, ovate, acuminate; the young shoots and leaves are purple. J. macrophylla, white, and J. amplexicaùlis, green, have very large oblong, lanceolate leaves, and are of a strong, woody habit. They are all easy of culture. (Soil No. 11.) Jasminum, Jasmine, is a favorite genus of shrubs for the exquisite fragrance of its flowers, of which none are more delightful than $J$. sàmbac or Arabian Jasmine. There are two other varieties of it, J. s. múltiplex, perfectly double; and $J$. s. trifoliatum, double Tuscan Jasmine or Grand Duke; J.s. IIaid of Orleans, large, very double, like a very perfect white rose, and exquisitely fragrant. There is also a semi-double variety in cultivation. J. multiflòrum is a profusely flowering and beautiful species. There are several others, all with white flowers, and generally easy of culture. (Soil No. 11.)

Játropha, Physic-nut, is a genus of six strong-growing shrubs, natives of the West Indies. J. multifida and $J$. 
panduræfotia have the handsomest foliage, and both have scarlet flowers: the appearance of the foliage of this genus is the only object: the flowers are small, in coarse disfigured panicles, and several of the species have not been known to flower in artificial cultivation. The seeds of J. curcas are often received from the West Indies; the leaves are cordate, angular and smooth. J. manitiot, now Manihot cannabina, is the Cassada root, the juice of which, when expressed, is a strong poison. They are all easy of culture; want of strong heat in winter will make them cast their leaves, but does them no other injury. (Soil No. 17.)

Justicia. A few species of this genus are fine show hothouse plants. J. carnea, flesh color flowers in large spikes, very fine, blooming nearly the whole season. J. coccinea has large terminal spikes of scarlet flowers, blooming from December to March, and is a very desirable plant, of easy culture, and should be in every collection; it is apt to grow spindley, if not kept near the glass. I. picta, with its varieties, I. lùcida and $I$. calyctricha, are fine shrubby species. I. speciòsa is a beautiful profuse purple flowering plant. (Soil No. 11.)

Làtàna, a genus of twenty species, all free-flowering shrubs; the flowers are small, in round heads blooming from the axils, in yellow, orange, pink, white and changeable colors; principally of a rough straggling growth, and are not esteemed. However, L. sellòi, light purple; L. mutabilis, yellow, orange and pink; $L$. Uicolor, white and pink, and $L$ : fucáta (or Douglásii of some), lilac and white; L. rosea, white, changing to rose; $L$. mexicana, very rich orange, one of the finest. These are very handsome growing plants, and will even keep in a good green-house; but in such case will only bloom in summer. They will not bear a strong fumigation; therefore, when the hot-house is under that operation, they must be set down in the pathway, or other low part in the house. (Soil No. 9.)

Lasiandra, a genus related to melastoma, of which there are several very handsome species. $L$. splendens with hirsute rich crimson foliage and brilliant purple flowers, blooming from January to May. L. Benthamiana with very elegant foliage and rich bluish purple flowers, grows freely in Soil No. 1.

Latànias.

This genus contains three species of handsome 
palms. L. barbonica is one of the finest of the Palmæ, not growing to great magnitude; the leaves or fronds are plaited. flabelliform, leaflets smooth at the edge, footstalk spiny, and the plant spreading. L. rùbra, fronds same as the former, but leaflets more divided and serrulate; footstalk unarmed: foliage reddish. L. glaucophylla same as L. riubra, only the foliage glaucous. They are all valuable plants, and are obtained by seed from the East Indies. They require plenty of pot-room. (Soil No. 12.)

Laúrus. This genus, though of no beauty in flower, is generally admired in collections for its fine evergreen foliage, and aromatic or spicy flavor, and several trees are important in medicine. The most esteemed are given to a genus named Cinnamomum, as has been observed in the green-house (see March). I. Chloróxylon is the Cogwood of Jamaica. L. pérsea is now Pérsea gratíssima, Alligator-pear, a fruit about the size of a large pear, and greatly esteemed in the West Indies; the plant is generally known in our collections. C. verum is the true Cinnamon of commerce.

The part taken is the inside of the bark when the tree is from five to eighteen years old. The leaves are threenerved, ovate, oblong; nerves vanishing towards the point, bright green above, pale beneath, with whitish veins. This plant ought to be kept in the warmest part of the hot-house. C. cássia is frequently given under the former name, but when compared, may be easily detected by the leaves being more lanceolate and a little pubescent. They both make handsome plants, but require great heat. Drain the pots well of the delicate sorts.

Mangifera, Mango tree. There are two species. $M$. indica is in our collections, and bears a fruit which is so highly esteemed in the East Indies as to be considered preferable to any other, except ${ }^{\circ}$ very fine pine-apples. The leaves are lanceolate, and from six to eight inches long, and two or more broad. The flowers are produced in loose bunches at the end of the branches, but of no beauty, and have to be artificially impregnated or it will scarcely produce fruit. The shell is kidney-shaped, and of a leathery crustaceous substance. They contain one seed, and in their indigenous state are more juicy than an apple. Drain the pots well, as the roots are apt to get sodden from 
moisture. The other species goes under the name of oppositifolia, but we question if it is not only a variety, for it has every character of the one just described. (Soil No. 11.)

Malpighia (Barbadoes-cherry), about eighteen species, all beautiful evergreen trees or shrubs. They are easily distinguished by having bristles on the underside of the leaves. These bristles are fixed by the centre, so that either end of it will sting. We are not aware of any other plant being defended in this manner. M. ùrens has oblong, ovate leaves, with decumbent stiff bristles; flowers pink. M. aquifòlia has lanceolate, stiff, spiny leaves, and we think the most beautiful foliage of the genus. M. fucàta has elliptical shining leaves, with lilac flowers. M. glábra, leaves ovate, entire, smooth; flowers purple. They all have five rounded clawed petals. The last species is cultivated in the West Indies for its fruit. The pots must be well drained. (Soil No. 17.)

Merica, a genus of hot-house plants, closely allied to Iris, between which there is no distinction in the leaves. The flowers of M. coerùlea are beautifully spotted with light and dark blue, the scape many-flowered. M. Sabini has flowers similar, but not so dark in color. M. Northiàna has splendid white and brown-spotted flowers, spathe twoflowered. These plants, when growing, require a liberal supply of water, and should be greatly encouraged by frequent potting, to flower well. (Soil No. 12.)

Melàstoma was once an extensive genus, on which the natural order Melastomacer is founded; but is now much divided into other genera contained in the natural tribe Micomere. There are about thirteen species remaining in the genus. They now display great unity of character, and many of them may be considered very ornamental. The finest are $M$. heteromàlla, bluish purple, and an abundant bloomer; M. malabáthrica, rose-colored; M. sanguínea, lilac; M. splendens, large violet; and M. aspera, rose. There is a plant in several of our collections known as $M$. purpùrea and M. tetragòna, which is Ossza purpurascens; leaves ovate, lanceolate, acuminate, five-nerved, pilose; the footstalk and nerves underside of the leaf covered with brown hairs; stem four-sided; flowers purple. All the 
species are easy of culture. M. nepalénsis is a green-house plant. (Soil No. 1.)

Mandevilla Suaveòlens, or Ohili Jasmine: this beautiful climber is a native of South America; the flowers are in clusters and nearly bell-shaped, white, and of exquisite fragrance; the bloom is produced on the extremity of the shoots. After the flowering season, the plants should be pruned back to within a few eyes of the preceding year's wood. (Soil No. 13.)

Mùsa (Plantain tree), contains eight species, and is greatly esteemed in the East and West Indies for the luscious sweet flavor of its fruit, which can be converted into every delicacy in the domestic cookery of the country. M. paradisiaca is the true plantain tree, has a soft herbaceous stalk, fifteen or twenty feet high, with leaves from five to seven feet long, and about two feet wide. M. sapiéntum is the true banana tree; habit and character same as the former, except it has a spotted stem, and the male flowers are deciduous. The pulp of the fruit is softer, and the taste more luscious. $M$. rosìcea, M. coccinea, and $M$. chinènsis, are more esteemed in artificial cultivation for their flowers, and for being smaller in growth. N. Cavendishii produces immense clusters of ripe and well-fiavored fruit, plants only four feet and a half high; will yearly produce about eighty pounds. $M$. dácca is another dwarf species, and in 1838 ripened a cluster of fruit in the Royal Botanic Gardens of Edinburgh which weighed fifty pounds. These dwarf bananas are now being cultivated in Europe expressly for their fruit, which is very delicious when perfectly ripened. They are Chinese plants, and will soon be introduced into the West India Islands, where they will entirely supplant the large varieties.

Myrtus Piménta, or, more properly, Piménta Vulgáris, is the Jamaica pepper or allspice; there is no beauty in the flowers - the leaves are highly aromatic, and it is a handsome evergreen. (Soil No. 9.)

Nepéntlies (Pitcher-plant). There are two species of this plant. N. distillatòria is an esteemed and valuable plant in European collections, and we are not aware of there being any in this country, except in Philadelphia. The leaves are lanceolate and sessile; from their extremity thore is a spiral, attached to which are long inflated append- 
ages that are generally half full of water, which appears to be confined within them by a lid with which the appendages are surmounted; hence the name of pitcher-plant. We have never observed the lids close again when once open. Writers have called it an herbaceous plant, but it is properly a climbing shrub. The pot in which it grows should be covered with moss, and the roots liberally supplied with water every day. It delights to be in a moist state. The flowers are small, and in long spikes. The plant is of easy culture, and even rapid in growth : a plant with us only nineteen months old is now five feet high. (Soil No. 5.)

Pancratium is a genus of hot-house bulbs, and now only contains five species. They are all free-flowering. Several of them are handsome and fragrant. $P$. maritimum and $P$. verecuindum are the finest; the flowers are white, in large umbels; petals long, recurved, and undulate. $P$. littoràlis, $P$. speciòsum, and $P$. caribrum, are now given to the genus Hymenocállis, and are fine flowering species. Care must be taken not to gire them water while dormant. The soil ought at that time to be in a half dry state. They are in flower from May to August.

Pandànus, Screw Pine. There are about twenty species in this genus, several of them very interesting, but none so greatly admired as $P$. odoratissimus. The leares in established plants are from four to six feet long, on the back and edges spiny; are spreading, imbricated, and embracing the stem, and placed in three spiral rows upon it. The top soon becomes heavy, when the plant throws out prongs one, two, or three feet up the stem in an oblique descending direction, which take root in the ground, and thus become perfectly supported. It is cultivated in Japan for its delightful fragrance, and it is said, "of all the perfumes, it is by far the richest and most powerful." $P$. uitilis, redspined. We question this species, and are inclined to believe that it is the former, only when the plants are newly raised from seed the spines, and leaves are red, changing to green as they become advanced in age. The plants are easy of culture, and will grow almost in any soil. (Soil No. 12.)

Passiflôra, "Passion-flower, so named on account of its 
being supposed to represent in the appendages of its flower the Passion of Jesus ('hrist." There are about fifty species, all climbing plants, that belong to the hot-house. Many are of no ordinary beauty; a few species are odoriferous; others bear edible fruits, though not rich in flavor. $P$. alàta is in our collections, and greatly admired; the flowers are red, blue, and white, beautifully contrasted, and flower profusely in pots. $P$. racemôsa, red flowier. $P$. ccerúleo-racemôsa, purple. $P$. quadrangulàris has beautiful red and white flowers. The plant is in several collections, but has seldom flowered ; it requires to be planted in the ground to make it flower freely, and it will also produce fruit. $P$. picturata is a scarce and beautiful various-colored species. $P$. kermesina, bright rosy crimson, and, beyond all question, the most profuse flowering species now in cultivation, and will do well in a good green-house. P. Loudònii, bright crimson. P. edúlis is cultivated for its fruit. There are many other fine species, but these are the most esteemed sorts; and, when well established, will flower profusely from May to August. They are desirable in every collection, and will take only a small space to hold them, by training the vines up the rafters of the hot-house. (Soil No. 13.)

Phcenix, Date-palm, about eight species, principally Asiatic plants. The foliage is not so attractive as many others of the palm family, but it is rendered interesting by producing a well-known fruit called Date. $P$. dactylifera will do very well in a common green-house. In Arabia, Upper Egypt, and Barbary, it is much used in domestic economy. $P$. paludósa has the most beautiful foliage, and the best habit. The flowers are diœcious. (Soil No. 12.)

Plumbágo rósea is a pretty free-blooming plant, with continued profusion of red flowers; it requires plenty of heat and a good drainage. (Soil No. 11.)

Plumèrias, above twenty species. Plants of a slow growth, robust nature, and are deciduous. The foliage is greatly admired. The plants are shy to flower, but are brilliant in color. P. acuminata has lanceolate, acute leaves, flowers corymbose and terminal. $P$. trícolor has oblong, acute, veiny leaves; corolla red, yellow and white. This and P'. rubrca are the finest of the genus. They ought not to get any water while not in a growing state. (Soil No. 11) 
Poinséttia* pulcherrima. When well cultivated, this is truly the most magnificent of all the tropical plants we have ever seen; from December to April it is crowned with flowers, surrounding which are bright scarlet whorls of bracter, frequently measuring twenty-two inches in diameter. To grow it to such perfection, we treat it as follows: in April we cut the young wood down to within two inches of the wood of the preceding year, and reduce the ball of earth, putting it into a smaller pot. About the end of May we plant it in the open ground, in light rich soil, giving it one or two waterings after planting. During summer it will grow three or four feet; about the end of September, it is carefully lifted and potted into a large-sized pot, and put into the hot-house, carefully shading it for a few days-when it requires no more attention except a regular supply of water, and to be kept in a temperature of from $55^{\circ}$ to $75^{\circ}$. There is also a pale yellow bracteced variety; but we are not aware of its being for sale in this country. When the plant is grown in pots during summer, it must be repotted every month to encourage its rapid growth. (Soil No. 18.)

Polyspòra axillàris, once called Caméllia axillàris, though in appearance it has no characteristic of a Caméllia, and has been frequently killed in the green-house by being too cold for its nature; leaves oblong, obovate, toward the extremity serrulate. The leaves on the young wood are entire. Flowers white; petals a little notched. It is worthy of a situation in every collection. (Soil No. 11.)

Pterospérmum, five species of plants that have very curiously constructed flowers, of a white color, and fragrant; the foliage is of a brown rusty nature, and, before expansion, silvery-like. P. suberifotium is in several of our collections, and esteemed. $P$. semisagittàtum has fringed bracteæ; leaves oblong, acuminate, entire, sagittate on one side. (Soil No. 11.)

Rhapis, a genus of palms that will grow very freely with heat and room at the roots. $R$. Alabellifórmis is an erect

* Named by Professor Graham, of Edinburgh, in compliment to the Hon. J. R. Poinsett (late Secretary of War), who introduced the plant in 1828 to this country from Mexico, while he was Minister Plenipotentiary to that Republic. He also, at the same time, introduced a rich and valuable collection of Cactæ. 
growing palm, with a spreading head. It is a native of China. (Soil No. 12.)

Rondelétia speciósa is a new and rare plant, in erery respect equal, if not supcrior, to Ixiora cócrinea; its large corymbs of orange-red flowers have a very striking appearance, and it is easily cultivated in soil No. 1. It should have frequent repottings when growing.

Ruéllia. There are a few species, very pretty flowering plants, of easy culture. $R$. formòsa, flowers long, of a fine scarlet color; plant half shrubby: R. fulyída has bright scarlet flowers on axillary long-stalked fascicles. R. persicifolia, with unequal leaves and light blue flowers, is now called R. anisophylla. (Soil No. 10.)

Russètia juncea, a slender plant of an upright habit, producing, when well grown; a profusion of scarlet tubular flowers, about one inch long each : it is of the easiest culture in soil No. 19.

Sagus, Sago palm. We are of opinion that the true palm from which the sago of the shops is produced has not been introduced into our collections. It is very rare in the most extensive collections of Europe, but it is not so fine a plant as the one we have under the Sago, which is placed in the natural order of Cycader; and Sagus is in that of Palmæ. The finest of this genus is $S$. vinifera and $S$. Rúphii. They grow to a great height; even in artificial cultivation they may be seen from ten to twenty-five feet. We have not introduced them here for their beauty, but to prevent error. (Soil No. 12.)

Solándra, a genus of four species, remarkable for the extraordinary size of their flowers, and are considered beautiful. S. grandiflora and $S$. viridiflora are the best two. The plants will bloom well if they are restricted in pot room, and are only introduced as being worthy of cultivation. If they are repotted once in two or three years, it is sufficient, except where the plants are small and want encouragement. (Soil No. 13.)

Strelitzia, a splendid genus of noble-looking plants, all of which do perfectly well in the green-house, except $S$. augusta, the flowers of which are pure white; the leaves are very large, being nearly six feet long and eighteen inches wide, and assume the appearance of the Banana tree: it requires great space for its roots.

(Soil No. 12.) 
Stephanotus florabundus, a new and splendid evergreen climber, with dark green thick leaves like a luxuriant waxplant, producing large bunches of pure white fragrant flowers; of easy culture in soil No. 13.

Swietenia, (Mahogany tree,) the wood of which is celebrated in cabinet-work. S. mahógoni, common. This tree varies much in general appearance, according to soil and situation. The leaves are pinnated in four pairs; leaflets ovate, lanceolate; flowers small, white, in axillary panicles. $S$. fubrifuga, leares pinnated, in four pairs; leaflets elliptical ; flowers white, in terminal panicles. The wood of the last is the most durable of any in the East Indies. They are fine plants, and require heat and pot room to produce flowers. (Soil No. 15.)

Taberncemontàna, a genus of little beauty, except for one or two species. A plant known in some collections as Nèrium coronàrium, is now, and properly, $T$. coronària. The variety flòre plèno is the one most deserving of culture, and will flower profusely from May to August; the flowers are double, white, fragrant and divaricating. The plant will lose its foliage if not kept in a strong heat; therefore place it in the warmest part of the hot-house. T. densifiora is a fine species, but very rare. Drain all the plants well, and keep them in the shade during summer.

Tecòma, a genus of plants closely allied to Bignònia, and are free-flowering; several of them much esteemed. $T$. móllis, T. digitáta, and T. splèndida, are the most beautiful of those that belong to the hot-house. They have large orange-colored, tubular, inflated, ringent flowers, in loose panicles. There is a plant known in our collections as Bignònia stáns, which is now T. stàns; has pinnated leaves, with oblong, lanceolate, serrated leaflets ; flowers in simple terminal raceme, and of a yellow color, and sometimes known by Ash-leaved Bignònia. It will always have a sickly aspect, if not well encouraged in light rich soil. Drain the pots well, as much moisture disfigures the foliage. (Soil No. 10.)

Thrinax parvifiora is a fine dwarf palm of the West Indies, with palmated fronds, plaited with stiff, lanceolate segments. The plant is of easy cultivation, and will grow in any soil. (Soil No. 12.)

Thunbérgia, a genus containing six climbing plants of a half shrubby nature. Some of them have a fragrant odor. 
T. coccinea, red; T. grandiflòra, blue; T. fràgrans, white sweet-scented; T. aláta has pretty buff and purple flowers, which are in great profusion. If sown in May, they will bloom from July until killed by frost. Tr. chrysops, beautiful blue, with a dark brown eye, a plant of dwarf habit requiring partial shade. This makes a very pretty annual in the flower garden, with its beautiful white variety, forming an elegant contrast. (Soil No. 13.)

Tradescántia díscolor. Purple-leaved spider wort. This is an herbaceous plant, and is only cultivated for its beautiful purple foliage. It has curious small white flowers. (Soil No. 10.)

Lránia speciósa, a gigantic-looking plant closely connected to Musa, from which it differs in habit by the large leaves being more erect: to grow it luxuriantly, give it plenty of heat, water, and pot room.

(Soil. No. 12.)

Zàmia, a genus of plants in the natural order of $C y c a-$ deæ. Several species of them are admired. ZZ. média, $Z$. furfuràcea, Z. ténuis, Z. integrifòlia, are the most showy that belong to the hot-house. The whole genus is frequently kept in this department. They are all plants of a slow growth, and the beauty is entirely in the pinnated fronds, with from ten to forty pairs of leaflets. The pots must be well drained. (Soil No. 11.)

Those genera of plants which we have enumerated under the head of repotting in this or next month, are composed of the finest hot-house plants that have come under our observation. There are perhaps a few of them that are not to be found in the United States, or even on our continent; but the great object, in a choice collection of plants, is to have the finest from all parts of the known world. There are many plants whose nature does not require much support from soil, which is frequently observed in those that are mentioned. And there are many hundreds of plants desirable for beauty, ornament, and curiosity, which would take volumes to specify and describe. In fact, every year brings many new things, and frequently both new and splendid, either in flower, fruit, or foliage.

We have previously observed, that plants ought not to be flooded with water when newly potted, as it saturates the soil before the roots have taken hold of it; and that the best draining for pots is small gravel or pot-shreds broken fine. 
We wish it to be understood that, when plants are repotted, any irregular branch or shoot should be lopped off that cannot be tied to advantage. And repotting may take place either before or after the plants are exposed to the open air, according to convenience.

\section{OF BRINGING OUT THE HOT.HOUSE PLANTS.}

Where the hot-house is very crowded with plants, the best method to have them exposed without danger is to take out those of the hardiest nature first, that have no tender shoots upon them, thereby thinning the house gradually. This may be done from the sixteenth to the twentieth of the month, which will admit of a free circulation of air among those that remain. All may be exposed from the twenty-fourth to the twenty-eighth of the month. This is a general rule, though in some seasons there may be exceptions. Having preriously given all the air possible to the house, that no sudden transition take place, which would make the foliage brown and otherwise materially injure the plants, choose calm days for the removing of them.

There are few plants while in pots that agree with the full sun upon them; or, if the plants receive the sun, the pots and roots ought not. The best situation for them is on the north side of a fence, wall, house, or other building, where they are excluded from the mid-day sun, and they should stand on boards or gravel, with the tallest at the back, firmly tied to a rail or some other security, to prevent them from being overturned by high winds. Make a fanciful bed, and cover it with sand or coal ashes, for the reception of the smaller plants, and setting them thinly and regularly thereon is preferable to crowding them with the taller sorts. And it may be desired to have some of the plants plunged in the garden through the flower borders. Of those that are so treated, the pots must be plunged to the brim, and regularly turned round every two weeks, to prevent the roots from running into the earth. If the roots were allowed to do so, it might for the present strengthen the plant, but ultimately would prove injurious.

Where a sufficiency of shade cannot be obtained, it would be advisable to go to the expense of a very thin awning, 
that would not exclude the light, but merely the powerful rays of the sun, attending to roll it up every evening. Plants will keep in beautiful order by the above method, which amply repays for the trouble or expense. Avoid putting plants under trees; comparatively few thrive in such situations.

When they are thus exposed to the open air, it will be very little trouble to give them a gentle syringing every evening when there is no rain, and continue your usual examinations for insects; when they appear, resort to the prescribed remedies. Green-fly will not affect them, but the thrips may. Give regular supplies of water every evening, and again in the morning to all that require it, carefully examining those that are in small pots.

\section{SUCCULENTS, OR THE CACTÆA TRIBE.}

The Céreus Mammallària, and Opuntia. Divisions of this family are, in their indigenous state, exposed on rocks, hilly lands, and arid situations, being at all times fully exposed to the sun: still, with us, we find that they thrive best with a partial shade, though we have frequently seen them doing well when fully exposed to the influence of the sun; but where they are to be kept out of doors all the season, be careful in choosing for them an airy situation, and never allow the pots to become saturated with moisture.

The habits of the Epiphyllum tribe are entirely different; they are generally parasites, growing on the branches and about the roots of decayed trees; consequently, they are often much shaded, and they evidently show it, for they still delight to be shaded from the direct rays of a noonday sun. If they are kept in the house through the summer months, take some whiting, and make a thin white-wash, and put it on the inside of the glass, which will be found an agreeable and effectual shade; but where time and means are at hand, a thin awning, of gauze or muslin, is preferable, provided it is regularly rolled up when the sun is not powerful. 


\section{JUNE AND JULY.}

As the plants of the hot-house are all exposed to the open air, the directions will include both months. If the repotting is over, as recommended last month, all the attention they will require until the end of August is, the administering of water at the roots, and by the syringe overhead. It will be impossible to say how great are their wants, these depending entirely upon the nature of the plant, the situation, and the season; but never neglect to look orer them every evening, and after dry nights they will need a fresh supply in the morning, observing to give to none except they are becoming a little dry. Make weekly examinations for insects of any description, and when they appear, have them instantly destroyed.:

Always after heary rains look over the pots, in case water should be standing in them, which would injure the roots. Where any is found, turn the pot on its side, and, in a few hours, examine the draining which is defective; small pots in continued rains should be turned likewise.

Tie up all plants and shoots to prevent them from being destroyed by the wind, and be attentive to pick all weeds from the pots. Turn round all the plants occasionally, to prevent them from being drawn to one side by the sun or light.

\section{AUGUST.}

THE plants of the hot-house that were repotted in May and June, according to the directions therein given, will, at present, be in an excellent state of health, provided they have got, at all times, the requisite supplies of watering. And as we already have been very explicit on that subject, more remarks now would be merely repetition. 
September.] HOT-HOUSE-OF DRESSING PLANTS. 177

REPOTTING.

If any of the repottings were neglected during May or June, let it be done about the first of this month. Let young plants that are growing freely, where the roots have filled the pots, and the plants required to grow, have pots one size larger. In turning out the ball of earth, keep it entire, not disturbing any of the roots.

OF PAINTING, REPAIRING, AND CLEANSING THE HOUSE.

The necessary repairs of the hot-house are too often put off to the last day or week; and then with hurry are superficially attended to. Previous to the first of September, have all the wood-work painted (which ought to have one coat every two years), and the glass all neatly repaired. Have the flues and furnace examined; plaster over all rents, and make good every deficiency. Give the flue a thick coat of lime white-wash. Have the walls, shelves, and staging properly painted. If there is a tan-bed, have that renewed; take out what is most decayed, using two-thirds new tan, which must be dried at least three days in the sun before it is housed, and carefully protect it from rains.

\section{SEPTEMBER.}

DRESSING THE PLANTS.

Having last month put the house in complete order, all that remains necessary to be attended to is the state of the plants and pots, which should be regularly examined, and of those where the roots fill the soil, a little may be taken off the top, supplying its place with fresh earth, thereby giving what is called a top-dressing. Give each that requires it a sufficient rod, tying the plant neatly thereto ; minutely scrutinize each for insects, and where they are detected, have them eradicated. 
Finally, wash all contracted foulness from off the pots, at the same time pick off any decayed leaves; thus all will be in perfect order to take into the house. If any plants have been kept in the hot-house during summer, they must likewise go through the same operation.

\section{OF TAKING IN THE PLANTS.}

From the $16 \mathrm{th}$ to the $24 \mathrm{th}$, according to the season, is the proper time to take in the hot-house plants. It is preferable to have them what might be deemed a few days too early, than hare them in the slightest degree affected by cold.

Commence by housing the largest first, and those that stand farthest in the house, observing to place the most tender sorts nearest the heat or warmest part of the house. For observations on them, see May. In regard to arrangement, that must be according to the taste of the operator. We may observe, that in a small collection it is better to have them in a regular than in a picturesque form. A dry shelf is indispensable in this department for placing on it all herbaceous plants, such as Cánna Hedychium, Zingiber, Kompféria, \&c., the watering of which by this time should be gradually suspended, that they may have their required cessation to make them flower well. This shelf may be in any situation; one in darkness, where other plants will not grow, will answer perfectly well. If there is a bark bed, do not until the end of December, plunge any of the pots therein. If any plants of the Poinséttia are in the ground, have them carefully lifted and shaded from the sun.

\section{GENERAL OBSERVATIONS.}

The plants being now all under protection, they must have as much air as possible admitted to them every day, by opening the doors, front and top sashes, closing only at night. The syringings must be continued, and care taken that plants of a deciduous or herbaceous nature are not over-watered. The tuberous species might be kept almost dry. Some practical men of sound science repot these plants in this month 
into fresh soil, and allow them to stand till January almost without water. We have never adopted this method with any description of plants, but do not doubt of its success with that genus.

See that the ropes and pulleys of the sashes are in good order, and fit to stand all winter.

\section{OCTOBER.}

VERY few directions remain to be given to the department of the hot-house. The supplies of water for this and the two succeeding months are, according to the state and nature of tropical plants, more limited than at any other period of the year. This is the first month of what may be called their dormant state. Observe the herbaceous plants, that they are set aside as soon as their foliage decays, in case of being too liberally supplied with water. Airing is highly essential about this period, that the plants may be gradually hardened; but guard against injuring them. The temperature should never be under fifty degrees: when the days are cool and the wind chilling, airing is not necessary; and, .when air is admitted, always close up early in the afternoon, while the atmosphere is warm, to supersede the necessity of fire as long as possible. If, at any time, you have recourse to it in this month, use it with great caution.

Examine all the shutters and fastenings, and see that they are in good substantial order, and, where deficient, repair them instantly, that they may be in readiness. Remove all leaves, and give syringings in the morning of sunshine days, twice a-week. Clear off, sweep out, and wash clean, that every part may be in the neatest order.

The succulent tribe will not require water more than once a-week, or once in two weeks. If any of them have ripened seeds during summer, wash such carefully from the pulp, and lay them past till the first of January, when they may be sown on the surface of sandy soil, and gently pressed down. Water them very earefully as they require; cover the pot with a piece or pane of glass, which will greatly 
assist their regetating. In a few weeks they will make their appearance; and when they are one-quarter of an inch high, plant them out into other pots and fresh soil. In a few months they will make wonderful progress in growth, and in the following year, will require to be potted singly, and treated as recommended for established plants.

\section{NOVEMBER.}

THe essential points to be attended to in the hot-house during this month are, fire, air and water. The former must be applied according to the weather, observing not to allow the temperature to be under fifty degrees; and it ought not to continue long at that degree, fifty-two degrees being preferable. The shutters should be on every night when there is any appearance of frost, and taken off early in the morning. Admit air in small portions every day that the sun has any effect and the atmosphere mild, observing that the temperature of the house be above sixty degrees previous to admission. Shut all close early in the afternoon, or when any sudden changes occur.

\section{OF A CISTERN AND WATER.}

In watering, it is important to have the water of the same temperature in this department as the roots of the plants. To have this, there are two kinds of cisterns or tanks that might be adopted; one may be sunk in the house under ground, either closely plastered, or lined with lead, and neatly covered up, having a small perpendicular pump therein, or placed so that the water could be lifted by hand. The other might, where convenience will admit, be placed over the furnace, either in the back shed, or inside of the house, and the water could be drawn off this by a stop-cock. These can be supplied, in part, with rain water, by having spouts round the house to lead into the cisterns, supplying any deficiency from the pump. Thus water of a congenial 
temperature may be always at hand, which is of great importance to the healthful constitution of the plants. The water must now be given in moderate portions, examining the plants every day. Be careful in watering bulbs, as the smallest supply is sufficient for them at present. Succulents will require a little every two weeks, except they are over the flues, when they may have some every week.

Constantly clear off all decayed leaves, and carry them out of the house, which sweep and wash clean, and keep all in the neatest order.

\section{DECEMBER.}

THE uncertainty of the weather in this month requires the operator to be constantly on guard, to ward off danger, either from frost, snow, or cutting winds. The temperature observed last month must be continued, but not exceeded, which would cause premature vegetation, of which the result and effects have already been observed. Always kindle the fires in time, to prevent the heat from being lower than what has been mentioned, lest a severe frost should take place, as then a considerable lapse ensues before the fire has any effect; and if the wind blows high, the result might be injurious, unless the house be very close.

\section{OF SHUTTERS.}

The benefit of these in severe weather is of material service, for the preservation of an even temperature in the house during the night, when changes are not observed; but they ought never to remain on through the day, when the fire can be properly attended to. If the front and the lowest sash of the roof are covered with these, it is generally sufficient. They should be made of three-quarter inch boards, closely grooved together, having a cross bar in the centre, and one at each end and each side, which will make them substantial. If they are frequently painied 16 
with care, they will last many years. Snow ought not to be allowed to lay on these while they are on the glass, for reasons that we have assigned. See January and February.

Some adopt double panes of glass to supersede the use of shutters, which they think are attended with considerable labor (at the most only fifteen minutes a-day, while in use). The sash frame is made a little deeper, so as to allow half an inch between the panes of glass. The one is glazed from the out and the other from the inside. It appears to answer the purpose tolerably well, but the glass must be both fine and even on the surface, lest a lens should be produced, which would scourge the plants. We are almost confident that we have seen this effect in some instances. There must be a small hole about an eighth of an inch in both ends of each row of glass, to allow a current to dry up the moisture that may arise. Double sashes during the severe months are frequently used; but shutters are preferable to either.

OF PLACING BULBS, \&c., IN THE HOT.HOUSE.

If any Hyacinths or other Dutch roots are wanted to flower early, a few of them may be put in the hot-house near the front glass, which will greatly tend to forward their time of flowering. By having some brought in every two weeks, a continued succession of bloom will be kept up.

\section{GENERAL OBSERVATIONS.}

If there is a tan-bed in the house, and it was renewed in September, the pots should now be half plunged therein. The violent heat will partly be over, and the plants are not so liable to suffer at root in this as last month. It will in part prevent the plants from being affected by sudden changes of temperature. Be attentive in keeping all insects completely under. This is the period that these are most neglected, but by attending to the modes of their destruction, as already given, no species of them will either be hurtful or unsightly. Syringe the plants about twice a-week, and 
always remember that decayed leaves or litter of any description, do not beautify healthy plants, neither do they form a part of a well-kept hot-house.

\section{ORCHIDEOUS EPIPHYTES OR AIR PLANTS.}

Before we close the hat-house subject, it may be interesting to some of our readers to know the nature and character of a few of the most desirable of those tropical parasites that have within these fer years caused so much excitement in Europe. In several instances, houses upward of two hundred feet long have been erected for their exclusive culture, and unless they do thus have an apartment adapted to their nature, no success will attend their cultivation. They grow only in a very humid atmosphere, kept at a temperature of from $70^{\circ}$ to $100^{\circ}$, and also in a partially shaded situation: it is only under such treatment that we have had any prosperity in blooming these peculiarly beautiful and interesting plants. Annexed are the names of a few that are of the easiest culture and most profuse of flower :-

Brássia maculàła, greenish yellow, spotted with purple.

Catasètun trifidúm, greenish yellow, spotted with dark brown.

Cáttleya críspa, white and purple, and is considered a superb plant.

Cattleya labiàta, rose and rich purple, striped and spotted with carmine.

Cáttleya Forbésii, yellow, white, green, and rose-colored, fine.

Dendròbium cucullatum, rose and pale yellow.

Dendròbium speciosùm, pale yellow flowers, in great profusion.

Epidéndrum cucullatum, dark brown, withyellow, is a very constant bloomer.

Gongôra atropurpuirea, dark purple; the plant must be suspended in a pot or small box.

Gongốra speciósa, yellow, with black spots. Maxillària Loddgésii, orange flowers in long racemes. Maxillària picta, yellow, beautifully spotted with red and 
crimson; it is in the mornings only delightfully fragrant.

Oncìdium crispum, brownish copper color, and profuse flowering.

Oncidium papilio, bright yellow, spotted with rich brown. Oncidium luridum, flowers of a brownish-green.

Renànthera coccinea, a very superb scarlet flowering plant, but does not bloom very freely; it grows in moss, and must be suspended in a pot or tied to a piece of stick.

Stanhòpia grandifòra has delicate, white, sweet-scented flowers.

Stanhòpia insignis, yellow and white, spotted with purple, and delightfully fragrảnt.

Vanda Roxbirighii, flowers pale yellow.

Zygópetalums, all very beautiful flowering, generally of a yellowish green color, spotted with brown. They require to be kept in a hot dry atmosphere.

Orchideous epiphytes generally grow upon trees, in the recesses of damp tropical forests, establishing themselves in the forks of the branches, and even upon rocks, stones, or decayed trees. Shade, therefore, is essential to their welfare; consequently, never permit them to be exposed to violent sunsbine. They require but little water at the roots, provided the atmosphere they grow in is very humid. The best soil for them is a sandy, turfy peat, containing a large portion of fibrous matter; mix with this pieces of pot-shreds or cork, and be careful not to place the plant deep in the pot; they will also grow on blocks or sticks of wood. Although we use and prefer small boxes (about six inches square) made of cork, in which they grow finely and bloom profusely. With some of the strong-growing kinds, we use, in addition to the above soil, a little leaf-mould, using always plenty of drainage. The house we cultivate them in has an eastern aspect. Shade can easily be given to them by having creepers trained up the rafters of the house, or an occasional large plant, placed in such a situation as will afford most shade during mid-day; and it must be observed, that, although the plants are fond of moisture, they never thrive, except the water has a free passsage from their roots. 


\section{AMERICAN FLOWER GARDEN DIRECTORY.}

GREEN-HOUSE.

ON THE CONSTRUCTION OF A GREEN-HOUSE.

IN many respects, the construction of the Green-house will be the same as the Hot-house, but might be made much more an ornamental object, and could be erected contiguous to the mansion-house, with large folding-doors to open at pleasure, and be connected with the drawing-room or parlor. The extent may vary according to the collection to be cultivated.

It was formerly the practice to build these houses with glass only in front, and even to introduce between the windows strong piers of brick or stone; but this is now abolished, and has given way to a more light and ornamental style, by which cheerfulness and the desired utility are better consulted. There should be conveniences for the admission of air in the highest part of the house, that a free current may be obtained whenever desired, which is an essential point. 


\section{GREEN-HOUSE.}

\section{JANUARY.}

THIs compartment requires particular attention, in order to preserve the plants in good health, and carry them through this precarious season of the year. A little air must be admitted at all convenient times. An hour or two at mid-day will be of the utmost importance in drying up damp and clearing off stagnated air, which is a harbor for every corruption. The top sashes being let down or turned a few inches, in mild days (that is, when there are not high and cutting winds), from ten or eleven o'clock to two or three, according to the intensity of the frost, will renovate the interior air of the house and harden the plants. When the weather will permit, let the front sashes be opened about one inch or more. An assiduous, experienced hand will never omit an opportunity.

With regard to fire heat, the temperature must be regulated to suit the nature of the plants in a general sense; so let the mercury, or spirits of wine, of Fahrenheit's thermometer, be from $35^{\circ}$ to $50^{\circ}$; if it begins to fall, give a little fire heat. No doubt we have seen the thermometer much lower in the green-house than the above, even as luw as $24^{\circ}$, without any immediate injury; but it was in an extensive collection, where the most hardy of the plants were selected into one house. Many boast how little fire they give their green-house, and how cold it is kept, not observing the miserable state of their plants-inexperience causing them to think that the least fire heat will make them grow, and would rather look on naked stems than healthy plants. The above temperature will not, in exotics, cause premature vegetation, but will cause the plants to retain the foliage requisite to vegetative nature. A high temperature is" not necessary for the generality of green-house plants; on the contrary, it might very much injure them. 


\section{OF WATERING.}

In this month very little is requisite, and must be given with great caution. Few plants will require much and some hardly any; but all must be attended to, and have their wants supplied. Some will need it twice, some once a-week, and some in two weeks, according to their shrubby and woody nature. Herbaceous and deciduous plants will seldom need water. Perhaps, from the shedding of the foliage to the commencement of vegetation, three or four times will be sufficient. Particular attention should be paid to the state of health and of growth, in which the plants respectively are, in the application of water; otherwise much mischief may be done, and many entirely ruined.

Green-house plants being now in an absolutely inactive state, require little more water than merely to keep the earth about their roots from becoming perfectly dry, by occasionally applying a very small quantity at the root; and, if done with a watering-pot, as described under this head in the hot-house of this month, very little will be spilt in the house to increase dampness, which, if it does appear, by any of the leaves of the plants becoming musty, they must be instantly picked off ; and, if it increases, give a little fire and air. Succulent plants will not need any water during this month, unless omitted in December.

\section{CAMELLIA JAPONICA.}

This magnificent and attractive flower, with all its splendid varieties, will, about this time, begin to open its beautiful flowers. But for this admired genus of plants, our greenhouses at this season would be void of allurement. It is, in this country, subject to the red spider, and more especially in the city, which appears to be from the nature of the air. The effects of the spider on these plants, if not prevented, would prove fatal; as from appearance, many bave died by it in several collections. If it has reached a great extent, the leaves are brownish, having the appearance of being decayed or scorched with the sun. In taking hold of the leaf, it feels soft, and altogether seems to have lost its nutritive 
substance; and when the young foliage expands, it becomes covered with dark brown spots, and finally very much disfigured; and when in this state the red spider is severe, and, ultimately, death ensues.

If any of the plants are affected as above described, take a sponge, and wash every leaf minutely with soft water, and syringe them with water three or four times a-week, which will clean them. All the young foliage will be healthy, and that which bas been affected will fall off. However, prevention is better than cure; and if the Camellias are properly syringed every evening during summer, and once or twice a week during winter, they will never be subject to the ravages of that destructive insect.

Tie up any of the flowers that are expanded to stakes, in case of accident; and, in syringing, observe not to let any water fall on the flowers, as it causes premature decay and change of color.

\section{OF ORANGES, LEMONS, \&.}

As there will perhaps be more leisure in the green-house this month than in any other during the winter, it is prosumed that there will not be a moment lost. If any of the trees are infested with insects, these, being now in their inactive state, may be more easily destroyed than at any other time. It is the brown scaly insect that generally infests them. For treatment, see Hot-house, January. The plant or tree, after being washed, before it becomes dry, will require to be syringed with water, otherwise the dust will adhere to the glutinous particles of the soap. Set the plant in an airy situation to dry, in case of damp. There are several others subject to this insect, such as Myrtles, Oleas, Oleanders, \&c., which treat in the same manner. Be careful that these trees are not over-watered; if the soil is moist, it is sufficient.

\section{OF CAPE BULB;, \&c.}

If there are any out of the ground, it is time that the whole were potted, such as Lachenailia, Wachendórfia, 
Eùcomis, Ixia, Gladiolus, with several others. Keep them in the shade until they begin to grow; then put them on shelves near the light. Those that are growing must be kept in front of the house, to prevent them being weak. Wachendorfiu has a beautiful large red tuberous root, and requires a pot about six or seven inches deep.

\section{OF HYACINTHS AND OTHER BULBOUS ROOTS.}

All these roots must be carefully examined. In case slugs or nails are preying upon the embryo of the flower, some of those that are farthest advanced may be put for a few weeks in the hot-house. It will greatly accelerate their flowering; but they must be brought out again before the florets expand, and carefully tied up, leaving room for the increase and extension of the flower stem. Give them plenty of water, and if saucers can be placed under them to retain it, it will be of advantage. "Change the water every week on those that are in glasses, and keep all the growing bulbs near the light. Nurcissus, Jonquils, \&c., may be similarly treated.

\section{FEBRUARY.}

TuE directions given last month respecting the airing and temperature of the house may still be followed, differing only in admitting air more freely as the season advances, and according to the power the sun has on the glass, which now begins to be considerable.

If the weather is tolerably mild, air may be admitted in time of sunshine, so as to keep the mercury as low as $50^{\circ}$, but be cautious in cold, cloudy, frosty weather. It is a practice with many in such weather to keep the shutters on the house night and day, for the space of a week, and sometimes more, never entering it; and, when the weather has induced them to look in, they find that the frost and damp have made many lifeless subjects; whereas, had the 
house and plants been attended to, in taking off the shutters, and giving a little fire when requisite, all would have been in safety, and many plants that cannot be replaced still in the collection.

When watering, strictly adhere to the directions of last month, except with Geraniums, and other soft-wooded plants, which require a little more water towards the end of the month. If the days are mild and sunny about eight or nine o'clock in the morning, all the plants would be benefited by a gentle syringing, which retards the progress of insects, and accelerates vegetation.

Succulents, such as Cáctus, Mesembryánthemum, Aloes, Furcroeas, Crássulas, Cotylèdons, \&c.; will very seldom need water; at the same time keep them from getting as dry as powder.

OF ORANGES, LEMONS, \&c.

Similar treatment to that recommended last month will do for this. Where the soil in the tubs or pots requires to be enriched, take of bone-dust or shavings, and fresh sheep dung, equal quantities; put the mixture into a large tub or barrel, until one-third full; and fill it up with water. Stir it well two or three times every day till it ferments, then give each tree one good watering with the compound. Continue to mix up afresh, and let it stand another week, and so on until all the trees requiring it are watered. This watering will greatly enrich the soil and invigorate the roots.

\section{OF CAPE BULBS, \&c.}

The bulbs of Ferrária undulata, and $F$. antheròsa, that were taken out of the pots in October, will now require to be planted. Five-inch pots will be large enough for good roots. The grand criterion for planting bulbs is when there is a protuberant appearance about the bottom, or root part of the bulb, showing by a principle of nature the true time for transplanting. When bulbous roots of any description appear above ground, they ought to be placed in an airy 


\section{February.] GREen-HoUse-CAMELLIA JAPONICA. 191}

situation. They are very frequently placed under other plants, by the inexperienced, until they show their flowers, and then brought to the light, having weak flowers, and comparatively of momentary existence.

Hyacinths, Narcissus, Gladiolus, Ixia, \&c., having flower stems, ought to have support, to prevent accident, especially the two former; keep them nigh the glass, and water freely. Change the water regularly once or twice a-week in the bulb glasses, observing that their roots are never allowed to become matted with fetid water. Any of the above plants that are in flower might, if desired, be taken into the drawing-room or parlor, washing the pots clean, and putting saucers under them, keeping therein a little water. Twice a-week the decayed ones can be taken out, and supplanted with those that are coming into bloom.

\section{CAMELLIA JAPONICA}

Will, in this month, show a profusion of flowers; and, where there is a variety, they have truly a magnificent appearance. From a good selection, endless varieties, by seed, of exquisite beauty, might be obtained by attention to the following rule: The best to select for bearing seed are, Carnea, Donkelaari, Rubricaulis, Tricolor, King, and Wuratah, and, in many instances, the pistil, or pistillum of Vuriegata, Regalis, Alexina, and Miss Percival are perfect, with "several others. When any of the above are newly expanded (Waratah is most perfect about one day before full expansion), take a fine camel-hair pencil, and put it gently on the farina or pollen, from the double sorts, which is a yellow substance on the anthers, and, when ripe, appears in thousands of small particles. Then, with this on the pencil, dust it lightly on the stile of those intended to carry seed. Between the bours of ten and twelre in the forenoon is the most proper time for the operation; the seed will be ripe in September or October, which will be taken notice of, and directions giren. For other particulars on cleaning and syringing, see January under this head. 


\section{OF SHIFTING, \&c.}

The best time to repot Camellias is in September or October. The most general time in shifting Camellias is in August, indiscriminately with other plants; and, if then not very gently handled, bad roots eventually are produced. Frequently very fine plants have been killed by probing, and breaking the young fibrous roots, thus causing mortification.

In the process do not, by any means, break or bruise any of the roots; and do not give large pots, with the idea of making them grow fast; it acts on most plants diametrically opposite to what is intended. A pot one or two inches wider and deeper than the one they have been in previously, is sufficient. Healthy plants, under five feet, will not require shifting oftener than once in two years; from five feet upward, in three or four years, according to the health of the plants. This treatment, in the opinion of some, will appear insufficient for their support : it will be found enough with a top-dressing every year to keep them in a healthy flowering condition, the soil being according to our description.

On turning the plant out of the pot, it may easily be observed if the soil has, in any degree, been congenial to it; for, if so, the roots will be growing all round the ball; if otherwise, no roots will appear.

Therefore, with a blunt-pointed stick, probe away all the bad earth, until you come to the roots; then put the plant in a pot about one inch in diameter larger than the combined roots, previously putting a few small pieces of broken pots, or clean gravel, to drain off the superabundant moisture, and give light waterings, as the roots in this case will grow but slowly.

Top-dress all that do not require shifting, probe out the soil down to the roots, and by the side of the pot, taking care not to break the fibres; then fill up with fresh earth, watering gently with a rose on the watering-pot to settle it. 


\section{OF CLEANING, \&c.}

If any of the plants require cleaning, either by fumigation or otherwise, let it be done before the young foliage appears, according to the directions heretofore given. Likewise tie neatly all that require it, clean and top-dress those that will not be shifted, having every plant, and all in the greenhouse, in perfect order before the throng of spring commences. The weather will now admit, in very fine mornings, of the plants being syringed, which may be done between seven and eight o'clock; and the path or pavement should be washed out once a-week, which is a great improvement to the appearance of the whole interior.

In winter, when any glass is broken it should be immediately mended. Broken glass in cold nights causes a very destructive current of air. It should always be made watertight, for if the drops fall into the pots upon the roots, they will frequently prove fatal to the plants; therefore care ought to be taken during rain to remove those that stand in any manner exposed.

\section{MARCH.}

THE plants in this compartment will begin to assume a different aspect, and air must be admitted every day if practicable, giving large portions in sunshine by the sashes regularly over all the house, opening those of the front a little, and likewise the doors in fine mild days. To perform this judiciously, give a little about eight or nine o'clock, more at ten, and the whole from eleven till twelve o'clock, shutting again by degrees.

Fire heat will now be dispensed with, but in frosty nights have the shutters on about sundown. The sun is now powerful, and the house can be early shut up in the afternoon, and will gain as much natural heat as will keep up the required temperature, viz., $36^{\circ}$ to $45^{\circ}$. Perhaps there may be un- 
commonly cold weather: at such times be attentive to ward off danger by applying artificial heat.

\section{OF WATERING.}

Look over the pots and tubs at least every alternate day, to see where water is wanted. In watering, too much caution cannot be used, especially during winter and the commencement of spring. It was observed last month what would be the effect of too much water. It may be remarked, that if the exterior of the pot is very damp, the soil inside is too wet, and in that state, is uncongenial to vegetation, which now begins to start, and ought, by all possible means, to be encouraged, which we do very effectively with Guano water once a-week, for a few weeks, using about one pound to five gallons of water, allowing it to stand twenty-four hours, and stir it up before using. If you are troubled with worms in the pots, give one or two waterings with lime-water, one pound of lime in four gallons of water; allow it to stand twelve hours to settle, pour the clear water into another vessel, and use it only. People may be frequently observed watering all plants indiscriminately, not taking the trouble to look into or feel the state of the soil in the pots or tubs, and thus, by going over them three or four times in this manner, will be sufficient to put the plants in such a state that they will not be recruited for some months. Hence the reason of so many sickly plants.

Caméllias, where there are collections, will continue to flower. Treat them according to the directions, given last month.

\section{OF ORANGES, LEMONS, \&c.}

Be sure they are not too wet, as too much humidity as well as aridity causes their foliage to have a yellow appearance, with this difference, that in the former case the foliage is the same to the touch as when green; but in the latter, it is soft and dry. We have observed trees in tubs and half barrels, with holes all round their sides. This is a ludicrous idea, having the appearance of kecping the water from reach- 
ing the bottom of the tub or barrel. For the best kind of tub for large trees, see August under this head. If any of the trees have stunted, straggling, or irregular heads about the end of this month or beginning of next, head or cut them down to the shape desired. The old wood will push fresh shoots. You may cut close, or shorten less or more, according as you desire young shoots to arise; at the same time observe that you do not cut below the graft or inoculation. Trees thus headed down should be kept until May, and then planted in the garden (see May), or, if that cannot be done, turn it out, and reduce the ball of earth by probing with a pointed stick all round the sides and bottom of the ball, cutting off any very matted roots. If any of the roots are decayed, eut them into the sound wood. By being thus reduced, it will go into the same pot or tub, if not a less one. Having a good supply of fresh earth ready, put a few inches in the bottom of the pot or tub, place the tree therein, and fill all around, at the same time pressing it down with the hand or a stick. Give very little water until there are signs of vegetation.

\section{MYRTLES, OLEANDERS, \&c.}

These, with similar exotics, may be treated as above. If any of them have been infected with the scaly insect, after heading down, \&c., scrub the remaining stems with a strong decoction of tobacco, heated to about $100^{\circ}$. Afterward clean with soap and water.

\section{GERANIUMS.}

These will be growing freely. Keep them in airy situations, so that they may not grow too weak, and flower imperfectly. To flower these plants strong and of good color, they must not be crowded together, neither far from the light, and have plenty of air admitted to them when the weather is favorable. Keep them free from the green-fly, by fumigating frequently. 


\section{HERBACEOUS PLANTS.}

Plants of this character will, by the first of the month, begin to grow. The best time to divide and fresh-pot them is when the young shoots are about one inch above ground. See under the head Shifting in this month.

\section{OF CAPE BULBS, \&c.}

Cape Bulbs, such as Lachenàtias, Oxalis, Ixias, Gladiolus, Watsònias, Babidnas, \&c., will, in many of the spccies, be showing flower. Keep all of them near the glass, to prevent them from being weak and unsightly.

Hyacinths, Tulips, Narcissus, \&c. Those that have been kept in the green-house during winter will be in great perfection. Have all the flower stems tied up neatly to small stakes (which, if painted green, will look much better), and keep them from the direct rays of the sun. The front of the house, perhaps, will be the best situation. They must be freely watered while in flower. Where there is convenience, it will be essential to keep the pots in saucers containing water: it will strengthen both stems and flowers, and likewise preserve them longer in perfection. Those that are blooming should be put aside, and watered sparingly, until the foliage begins to decay, when the pots may be laid on their sides to ripen the bulbs.

\section{REPOTTING.}

We have always considered that this month is the best period for repotting the generality of Cape and New Holland plants, and more especially those that you are desirous of encouraging. Large plants of the Citrus, Myrtus, and Oleánder tribes may be deferred till August: these are of a strong, robust habit, and will not be affected at that period; and they will then be out of doors, and more room can be had for the operation, but by no means defer repotting your Acacias, Ericas, Leptòspermum, Epácris, \&c.; and, for the guidance of our more inexperienced friends, we give a de- 
scriptive list of many of the finest, with a faint outline of their characters and general treatment, which will prove a desideratum for those who are inexperienced, and strangers to the beauties, pleasures, and arts of exotic flora culture. Therefore, if you have any of the following plants that you are desirous of encouraging, they should be repotted this or next month at the latest. Large plants will not require it, if they were done in August. Pots one size larger than those that they are in are sufficient.

Acàcias and Mimòsas being now united into one genus, there are above two hundred species. About one hundred and thirty belong to the green-house. Among such a beautiful family, both for elegance of flower and beauty of foliage, it will be difficult to specify the most handsome and desirable for this department. A. dealbcita, A. glancéscens, A. verticillàta, A. florabúnda, A. diffùsa, A. armàta, A. decípiens, A. fragràns, $A$. pulchélla, A. lophántha, A. decúrrens, $A$. púbescens, A. myrtifòlia, A. conspìcua, A. lineáris, \&c. These will afford a great variety of foliage, and are very desirable, flowering principally in winter, or early in spring. The flowers of those belonging to the green-house are of a yellow or straw color; the most of those that are red or purple, with the celebrated medicinal species, belong to the hothouse, for which see May. There are some of the species very subject to the white scaly insect, which must be attended to, that they may not get to any extent. (Soil No. 1.)

Agapánthus, three species. A. umbellàtus, with bright blue flowers, is very celebrated, and well known in the collections of the country. There is a variegated variety of it highly desirable, the foliage being white striped, and frequently the flower stem and the flower $A$. álbidus has pale white flowers, and as yet rather scaree. They have very strong roots, and require plenty of freedom. Plants are always large before they flower, and when the pots, by frequent shifting, become inconvenient, the plant should be divested of all the earth, and, if too large, divide it, cutting off the strongest of the fibres; then they will admit of being put into smaller pots. If the above operation is performed in August or September, it will not retard their flowering, which, when well grown, is very handsome, the flower stem arising about three feet, and crowned with twenty or thirty blossoms, continuing to bloom successively.

(Soil No. 12.) 
Achimenes-about sixteen species. The type of this new genus has been long known in our collections under the name of Trevirània coccinea, now $A$. coccinea, flowers bright scarlet; $A$. longiflora, large blue; $A$. grandiflora, fine rose; $A$. hirsuta, bright rosy purple; $A$. rosea, profuse flowering, and $A$. picta, the foliage of which is beautifully variegated and striped; $A$. pedunculata, spotted; $A$. elegans, purple; A. pyropa; A. patens; with a host of other new and worthless sorts, all inferior to the above, though some of them cost us balf a guinea each. They have all scaly tuberous roots requiring the pots to be kept entirely dry during winter; in this month they should be taken from the old soil and planted into fresh, giving gentle waterings till they begin to grow. They delight in a warm close moist atmosphere, and will bloom freely from July to October. (Soil No. 10.)

Aloe. Nearly a hundred species of grotesque-looking succulent plants, and are principally natives of the Cape of Good Hope, and, consequently, will do well in the warmest part of the green-house, although, when conrenient, they frequently get a situation in the hot-house. A. vulgàris, known as A. barbadénsis, has orange yellow flowers; $A$. oblíqua, now called Gastèria oblíqua; A. dichótoma, and $A$. variegata, which is perbaps the finest of the genus: the leaves are beautifully striped, and commonly known as the partridge-breast Aloe; flowers scarlet and green. They ought to have very little water; once a month is sufficient. They would grow without it, and several of them would also grow by being suspended in the house, without earth or any substitute about their roots, by being frequently sprinkled with water. Few of them are admired for the beauty of their flowers, but the whole are considered curious. They flower from May to September.

(Soil No. 9.)

Alonsòas, five species, all soft-wooded, small, shrubby plants, with scarlet flowers. A. incisifolia is known among us under the name of Hemimeris urticifolia, and A. linearis as $H$. linedris. If well treated they form very handsome plants, and flower freely. They will not bear strong fumigation; and, when the house is under that operation, they must be put on the floor of the green-house, where they will not be so much affected. They flower from April to August. (Soil No. 9.)

Alóysa citriodòra, known in our collections as verbena 
triphylla. The flowers are small, in long spikes of a pale filac color; the celebrity of the plant is in the delightful odor of its foliage, which is linear, lanceolate, and ternate. It is of very easy culture, and has been known to survive winter in the open air in Philadelphia. Where large plants are desired, they should be planted in the ground during surnmer, and lifted in November, and put in a dry cellar or under the stage in the green-house. Before they begin to grow in the spring, trim the plants into a neat shape. (Soil No. 9.)

Alstromèrias, about sixteen species, all exceedingly desirable, and many of them particularly beautiful; such are $A$. áurea, golden flowered; $A$. bicolor, salmon and orange; A. carminata, carmine-colored; A. Hookerii, rose-colored; A. pelegrina, elegantly spotted; A. pulchélla, red-flowered, and will grow six feet high, having its shoots crowned with a profusion of flowers; $A$. psittacina, red, yellow and green; A. tricólor, black, white and yellow; very beautiful. They have, generally, tuberous roots, and should be potted into fresh soil as soon as they show symptoms of growth, and they will require repotting about every month previous to flowering, taking care never to break the ball of earth while they are in a growing state.

(Söil No. 10.)

Amaryllis. This is a genus of splendid flowering bulbs, containing about eighty species and one hundred and forty varieties. They are natives of South America, but more than one-half of them are hybrids grown from seed by cultivators. They are generally kept in the hot-house, but in our climate will do perfectly well in the green-house; and we have no doubt that in a few years many of them will be so acclimated as to keep as garden bulbs, planting about the end of April, and lifting them in October. As the beauty of these plants is in the flowers, it will be proper to give a small description of a few of them. A. bella, pure white striped with rose; $A$. Bartonii, creamy white striped with pink; A. Buistii, large pure white, striped with cherry color; A. ignescens, bright red, with white at the base of the petals. A. Johnsoni, the flowers are a deep scarlet, with a white streak in the centre of each petal, four bloom on a stem of about two feet, each flower about six inches in diameter; a bulb well established has two stems. A. reyina, Mexican Lily, has large scarlet pendant flowers, tube of the 
flower fringed-like, with three or four on the stem. $A$. vittita is an admired species with scarlet flowers, striped with pure white; there are two or three varieties of it; corolla campanulate, three or four on the stem, about three inches in diameter; petals a little undulate. A. fülgida, flower scarlet, large, tube striped, petals acute, two flowers on the stem. A. aulica is magnificent, has from two to four flowers about seven inches in diameter, erect on a stem about two and a half feet high; six petals, strongly united to the capsule, bottom of the petals green, connected with spots of dark crimson, which spread into fine transparent red, covered with rich tints, nerves very perceptible, anthers bold; it is called Crowned Amaryllis. A. psittácina, Parrot Amaryllis, is scarlet striped with green, two or more flowers on the stem, each about five inches in diameter. A. longifòlia is perfectly hardy; flowers pink, inclining to white, in large umbels, leaves long, glaucous, and is a desirable garden bulb. A. longifiòra striàta has pure white flowers with bright pink stripes, and each flower is about seven inches long; it was introduced from South America by Mrs. R. Alsop, and is a most superb flowering bulb. $A$. solandriflòra, large red; $A$. elegáns, red and green, and many other superb kinds, especially the hybrid sorts; from Johnsòni there are above twenty cultivated varieties; from formòsa about twelve; and from Griffini about ten, all of them esteemed. Where they have been kept in the earth in which they were grown last year, the ball ought at this repotting to be reduced; when the bulbs are in a growing state, they ought to have plenty of water, and be fully exposed to the sun, so that the foliage may have its full influence, and as the roots grow to the outside of the earth, give them another and larger pot. They must have plenty of drainage, and be kept from heavy rains. We prefer growing them in the green-house all summer, or into frames under glass; about the end of October the watering must be gradually withheld, and by the middle of November put the bulbs where they will be kept dry till February or March next, when they must be again potted (in soil No. 12).

Araucaria. This noble genus contains four species, which are without exception the most noble plants we are acquainted with, for the beauty of their foliage and symmetry of their growth, that belong to the green-house. A. excelsa, Norfolk 
Island Pine, has leaves closely imbricated as if with a coat of mail, and are imperishable. A. imbricàta, Chile Pine, is one of the grandest of trees, and is the hardiest of the genus; grows in the open air with me; the leares are also closely imbricated. A. bragiliensis is more tender and more rapid in growth. The foliage of either of the species will adhere to the wood many years after the plant is dead. They are all highly valued; the pots must be well drained; for if the plants get much water while dormant, the foliage becomes yellow, and never attains its beautiful green color again; otherwise they are easily grown. (Soil No. 11.)

Arbutus, ten exotic species and six varieties. They are generally hardy in England; but we question if they stand out in the Middle States. A unido rivbra has the finest crimson flowers; $A$. serratifólia the largest panicles; and $A$. andráchne the finest foliage; and very profuse of bloom. They flower in nodding panicles. A. canàriensis has very neat pink flowers. They bear a pretty fruit similar to a strawberry; hence it is called strawberry tree, and the fruit will remain on the bush a long time. They are very fine evergreens, and if any of them become acclimated, they will be a great acquisition to our gardens. In the Southern States they make lovely evergreen shrubs. (Soil No. 9.)

Aster argophyllus, or musk plant, has no beauty in its flowers, but is esteemed by some for its musky odor when the leaves are gently rubbed. Leaves ovate, lanceolate, and silky beneath; the plant is of strong growth. (Soil No. 9.)

Aùcuba japónica is the only species. The flowers are small and almost insignificant, color purple: but the foliage is a desirable object, being yellow, spotted, or blotched. It is tolerably hardy, and withstands our winters. It prefers shade, and, if the situation were such when planted out, it would grow more freely. The hot rays of the sun are very prejudicial to its growth. It is an evergreen shrub, and very desirable. (Soil No. 2.)

Azaleas. The Chinese varieties of Azàtea indica are almost without an end; we might properly say that they are without end; but the finest we have seen are those we shall enumerate. The one that has been longest known in the collections of this country is Inclica, a most splendid shrub, with red flowers and dark spots. Indica allba, the flowers of the purest white, rather larger than the former. Indica pur- 
purea pleno, double purple. This variety is not so fine as many of the others. Properly it is not purple, or, if it may be termed so, the color is very light, and the flower irregular. Indica phoenicea, rich purple and a free grower. Indica smithii of the French, and Indica purpirea of the English, are alike, pale lilac and very profuse of flower. Indica coccinea, bright scarlet, a superb variety, and extremely abundant of bloom. Indica flore variegàta flowers beautifully variegated, pink and white. Lateritía, salmon color, fine. Williamsii, bright, rich crimson. Pouleii, rosy purple. Prince Albert, very large, bright rosy crimson, of strong growth. Maitlandii, pure white, striped with pink, dwarf habit. Copeii, bright rose. Danielsiana, bright red. Indica carnea, delicate flesh color. Indica nova blanc, white, with a greenish-yellow spot on the upper petals. Rubro pleno, double red, of very erect growth. Spectabilis, rose and violet. Indica eleyàns, bright rosy purple, a very profuse flowerer and of a neat habit. Indica Gillinghamia, very large lilac, and of a strong habit. Striata formosissima, white striped rose. Hnrtwig, very brightcrimson. Azàlea sinénsis does not belong to the indica tribe; it is of a hard woody nature, flowers of a golden yellow, in large clusters; it no doubt will prove a hardy species. The varieties and sub-varieties of indica will, in a few years, be so numerous that the greatest difficulty will be to keep clear of those that are not decidedly distinct: to obtain this object our own fecble exertions will be industriously applied. We might have named a few other varieties, but they so nearly approach some of the above, that it is better to avoid them. A choice selection of the Chinese Azalea ought to be in every green-house; they are all easy of culture, and bloom freely from February to May. The pots must be well drained and shaded from the sun during summer, though the tops of the plants do best to have the full rays, to which we have them fully exposed, and find that by such treatment they are every year completely covered with their flowers and grow more stiff in habit than when the whole plant is shaded. They should be repotted as soon as done flowering in soil No. 6 when they are flowering plants, and in soil No. 5 when young plants.

Pánksicus. There are about thirty-two species, all curious in flower, and handsome and rarious in foliage; flowers in large heads of cone shape, anthers mostly green, and continue a considerable time in tower; produces a cone in shape of a 
pine, but not imbricate. The substance is as hard as bone, and contains many seeds. A cone of $B$. grándis in our possession weighs one pound and twelve ounces, and contains about one hundred and seven seeds. Those most admired for the foliage are, $B$. dentáta, B. æmuila, $B$. serràı, B. latifòtia, $B$. grandis, which is the largest. $B$. speciòs $a$ has the longest foliage. B. Cunninghámii, B. spinulòse, B. palludósa and $B$. repèns, these will afford a good variety. $B$. verticillàta is entirely different in appearance from the others.

They must be well drained, and placed in an airy part of the green-house. Great care should be taken that they do not get too dry, for they seldom recover if allowed to flag for want of water. This genus is named in honor of Sir Joseph Banks, a distinguished promoter of the study of natural history. (Soil No. 6.)

Baròsmas, above ten species of pretty plants, separated from Diòsma. B. serratifolia, white; $B$. pulchella, purple; B. foetidissima, blush; B. odoráta white; and B. dioica, pink, are the finest. (Soil No. 8.)

Beaufórtias, only two species. B. decussàta is splendid; the flowers come out of the wood with stamens in fine parcels, color bright scarlet, foliage decussate, oval, and many-nerved, bloom persistent, and much esteemed. B. spársa, in flower similar to the other; color light pink, foliage scattered, both of easy culture, and flower abundantly. (Soil No. 8.)

Begònias, a few species, are desirable for the green-house especially. B. fuchsioides, scarlet; B. incarnáta, flesh color, and blooms during winter; B. zebrina, zebra-like, very pretty; they are of a soft woody nature, and should be kept in the warmest part of the green-house. (Soil No. 9.)

Benthàmia fragiféra. This beautiful new plant will make a splendid hardy evergreen for the Southern States, where it will produce its pale white flowers in July, and an abundance of fruit very much like strawberries, of a slight acid taste: but we are doubtful if it will fruit in our green-houses unless greatly encouraged. (Soil No. 9.)

Bletia hyacinthina is the only species belonging to the green-house, once known as Cymbidium hyacinthinum. It is herbaceous, and before it begins to grow, divide the root, putting the best into six-inch pots. The spike of flowers are hyacinth-like, and of a beautiful purple, flowering from A pril to July. (Soil No, 9.) 
Bouvárdias, three species. B. flava yellow; B. pallida pale red; $B$. triphylla is well known among us, has brilliant scarlet flowers, and, when well grown, will flower beautifully from May till September. To keep the plants, they should be frequently renewed; otherwise they are liable to grow straggling and become subject to the small white scaly insect. (Soil No. 3.)

Borònia is a beautiful genus of New Holland plants, contains about nine species; most of them have been universally admired; the flowers are star-like, rose-colored, and some of them sweet-scented. B. pinnata grows and flowers freely. $B$. serrulata, foliage serrated and very crowded, bearing the flowers on the extremity of the shoot, and does extremely well in this country; the flowers are bright rose, and sweet-scented. $B$. alcita has a fine appearance, and grows handsomely. The foliage is winged and pinnate, strong-scented; of a hardy nature, and easy culture. They are in flower about April and May, and continue a considerable time; are subject to mildew if not frequently syringed: drain the pots well. (Soil No. 8.)

Brachysèmas, two species, both evergreen climbers. $B$. latif ollium has the best foliage, and large purple leguminose flowers. B. undulatum, flowers yellow, and more plentiful than the former, continuing in long succession. The pots require to be well drained; very few plants of either in the country. (Soil No. 6.)

Brugmánsius, four species of strong, coarse-growing plants; requiring great nourishment to flower them well. $B$. sauvéolens has very large white flowers, about five inches in diameter, and sweet-scented. B. sanguinea has flowers with a green thorax; the brim of the corolla is of a dark orange color. B. Knightii, large balf double flowers of snowy whiteness, does well when planted in the upen ground. $B$. florabunda, orange-colored. They must have very frequent repottings, and be liberally supplied with water while growing. (Soil No. 18.)

Brùnias, about ten species; have heath-like foliage, xery fine; generally, on close observation, found to be three-cornered. The flowers are white and globular, the plants, when young, are very handsome; the finest are, $B$. nodiflora, $B$. lanuginósa, $B$. comòsa, $B$. abrotanoídes, and $B$. formosa. They require an airy situation, and, in summer, to bo pro- 
tected from the powerful rays of the sun. Drain the pots well. (Soil No. 6.)

Brunsvigias are all large bulbs from the Cape of Good Hope, and will keep in the green-house during winter, but are better where they can obtain a situation in the hot-house. It is a splendid genus, containing about ten species. Some of the bulbs grow to an enormous size, and all of them, while growing, require a liberal supply of water; but when dormant, it must be wholly withhe!d, and they should have large pots, to make them grow and flower in perfection. B. multiflora, flowers scarlet and green; the leaves lay on the surface of the pot. $B$. laticoma, flowers pale purple. B. Josephinæ has splendid rose-colored flowers, and the most admired species of the genus; the foliage spreading, half erect, and glaucous; flowers numercus, and in large umbels, on a stem two feet high, blooming successively: there is a variety that has striped flowers.

Several other species have been given to different genera. $B$. fulcuta is now Ammócharis falcàtà; $B$. margináta, now Imhófia; and B. cilliàris is now Buphóne cilliaris. They all flower in umbels, on stems from six inches to two feet; flowers lily-like, with six petals.

Burchéllias, two species. B. capénsis is a beautiful dwarf evergreen shrub, with tubular orange-colored flowers, in large terminal clusters; when well treated, grows and flowers freely, and highly deserving of attention. B. parvifiora differs from the above in the flowers being smaller and paler, and the foliage more pointed. (Soil No. 10.)

Cactus: for descriptions of, see hot-house in May.

Culcerlìria. This genus of plants has undergone a complete rcvolution. Within these few years, hundreds of superb hybrid varieties have been brought to notice, many of them truly splendid. With us the herbaceous kinds are very delicate during summer; they are generally all cut off by our intense heat, or scvere droughts. The shrubby varieties appear to withstand the vicissitudes of our climate better, though, as yet, we confess we are not even altogether successful in their summer culture. However, a few of them have done well, and are C. angustifolia, bright yellow, and in great profusion; C. jupiter, brown and yellow; C. marjoriána supèrba, nearly scarlet; C. smìthii, red and yellow; C'. ignèa, bright crimson; C. métcor, dark crimson; C. Vutcan, dark 18 
red; C. maculata, superbly marked with red or crimson. There are many others of very great merit of the shrubby kinds cultivated in Europe, such as whites of different shades, dark crimsons, with white capes, and others blending into almost every description of color and character. Any quantity of new sorts may be obtained by cross impregnation between any two of very different colors; the seeds will ripen in July, when they may be sown on light soil, and they will flower the following season. Flowering plants require to be greatly encouraged, and must be shaded during summer from the violent noonday sun.

(Soil No. 10.)

Calothimmus, four species. This genus is named in allusion to the splendid appearance of the branches, covered with scarlet flowers of curious construction, which come out of the old wood. All the species are of easy culture, and very like dwarf pines. $\quad C$. quadrifficia has the largest flowers; $C$. claváta the most abundant. They are all evergreens, and flower from April to November, and are very desirable in a collec. tion. (Soil No. 6.)

Callicôma serratifotic, the only species, and remarkable for tufted yellow heads of flowers, which come out at the axils, and continue from May to July. The foliage is orate, lanceolate, deeply serrated and opposite. (Soil No.6.)

Caméllias. There are about eight distinct species of this plant known in our collections; and the varieties of japonica approach to one thousand, to which many are yearly added; but, unfortunately, their merits are not fully scrutinized before they are sent forth to the floral world, under names representing and expressing every quality that is grand or beautiful in foral imagination. Such has been the rapid increase of varieties in Europe, and even in this country, that, in many instances, three or four distinct plants have come out under the same name; consequently, a great confusion of names has been the result, which has caused much difficulty in attaining the best of the names. The collections of this country were kept comparatively pure till within the last few years, when the anxiety of our cultivators to obtain variety caused them to import from the French and German markets, which has thrown the nomenclature into an almost impenetrable chaos. But still we can unite in saying, "What species of plant is there which better merits the intelligent and vigilant care of the 
amateur and horticulturist?" The elegance of its form, the beautiful verdure of its foliage, and the pure and brilliant colors of the large and elegant flowers, sufficiently justify the admiration of all. In fact, we may say, there is not a green-house in which this lovely plant has not found a place, where it stands in the first rank of floral population. To give a full description of all the varieties we know would occupy this rolume. However, we will give lucid details of nearly one hundred of the finest we have seen in cultivation. But, in regard to the shades and spots of color, we must throw ourselves on the charity of our readers; for many sorts are very capricious in that particular: though styled self-colored, they may come spotted, and even those that are generally spotted sometimes show themselves of one color.

C'améllia euryoídes, flowers small, single white, and a little fragrant; plant of a slender growth.

C. oleiffería is cultivated principally in China for the oil which is expressed from its seeds, which is much used in the domestic cookery of the country; flower single white.

C. Sesanqua, Lady Banks's. The foliage of this species is very small, and paler, and the green not so fine as any of the others. It seeds freeely, and is often used as the fcmale parent in producing new varieties; flowers snuall, white, and single, with many anthers. There are a semidouble and double variety of it of the same color.

C. sesanqua rósea, or mallifiòra of some, double pink, small flowers, but in very great profusion; the plant is of a free, upright growth. The flowers are of about four weeks' duration; it is very much esteemed.

C. Tissi. Small single white; the only species that is a native of Nepaul.

C. reticulata was brought from China by Capt. Rawes in 1822. The foliage is very characteristic, being stiff and flat, distinctly serrated, nerves deeply sunken; Howers bright rose, of a loose form, and above six inches in diameter, semi-double. From present appearance, it will never be so plenty as many of the others, being tardy of propagation; only a few eyes on the extremity of each shoot make young wood, and if these are cut off, the plant does not seem to push afresh. Magnificent.

C. japonica, small, single, red. It is supposed that this is the type of all the garden-cultivated varieties of the 
Camellia, though some are inclined to think that it is a variegated or striped species, not yet introduced, that has been the origin of so many beautiful Chinese sorts.

The following are supposed to be its varieties:-

C. alba-plèna, common double white, is admired by the most casual observer, and is generally considered a very superior flower, from the purity of its whiteness and the abundance of its large flowers, which are closely and regularly set with round petals. The foliage is large, and the plant grows freely; we have seen one shoot grow two feet in one summer. It was imported into Europe from China, among the first of the varieties, about eighty years ago. Magnificent.

O. semplex* álba, single white. It is mentioned somewhere as boing very sweet-scented, though not very perceptible to us. The foliage and wood are very strong, the finestriped sorts have been raised from it; consequently, it is particularly desirable as a stock to grow new varieties from. Its flowers are large and abundant. Good.

C. althxflóra, hollyhock flowered, is a great beauty, with large double dark red flowers; the veins are very prominent, petals frequently irregular; foliage large, smooth, and very dark green, and is much esteemed. Fine.

C. anemonefiora, or Waratah (from the centre petals, having the appearance of the Waratah plant, Telopia speciosissima). 'I'his variety is very characteristic, both in flower and foliage. - The flower is dark crimson, with five regular large outside petals; those of the centre are very small and neatly plaited, with the stile (female organ) prominent; the foliage is large and oblong, nerves very smooth, and the wood strong, bark light. Had this kind not been found, we would hove been deprived of many most splendid varieties which have originated from it, and we have no doubt they may become as diversified as the roses of the garden: this variety, in a collection, for that alone is invaluable. It seeds freely, and the pollen of any of the others applied to the style of this will produce a'new variety, which seldom fails of being

* We have now, 1839 , in flower, a single white, very similar to this, which we have raised from the seed of Dahlicflora, a good double red variety; it, therefore, appear's impossible to predict their character from the parent that produced the seed. 
double, provided the pollen is from a double variety. It must be applied the first day that the flower is expanded, for the bloom is only of a few day's duration. Those that are not acquainted with the buds of this Caméllia, will take them to be dead, because, before expansion, they are very dark brown, and have a dried appearance. Superb.

C. amàbile. This exceedingly perfect flower was raised from seed by J. B. Smith, Esq., of this city ; it is regularly imbricated, the extreme petals are bright rose, shading to delicate pink, and then again shading in the centre to light red. The plant is full of foliage and of excellent habit, flower about three and a half inches in diameter. Mragnificent.

C. atrorùbens, Loddiges' red, is a good variety; color dark red, outside petals large, inside small and irregular, forming a very distinct character; foliage stiff; grows freely and flowers well; and of long duration. We have seen a flower stand fresh on the plant two months; however, that cannot be a rule, as it depends on the situation. Good.

C. américana, blush, medium size, finely cupped forn, generally spotted with rose, an American seedling by Mr. Dunlap, of N. Y. Magnificent.

C. Alexina, rose white, spotted and striped, dark rose imbricated, and fully ciouble foliage, dark green, cordate, a plant of neat habit. Superl.

C. albicans, pure white, perfectly double, in shape growth and form very like myrtifulia alla. Superl.

C. Binncyii, rosy crimson, very perfect form, luxuriant foliage, of free growth and bloom. Supert.

C. Bealiana, or Leana Super'u, dark crimson, very large, superbly double, cup fơrm. Magnificent.

C. candidissima, purest white flowers, very large, four inches or more in diameter, full and most regularly imbricated, and resemble very much the old doulle white, though more perfect in form-leaves rather small, of an elongated form, smooth and pule green, often spotted with yellow. The plant is of vigorous growth, and a Japan variety. Maynificent.

C. cámea, frequently known as Middlemist's blush. Double pink, one of the original varieties, and frequently produces seeds, from which miny rery fine varieties have been obtained; grows freely. Good.

C. chalmerii perfecta, delicate waxy rose, perfectly imbri18* 
eated form, flower medium size, very persistent, foliage pale green, plant of regular pyramidal growth. Magnificent. An American seedling in the possession of Mr. William Chalmers, gardener to the late Geo. Pepper, Esq.

C. chandlerii or verșicolor, perfectly double, color vivid red, with occasional splashes of pure white; the flowers vary, and are often only red-they are of long, duration, from six to eight weeks ; foliage large and dark glossy green. Magnijicent.

- C. colvillea, pale blush, with rose spots and pink stripes, is partially anemone formed; but very compact and of free growth; leares cordate. Superb.

C. concinna, deep cherry red, a very perfectly imbricated double flower, about three and a half inches in diameter; folinge generally a little undulated, wood slender. Superb.

C. conspicua, (Loddiges,) a shrub of strong handsome growth, with large dark green foliage; flower very double; five inches in diameter; bright orange red, hemispherical shape; petals erect, and appear as if three or four flowers were united; it is profuse of bloom and very conspicuous. Mugnificent.

C. coquette, rosy crimson, frequently blush, imbricated with large petals of a rather coarse texture ; foliage large cordate, pale green. Good.

C. Comtesse Nencini, pure white, beautifully striped with rose of perfect formation; foliage cordate acuminate, of good habit. Magnificent.

C. Donkelàri, bright red, variegated and sprinkled with pure white, three rows of large petals about one inch broad and two inches long; centre full of stamens, flower fully four inches in diameter; leaves about two inches broad and four inches long; this will be an elegant viriety to seed from, and is of Chinese origin. Magnificent.

C. delectissima, white, profusely striped with rose, exterior petals large and round; those of the interior are closely set; flower nearly four inches in diameter; leaves very large, ovate, acuminate. Superl.

C. Duchess of Orleans, rose white, beautifully spotted or striped with rose, perfect form, large, a free bloomer. Magnificent.

C. Clorséttic or parthoniana, of the Belgians; leaves flat and closely set, of a dark shining green; flower very large, 
nearly five inches in diameter, of a pale red, mixed with rose and white; petals closely imbricated, irregular, and numerous; those of the centre small. Magnificent.

C. eclipse or Préssi, of the English, or imperialis of the French; flower pure white, with rose stripes, four inches in diameter; irregular, full, and double, with a few stamens appearing among the petals; the whole flower forms an arched centre, almost hemispherical; leaves long and pointed, of a clear rich green: we have seen flowers of this plint entirely rose. Maynificent.

C. élegans ( Chandler's), flower rosy red, fading to nearly white in the centre; three and a half inches in diameter; exterior petals large and rounded; those of the interior very numcrous, and beautifully harmonize; forming, as it were, a depressed sphere; a profuse bloomer, and of a neat habit. Magnificent.

C. elata, violet crimson, spotted with white, flower three and a half inches in diameter, perfectly imbricated to the very centre, and of the most perfect double; foliage dark green; plant of a good habit. Magnificent.

(\%. elphingstònia, red spotted with white, frequently four inches in diameter; exterior petals very large, regularly graduating to the centre, which cover a few hidden stamens; foliage dark green; plant of a fine habit. Magnificent.

C. Davy Crocket, rosy crimson, exceedingly large, fully five inches in diameter; round petals fully double and very showy. Magnificent.

C. De la Reine, white frequently striped with dark rosy violet very double; a magnificent flower, but a plant with very indifferent foliage.

C. Dunlop's white, pure white, perfectly imbricated : a free grower. Magnificent.

C. eximia (Chandler's), flowers bright crimson, four inches in diameter, of a perfect double imbricated form; foliage light green and deeply serrated; nerves smooth; it is of free growth, but with us does not bloom freely. Magnificent.

C. Emily, an exceedingly large irregular flower; blush white, striped and spotted with rose; foliage shining green; plant of strong growth. Magnificent.

C. Fultorii, pale waxy rose; regular flower of medium size; a profuse bloomer. Magnificent. 
C. Fáirlea, foliage large, ovate, acuminate; of a smooth shining dark green; flowers nearly four inches in diameter, of a rich crimson, marked with pure white; very double. Superb.

C. Feastii, pure white, with a few spots of rose, fully double, imbricated, very distinct; foliage dark green; of free growth. Magnificent. A seedling by Mr. Feast, of Baltimore.

C. fimbriàta: fringed white. The size, shape and set of the flower same as alba-plena, and the white as pure, with the edges of the petals deeply serrated, or rather fringed; is equally as free in flowering, though not so strong in growth. It is universally admired, and in great demand. Magnificent.

C. flavéscens, or inc'ínata. Lady Hume's blush, and by some called buff. It is a very double flower, beautifully regular and imbricated, and frequently hexangular, or starlike; the bottom of the petals is most delicately tinged with blush; on looking into it, it shows more like a blush rapor than nature, and is a great favorite, and deservedly so; flowers and grows freely; foliage rhomboid, elongate, nerves very visible, surface smooth and pale green, distinctly serrate; growth strong and erect. Muynificent.

C. fóridu. Flower clear cherry red, large, frequently above four inches in diameter; very persistent; exterior petals large and well rounded; the interior small and closely set, rising in the centre; it is a profuse bloomer; foliage dark green. The plant is of a neat and regular habit. Magnificent.

C. Flóyii, one of the most noble of the Camellias, both in flower and foliage; leaves three inches wide, and nearly five long; smonth, dark green plant of strong growth; flower five inches in diameter, of a perfectly double form; the extremity is cherry red, diverging to a pale rose in the centre; the exterior petals are bold, round and elegant, of a cup shape when newly opened. It is frequently sold in Europe under the imposing name of Frederick the Great, though grown from seed by Mr. Floy, of New York, who has been very successful in producing several other esteemed sorts. Mugnificent.

C. Fórdii, a free-growing plant, with lively green foliage and graceful habit; flower dark rose, three inches and a 
half in diameter, perfectly double, and regularly imbricated, forming a symmetrical bloom. Magnificent.

C. formósa, foliage very dark green; flower fully four inches in diameter, of a dark rose color, regularly double, petals large and erect; interior shortened, covering a few stamens. Superb.

C. frantcofortensis, or Wellingtoni, a plant of a very compact habit; flower three inches and a half in diameter, beautiful rose, occasionally spotted with white. Mugnificent.

C. fúlgens, flower three inches and a half in diameter, and very bright double crimson, approaching to $C$. atrorubens, but more brilliant; petals regularly decreasing to the centre; foliage a lucid green, very smooth; young wood and wood buds have a red appearance. We have no doubt but it will occasionally seed; if so, it will be a first rate breeder. Superb.

C. Gilèsii, or Nancy Dawson. The leaves are large, ovate, oblong and pointed; flowers above four inches in diameter, of a fine dark red color, often striped with white, and is "distinguished for fragrance as well as beauty." Magnificent.

C. grunèlla, foliage oval and acute, of a deep glossy green, flower white, three inches and a half; rather irregular, but perfectly double, a profuse bloomer, and of good habit. Superb.

C. Hendersòni, raised by the celebrated camellia grower, Mr. Henderson, of Woodhall, Scotland. It is a large flower, four inches and a half in diameter, beautifully imbricated, and perfectly double, of a bright rose color; foliage round, ovate, and distinctly serrated. Magnificent.

C. Hampsteadii, large rosy crimson, quite double, with bold petals; foliage dark green, heart-shaped, a free-grower. An American seedling sent out by Messis. Ritchie and Dick.

C. Henri Favre, a beautiful rose color, of French origin, perfectly double, being similar to Landrethi. A free bloomer, foliage pale green. Magnificent.

C. Hosackia, large dark crimson, nearly five inches in diameter; flower rather flat, petals numerous, regularly decreasing to the centre, which has an occasional speck of white. It does seed, and will prove a first-rate variety for 
that purpose; foliage long and pointed, rather drooping; is of a free growth and bloom. Superb.

C. imbricata, foliage very large, three inches wide and four and a half long, of a pale green, often marked with white; flowers rich crimson, almost in variably marked more or less with white; they are full four inches in diameter; the petals are round, and regularly disposed, and imbricated on each other, gradually decreasing to the centre, forming a most perfect flower. The plant grows freely, and blooms profusely; no collection can be perfect without it. Magnificent.

C. intermérlia is a sport from S. pronifiòra; it is a very large blush, beautifully suffused with rose. Magnificent.

C. invincille, or punctàta, flower three inches and a half in diameter, rose ground, marked and striped with cherry red; the circumference petals are broad and convex; those of the centre small and erect. This Camellia sometimes produces flowers entirely red or rose-colored; it is of free growth; leares round, acuminate, and of a dark green. Superb.

C. Jeffersonii, rosy crimson, perfectly imbricated to the centre; flower of medium size; foliage shining green, three to four inches long, and two wide. A seedling by Dr. J. S. Gunnell, of Washington city. Magnificent.

C. imbricata (Dunlop's), flowers rosy crimson, most perfectly formed, marked with white shading to blush; foliage large, recurved, of a pale green color. Margnificent.

C. Landréthii, or Jacksònia, very beautiful pink, fading to the centre, a perfectly double and finely imbricated flower, about four inches in diameter, a free bloomer, and a plant of good habit; leares ovate, acuminate, pale green. We have seen the flower profusely spotted with white. This elegant Camellia was grown from seed by D. and C. Landreth, and bloomed first in the spring of 18:9. Magnificent.

C. latifòlia, leaves three inches wide and four inches and a half long, point recurved, a fine glossy green ; flower cherry red, cup form, interior petals irregular, festooned and curled, those of the exterior bold and round, about three inches and a half in diameter. Superl.

C. Lowii, very dark crimson, imbricated flower; fine bold petals; foliage cordate, pale green. Magnificent.

Mrs. Fetter's, large dark red, shading to rose in the centre, 
perfectly imbricated; fine round petals, very regularly disposed; foliage dark green. One of the best of its color. Magnificent.

C. mutábilis travèrsii, foliage very large and almost cordate; plant of an elegant and free growth; leaves rather reflexed and of a lively green, nerves very conspicuous; flower four inches and a half in diameter, regular, and very double; it opens a delicate rose, and soon changes to a violet purple, shaded with a faint line of white, an unique plant and flower. Magnificent.

C. myrtifólia, known in our collections as involuta. There are two varieties of it, major and minor; the former is certainly the best, and has a very handsome, large and regular red flower; the centre frequently is pink and purple ; it is much the shape of double white, only the petals are more cupped. The flower is of considerable duration. The foliage, though small, is much larger than that of any of our common myrtles, which might make many mistake its character; and another prominent feature is, the leares are much recurved and shining; plant pendulous, of a pale green. Magnificent.

C. Madonna, very pure white, delicately striped with bright rose; perfectly imbricated and above medium size; foliage dark shining green. Magnificent.

C. Mrs. Abby Wilder, white striped with pink; a regularly imbricated flower of fine formation; foliage large, coarse, sickly green. Magnificent.

C. Miss Percival, large flower, pure white, very fine when in bud, not fully double; foliage dark shining green. Good. When we have the pleasure of giving a Camellia this name, it will be, in our estimation at least, without a fault.

C. proniflòra: bright pink, large flower, fully four inches in diameter, two rows of circumference petals ; those of the centre numerous, very close, erect, and in the form of a sphere; plant of a slender growth; leaves two inches broad and three inches long, of a delicate green. Superb.

C. Palmer's perfection, dark crimson, inclining to purple, very large, perfectly double, and of handsome form; a free bloomer. Magnificent.

C. Philadélphica (Smith's), flowers four and a half to five inches in diameter; the circumference petals large and round; those of the interior smaller with a little convexity, 
perfectly double, color changeable, bright crimson, spotted with white; dark rose, fading to the centre, or all crimson; even the same plant producing all the variety; plant of an upright branching habit; leaves ovate, acuminate, of medium size, and a very dull dark green; bloomed first in 1834, when only two years from the seed, and the flower was then four and three-quarter inches in diameter. Magnificent.

C. picturàta: leaves three and a half inches wide and four and a half inches long, of a bright green; flower four inches in diameter; spherical and extremely double; petals of the centre irregular and closely folded: those of the periphery or circumference round and entire, of a pure white, occasionally striped with red-a few hidden stamens-plant of an elegant habit. Magnificent.

C. pompónia, or Kew blush, flowers over four inches in diameter; white, with a tinge of blush at the bottom of the petals, which has a good effect in setting off the flower. They frequently bloom all blush, having one or two rows of guard or outside petals; those of the inside are short, stubby, and generally irregular; continues long in flower; yellow anthers among the short petals, and seeds when the female organ is perfect; foliage similar to proniflóra; a very fast grower, and flowers freely. Supert.

C. Prattii ; * flower bright rose, full four inches in diameter, frequently every petal having a white stripe from the apex to the base, very closely and regularly imbricated to the very centre : in every respect equally as woll-formed as C. imbricata; leaves two and a half inches wide and four inches long, of a rich smooth green-is a plant of free growth and profuse flowering; bloomed first in 1836. With pleasure, we say it is our first seedling of merit. Muynificent.

C. Punctitu, see Invíncille.

C. Prince Allert, pale rose, striped with bright red, very distinct; a Chinese variety perfectly double, a lirge flower; petals rather short in the centre. Marnificent.

C. Qucen of England, dark rosy crimson, with an occasional spot of white; large, imbricated, and fully double. Magnificent.

* In compliment to our late and esteemed patron, H. Pratt, Esq., of Lemon Hill. 
C. Queen Victoria (Priestley's), crimson, occasionally marked with white; flower large, perfectly imbricated; foliage strong, dark green. Magnificent.

C. rósà sinénsis, a large double flower, four inches in diameter; color bright rosy pink, petals long and full, closely imbricated to the centre : a very distinct variety, with beautiful dark green shining foliage, two inches wide and three and a half long; grows and flowers freely. Magnificent.

C. róseà (China), petals regularly and pérfectly imbricated, flower frequently star-shaped, like Hume's blush, about three inches in diameter; color bright rose, changing to rosy purple; foliage pale green; leaves one and a half inches wide and three inches long; plant of slender habit, though well-formed, and a profuse bloomer. Magnificent.

C. viubra-plèno, or Greavill's double red, is a strong-growing and free-flowering variety. The flowers are large, irregular, and very double, and are of long duration; foliage of a yellowish-green, leaves two inches wide and three inches long; plant of a stiff habit. Superb.

C. Saccoi, bright rose, imbricated form, very perfect, fading to a pale rose; a free bloomer. Mainnificent.

C. Saccoi de nova and Magnifii are the same, very similar to the former, merely a shade paler in color ; foliage more distinctly nerved and serrated. Magnificent.

C. Sarah Frost, rich crimson, of perfectly imbricated form, very full, a profuse bloomer, growing freely, of upright habit. Magnificent.

C. Sherwoodii, rosy crimson, frequently spotted with pure white; very double; petals reflexed when fully open; a free grower and profuse bloomer. Magnificent. A seedling by Mr. Sherwood, of Laurel Hill.

C. sesànqua rosea. See among the species.

C. speciósa is a most splendid variety, has been called Chinese striped Wuratah. The guard petals are large, round, and bold; color crimson with stripes of white; the centre is full of irregular small petals, and spotted; the foliage three inches wide and four inches long, and more heart-shaped than any of the others; grows freely, flower persistent, four inches in diameter, and highly esteemed, and considered one of the finest of the colored Camellias. Magnificent.

C. spléndens; rosy red, flower full and bold, nearly four inches in diameter; petals few, but very large and round, 
lying gently over each other, showing a few stamens in the centre - is very attractive and conspicuous in a collection; foliage dark green, ovate, acuminate. Superb.

C. spofforthiana; foliage deep plain green, acutely serrated, plant handsome and vigorous; flower three and a half inches in diameter, of a pure white, with an occasional red stripe; petals rather irregular, full and double, though showing a few stamens. Superb.

C. spofforthiana cárnea; flower larger than the former, otherwise very similar. Superb.

C. Sweetia vera; leaves three inches long and four inches wide, distinctly serrate, of a fine shining green, plant of an upright free-growing habit; flower nearly four inches in diameter, with three rows of circumference petals - rose white, sprinkled with bright red; those of the centre small and erect, concealing a few sterile stamens. Magnificent. There is a spurious plant out under this name, which is very inferior.

C. tricòtor; foliage pale green, two inches wide and three and a half inches long, distinctly serrated, with the nerves very prominent; flower full four inches in diameter-semidouble; petals large and round-rery beautifully set; color white, shaded with various shades of red, rose, \&c. A superb variety to produce seeds, having the female organ very perfect, and was introduced from China by Dr. Siebold. Superb.

C. triùmphans; foliage dark green; leaves roundish oval, slightly pointed with nerves, and serratures very distinct; flower nearly four inches in diameter, of a bright cherry red, shaded with rose; petals regular, round, and large, a little recurved at the extremity, and gracefully imbricated to the centre, which is occasionally striped with white; the plant is of a good habit and free growth. Magnificent.

C. varialtilis; this is a sportive variety of C. pcooniflora, with flower and foliage of same character; frequently blooming rose-striped, or marked with pink, blush, \&c. Magnificent.

C. variegàta is one of the old standard varieties, and very much esteemed. It is striped with red and white; sometimes the ground is red, with white streaks or blotches, and vice versâ; nearly four inches in diameter, petals large and round, rather loose, centre showing a number of stamens; 
foliage very fine dark green, three inches wide and four inches long. We have had seed from it. Plant of a good habit and a profuse bloomer. Superb.

C. teutonia, an imbricated flower, of perfect form, rosy crimson, frequently inclining to pale rose. Magnificent.

C. Walbankiana; foliage pale green, two inches broad and nearly four inches long; plant of rather loose habit; flower greenish-white, full four inches in diameter; petals large and oval, irregularly tufted, showing a number of stamens, though very double. We are inclined to believe that this is the lutea alla of some catalogues. Superb.

C. Wardii; very dark green foliage; leaves rather cordate and undulate, of a coriaceous texture; plant of a branching stiff habit; flower full three inches in diameter, very persistent-circumference petals large and round; those of the interior small, round, and closely set, rather flattened, color vivid crimson. This fine variety is another by Mr. Floy, of New York. Superl.

C. Washington (Gunnell's); dark rosy crimson, of exquisite form, imbricated to the centre; a plant of neat habit, an abundant bloomer, always opening perfect. Magnificent.

C. Wilderii; very bright rose ; perfectly imbricated ; petals regular to the centre; almost a fac simile of the C. Fordii, except the foliage, which is more heart-shaped. Magnificent.

C. Wóodsii; foliage light green; leaves two inches wide and four inches long; plant of a rapid growth and regular shape; flower four and a half inches in diameter, of a bright rose color; petals large and rounding in the periphery; those of the centre rather irregular-perfectly double, and blooms with difficulty. We have observed it to bloom finest when a gentle heat was applied, or when the plant flowered in March or April. Magnificent. (Soil No. 11 for the whole family.)

We beg to observe that, in giving descriptions of the camellia, we have invariably, as far as known, described the - best variety, where there were several varieties under one name. The new varieties in this beautiful family of plants are increasing with astonishing rapidity. The seedlings of this country alone would of themselves form a collection of every shade and color, though many of them are almost alike, especially among the whites and reds-nearly fac-similes ex- 
cept in foliage. The description of such we have carefully aroided. Indeed, we boldly assert, though an extensive cultivator of over two hundred varieties, that there are not more than one hundred varieties known worthy of a passing remark, except for their deformed character.

Carmichcelía australis, the only species; has very curious foliage, which the lilac leguminous flowers come out of, and continue from April to June. (Soil No. 6.)

Ceanothus azìreus is the only species of the genus worth cultivating; it blonms profusely from May to July, and has considerable attraction with its brilliant blue spikes of small flowers. (Soil No. 6.)

Cestrum; a genus of about ten species; some of them very popular under the name of Night-blooming Jasmine; which are $C$. nocturnum and parquii with long greenishwhite flowers; C. diurnan, pearly white, the centre of the flower sparkling like a diamond; $C$. aurantiacum, dark orange flowers in large clusters, very handsome, blooming in winter. (Soil No. 12.)

Chorizèmas, about ten speçies, foliage very variable; flowers small and papilionaceous, often very profuse; color red and yellow; though small, they are very neat. C. nana and C. ilicifotia are pretty; but nothing of the kind can exceed $C$. ovata and $C$. varium, with their beautiful scarlet and orange blossoms, which are in great profusion; if grown from seed, they will flower freely the second year; drain the pots well. (Soil No. 6.)

Cinerarias, Cape aster, about twelve belong to the greenhouse. They are herbaceous, or half shrubby, soft wooded plants. C. speciosa, C. amelloides, (now called Agathra coelestus), C. purpirrea, and $C$. lanata, are among the finest of the species; flowers blue or yellow; the latter is considered the handsomest of the genus. The exterior petals are bright purple, and the interior ones white, and, with $A$. cceléstus, flowers most of the year; flowers syngenesious and star-like. The herbaceous species must be treated as preriously mentioned for that kind of plant. The new hybrids of this genus are rivaling the species, both for beauty of color and size of flower; among these are C. Kingii, C. triumphant, C. Scottii, C. Queen, C. Perfection, and C. Beauty. (Soil No. 12.)

Cinnamomum camphòra is the camphor tree of commerce; 
is an excellent evergreen, but has no beauty in its flower. The foliage, when bruised, has a camphorated odor. (Soil No. 10.)

Cistus, or Rock rose. There are above thirty species, principally natives of Europe, consequently hardy there, and form a great ornament to their gardens, being very abundant and various in flower; but with us they will not stand the rigor of winter. We have no doubt, however, but, through time, some kinds may be grown that will withstand the greatest cold of the Middle States; they are low shrubby plants, of easy cultivation. C. ladaniferus, C. salignus, C. populifolius, C. undulatus, and C. formosus, are perhaps the best; the flowers are of short duration, frequently only for one day; but the quantity makes up this deficiency, being constantly in flower in May and June, and sometimes flower again in autumn. C. crêticus is most productive of the gum laudanum, which is secreted about its leaves and branches. The flowers are generally five-petaled, and some of them large and showy; centre full of stamens. (Soil No. 3.)

Citrus. This genus contains the most grand and noble of fruit-bearing trees; Loudon says, "The golden apples of the heathens, and forbidden fruit of the Jews, are supposed to allude to this family." They are all handsome evergreen shrubs or trees, bearing highly odoriferous flowers and beautiful golden fruit. In cultivation, the orange fruit is dry and more insipid than in the tropies, but the lemon is far superior in its quality. The varieties of orange are extensive, nearly eighty kinds being cultivated in Italy; but, with us, the sweet, sour, and rough-skinned are the principal sorts, and more recently we cultivate the mandarin, Otaheitan, and other beautiful dwarf Chinese varieties; also, the striped-leaved varieties of Bergamotte. The lemon are nearly as numerous, though not so apparently distinct; it is very valuable as a cultivated fruit, and should be in every green-house or conservatory. The lime and the shaddock should not be overlooked, as they are very ornamental, especially the latter when it arrives at a fruit-bearing state. (Soil No. 18, when young plants, and when fruit-bearing keep from it the portion of sand.)

Clématis, Virgin's Bower. There are only six of these belonging to the green-house, all climbing plants. C. aristata and $C$. brachiata are the best; flowers in racemose $19 *$ 
clusters, pure white; foliage small; and natives of the Cape of Good Hope. The foliage of C. aristata is cordate and blotched. Some of the hardy species and varieties make beautiful plants for the green-house, such as fórida, Sieboldii, and ccerillea; they are profuse bloomers and fine growers. (Soil No. 3.)

Clerodéndron frágrans multiplex, double white, frequently known under the name of Tolkamènia Japónica, which is a very different plant, and not supposed to be in this country. It keeps in a good green-bouse, and flowers well, frequently blooming during winter, and, if planted in the garden during summer, will flower superbly. The flowers have a delicious fragrance; if the foliage is rubbed with the hand the smell is not so pleasant. The leaves are large, round, ovate, and tomentose ; flowers corymbose, compact, and terminal. (Soil No. 12.)

Clethra arbórea and C. artoirea variegata are both fine shrubs; the latter is preferable; leaves are oblong, acuminate, and serrated, having a gold-colored edge ; flowers white, downy, in large branching racemose spikes, and sweet-scented; grows freely. (Soil No. 2.)

Cliánthus punícens, or Glory fiower. This magnificent plant produced great excitement among. European cultivators, which consequently reached this country. The plant sold at extravagant prices, and cost the writer upwards of fifty dollars to introduce a living plant of it, which was done nine years ago. The plant has been cultivated in pots, and has not yet given general satisfaction; the leaves are smooth, pinnated, of a delicate green, consisting of eight pairs ; the stem is of a soft woody nature; the splendid large scarlet, leguminose, pea-like flowers grow in clusters, hanging down from the axils of the leaves on the lateral branches; each flower is about two inches long. It is a native of New Zealand, and is tolerably hardy. We have not been able to grow a solitary good specimen of it, and the only handsome plant we hare seen was in the collection of Gen. R. Patterson; where. it was planted out in the conservatory in Soil No. 10.

Cliveca nóbilis, a tuberous herbaceous plant, closely allied to Brunsvigia. The flowers are said to be very splendid; color scarlet and green: although it has been in the coun- 
try several years, we are not aware of its ever having bloom. ed. (Soil No. 11.)

Cobra scandens, the only species. It is a climber of very rapid growth; has been known to grow above two hundred feet in one summer; large bell-shaped flowers; when they are newly expanded, they are of a pale green color, and change to dark purple: will grow in the garden during summer, bearing a continual profusion of flowers, but will not stand frost. When this plant becomes too large in the house, do not cut it close to the root, except there is a young shoot arising to carry off the superabundant sap, for the old wood will not push, which will soon cause a mortification.

The best method to adopt in such a case is, to turn back a shoot, and lay it in the ground to root, when it will become a young plant, which should always be done as soon as it appears unsightly. It does best to be planted in the ground, but will not give any satisfaction as to flowering in a pot. It will flower as an annual if sown in pots this month, and placed in a warm room or hot-bed, and planted into the garden about the middle of May; it seeds freely. (Soil No. 11.)

Coronitla, a very few are fine species in the green-house. C. glaica is a celebrated plant among us, as a free and early flowering shrub. C. valentíana and C. viminális are equally so ; flower from April to June, color yellow; papilionaceous flowers in clusters; agree best in summer with partial shade. Drain the pots well. (Soil No. 12.)

Corrèa, five species and several varieties, all very pretty dwarf shrubs, and flower profusely; foliage ovate, cordate, and either rusty or downy beneath. C. álba and C. rífa have both white flowers a little tubular. C. pulchélla is a very handsome, erect-growing plant; flowers large and tubular, of a bright red color, and grows freely. C. speciòsa has been long admired as a splendid free-flowering plant; flowers same shape as C. pulchélla, but more elongated; color red and yellowish-green. C. virèns is a very free grower, flowers same shape as the last two, color entirely green; C. multiflora red-C. bicolor green and whiteC. Harrisii spotted. They are abundant flowerers, when the plants are well established; having a continued succession from November to June, possessing the valuable requisite of flowering through the winter, and ought to be in every 
collection. They require an airy situation and the pots to be well drained. The plants in summer must not be fully exposed to the sun. (Soil No. 6.)

Cràssula. This genus has now no plant in it attractive in beauty. Several beautiful plants in our collections belong to Rôchea and Kalosinthus. There is a strong growing succulent plant, known in our collections as $C$. falcàta which is $R$. fulcata. It seldom flowers; the minor variety blooms profusely every year from May to August, and has showy scarlet flowers in terminal panicles. The plants known as $C$. coccínea and $C^{y}$. versicolor are now given to the genus Kalosánthus. The flowers of the former are scarlet, wax-like, terminal, and sessile; those of the latter are rose and white, also wax-like, and are both desirable plants, requiring very little water during winter. (Soil No. 18.)

C'uphæa, a genus of rather unattractive plants were it not for the very brilliant $C$. platycintera, which is continually in bloom with its profusion of tubular, waxy, scarlet-colored edged with white and tipped with black: the plant is of dwarf habit and does well in almost any locality. (Soil No. 12.)

Cratregus. There are none of these belonging to the green-house; but there is a plant in the collections, known as C. glabra, which is Photinia serrulata, a native of China, and is a very handsome plant; has long foliage, deeply serrated, very shining. P.arbutifolia, a native of California, and is the finest of the genus; flowers in large dense panicles, foliage larger than the former, and not so deeply serrated; they are both comparatively hardy, and we soon expect to see them acclimated. (Soil No. 11.)

Crinum, several species do well in the green-house, especially C. Mexicánum, C. capense, and C. ascótica: they require considerable pot-room to make them do well. (Soil No. 12.)

Cròwea saligna is among one of the finest plants of New South Wales. It flowers at the axils of the leaves, color pink, with five petals, connected by entangled hairs; in Hlower from April to -December, and frequently through the winter; foliage lanceolate, and a fine green. The plant grows neat, and requires an airy situation: drain the pots well. (Soil No. 1.)

Cunônia capnésis, the only species, and a handsome shrub, with large pinnated shining leaves, beautifully contrasted by 
numerous dense elongated branches of small white flowers, and twigs of a red color, having more the habit of a tropical than of a Cape of Good Hope plant. (Soil No. 2.)

Cupréssus may be desired in collections, as erect and handsome-growing evergreen shrubs. C. Iusitanica, the famed cedar of Goa; C. péndula and $C$. juniperondes are the most desirable; the flowers are insignificant and yellowish; we have no doubt they may prove hardy. C. Lusiánica is the handsomest tree of the genus. Its abundant, very long dichotomous branchlets distinguish it from all the evergreens of the conoferious tribe. (Soil No. 11.)

Cyrtinthus, a genus of Cape bulbs, containing nine species, and will do very well in the green-house; but we find the assistance of the hot-house a great advantage. They are closely allied to Crinum. The tubes of the flowers are long and round, with various shades of orange, yellow, red, and green. C. odòrus, $C$. striátus, C. obliquus, and C. vittàtus, are the finest. When the bulbs are dormant, which will be from October to January, they should not get any water; before they begin to grow, turn the bulbs out of the old earth, repotting it immediately. At this time they should be potted with the bulbs of earth entire, which will cause them to flower stronger. (Soil No. 12.)

Dampièras, four species. The genus is named in honor of Captain W. Dampier, a famous voyager : has Lobelia-like flowers, either blue or purple. C. purpurea, C. undulata, and $C$. stricta, are the finest; the former two are shrubby; the latter is herbaceous; they all flower freely. (Soil No.6.)

Davièsias, above ten species, principally natives of $\mathrm{New}$ South Wales, all yellow papilionaceous flowers. D. ulicina, $D$. latifòtia, $D$. acicularis, and $D$. incrassata, are very fine species, flower and grow freely, and require to be well drained: bloom from April to August. (Soil No. 6.)

Dillwynias, above twelve species, and plants very little known. $D$. cineréscens, $D$. floribuinda, D. teretifòtia, and D. phylicoides, are desirable plants; flowers small, papilionaceous, and color yellow and red. They are very liable to suffer from too much wet; while dormant, therefore, the pots niust be effectually drained. (Soil No.6.)

Diósmas. This pretty genus of heath-looking plants has recently been very much divided by botanical professors. The genera that they have been given to are Adenándra, 
Acmàdenia, Agathósma and Barósma. However, we incline to adhere to the original name, and recommend $D$. capitáta, $D$. oppositifotlia, $D$. ribra, $D$. álba, $D$. fragrans, $D$. uniflora, $D$. serratifolia, $D$. speciòsa, and $D$. pulchélla. They are all profuse blooming plants, with generally small flowers of a white lilac or pink color. It is supposed that the dried leaves of pulchélla are used by the Hottentots as powder to mix with the grease with which they anoint their bodies. Some travelers assert that it gives them so rank an odor that they sometimes could not bear the smell of those who were their guides. In fact, the foliage of all, if rubbed by the hand while on the plant, has a very strong smell, some of them very agreeable, others disagreeable. They are all evergreen small neat-growing shrubs. They require, while growing luxuriantly, to have their young shoots topped to make them bushy; drain all the pots well and keep them in airy situations, and not crowded with other plants, or they will become slender and unsightly. (Soil No. 6.)

Diplàcus puniceus. This shrubby (mimulus) plant was introduced by Mr. Nuttall from California, by seeds, in 1836, and sent by us to England in 1837. The flowers are of a scarlet orange, about one inch and a half long, and produce in pairs; from the axils of the leaves, or young wood, the plant requires considerable nourishment; for the more rapid it grows, the more profuse are its flowers, which bloom from May to September, and are rather showy. In the Southern States it will prove a hardy shrub, blooming nearly the whole year. (Soil No. 12.)

Dracæna, or Dragon tree. The D. austrilitis and D. ferrea will keep in the green-house, and are attractive plants for their foliage, especially the latter, which is of a purple crimson and very unique; the flowers are on large terminal spikes. (Soil No. 11.)

Doryinthus excélsa, a Yucca looking plant belonging to the natural order of Amaryllidea; the leaves arise from the root, and are about three inches wide and three feet long; the flowers are bright crimson, surmounted on a stem about twenty feet high. The plant does not bloom till it is of considerable size. (Soil No. 10.)

Dryándrus. This genus is closly allied in character and habits to Bánksia, and contains above sixteen species. $D$. nivea has most beautiful foliage, very long and deeply in- 
dented. $D$. formòsa has a scent like the fruit of an apricot. D. nervòso, D. floribúnda, D. armàta, D. plumòsa, D. Baxtèri $D$. nervòsa and $D$. falcàta are the most conspicuous, and all highly desirable plants in collections. They are very delicate of importation; flowers are straw and orange-colored, and thistle-like. Seeds in small cones. Treat them the same as directed for Bánksias. (Soil No. 6.)

Dyckìs, two species of very curious growing plants, of a dwarf habit, with bright orange flowers; they may be cultivated with the aloe tribe, to which they have a similarity. $D$. rarifiòra and $D$. ramotifiora; the latter is in the country. (Soil No. 18.)

Echevèria, a genus of succulent plants chiefly from Mexico and California. D. grandifòra, flowers green and red. $E$. pulverulènta, flowers red. The foliage of this species is delicately covered with powder, which gives it a very beautiful appearance. E. bicolor is also a pretty species: they require to be kept very dry during winter. (Soil No. 10.)

Edwárdsias, about four species, very beautiful foliaged plants, and have very curious yellow flowers, but do not flower until the plant becomes large. $E$. grandiflora, $E$. chrysòphylla, and E. micròphylla, are the best, and are tolerably hardy, though doubtful of ever being acclimated. The flowers are leguminose, foliage ovate, pinnate, from eight to forty on one footstalk, and appear to be covered with gold dust. The hardier they are grown, the more visible it will appear. (Soil No. 11.)

Elichrysums. This genus is now extinct, and two splendid species of it given to others. E. proliferum is now Phocnacoma prolifera, and has beautiful purple-rayed flowers, and highly esteemed: the foliage small, round, ovate, smooth, and closely imbricated. E. spectábíle is now Aphélexis hùmilis, has pine-like foliage, and large light purple flowers. Care must be taken that they are not over-watered; drain the pots well. (Soil No. 6.)

Enkiánthus, only two species, both very fine. E. quinquefiorus has large ovate, acuminate foliage, flowers pink and pendulous; very handsome. E. reticulatus, the foliage is netted, and the flowers blush : they are liable, when dormant, to suffer from wet. Be sure to drain the pots well, and be sparing in water while in that state. (Soil No. 11.)

Epacris, above twelve species, and all very ornamental. 
E. grandiflòra has been celebrated ever since it was known; the foliage is small, flat, and acuminate; flowers tubular and pendulous, bright crimson, with a tinge of white, and very abundant; in flower from January to June. E. pulchélla is likewise a most beautiful plant; foliage very small and closely set, flowers pure white, and in long spikes, sweetscented. E. impréssa, foliage impressed, and flowers of a rose color. E. paludósu, flowers white, grows and flowers very handsomely, and is very fragrant. $\quad E$. purpuráscens riubra is a variety, with good bright red flowers. E. pallida, rose-colored, long tubular flowers. $E$. nivalis, rosy white. E. Townii, beautiful rosy blush color. These with several others are very desirable. They are mostly erect-growing plants; flower from January till August, and a rough, turfy, sandy soil is found most congenial. They are natives of the mountainous districts of New South Wales. The pots must be well drained; the roots will run with avidity among the potshreds. (Soil No. 6.)

Ericas, heath. There are in cultivation in Europe above five hundred and fifty species and rarieties of this magnificent genus. About sixty years ago it consisted only of a few humble British plants, with the heath of Spain, E. Mediterranea, which is at present most common in our collections, though in a few years we may expect tó see it supplanted by others more splendid.

In their native countries they are adapted to a great many useful purposes. In the North of Britain the poorer inhabitants corer their cabins or huts with heath, and build the walls with alternate layers of it and a kind of cement made with straw and clay. They likewise brew ale and distil spirits from the tender shoots; and it has been known to be used in dying, tanning, and many other useful domestic purposes. Encomium on their beauty is not requisite; they are almost as diversified in color as color itself. Many are graceful and elegant; hundreds are pretty; a fer noble and splendid; others grotesque, curious, and odoriferous. To cultivate and propagate them is considered one of the most delicate branches of floriculture. Nevertheless, it has been said by a scientific writer, that "those who complain of the difficulty of growing the lieath, are ignorant people, who have never had a heath to grow." The most splendid collection in Europe is under the care of Mr. M'Nab, of the Royal Botanic Garden, 
Edinburgh, where there are two large houses devoted to their culture; and through the whole year a continued profusion of bloom is kept up. Some of the plants are eight feet in diameter and fourteen feet high. The soil used is a coarse sandy peat. Pots drained with potshreds, and pieces of freestone are put down the sides of the large pots and tubs; where these can be had they are essential to the culture of mountainous plants, preventing them from being saturated with moisture, or from becoming dry, thus keeping the roots in a medium state; for if once the roots are allowed to get thoroughly dried, no art of the gardener can recover them. This may be the true reason why they are said to be difficult of cultivation.

In the summer season, the pots must be kept out of the violent sun, for in a few hours the pot would become heated, dry the roots, and cause death, or a brownness of foliage which would never again become natural. In winter, too, much fire heat will also hurt them. They only require to be kept free from frost, need a great deal of air, and plenty of light; consequently, should be placed near the glass, that they may have the benefit of all the air that is admitted. Their flowers are as varied in shape as variety or color, but they all partake of a wax-like nature, and are very persistent. (Soil No. 5 for young plants: when older, No. 6 will do better.)

The finest and most select varieties that appear to withstand the severity of the summer are the following:-

WHITE FLOWERS. YELLOW FLOW- RED FLOWERS ERS.

Arborea,

Bowieana,

Cáffra,

confèrta,

Jesminaflòra,

Margaritácea,

Odoràta,

Pellícida,

Phylicòides.
Capitàta,

Epistóma,

Grandiflòra.

SCARLET FLOW. Plukenétii, ERS.

Ardens,

Coccínea,

" grandiflòra, PURPLE FLOWERS.

Vernix coccinea,

Véstita coccínea.
Bélla,

Canalicùlata,

Ourviflòra rúbra

Grácitis,

Ignèscens,

Pinèa,

Mediterránea.

Amoena, 
Denticulcita, Fascicularis, Hispiduile, Mammósa, Putèscens, Tenèlla.
VARIOUS CO. LORS.

Abetina, Báccans, Cerinthòictes,
Crienta supèrba, Rúbida, Tubifiòra, Tentricòsa supèrba.

Eriabòtrya japónica, Loquat, or Mespilus japónica, is a fine plant, with large lanceolate, distinctly serrated leares, white underneath; small white flowers on a racemose spike, and produces a fiuit about the size of a walnut, of a fine yellow blush color, and of tartish fiavor. If it flowers in the autumn, it will require the heat. of a hot-house to ripen the fruit. It is of very easy culture, and its noble aspect is nerer passed unobserved. It is perfectly hardy in the Southern States, and forms a handsome evergreen.

No. 11.)

Erôdiums, Heron's bill. There are about thirty species, all of a geranium character, and there are among them some very pretty flowering, soft-wooded, shrubby, herbaceous, and annual plants. Only a few of them belong to the green-house, of which $E$. incarncitum, $E$. crassifolinm, and E. laciniatum are the finest; culture similar to Gerinium. The flowers of these are scarlet, pentapetalous and reiny. (Soil No. 10.)

Erythiina cristágalli, or Coral plant. If this magnificent scarlet flowering plant is desired to be kept in a pot or tub, it must hare a repotting every month till September: to keep it in fine blooming condition, it is worthy of extra care, as it will bloom three times during the season, if well treated. (Soil No. 18.) For other methods, see Flower Girden for April, May and Norember.

Escallimia, a shrubby genus, of about ten species, of rather neat blooming plants, of a strong shrubby habit. They require great encouragement to flower them well, if -kept in pots : the best mode of treatment would be to plant them in pits with other half hardy shrubs. E. ribra, red flowering; E. glandulósa, white; and E. bifida, pink, are the finest. (Soil No. 12) They are perfectly hardy south of Virginia, and we are not certain but they may become acclimated here.

Eucalyptus, above fifty species of them, and the tallest rowing trees of New Holland; foliage very diversified, 
generally of a hard glaucous texture. From their rapid growth, they soon grow higher than the loftiest house. The most conspicuous are, $E$. cordàta, $E$. rostràta, $E$. racliàta, E. pulvigéra, E. glòbifera, E. pulverulénta, and E. resínefera. In Van Dieman's Land, a manufactory has been established, where a tannin is extracted from many of the species. The last-mentioned produces gum like that which the druggists call Kino. They ought not to be too much fostered, as it, would in some degree retard their growth. They are of a very hardy nature. When large, the plants will flower freely, and are similar in flower to Myrtle; many stamina, proceeding from a hard nut-like capsule. (Soil No. 6.)

Enónymus, a few of this genus have been recently introduced from China and Japan. Such as E. japonica, * with its burnished green foliage, and its variety with silver-edged foliage--E. fimbriata, large dark green foliage. They all produce scarlet berries in winter, and are highly ornamental in the South for hedges, lawns or edgings. They are green-house plants in the Eastern and Northern States. (Soil No. 11.)

Eupatòium. There is only one species deserving of cultivation in the green-house; flowers syngenesious, white, and in large flattened panicles; very sweet-scented. The plant, when growing freely, in the beginning of summer, should be topped, which would make it more bushy; if not, it is apt to grow straggling. Known in our colloctions as E. elegáns. (Soil No. 3.)

Eutáxias, two species. E. myrtiforia is a most beautiful free-flowering evergreen shrub; foliage small, but very neat; flowers leguminose, small and very many; color yellow and red; grows freely. The young plants should be frequently topped, or they will grow naked and unsightly. H. pingens, similar to the other except in foliage. They flower from March to June, and ought to have a place in every greenhouse. Culture very easy. (Soil No. 6.)

F'cus, a few species, are good plants for this department, especially $F$. elcistica; leaves smooth, shining green, frequently six inches wide and twelve long: this is the plant that produces the gum elastic, or Indian rubber. $F$. austràlis is also an excellent evergreen, with elliptie dull green

* This plant is in some collections as a variegated leaved camellia, and is perfectly hardy with us. Does well in the shade. 
foliage; very rusty underneath ; they grow almost too freely. (Soil No. 11.)

Fúchsia, or Ladies' Ear-drop. There is an endless variety of this lovely genus of deciduous small shrubs now cultivated, but there are only a few to surpass the common and celebrated Cóccinea: true, many have been, and are, represented as far surpassing it, but when brought to the test, they are, in some particular, found wanting. However, among the many, F. Caroline, F. Exoniensis, F. Gigantea, F. Robusta, and F. Coccinea rosea. These are very superb varieties; some of the flowers are two and a half inches long and two inches in diameter. The following are light-colored varieties, indeed nearly white, with a purple or pink centre, forming a beautiful contrast with the deep crimson and purple sorts; $F$. Napoleon, $F$. One in the Ring, $F$. Magnificent, $F$. Acantha, $F$. delicata, $F$. Snow-drop, and $F$. flavescens. To grow these in perfection, they require to be very frequently shifted, as they advance in growth till you have them in pots ten inches wide. Just now, I have plants only six months from the cutting that are four feet high and sixteen feet in circumference, loaded with thousands of flowers, and are the admiration of every beholder. They require liberal supplies of water. $F$. fúlgens is a distinct species; the foliage is very different from any other sort; leaves of a well-grown plant are four inches wide and five inches and a half long: the flowers are from two inches and a half to three inches long, of a pink and scarlet color, and the plant is nearly tuberous. We would recommend our readers to grow them from seeds when obtained: it is well known they will produce variety, and it is even supposed by some that the seeds of $F$. coccinea have produced by hybridizing nearly all the varieties of the present day, which exceed one hundred : most of the flowers are a bright scarlet, the stamens are encircled with a petal of bright purple, and are of very curious construction; they boar a dark purple berry, and are of the easiest cultivation; but during summer the pots must be carefully kept from the sun, although the plants will not be affected by it. If the plants are young and growing freely, we find that a deluge of rain, and afterwards a hot day, is their instant death. Some of them do tolerably well when planted in the flower garden early in May. (Soil No. 10.) 
Fabiana, a genus of new plants that will prove entirely hardy in the Southern States; they are upright growing shrubs, with delicate foliage. $\quad F$. imbricata is the most popular, producing a profusion of white tubular flowers about an inch long, of easy culture in soil No. 12.

Gardoquìa Hookèri, a very pretty dwarf plant-native of the Floridas; it blooms profusely from June to October; flowers are about one inch and a half long, of a tubular labiate form, of a bright orange color; it is easy of culture in soil No. 1 .

Gelsèmium nitidum, Carolina jasmine, a most beautiful climbing evergreen, flowering shrub. In the months of April and May it produces many large yellow trumpet-like blossoms of delicious fragrance. If much encouraged in growth, it will not flower so freely. (Soil No. 6.)

Genista: a few of these are very pretty free-flowering shrubs. G. ramòsus, G. canariénsis, G. tricuspidáta, G. cuspidòsa and G. umbellata, are the finest green-house species. All of them have yellow leguminose flowers in great abundance; leaves small, lanceolate. (Soil No. 1.)

Geranium, Cranes-bill, a distinct family from the Pelargonium, though adapted to the same culture and even more, extensively as border or bedding-out plants that ornament the parterre from May to November with their dazzling scarlet and bright pink flowers, very generally known as Fish or Horse-shoe geraniums. In pots, they bloom in the greenhouse the whole winter; and where that convenience is not at hand they do very well in a dry cellar free from frost, from whence take them in April, cut them well down, and plant them into the garden in rich soil: the cuttings, after being allowed to dry a few days, may be planted, and will by midsummer bloom profusely: when frost approaches place them in their winter quarters. The best are, Brighton Hero, Compactum, Queen, Shrubland, General Tom Thumb, all scarlet; Lucey Rosea, and Lucey Major are pink-colored, and make an elegant contrast with the others.

Gnaphilium, everlasting. There are above ten species, most of them very splendid, persistent flowers. G. eximia has brilliant red flowers. $G$. spiralitis, $G$. speciosíssima, $G$. frìticans, $G$. oriantàlum, and G. imbricatum, are all very fine; pots must be well drained. (Soil No. 8.)

Gnúlias, about ten species of pretty green-house shrubs. $20 *$ 
G. simplex, G. sericea, G. imbérbis, and $G$. pinifôtia, flower the most freely; flowers straw color, tubular, and corymbose. $G$. simplex is sweet-scented, leaves small; the pots must be well drained, and care taken that they do not get either too wet or too dry, for the roots are very delicate. The plants must be kept near the glass, or they will be drawn weak. (Soil No. 6.)

Gorteria personata is the only species that belongs to this genus, and is an annual. There are several plants in our collections known as Gorterias, but which properly are Gazdnia, of which there are five species. $G$. ringens, when the flowers are fully expanded, (which will only be while exposed to the sun, closing at night and opening again with the influence ef the sun's rays,) is a great beauty. The rays of the flowers are bright orange, and the centre dark purple. $G$. pavònia has handsome foliage; flower similar to G. ringens, except the centre of the flower being spotted, and is thought to be the finest, but does not flower so freely. $G$. heterophylla is of the same character, except the foliage, which is variable, the color orange and vermilion. They are dwarf-growing plants, and duringt he months of July, August, and September, are liable to damp off at the surface of the earth, from the action of heat and too much water. Pots must be well drained, and the plants kept partially in the shade. Their flowers are syngenesious, and about two inches in diameter. (Soil No. 9.)

Grevilleas, about thirty species. A few of them very handsome in flower and foliage, among which are $G$. punicea; G. acanthifolia, (beautiful foliage;) $G$. concinna, very pretty straw and rose-colored flowers; $G$. juniperina, green and straw-colored; $G$. lineciris, white flowers. The flowers of the whole are curious, though not very attractive. Some carry their flower's in racemose spikes, others on flowering branches, which are recurved; the petals are very small and rugged; the stile longer than the appendage. They grow freely, flower and ripen seeds; all evergreen dwarf shrubs. (Soil No. 1.)

Habránthus, about ten species of small South American bulbs, nearly allied to Amaryllis. H. Andersónii, H. versicolor, $H$. candida, and $H$. robusta, are fine; they are in color yellow, blue, white, and lilac. We have very little doubt but these bulbs will do to plant out in the garden in 
April, and be lifted in October. Keep them from frost. Thus treated, they are very desirable. (Soil No. 12.)

Helychrysums, above forty species, chiefly belonging to the green-house-all everlasting flowers. $H$. grandiflorum, $H$. arboreum, H. fràgrans, H. adoratissinum, H. frùticans, and $H$. fúlgidum, are all very esteemed species, mostly with soft downy foliage. The pots should be well drained, and the plants kept in an airy situation, as they suffer from the least damp. If the flowers are cut off before they fade, they will retain for many years all the splendor of their beauty; but if allowed to decay on the plant, they will soon become musty, and all their color fade. (Soil No. 6.)

Hibbertias, about ten species. Three of them are known to be fine climbing evergreen shrubs, namely, $H$. glossularirfolia; H. dentàta; H. volubilis, if closely approached, has a disagreeable smell; $H$. fasciculáta, $H$. Salígna, and $H$. pedunculata, are evergreen shrubs; they have pure yellow flowers of five petals, blooming from May to September. (Soil No. 12.)

Hòveas, about eight species, pretty plants of New South Wales, blue pea-flowering evergreen shrubs; the finest are H. panósa, H. atropurpùrea, H. lineàris, H. rosmarinifòtia, $H$. longifólia, and H. Oélsii, which is the most superb, and flowers in abundance. They grow and flower freely; the pots should be drained. (Soil No. 6.)

Hypéricums, St. John's-wort, about twenty species. A few of them are very showy, and with few exceptions have yellow flowers. H. monôgynum, H. balearicum, H. floribundum, $H$. canariense, H. æyyptiacum and $H$. cochin-chinènse, which has scarlet flowers, are among the best, and all of them flowex freely; five petals, filaments many in three or five parcels. They are all of very easy cultivation, and bloom generally from April to September. (Soil No. 11.)

Hydràngeà horténsis is a well-known plånt, and much esteemed for its great profusion of very elegant, though monstrous flowers. They are naturally of a pink color, but under certain circumstances of culture they become blue. If grown in brown loam with a little sand, they will preserve their original color; but if grown in swamp earth with a little mould of decayed leaves, they will become blue.*

* Mix the iron sparks from the blacksmith's shop with any kind of soil, and they will be $a$ beantiful bue. One and a half quarts to a bushel will do. 
The swamp earth and vegetable mould being more combined with aluminous salt than brown loam is the cause of the change: and, when first found out (which was merely by chance), was thought a great wonder. It must have a very plentiful supply of water when in flower, which is produced on the shoots of the previous year. They will neither grow nor: flower well if they are not kept constantly in the shade. When kept in the sun, the foliage is very brown; and by being neglected in watering, we have seen the flowers completely scourged. H.japónica, a new variety with pink flowers, and the same disposition to change color, a little fragrant. Being tolerably hardy, when the winters are mild, by a little protection in the open air, they will flower profusely; the flowers will be very large, and in bloom from June to October. They are deciduous, soft-wooded shrubs.

Ilex, Holly, of I. aquifotium. There are above one hundred of them in cultivation in Europe, differing in variegation, margin shape, and size of the leares: some are only prickly on the margin of the foliage, others prickly over all the surface. In Europe they are all hardy, but with us few or none of the varieties are so. If they become acclimated, they will be a great ornament to our gardens, being all low evergreen shrubs. The most common and conspicuous varieties are the hedge-hog, striped hedge-hog, white hedge, gold edged, and painted; the flowers are-white and small, berries yellow or red; they do not agree with exposure to the sun. J. Cassine and J. vomitoria have very bitter leaves, and, though natives of Carolina, we have to give them the protection of a green-house. It is said that at certain seasons of they ear the Indians make a strong decoction of the leaves, which makes them vomit freely, and after drinking and vomiting for few days they consider themselves sufficiently purified. (Soil No. 15.)

Illiciums, Anise-seed tree, three species. I. floridànum has very sweet-scented, double purple flowers, and the plant grows freely and systematically if properly treated, and deserves particular attention. I. parvifiorum has small yellow flowers; I. anisàtum is so very like I. parviftorrum in every respect as to make us conclude they are the same, were $I$. anisútum not a native of China, and the other two natives of Florida. When the leaves and capsules of either of them are rubbed, they have a very strong smell of anise; they grow very freely. (Soil No. 1.) 
Indigòferc ; Indigo tree, about twenty species, belong to the green-house, and are chiefly pretty free-flowering shrubs. I. denudàta, I. amæna, I. austràlis, I. angulàta, I. càndicans, and I. filifölia, are very fine; flowers papilionaceous, in long panicles; color various, red, blue, yellow and pink. (Soil No. 6.)

Jacksónias, a genus consisting of five species. The foliage is varied, and all natives of New South Wales. J. scoparia, $J$. hórrida, and J. reticulata, are the finest; the small flowers come out of the young shoots, are yellow and papilionaceous; the pots should be well drained. (Soil No. 6.).

Jambòsa vulgàris or Eugenì jámbos is a splendid evergreen tree, producing a fruit of an agreeable odor and called rose apple. J. australis has a very neat habit, and produces purple fruit; they are of the earliest culture in soil No. 12 .

Jasminum, Jasmine. A few species of this genus are celebrated either for the green-house or rooms, J. odoratissimum, Azorian, has very sweet-scented yellow flowers, blooming from April to November. J. revolitum is the earliest flowering one, and of the same color; it is apt to grow straggling, and should be close pruned as soon as done blooming, which will be in May. J. pubigérum is also yellow. $J$. grandiftorrum is frequently called Catalonian, and should be pruned early in spring to make it bloom well, especially old plants. J. multiflòrum, profuse flowering white. These plants are all perfectly hardy in the Southern States. $J$. officinàle is a hardy climbing plant for arbors, walls, \&e. There are several varieties of it. (Soil No. 3.)

Justicias. Only a few of these belong to the green-house. $J$. carnea is the most splendid, being crowned with its bright rosy pink spikes of flowers nearly the whole year. Give it good large pots, well drained. J. Adhátoda, Malabar-nut. These are the only ones that are worth observation, and are very easily cultivated in any soil.

Kennédias, about twelve species, all beautiful evergreen climbers of the easiest culture, and flower abundantly. $K$. monophylla, blue-flowered, and $K$. rubicúnda, crimson-flowered, are common in our collections. $K$. prostràta, oneflowered scarlet, and $K$. coccinea, many-flowered scarlet, are very pretty. $K$. Comptoniàna has splendid purple flowers, $K$. nigrícans, black flowers, and $K$. spléndens and $K$. marryatta are thought the most superb. They have bright crimson 
Howers, and are yet rare in our collections. The pots should be well drained; flowers are either in racemose spikes or solitary, which is rather too much distinction for the same genus. (Soil No.6.)

Lasiopètalums, only two species. There were a few more, but they are now Thomcisias, plants of no merit whatever in regard to flower; foliage three-lobed, small, rough, and rusty-like. Thomàsai solanácea and $T$. quercifotia are the best species; foliage of the former is large, cordate, and deeply indented; they are all of the easiest culture. (Soil No. 1.)

Laurus. A few species are green-house plants. This genus has been divided to Cinnamòmum; still there are a few celebrated plants in the original. L. nòbilis, sweet bay, though hardy, is kept under protection. It will bear the winter with a little straw covering; notwithstanding, there should be a plant kept in the house in rase of accident by frost or otherwise; there is a variegated variety of it. $L$. indica, royal bay, $L$. foetens, $L$. aggregita, and $L$. glauca, are favorites. There is a species known in our collections as L. scabra. The Camphor tree, known as L. campliòra, is Cinnamomum camphora; the wood, leaves, and roots of this tree have a very strong odor of camphor. It is obtained by distillation from the roots and small branches, which are cut into chips, and put into a net suspended within an iron pot, the bottom of which is covered with water, having an earthen head fitted in it; heat is then applied, and the steam of the boiling water acting upon the contents of the net, elevates the camphor into the capital, where it concretes on the straws, with which this part of the apparatus is lined. They are all fine evergreens (which the name denotes), and easily cultivated. (Soil No. 10.)

Lavaindulas, Lavender. About seven species belong to the green-house, and a few of them very pretty soft-wooded, half shrubby plants, and, if touched, are highly scented. $L$. dentìta has narrow serrated foliage, very neat; $L$. formòsc and $L$. pinnata are desirable; blue flowers on a long spike; should be kept near to the glass; they are of the easiest culture. (Soil No. 7.)

Lechenailltia; four species of pretty dwarf blooming plants. $L$. formòsa is almost always a picture with its bright scarlet flowers and heath-like foliage, and ought to be in every col- 
lection; L. Zilòba and L. Drummóndii are both blue, though very rarely seen in bloom; fine plants two years old with us have not yet shown a flower; they must have an airy situation, and near the front glass; otherwise they will be weak and spindling. (Soil No. 19.)

Leonòtis, Lion's-ear, four species. They have very fine scarlet tubular. fiowers, orifice-toothed. They come out in large whorls, and look elegant; but neither plant nor foliage has an agreeable appearance. They are of the easiest culture. $L$. intermedia and $I$. Leoniorus are the best flowering species. (Soil No. 7.)

Leptospérmuns, about thirty species, all pretty $\mathrm{New} \mathrm{Hol}-$ land evergreen dwarf shrubs, with small white flowers. $L$. baccítum, L. péndulum, L. juníperinum, $L$. ovátum, $L$. stellètum, L. grandiflorum, and L. scoparium, are the best of the species. The latter was used as tea by the erew of Captain Cook's ship. It is an agreeable bitter, with a pleasant flavor when fresh. When young plants are growing, they ought to be frequently topped to make them bushy, and kept in an airy situation, or they will be drawn and unsightly. They are of very easy culture. (Soil No. 1.)

Lencadéndrons, Silver tree, above forty spesies, all natives of the Cape of Good Hope. They are evergreens, with handsome silvery-like foliage. L. argentéum (once Pròtas argentéa) is a great beauty; foliage white, lanceolate and silky. It is a plant that has been long in cultivation, greatly admired, and much sought for, and is the finest of the genus. L. squarròsum, L. stellàtum, (once Pròtea stellàris.) L. tortum, L. serviceum $L$. marginàtum, and L. plumòsum (once $P$. parviflora, are all fine species. The pots must be well drained and the plants never over-watered. They are very desirable in collections for their beauty of foliage. (Soil No. 9.)

Iencospérmums, about eighteen species of Proteacous plants, chiefly low growing, and are mostly downy or hairy; flowers yellow, in terminal heads. L. formósum, L. grandiflòrum, $L$. tomentósum, and $L$. candícans, rose-scented. These are fine species. For treatment, see Prôteas. (Soil No. 9.)

Linums, flax, two or three species are very fine, and flower freely. L. trigynum has large yellow flowers in clusters, and L. ascyrifotium, whose flowers are large, blue and white, and in long spikes. They bloom in February; the shape of then 
is very like the flower vulgarly called Morning-glory. (Soil No. 4.)

Liparias, about five species, much esteemed for their beauty of foliage; leaves ovate, lanceolate, downy or woolly; flowers yellow, leguminose and capitate. L.sphærica, L. tomentósa, $L$. villósa and $L$. sericea, are the finest. $L$. vistita and $L$. villósa are the same, although put in many catalogues as different species. None of them ought to be much watered over the foliage, as it adheres to the down, and causes the young shoots to damp off. Drain the pots well, and keep the plants in an airy situation. (Soil No. 6.)

Lobètias. Several of them, when well treated, form pretty flowering plants; they are principally herbaceous. The genus consists of about eighty species; seventy of them are exotics; many of them natives of the Cape of Good Hope, with little flowers of brilliant colors. L. cærrìtea, L. T'hunbérgii, $L$. corymbòsa, L.pyramidalis, L. érines, and L. illicìfolia, are very fine species, of weak growth, but flower freely. (Soil No. 4.)

Lonicerc japónica. There is a plant in our collections known by that name, which is now Nintoóa longiflora; flowers of a straw color, but come out white. It has been known to withstand the winter, but does not flower, and is frequently killed entirely; is a fine climber, and much esteemed in the south for its fragrance. (Soil No. 3.)

Lophospérmum scándens. This is a magnificent climbing soft-wooded shrub, with rosy purple, campanulate flowers, which are produced from the axils on the young wood; they bloom from May to September; leaves large, cordate, and tomentose; grows rapidly, and flowers abundantly. (Soil No. 3.)

Lychnis coronàta is an esteemed Chinese plant; flowers in abundance, pentapetalous, large, and a little indented at the edges; color a red-like orange; flowers terminal and axillary. A good method of treatment is to divide the roots, and plant some of them in the garden; they will flower well, and could be lifted in the fall, and put under protection. If not done so, plant them in four-inch pots, and repot them into those of six-inch in May. Do not expose them while in flower to the mid-day sun, for it will deteriorate the fine orange color. (Soil No. 9.)

Lysinènas, four species, closely allied to Epácris. In 
every respect treatment the same. L. pentapitalum, L. conspicum, and $L$. ròseum, are the best; the flowers of the former two are white. (Soil No. 6.)

Magnotias. There are four species that require the protection of our green-houses; all the others are hardy. $M$. fuscàta and M. annonæfolica are very similar in foliage and flower; the young branches and leaves of $M$. fuscaita are covered with a brown, rusty-like down; the other by some is considered merely a variety; flowers small, brown, and very sweet-scented. IM. pumila is very dwarf-growing; leaves large and netted; flowers semi-double, white, pendent, and exceedingly fragrant. 'They are natives of China. We have several others from the east, but being deciduous are perfectly hardy. M. odoraíssima, now Talduma Condólii, is a native of the Island of Java, and considered odoriferous, but it is very rare even in Europe; said to have a strawcolored flower. (Soil No. 9.)

Mahèrnia; a genus of dwarf plants, with yellow, orange, or pink flowers. $M$. odorata is extensively cultivated for the fragrance of its bell-shaped blossoms, that hang in great profusion early in spring. Foliage small, crenulated, and heart-shaped. (Soil No. 17.)

Manèttia; a genus of pretty climbing plants, producing a profusion of scarlet flowers, especially M. glabra, (of Don), or cordifolia (of Paxton), which is a complete mass of flowers from July to October, and is a lovely object when turned into the borders during the summer. $M$. bicólor, red and yellow, blooms through the winter, and is a charming climber in that dull period of flowers; they are of the easiest culture in soil No. 17.

Melalèucas, above thirty species, and a beautiful genus of New Holland plants, of easy culture; flowers come out of the wood-like fringes. $M$. ellíptica, $M$. fuilgens, scarlet, $M$. decussàta, $M$. hypericifòlia, $M$. squarrósa, M. linarifólia, M. incána, M. tetragonia, $M$. thymifólia, are all very fine species, and flower freely if they have been grown from cuttings; the singularity of flower and diversity of foliage make them generally admired. (Soil No. 1.)

Melástoma nepalènsis is a good green-house species, flowering freely during winter, of a pale blush color, and is of the easiest culture. As soon as done blooming, the plant should be well cut in to keep it into shape. (Soil No. 1.) 
Méspilus. See Eryabotrya.

Metrosidèros, about fifteen species. Many have been added to Callistèmon. M. fiòrida, M. umbellàta, and M. angustifòtia, C. satignum, C. lanceotàtum, C. semperfòrens, $C$. ylaìcum, once M. speciòsa, and C. formòsum; these are.all beautiful plants, with scarlet flowers. Other two beautiful species with white flowers have been given to Angophóra. $A$. cordifòtia, once $M$. hispida, and A. lanceolata, once III. costata; these genera are very easily distinguished from any other Australasian shrubs, by the peculiar character of having both sides of the leares alike. The flowers consist of stamens, stiles, and anthers, coming in hundreds out of the young wood for the length of three or four inches, forming a dense cone crowned with a small twig; hence frequently called "bottle brush plant;" learing capsules in the wood, which will keep their seeds perfect for a great number of years. They grow freely, and the pots should be well drained. (Soil No. 1.)

Myrsines, Cape Myrtle, dwarf cape evergreen shrubs covered with small flowers from March to May. M. retissa has purple flowers; II. rotundifolia, flowers white and purple. They will grow in any situation, and are of easy culture. (Soil No. 1.)

Myrtus, Myrtle, is a well-known and popular shrub, especially the common varieties, and was a great farorite (even to adoration) among the ancients. It was the mark of authority for Athenian rulers, and is among the moderns an emblem of pre-eminence. They are elegant evergreen shrubs with an agreeable odor. M. commùnis multiplex, double flowering, is a very neat shrub, and flowers abundantly. $M$. communis, ใeucocárpa, white-fruited myrtle. M. itálica variegáta, striped leaved; M. itálica maculàta, blotch-leaved, are very fine shrubs; and M. tomentòsa, Chinese myrtle, is a magnificent erect-growing shrub, with a white down over the foliage; the flowers are the largest of the genus. When they first expand they are purple, and afterwards change to white, so that there are beautiful flowers of several shades of color on the plant. We have not the smallest doubt but this species will become, in many instances, as plentiful as the common myrtle. It is more easily grown, but cannot stand much exposure to the sun in summer. M. tenuifolia is a very fine plant, and a native of $\mathrm{New}$ South Wales. Myrtles in general 
should be sprinkled with water in the evening, to keep off the red spider. (Soil No. 11.)

Nandina doméstica, a very hardy species, and a popular shrub in the gardens of Japan, where it is called Nandin. It has supra-decompound leaves, with entire lanceolate leaflets, a kind of foliage that is very rare; the flowers are small, whitish-green, in panicles, succeeded by berries of the size of a pea; drain the pots well. (Soil No. 1.)

Nèrium (Oleander) is a genus of beautiful erect-growing evergreen shrubs, of the easiest culture, and abundant in flower. $N$. oleander is the common rose-colored single flowering species, from which many varieties have originated. At present the most popular is $N$. oleander spléndens, which has a double rose-colored flower, $N$. o. striáta $f$. pl. has doubled striped flowers. $N$. macróphyllum has very large double pink flowers. N. o. raginót, or tanglè, has deep crimson flowers striped with white, though they are frequently of a pink color. N. o. purpùrea, dark red. - There is one that has got into our collections as double white, which is only semi-double. $N$. oleánder elegantíssimum, a most beautiful plant with deep silver-edged foliage; and the young wood is striped white and green. There are likewise single yellow, single white, and single blotched varieties of $N$ oteánder. They are subject to the small white scaly insect, and should be frequently washed, as has been directed, to kecp it off. (Soil No. 12.)

Oleas, Olive, about trielve species and rarieties. O. Europcea longifolia is the species that is cultivated to such an extent in the south of France, and Italy. O. Europcea latifotia is chiefly cultivated in Spain. The fruit is larger than that of Italy, but the oil is not so pleasant, which is obtained by crushing the fruit to a paste, and pressing it through a woolen bag, adding hot water as long as any oil is yielded. The oil is then skimmed off the water; and put into barrels, bottles, \&c., for use. The tree seldom exceeds thirty feet, and is a branchy, glaucous evergreen, and is said to be of great longevity. Some plantations at Turin, in Itlay, are supposed to have existed from the time of Pliny. It frequently flowers in our collections, but seldom carries fruit; flowers white, in small racemose axillary spikes. $O$. capénsis has thick large oblong foliage; flower's white in large terminal panicles. O. verrucòsa, foliage flat, lanceolate, and 
white beneath, branches curiously warted. O. fragráns blooms in winter; foliage and blossoms are both highly odoriferous; the plant is much esteemed in China, and is said to be used to adulterate and flavor teas. Leaves are elliptic, lanceolate, and a little serrated; flowers white in lateral bunches. It is subject to the small white scaly insect, and ought to be carefully kept from them by washing. $O$ rósea has pink flowers. O. paniculata is also a fine species. They are all very easily cultivated. (Soil No. 11.)

Oxylobiums, seven species, plants very similar to Callistachys, with ovate, cordate, light-colored, pubescent foliage, with papilionaceous flowers. O. obtusifölium has scarlet flowers; O. retùsum, orange flowers; and O. ellípticum, yellow flowers. They grow freely, and should be well drained; flower from May to August. (Soil No. 6.)

Passiflóra; a celebrated genus of climbing plants, called in common "Passion Vine." Those belonging to the greenhouse flower during summer. Several of them are both beautiful and profuse in bloom, especially $P$. Kermósine, $P$. princèps, $P$. hybrìda, $P$. fragrans, P. Newmannia, P. Lemochentziana, and are very distinct species; the former is of a beautiful rosy crimson color. (Soil No. 13.)

P'elargòniums, Stork's Bill. This genus, so universally known among us as Gerànium, from which it was separated many years ago, is a family of great extent and variety, for which we are principally indebted to the Cape of Good Hope. There are many hundred species, with upwards of twelve hundred beautiful and well-marked rarieties, which have been obtained from seed. They are of every character, color and shade, of the most vivid description. The easy cultivation of the Pelargònium tribe, or Gerinniums, as they are commonly called, has rendered them very popular; also the agreeableness of scent and fragrance, of which many of them are possessed, makes them favorites.

Their flowering season is also of considerable duration, especially the bright scarlet and crimson varieties, which bloom from March till August, rendering them quite indispensable in collections. Some growers complain of their straggling habits; but it is only those that do not know how to prune them: even some of the choice kinds of the present day could not be made to grow irregularly-such as Perfection, King, Mary, Margaret, and others; indeed, within these few 
years, the habits and beauties of the plant are improved a hundred-fold, and those who are only acquainted with the old sorts would be transported with a view of the dazzling and beauteous colony of the new kinds that have been procured by hybridizing those of good habit and character.

The best method to adopt in impregnating these is to choose the female, one that has large flowers, of easy cultivation, and as nearly allied in character and other habits as possible. When a flower of the intended female is newly expanded, take a pair of very fine-pointed scissors, and cut off the anthers before the pollen expands; then, as soon as the summit of the stile divides, apply the pollen taken from the anthers of the intended male plant on a very fine camel hair-pencil, or cut out the stigma entirely, and place the anther on the summit of the stile, which if correctly done will have the desired effect. As soon as the seed is ripe, sow it in light sandy soil; and when it has come up, take care not to over-water the soil, which would cause them to damp off. When they are about one inch high, put them into small pots, and treat as the other varieties. Have them all distinctly marked until they flower, which will be in the second year from the time of sowing

The tuberous and fleshy stemmed species are very interesting to the discriminating inquirer. Their habit and constitution are so peculiar that we have frequently wondered that they have not been separated into distinct genera. The cultivation of them is more difficult, water being very prejudicial to them when they are inactive. If they are well managed, they flower beautifully, and the color's are very superior and peculiar, having frequently bright green and purple in the same flower.

The following list comprehends the most desirable varieties that we have seen:- 
PURE WHITE,

MARKED OR STRIPED WITH RED, PURPLE, OR CRIMSON.

Alexandrina,

Desdemone,

Cecilia,

Lord Warden,

Pearl,

White Flag,

Queen of Scots,

Witch.

\section{BLUSH,}

MARKED OR STRIPED WITH RED, \&c.

Acme,

Bell of Ware,

Cyrus Superb,

Juliette,

Miss Percival,

Queen of Fairies,

Miss Holford.

\section{PINK,}

MARKED OR COLORED WITH RED OR CRIMSON.

Admiration,

Bella,

Blood Royal,

Captivation,

Hebe's Lip,

Matilda,

Nestor.

\section{ROSE,}

WITH STRIPES OR SPOTS.

Celestial,

Gigantea,

Hebe,
Hector,

Mrs. Brooks,

Mark Anthony,

Rosy circle,

South Western.

\section{RED OR SCARLET,}

WITH STRIPES OR SPOTS.

Aurora,

Agrippina,

Brutus,

Chieftàin,

Duke of Cornwall,

Emperor,

Forget-me-not,

Lady Napier,

King,

Perfection,

Orion,

Shield of Achilles,

Star of the West.

\section{FANCY COLORS}

OF VARIOUS SHADES.

Anais,

Madam Meilez,

Ytolmshii.

VERY DARK CRIMSON, OR PURPLE,

MARKED WITH BLACK.

Ajax, (purple,)

Arabian,

Lady Macbeth,

Nustii,

Negress,

Seline,

Sir Walter Raleigh,

Sir Henry Smith,

Salamander. 
VARIOUS, CURIOUS AND FINE

Bipinnatifidum, SORTS.

Comptonianum, Echinatum,
Maculatum, Sanguineum, Tricolor, Tricolor major.

There are several others very recently introduced, which have not bloomed so as to allow us to judge of their merits; but their foreign characters are highly flattering. The repotting of the geranium tribe should be done as early in the month as possible, or even about the end of last month would be advisable in some seasons. (Soil No. 12, with a little more manure.)

Phórmium tènax, New Zealavd flax lily, the only species; foliage resembling an Iris, and very thready. In New Zealand and Norfolk Island the natives manufacture from this plant a kind of stuff like coarse linen, cordage \&c.; the plant is very hardy, and we would be nowise surprised to see it stand the severity of our winters. It bears exposure to the open air in Europe in the fifty-sixth degree of north latitude. The flowers are said to be yellow and lily-like; of the easiest culture. (Soil No. 7.)

Phylicas, above twenty-five species. Several of them are very pretty-growing evergreen shrubs, and of easy culture. $P$. horizontális, $P$. squarrósa, $P$. imbricàta, $P$. myrtifòtia, $P$. callòsa, $P$. bícolor, and $P$. ericoides, are all neat growing; flowers small white, in heads: drain the pots well, and keep. them in an airy situation. The foliage of several of the species is downy. (Soil No. 6.)

Phascólus caracálla, or snail-flower, is a very curious blooming plant, with flowers of a greenish yellow, all spirally twisted, in great profusion when the plant is well grown. (Soil No. 12.)

Phoenix dactylifera, common date palm; a plant that attains a large size and of rather a rugged appearance; its fruit is the common well-known date. (Soil No. 12.)

Pimileas, about fourteen species. Nost of them are highly esteemed, and are not often seen in our collections. $P$. decusstata is the finest of the genus, both in foliage and flowers, which are red, and in large terminal clusters; $P$. hispìda, P. ròsea, P. linifolia, $P$. spicàta, and $P$. spectabilis, are all fine species. The latter has rery beautiful lanceo- 
late foliage and of an elegant habit. They should be well drained. They are very small evergreen shrubs, with white, red, or pink flowers. (Soil No. 6.)

Pistàcias, seven species of trees, principally of the south of Europe. There is nothing particular in their appearance, except their productions in their native country. P. terebinthus is deciduous, and produces the Cyprus turpentine. $P$. lentiscus is the true mastich tree, which is obtained by cutting transverse incisions in the bark. P.vera, P. reticulata are good species; leaves pinnated; leaflets ovate, lanceolate; easily cultivated. (Soil No. 2.)

Pittósporums, about nine species, with handsome foliage, and small white flowers in clusters, which are fragrant. $P$. tobira is a native of China, and nearly hardy; leaves lucid, obovate, obtuse and smooth; there is a beautiful variegated variety of it. $P$. undulàtum, $P$. coriàceum, $P$. revolìtum, $P$. fúlvum, and $P$. fermigineum are very ornamental evergreens, and will grow with the most simple treatment. (Soil No. 13.)

Platylobiums, Flat Pea, four species of fine free-flowering plants, flowers leguminose; color yellow. $P$. formòsum, $P$. ovatum and $P$. triangulàre are the best; the foliage of the former two is cordate ovate; the latter hastate, with spiny angles. (Soil No. 6.)

Plumbagos, Lead-wort. The two most beautiful species for green-house culture are $P$. capensis, of a beautiful light blue, flowering in spikes from June to December; foliage pale green, oblong, entire, and glaucous-P. Larpania, Lady Larpant's Leadwort, is of a very dwarf habit, small dark greenish-brown foliage, crowned with flowers of the finest azure blue, and is tolerably hardy in the open ground; in fact, they are both perfectly hardy in the Southern States. (Soil No. 1.)

Podalyrias, about fourteen species of pretty Cape shrubs; foliage oblong, obovate, and silky-like; the flowers leguminose; color blue or pink. $P$. sericea, $P$. stiracyfotia, $P$. coríscans, $P$. argentea, $P$. liparioídes, and $P$. subiflòra, are the finest and most distinct species, and flower abundantly. (Soil No. 6.)

Pròteas, about forty-four species. The foliage of this genus is very diversified; flowers very large, terminal; stamens protected by an involucrum, many-leaved and imbricated; 
which is very persistent. $P$. cynaroides has the largest flower, which is purple, green, and red. P. speciosa, $P$. umbonàtis, once $P$. longifölia, $P$. melateùca, $P$. grandifiòra, $P$. coccinea, $P$. cenocárpa, $P$. pallens, $P$. formòsa, P. magnifica, $P$. speciòsa rubra, and $P$. mellifera, will afford a very good variety. It is almost impossible to describe their true color, it being so various; red, white, straw, brown, green, and purple, are most predominant, and frequently to be seen the same flower. The plants must be well drained; and during warm weather be careful that they are not neglected in water, for if they are suffered to droop, they seldom recover. For this reason the pots ought not to stand in the strong sun; the plants can bear it, but to the roots it is injurious. (Soil No.9.)

Pultenæus, about forty species, pretty little dwarf-growing shrubs of New South Wales; flowers small, leguminose, ali yellow with a little red outside of the petals. $P$. subumbetlàta, $P$. villosa, $P$. obcordàta, $P$. argéntea, $P$. plumòsa, $P$. flexiiis, shining-leaved, fragrant; $P$. càndida, and $P$. strìcta, are all fine species, and esteemed in collections. The leaves are all small; they require an airy exposure, and the pots drained. (Soil No. 6.)

Rhodochiton volubile, or Lophorspérmum rhodochiton: this is a very fine climbing plant, with large tubular dark brown flowers, blooming from July to October; it is of rapid growth, and is an excellent plant for the fiower-garden. The plant must have frequent repotting to make it grow rapidly, for the finer it grows the more profusely it flowers. (Soil No. 12.)

Rhodorléndrons, (Rose tree,) a magnificent genus, and contains some of the most sûperb and gigantic plants that adorn the green-house. At present the most admired is $R$. arbòreum, with its varieties. It has deep crimson flowers, with dark spots and flakes canmpanulated, and in large clusters; leaves lanceolate, acute, rough and silvery beneath. $R$. arbòreum albrim is very rare. $R$. arbòreum superbum, flowers same shape as arbòreum, color bright rosy scarlet; foliage one-third larger, but not silvery beneath; grows freely, and generally thought the finest variety. R. arborea altaClàrence is also very superb. R. arbòrea Russetianum, pictum, venústum, guttátum, tigrínum noblcánum, grandifiòrum, spectálite, are all very distinct; but there are so many other varieties from seed that they will soon be so 
much amalgamated that the named sorts will not be distinguished. A green-house without some of the choice varieties of this plant is deficient of a flower whose beauty and grandeur are beyond the highest imagination. It is a native of Nepaul, in India, and when found by Dr. Wallach, awakened the ambition of every cultivator and connoisseur in Europe.* There are several other species lately brought from that country, which are highly valued: the species are $R$. campanulatum, $R$. anthopoyon, and $R$. cinnamomum. They are rarely seen in our collections, but a few years will make them more plentiful. Their beauty of flower is beyond description. The pots should be well drained, and if they are large, put several pieces of sandy stone or potshreds around the side, for the fine fibres delight to twine about such, being mountainous plants. When growing, give copious waterings at the root. For young plants, soil No. 6. And for blooming plants, use one portion of leaf mould.

Roéllas, pretty leafy shrubs, with blue terminal funnelshaped flowers, lip-spreading; $R$. cilliàta, $R$. spicàta, and $R$. pectunculata are the finest of the genus. The pots must be well drained, and care taken that they are not over-watered. (Soil No. 6.)

Sálvia (Sage) is an extensive genus of soft-wooded, shrubby, or herbaceous plants; very few of them do well in the green-house, and many of them are very trifling, having no other attraction than the flower; and those of the tender species, when compared with S. fúlgens, crimson, S. splèndenis, scarlet, S. angustifólia, pale blue, S. pátens, dark blue, S. involucrata, pink (which in artificial climates constitute the standard of the genus), are not worth cultivation. The best method to adopt with the summer flowering kinds is to plant them in the garden in May : they will grow strong and flower abundantly, and in the fall they can be lifted, and preserved during winter in pots. They neither grow nor flower so well as when planted out, and even a slip planted in the ground in moist weather will root in a few days, grow, and flower in a few weeks. S. splèndens is the best to select for the purpose. All will grow easily with encouragement. (Soil No. 12.)

* Mr. Hogg, the eminent horticulturist of New York, raised the first plant of arboreum from seed in England. 
Scottias, three species of valuable plants; S. dentita, with rosy leguminose blossoms; leaves opposite, ovate, acuminate, serrate; $S$. angustifólia has brown fiowers; $S$. trapeziformus, leaves ovate, acute, serrulate. We do not know the color of its flowers; the pots must be well drained, and the plants kept in the warmest part of the green-house, and near the light. (Soil No. 6.)

Senècios. Some species of this genus are pestiferous weeds all over the world. They are even found near the limits of perpetual snow, where neither tree nor shrub is able to rear its head, and yet there are a few species that are neat little plants, and are worthy of a situation, namely, S. grandiflòrus, S. venusisus, and S. cineráscens, with the double white, purple, and red variety of $S$. élegans. The last three varieties are free flowering, but if allowed to grow several years, they become unsightly. Being very easily propagated, a few cuttings of them should be put in in September, and in two weeks they will strike root, when they may be put in pots to keep through the winter, and then planted in the garden, continuing to renew them. The other mentioned species should be frequently done the same way. Do not keep them damp during winter, or they will rot off. Give them an airy exposure. (Soil No. 12.)

Sóllya heterophylla: a good climbing plant, with bright blue clusters of drooping flowers; it is a native of New Holland, and will prove a hardy plant south of latitude $36^{\circ}$. (Soil No. 4.)

Sparrmánnias are strong-growing green-house shrubs. S. Africana is a plant very common in our collections, with large three-lobed cordate leaves, hairs on 'both sides; flowers from March to July. S. rugósa. The leaves are rugged; flowers of both are white, in a kind of corymb, supported by a long footstalk; buds drooping, flowers erect. There is a plant known in our collections as the free flowering Sparrmánnia (which is Entètia arboréscens), and is easily distinguished from Sparrmánnia by the leaves being cordate, acuminate, and otherwise, by all its filaments being fertile, and the flowers more branching, and blooming from November to June, profusely; very easily cultivated, and desirable. (Soil No. 12.)

Sphcerolobiums, only two species of leafless plants, with yellow and red leguminose flowers, which proceed from the 
young shoots. S. vimineum and S. medium. They flower freely, and are easily cultivated. The old wood should be frequently cut out where it is practicable. Drain the pots. (Soil No. 6.)

Sprengétia incarnàta, the only species, a very pretty plant, allied to Epacris; foliage acuminate, embracing the stem; flowers small, pink, bearded, and in close spikes; grows freely. The pots must be well drained, and the plants, when dormant, watered sparingly; for if they get sodden about the roots, they very seldom recover. (Soil No. 6.)

Strelitzia, or queen plant: a genus of fine plants belonging to the natural order of IIrsacea. S. regina, S. ovaita, and $S$. humilis are the most free and beautiful flowering species, and are very similar, except in habit. The flowerstalks is from one to two feet long, producing about five flowers of a bright yellow, having a large blue stigma, which forms a distinct contrast. $\quad S$. júncec and $S$. parviflòra are also desirable species, but are more rare than the former, which ought to be in every green-house. (Soil No. 19.)

Streptocarpus rhéxii, a free-blooming dwarf plant, of easy culture in soil No. 4.

Stylidium, six species of pretty little plants, with small linear leaves, and remarkable for the singular elasticity of the style or column, which, when the flower is newly expanded, lays to one side, and, on being touched with a pin, starts with violence to the opposite side. S. graminifotium, S. fruticòsum, S. lancifòtium, and $S$. adncitum, are all freeflowering; flowers in spikes, very small; color light and dark pink; blooms from April to July. S. adnatum is half herbaceous, and should, when growing, be kept nigh the glass, or it will be drawn, and the flowers become of a pale color. They are all of easy cultivation. (Soil No. 10.)

Styphètias, seven species of very showy flowers, with mucronate leaves; corolla in long tubular form, having several bundles of hairs in it; segments reflex and bearded. $S$. tubiflòra, crimson; S. triflòra, crimson and green; S. adscéndens, and S. longiflora, are beautiful species. They grow freely, and should be well drained, as too much water is very hurtful to them. In summer, they ought not to be much exposed to the hot sun, or the foliage will become brown. (Soil. No. 6.) 
Sutherlàndia frutèscens, very similar to Swainsònia; flowers fine scarlet. (Soil No. 2.)

Swainsònias, four species of free-flowering, soft-wooded shrubs, natives of New South Wales. 'S. galegifolia, $S$. coronillaxfòlia, and S. astragalifòtia, are red, purple, and white; leguminose flowers in spikes from the axils, are of easy culture and deserving of a situation; the foliage is pinnate; leaflets ovate, acute. (Soil No. 2.)

Tecòma is a genus of beautiful flowering plants, separated from Bignònia. They are of easy culture and desirable in all collections. T. capénsis has bright orange flowers in large clusters, and very profuse on large plants. T. austràitis, known as Bignònia pandòra, has white and pink flowers in great profusion. T. jasminóides is quite a new plant, producing very large clusters of white flowers with a bright pink centre; it is a charming plant for climbing, and the foliage is of a very agreeable shining green. The plants require encouragement. (Soil No. 10.)

Telopèa speciosissimus is the only species, and was once called Embóthrium speciosissimus. It is now called Telopèa, in allusion to the brilliant crimson flowers, which from their large size are seen at a great distance, and which render it one of the most conspicuous productions of New South Wales. The leaves are oblong, deeply toothed, veiny, and smooth; wood strong; flower ovate, connate, and terminal, and of considerable duration. There ought to be a specimen of it in every collection. The pots must be well drained, and the plant in the extreme heat of summer not too much exposed to the sun. Very scarce. (Soil No. 19.)

Testudinària, Elephant's foot, or Hottentot's bread, two species remarkable for their appearance. The root or bulb, if it may be so called, is of a conical shape, and divided into transverse sections. Those of one foot diameter are computed to be one hundred and fifty years of age. It is a climbing herbaceous plant, with entire reniform leaves of no beauty; flowers small; color green. The pots must be well drained, for when the plant is inactive, it is in danger of suffering from moisture, and ought not to get any water. $T$. elephantipes and T. montana are the species, natives of the Cape of Good Hope, and require the warmest part of the house. (Soil No. 10.)

Thea: a genus celebrated over the known world as fur- 
nishing the domestic drug called Tea. T. viridis, and $T$. bohèa are said to be the species which supply the tea. Some have asserted that there is only one shrub used, but by examination it may be easily perceived that there are leaves of various shape and texture, some of them similar to Camellia sesanqua. Dr. Abel gives an explicit detail of the growing and manufacturing process of tea, from which, in compliment to our fair patrons, we give a few extracts:

"The tea districts of China extend from the twentyseventh to the thirty-first degree of north latitude. It seems to succeed best on the sides of mountains. The soil from which I collected the best specimens consisted chiefly of sandstone, schistus, or granite. The plants are raised from seeds sown where they are to remain. Three or more are dropped into a hole four or five inches deep; these come up without farther trouble, and require little culture, except that of removing weeds, till the plants are three years old. The more careful stir the soil, and some manure it, but the latter practice is seldom adopted. The third year the leaves are gathered, at three successive gatherings, in February, A pril, and June, and so on until the bushes become stunted or slow in their growth, which generally happens in from six to ten years. They are then cut in to encourage the production of fresh roots.

"The gathering of the leaves is performed with care and selection. The leaves are plucked off one by one: at the first gathering only the unexpanded and tender are taken; at the second those that are of full growth; and at the third the coarsest. The first forms what is called in Europe imperial tea: but, as to the other names by which tea is known, the Chinese know nothing; and the compounds and names are supposed to be made and given by the merchants at Canton, who, from the great number of varieties brought to them, have an ample opportunity of doing so. Formerly it was thought that green tea was gathered exclusively from 7 . viridis; but that now is doubtful, though it is certain that there is what is called the green tea district and black tea district; and the varieties grown in the one district differ from those of the other. I was told by competent persons that either of the two plants will afford the black or green tea of the shops, but that the broad thin-leaved plant ('I'. viridis) is preferred for making the green tea.

"The tea leaves being gathereu, are cured in houses which 
contain from five to twenty small furnaces, about three feet high each, having at top a large flat iron pan. There is also a long low table covered with mats, on which the leaves are laid, and rolled by workmen, who sit around it : the iron pan being heated to a certain degree, by a little fire made in the furnace underneath, a few pounds of the fresh-gathered leaves are put upon the pan; the fresh and juicy leaves crack when they touch the pan, and it is the business of the operator to shifit them as quickly as possible, with his bare hands, till they cannot be easily endured. At this instant he takes off the leaves with a kind of shovel resembling a fan, and pours them on the mats before the rollers, who, taking small quantities at a time, roll them in the palms of their hands in one direction, while others are fanning them, that they may cool the more speedily, and retain their curl the longer. This process is repeated two or three times, or oftener, before the tea is put into the stores, in order that all the moisture of the leaves may be thoroughly dissipated, and their curl more completely preserved. On every repetition the pan is less heated, and the operation performed more closely and cautiously. The tea is then separated into the different kinds, and deposited in the store for domestic use or exportation.

"The different sorts of black and green arise not merely from soil, situation, or the age of the leaf; but after winnowing the tea, the leaves are taken up in succession as they fall; those nearest the machine, being the heaviest, are the gunpowder tea; the light dust the worst, being chiefly used by the lower classes. That which is brought down to Canton then undergoes a second roasting, winnowing, packing, \&c., and many hundred women are employed for these purposes."

Kæmpfer asserts that a species of Camellia as well as Olea Fràgrans is used to give it a high flavor.

T'acsònia, a genus of plants much resembling Passifloras both in flower and habits. T. pinnatistipulata and T. mollis, when planted into the ground and trained up the rafters of the green-house, make a pretty appearance with their profusion of rosy blush-colored flowers. (Soil No. 13.)

Tropæólum, a genus of generally delicate-growing plants, principally from South America. They require nicety of treatment to bloom them well, unless a large bulb can be procured, when it may be planted in a seven-inch pot, and "ill then flower without farther care by training their deli- 
cate shoots on a wire trellis, or small twigs of branches stuck in the pots. T. tricolorìm, T. tricolorum supérbum, and T. pentaphyllum have beautiful scarlet flowers marked with yellow and black, and are superb and lovely when in bloom. T. brachyseras has yellow flowers. (Soil No. 10.)

Verbena. The beauty of the green-house in spring and the flower-garden in summer is greatly augmented by the late introduction of this lovely family of perpetual flowering plants. There are among them every shade of color, from the richest scarlet to the purest white, and, in addition to the beauty and profusion of their flowers, several of them are exquisitely scented. $V$. chamæidryfolia, or melindres, was the first scarlet species introduced, and it is yet pretty. $V$. bicolor grandiflora, scarlet erimson eye. V. Blue Queen, fine blue; V. Beauty, rose; V. Feastii, large; white fading to lilac; $V$. Beauty supreme, beautiful large rose; V. Mestonii, bright scarlet; $V$. Queen, pure white; $V$. Polkii, very dark purple crimson; $V$. perfection, purple; $V$. Wilsonii, bluish purple; V. Nymph, beautiful pink; V. Triumph, very dark crimson.

Robeson's Defiance, the best scarlet; Buist's Perfection, the best sweet-scented lilac.

These are principally new varieties, of perfect formation; the flowers in many are as large as a dime, far outvieing those cultivated a few years ago. It is only twelve years since I grew the first white, pink and crimson verbena, from seed received from Buenos Ayres. They created a very great excitement in the Floral world, both in this country and Europe. Now there are thousands produced from seed annually. In England, they bear the titled name of Ladies, Marquesses and Queens, commanding a very high price; but with all their titles, none of them excel a few of those named above. They require very little water during winter, and should be kept on a dry airy shelf till February, when the pots may be enlarged except those intended for the garden, which can be planted out about the middle of April. Cuttings of the young shoots, placed in sandy soil and covered with a glass, will root in a few weeks. The whole family should be industriously collected and cultivated; for truly we are not acquainted with a tribe of plants that will give as much satisfaction with as little cost and trouble: they naturally 
grow on hills and elevated plains, so that they must not be kept wet. (Soil No. 9.)

Verónica, an extensive genus of plants that are cultivated isirgely as ornaments for the flower garden. Within these few years some very beautiful species have been discovered in New Zealand. Among them is $V$. speciósa, a picture of a plant with foliage equal to a Camellia, producing spikes about three inches long, of bright purple flowers, fading to a pale blush. $\quad V$. Lindleyana, with ovate lanceolate leaves, and spikes of delicate blush flowers; blooming in winter. They are of the simplest culture-growing freely and symmetrically in soil No. 9 .

Viminciria denuctuta, the only species. This plant is remarkable for its twiggy appearance, but it has no foliage, except when growing from seed. It has at the extremity of the twigs or shoots an ovate, lanceolate leaf, disappearing when the plant grows old; the flowers are small, yellow, coming out of the young shoots, to the astonishment of the beholder. It grows freely. (Soil No. 6.)

Viburnums. A few of these are very ornamental evergreen shrubs, and almost hardy. $\quad V$. tìnus is the well-known Laurestine, (or what is commonly called Laurestinus,) is of the - easiest culture; flowers small white, and in large flattened panicles; blooming from February to May, and universally esteemed. It will stand the winter by a litle protection, but the flower buds being formed in the fall, the intense frost destroys them; consequently, it will not flower finely, except it be protected from severe frost. $V$. lùcidum is a good species, and superior in flower and foliage to the former, but does not flower so freely when the plants are small. When they grow large, they flower profusely. There is a desirable variegated variety. $V$. odoratíssimum has smooth, evergreen, oblong elliptic, distinctly toothed leaves, and frequently a stripe in them, is sweet-scented, but not a free flowerer. $V$. hirsuitum has flowers similar to the above; foliage ovate, with rough brown hairs on both sides, and very characteristic. $V$. strictum variegàtum is a very fine variety, and upright growing. These plants are all very desirable, blooming early a spring, and continuing for several months; all easily culvated. (Soil No. 17.)

Westringias, a genus of four species, very like the common iosemary. W. rosmariniformis, leaves lanceolate, and sil- 
very beneath. $W$. longifolia is similar; both have small silvery white flowers, and are easily cultivated. (Soil No. 2.)

Witsènias, four species. W. còrymbòsa is a plant that has stood in high estimation ever since it was known, but, unfortunately, there is a very inferior plant. Aristèa cyanea got into our collections under that name. The panicles of $W$. corymbòsa are quite smooth; those of Aristèa are hairy, which is itself sufficient to detect them; but otherwise the appearance of $W$. corymbòsa is much stronger and more erect growing, not inclining to push at the roots so much as Aristea. The foliage is lanceolate and amplexicaule, the leaves having much the nature and appearance of Iris. The plant is of easy culture, and blooms from July to November; color fine blue. W. ramosa is a very fine species, similar to the above; flowers yellow and blue; plant branching. (Soil No. 8.)

Yúcca aloefólia, and its beautiful variety variegata, are desirable plants. They do not bloom till they have grown to considerable size; but still they make a decided contrast among other plants; the flowers are white and produced on terminal spikes. (Soil No. 11.)

Zàmias, about twenty species, eight of which belong to this compartment. The foliage is greatly admired, and is in large fronds, with oblique, lanceolate leaflets. Several of them glaucous. They bear heads of flowers of a brown color in the centre of the plants, very like large pine cones. $Z$. hòrrida, the finest; $Z$. púngens, $Z$. spiralis, and $Z$. latifolia, are the most conspicuous. They must be kept in the warmest part of the green-house ; and give them large well-drained pots, watering sparingly during winter. They are imported from the Cape of Good Hope. (Soil No. 11.) All the plants herein named requiring to be drained, in preparing the pots, place first a piece of broken pot, oystershell, or any similar substitute, with the convex side on the hole of the pot, and then put in a few, or a handful (according to the size of the pot) of shivers of broken pots, or round gravel about the size of garden beans. Those that we have mentioned in this Repotting, as to be done in this or beginning of next month, is not intended to apply to plants in general, large and small, but to those that are young, and require encouragement, or to those that were not shifted last autumn. The roots must not be disturbed, but the ball turned out entire; and put as much earth as will 
raise the ball within about a half an inch of the rim of the pot. Press the earth down around it with a thin narrow piece of wood, called a potting stick, frequently shaking it that no vacancy may be left. If the roots are rotten, or otherwise injured, take all such off. If this be the case, the plant will be sickly. Give it a new pot of a smaller size, administering water moderately until there are visible signs of fresh growth. The plants must not be disturbed while flowering; let the repotting be done afterward. Plants are, at certain stages, if in good health, in a state that no one can err in shifting them when desirous to hasten their growth. Those plants that make two or more growths during the summer may be repotted in the interim of any of these growths, and all others just before they begin to push in the spring; that is, when the wood buds are perceptibly swelled. Never saturate with water fresh-potted plants. There are many kinds that, without injury, can be repotted when growing. When done potting, tie all up neatly with stakes rather higher than the plant, that the new shoots may be tied thereto during the summer, to prevent them from being destroyed by the wind. There may be many that do not require repotting, but would be benefited by a top-dressing. This should be done by probing off all the surface earth down to the roots, replacing it with fresh compost, suitable to the nature of the plant.

When the above is done, arrange all the plants in proper order, and syringe them clean; but if there are any of the green-fly, they must be fumigated previous to syringing. The pavement of the house should be cleanly and neatly swept every day, and washed at least once a-week. Thus, every part of the house will be in order before the hurry of the garden commences.

\section{OF ENARCHING, OR GRAFTING BY APPROACH.}

In this method of grafting, the scion is not separated from the parent plant until it is firmly united with the stock; consequently, they must stand contiguously. We intend the following method to apply directly to Caméllias, as they are the principal plants in the green-house that are thus worked. The criterion for the operation is about the first of March or 
June. Place the stock contiguous to the plant where the graft or enarch is to be taken from. If the branches, where the intended union is to take place, do not grow at equal heights, a slight stage may be erected to elevate the lower pot. Take the branch that is to be enarched (the wood of last year is the most proper), and bring it in contact with the stock; mark the parts where they are to unite, so as to form a pointed arch. In that part of the branch which is to rest against the stock, pare off the bark and part of the wood to about two or three inchẹs in length, and in the side of the stock which is to receive the graft do the same, that the inside rind of each may be exactly opposite, which is the first part where a union will take place. Bind them firmly and neatly together with strands of Russia matting, and protect the joint from the air by a coat of close composition; clay of the consistency of thick paint, turpentine, or wax, will equally answer. Finish by fastening the grafted branch to the head of the stock or a rod. Many practitioners make a slit or tongue into the enarch and stock, but we find it unnecessary, more tedious, and likewise more danger in breaking. Caméllias are also grafted and budded, but these two operations require great experience and continued attention, and seldom prove so successful as enarching. When they have perfectly taken, which will be in from three to four months, begin to separate them by cutting the scion a little at three different periods, about a week apart, separating it at the third time. If the head is intended to be taken off the stock, do it in like manner. By the above method, many kinds can be grown on the same stock. The same plan applies to all evergreens.

\section{APRIL.}

REgarding the shifting or repotting of plants, the directions given last month may be followed. If the plants that require it are not shifted, get them done as soon as possible. Those that were repotted last month will have taken fresh root in the new soil, and the advantage will soon be per- 
ceptible. In order to strengthen the plants, and keep them from becoming drawn and spindly, admit large portions of air every mild day. Indeed, there will be very few days in this month that a little air may not be given, always observing to divide the quantity regularly over the house, in cool nights closing in time. About the end of the month an abundance of air is indispensable, leaving the sashes and doors open every mild night, that the plants may be inured to the open exposure they will have in a few weeks.

\section{WATERING.}

As the season advances and vegetation increases, the waterings will require to be more copious and more frequent. Look over all plants minutely every day, and with judicious care supply their wants. Those that are of - a soft shrubby nature, and in a free-growing state, will require - a larger portion at one time than those of a hard texture, which may only want it every two or three days. The weather and situation, in some instances, may require a modification of these directions. Plants in general will not suffer so soon from being a little dry as from being overwatered. The health and beauty of the foliage of the plants may be much improved by syringing them freely three evenings in the week, except in moist weather, when it ought not to be done. The ravages of many insects also will be retarded, especially mildew and red spider, which will be entirely destroyed. If the red spider is on any of the plants particularly, take them aside evening and morning, and give them a good dashing with water through the syringe. Where there is mildew, after syringing the plant, dust it on the affected parts with flower of sulphur, and set them for a few days where they will be sheltered from the wind, after which wash off the sulphur. If the cure is not complete, renew the dose. Always sweep out and dry up the water in the house when any is spilt. The succulent plants will be in want of a little water about once a-week, but do not over-water them, as there is not heat enough to absorb much moisture. If the soil is damp, it is quite sufficient. 


\section{ORANGES, LEMONS, \&c.,}

Will, in many instances, about the end of this month, be showing flowers or flower buds. They must, under these circumstances, have plenty of air to prevent them from falling off when entirely exposed. The reason that we see so much fine blossom falling to the ground where the trees are brought out of the house in May, is from the confinement they have had. Where there is a convenience of giving air from the back of the green-house, it should always be given in mild days, especially in those houses that have a recess back from the top of the sashes, for even if the sashes are let down every day, still the house will not be properly ventilated. Any plants that are sickly and intended to be planted in the garden next month to renovate their growth, may be cut back (if not already done) as far as is required to give the tree a handsome form, taking care not to cut below the graft of inoculation. Let the operation be done with a fine saw and sharp knife, smoothing the amputations that are made by the saw; and if they are large, put a little well-made clay over the wound, to prevent the air from injuring it. Beeswax and turpentine are preferable to clay, not being subject to crack or fall off by the weather.

If there are any Lagerstromias, Pomegranate or $H_{y}$ drangeas in the cellar, they should be brought out about the first of the month, and planted in their respective situations. Give the Iydranger a very shady spot. It does not require much sun, provided it has p?enty of air, and do not plant it into soil that has been lately manured. A large plant must have great supplies of water in dry weather. If the plant is very thick, the oldest branches may be thinned out, but do not cut out any of the young shoots, as they contain the embryo of the flower. Lagerstroemias will flower abundantly without pruning, but, to have fine large spikes of flowers, cut in the wood of last year to about three eyes from the wood of the preceding year; by this they will be nuch finer. I'umegranates will only require a little of the superfluous wood cut out. Perhaps some of them may be desired to flower in pot or tubs during summer; the balls will admit of being nuch reduced, and by this a pot or tub 
very little larger will do for them. Do not give much water until they begin to grow.

\section{MYRTLES AND OLEANDERS.}

If any of these have grown irregularly, and are not headed down or otherwise pruned, as directed last month, it should now be done. Oleanders are very subject to the white scaly insect, and, before the heat of summer begins, they should be completely cleansed. This insect is likewise found on Myrtles, which are worse to clean, and ought to be minutely examined twice every year. We have observed the red spider on these shrubs, which makes the foliage brown and unsightly. If it is detected in time, syringing is an effectual remedy.

\section{GERANIUMS.}

These will now begin to flower, and the sun will greatly deteriorate their rich colors where they are near the glass with a southern aspect. The glass sliould be whitewashed or covered with thin muslin, which will cast a light shade over them, and prolong the duration of the bloom; but if they are above five feet from the glass, shading is not requisite. The strong linds will be growing very luxuriantly, and require liberal supplies of water. When syringing, do not sprinkle the flowers, as it would make the colors intermingle with each other, and cause them to decay prematurely. If they have been properly attended to in that respect, it may be dispensed with after they have come in flower.

Cape Bulls. Those that flowered late in autumn, as soon as the foliage begins to decay, may be set aside, and the water withbeld by degrees. When the foliage is entirely gone, and the roots dry, clear them from the earth, and after laying exposed in the shade for a few days to dry, pack them up in dry moss, with their respective names attached, until August, when they may be again potted. 'Treat those that are in flower the same as directed in last month. 
Dutch Roots. All the species and varieties of these that have been kept in the green-house during the winter will now be done flowering; the water should be withdrawn gradually from them; and then the pots turned on their sides to ripen the bulbs. Or, a superior method is, where there is the convenience of a garden, to select a bed not much exposed. Turn the balls out of the pots and plant them; the roots will ripen better this way than any other. Have them correctly marked that no error may take place. They can be lifted with the other garden bulbs.

\section{FLOWERING PLANTS.}

The best situation for most plants, while in flower, is where they are shaded from the sun and fully exposed to the air. Primroses, both European and Chinese, flower best, and the colors are finest, where the plants are in the front of the house and entirely shaded. The Chinese Azaleas and Rhododéndrons require, while in flower, a similar situation. Have all the shoots tied naturally to neat rods, and keep them clear from others by elerating them on empty pots, or any other substitute. See that there are no insects upon them; for they make a miserable contrast with flowers. The C'alla Aithiopica should stand in water when in bloom, and even before flowering they will be much strengthened by it.

\section{INSECTS.}

Insects will, on some plants, be rery perplexing. The weather may admit of those that are infected to be taken out of doors, and put into a frame in any way that is most convenient. Fumigating them about fifteen minutes, if the day is calm, will be sufficient; but if windy they will take half an hour. When done, syringe them well and put them in their respective situations. By the above method, the house will not be made disagreeable with the fumes of tobacco.

Tie up neatly all the climbing plants. Keep those that are running up the rafters of the house close to the longi- 
tudinal wires. As previously observed, running plants should not be taken across the house, except in some instances where it can be done over the pathway, otherwise it shades the house too much. Clear off all decayed leaves and all contracted foulness, that the house and plants may in this month have an enlivening aspect, as it is undoubtedly one of the most interesting seasons of the year in the green-house.

\section{FLOWERING STOCKS.}

Those that have been kept in the green-house, or in frames, should be planted into beds or the borders, where they will seed better than if kept in the pots. The method generally adopted is, to select the plants that are intended for seed; plant the different kinds distinctly and separately; then take a few double flowering plants of each kind, which plant round their respective single varieties that are to be kept for seed. Whenever any of the colors sport, that is, become spotted or striped with other colors, plant such by themselves, for they will soon degenerate the whole, and ought never to be seen in collections that have any pretensions to purity. Many have been the plans recommended as the best for saving and growing from seed the double varieties of German stock. In every method we have tried we have been successful and unsuccessful; although we generally practice planting the double kinds beside the single, where they are intended for seed. We have no scientific reason for it; not seeing what influence these monsters of flowers can have over a flower where the male and female organs are perfect; which in these are wanting. Some say that the semi-double sorts are best; we have likewise found them both abortive and fruitful in the desired results. 


\section{MAY.}

ABout the first of the month all the small half-hardy plants may be taken out of the green-house, and those that are left will be more benefited by a freer circulation of air, which will inure them to exposure. The Geraniums ought to stand perfectly clear of other plants, while in flower and growing, or they will be much drawn and spinaily.

\section{WATERING.}

We have advanced so much on this subject, another observation is not necessary; except as to succulents, which are frequently over-watered about this period. Before they begin to grow, once a-week is sufficient.

\section{OF BRINGING OUT THE GREEN-HOUSE PLANTS.}

Those trees or plants of Orange, Lemon, Myrtle, Nerium, \&c., that were headed down with the intention of planting them into the garden, to renovate their growth, should be brought out and planted in the situations intended for them. A good light rich soil will do for either, and the balls of earth might be a little reduced, that, when they are lifted, they might go into the same pot or tub, or perhaps a less one. This being done, the plants, generally in a calm day from the 12th to the 18th of the month, should be taken out, carrying thern directly to a situation partially shaded from the sun, and protected from the wind. In regard to a situation best adapted for them during summer, see Hot-house this month, which will equally apply to green-house plants. All Primroses and Polyanthus delight in shade. The reason of so many plants of the $D$. odora* dying, is from the effects

* On examining these plants, when the first appearance of decay affected them, the decayed part was without exception at the surface of - the soil, which was completely mortified, while the top and roots were apparently fresh. This led us to conclude that the cause was the effect of sun and water on the stem. We have since kept the 
of the sun and water. We keep them always in the greenhouse.

The large trees may be fancifully set either in a spot for the purpose, or through the garden. Put bricks or pieces of wood under the tubs to prevent them from rotting, and strew a little litter of any description over the surface of the soil to prevent evaporation, or about one inch of well-decayed manure, which will, from the waterings help to enrich the soil. . A liberal supply of water two or three times a-week is sufficient. A large tree will take at one time from two to four gallons. We make this observation, for many trees evidently have too limited a supply. Continue to syringe the plants through the dry season every evening, or at least three times per week. All the tall plants must be tied to some firm support, because the squalls of wind frequently overturn them, and do much harm by breaking, \&c. Keep those that are in flower as much in shade as will preserve them from the direct influence of the sun.

\section{REPOTTING PLANTS.}

After the following-mentioned plants, or any assimilated to them, are brought out of the house, and before they are put in their respective stations, repot them where they are required to grow well. Aloes. These plants, so varied in character, have been divided into several genera. These are, Gastèria, Pachidéndron, Riphidodéndron, Howárthia, and Apicra: of these there are about two hundred species and varieties; to enter into any specific detail would be beyond our limits, especially with a tribe of plants that as yet have but a few patrons. (Soil No. 10.)

Chamærops. There are about seven species of these palms ; four of them belong to this department, and are the finest of those that will keep in the green-house. They all have large palmated fronds, and require large pots or tubs to make them grow freely, and are tenacious of life if kept from frost.

Gardènia. This is an esteemed genus of plants, especially

earth in a conical form round the stem, thereby throwing the water to the sides of the pot, and kept them in the shade. Previously to doing this, great numbers perished every year, and now no plants thus treated die with us. 
for the double flowering varieties, which are highly odoriferous, and have an evergreen shining foliage. G. flòrida flore plèno, Cape Jasmine, is a plant universally known in our collections, and trees of it are frequently seen about seven feet high, and five feet in diameter, blooming from June to October. $G$. rádicans, dwarf Cape Jasmine, G. longifòlia, G. multifiòra, G. latifòlia, G. Fortùnii, and G. camelliafóra, are also in several collections, but not so generally known; the flowers are double, and all equally fragrant. We are inclined to think they are only varieties of G. Alorida, of which camelliaflora is one of the finest. Any of the above will keep in the coldest part of the green-house, and even under the front of the stage is a good situation for them, where the house is otherwise crowded during winter. They must be sparingly watered from November to March. Much water, while they are dormant, gives the foliage a sickly tinge, a state in which they are too frequently seen. G. rothmànnia and G. Thunbérgia are fine plants, but seldom flower; the flowers of the former are spotted, and are most fragrant during night. " (Soil No. 10.)

Mesemoryánthemum, a very extensive genus, containing upward of four hundred and fifty species and varieties, with ferr exceptions, natives of the Cape of Good Hope. They are all singular, many of them beautiful, and some splendid; yet they have never been popular plants in our collections. The leares are almost of every shape and form; their habits vary in appearance. Some of them are straggling, others are insignificant, and a few grotesque. When they are well grown, they flower in great profusion; the colors are brilliant and of every shade; yellow and white are most prevalent. Each species continues a considerable time in flower. The flowers are either solitary, axillary, extra-axillary, but most frequently terminal; leaves mostly opposite, thick, or succulent, and of various forms. They are sometimes kept in the hot-house, but undoubtedly the green-house is the best situation for them. They must not get water above twice a-month during winter, but while they are in flower, and through the summer, they require a more liberal supply, and they seldom need to be repotted; once a-year is sufficient (Soil No. 18.) 


\section{CAMELLIAS.}

These plants, when they are brought from the green-house (which should be about the end of June), ought to be set in a situation by themselves, that they may be the more strictly attended to in watering and syringing. An airy situation, where the sun has little effect upon them, is the best. They should be syringed every evening when there has been no rain through the day. After heavy rains examine the pots, and where water is found, turn the plant on its side for a few hours to let the water pass off, and then examine the draining in the bottom of the pots, which must be defective.

\section{CAPE BULBS.}

As soon as these are done flowering, and the foliage begins to decay, cease watering, and turn the pots on their sides, until the soil is perfectly dry; then take out the bulbs, and preserve them dry until the time of planting, which will be about the end of August or first of September.

\section{JUNE AND JULY.}

THE plants being out of the house, there need be little added under this head. Their treatment is in the general, and the required attention is in giving water according to their different constitutions and habits. Where there is no rain nor river water, it should stand at least one day in butts or cisterns, to take the chilly air from it, and become softened by the surrounding atmosphere. This is more essential to the health of the plants than is generally supposed. The small plants in dry weather will need water evening and morning. Continue regular syringings as directed last month. There are frequently rains continuing for several days, which will materially injure many plants if they are not turned on their sides, or defended by sash or shutters, until 
the rain is over, especially small plants. The syringings should never be done till after the waterings at the roots, and they should never be more seldom than every alternate evening. Turn all the plants frequently, to prevent them from being drawn to one side by the sun or light. Carefully look over them at these turnings to detect any insects; and observe that the tuberose-rooted or deciduous geraniums, such as Ardéns, Bicólor, Comptónia, Echinàtum, Tristum, \&c., are not getting too much water, they being now dormant.

\section{AUGUST.}

Any of the Myrtles, Oranges, Lemons, Oleanders, \&c., that were headed down in A pril or May, will be pushing many young shoots. The plant must be carefully examined, to observe which of the shoots ought to be left to form- the tree.

Having determined on this, cut out all the others close to the stem with a small sharp knife; and if the remaining shoots are above one foot long, pinch off the tops to make them branch out.

The trees that were entirely headed down should not have above six shoots left, which will, by being topped, make a sufficient quantity to form the bush or tree.

\section{GERANIUMS.}

These plants, about the first of the month, require a complete dressing. In the first place collect them all together, and, with a sharp knife, cut off the wood of this year to within a few eyes of the wood of lisst year. Citriodómum and its rarieties do not need pruning. The plants grown from cuttings during the season that have flowered, cut them to about three inches from the pot. This being done, have the earth all prepared, and potsherds or fine gravel at hand, for draining the delicate kinds. Choose a cloudy day for the operation, and turn the plants progressively out of the pots they are in, reducing the balls of earth so that the same 
pots may contain them again, and allow from half an inch to two inches, according to the size of the pot, of fresh soil around the ball, carefully pressing it with the potting-stick. Finish by leveling all neatly with the hand. Give very gentle waterings from a pot with a rose mouth, for a few weeks, until they have begun to grow. The tuberous-rooted and deciduous species must be very moderately supplied. Be careful, when watering, that the new soil does not become saturated with water, for, though allowed to dry again, it will not be so pure. When they grow afresh, expose them fully to the sun, turn them regularly every two weeks, to prevent them growing to one side.

\section{ORANGES, LEMONS, \&c.}

As it is frequently very inconvenient to shift these trees into larger tubs in the months of March and April, this month is a period that is suitable, both from the growth of the trees and their being in the open air. It would be improper to state the day or the week, that depending entirely on the season. The criterion is easily observed, which is when the first growth is over, these trees making another growth in autumn. When they are large, they require great exertion, and are frequently attended with inconvenience to get them shifted. Where there is a quantity of them, the best plan that we have tried or seen adopted is as follows: Have a strong double and a single block trimmed with a sufficiency of rope; make it fast to the limb of a large tree, or anything that projects and will bear the weight, and as high as will admit of the plant being raised a few feet under it. Take a soft bandage and put around the stem, to prevent the bark from being bruised; make a rope fast to it, in which hook the single block. Raise the plant the height of the tub, put a spar across the tub, and strike on the spar with a mallet, which will separate the tub from the ball. Then with a strong pointed stick probe a little of the earth from among the roots, observing to cut away any that are affected by dry rot, danip, or mildew, with any very matted roots. Having all dressed, place a potsherds over the hole or holes in the bottom of the tub; measure exactly the depth of the ball that remains around the plant, and fill up with earth, press- 
ing it well with the hand, until it will hold the ball one inch under the edge of the tub. If there is from two to four inches of earth under it, it is quite enough. Fill all around the ball, and press it down with a stick, finishing neatly off with the hand. Observe that the stem of the tree is exactly in the centre. This being done, carry the tree to where it is intended to stand, and give it water with a rose on the pot. The earth will subside about two inches, thus leaving three inches, which will, at any time, hold enough of water for the tree. Trees thus treated will not require to be shifted again within four or five years, having in the interim got a few rich topdressings.

Frequently, in attempting to take out of the tubs those that are in a sickly state, all the soil falls from their roots, having no fibres attached. When there are any such, after replanting, put them in the green-house, and shut it almost close up; there give shade to the tree, and frequent sprinklings of water, until it begins to grow, when admit more air gradually until it becomes hardened. Sickly trees should be put in very small tubs, and a little sand added to the soil. Give very moderate supplies of water, merely keeping the soil moist Tubs generally give way at the bottom when they begin to decay, and in the usual method of coopering after this failure they are useless, the ledging being rotten, and will not admit of another bottom. The staves should be made without any groove, and have four brackets nailed on the inside, having the bottom in a piece by itself, that it can be placed on these brackets, and there is no necessity of it being water tight. Then when it fails, it can be replaced again at a trifling expense. A tub made in this way will outlast three or four bottoms, and is in every respect the cheapest, and should be more wide than deep. When made in this manner they are easier shifted; you have only to set the tub on a high block of wood, and drive the tub off with a mallet, when the tree can be easily replaced into another tub. Large Myrtles and Oleanders may be treated in the same manner as directed for the above.

OF PRUNING ORANGES, LEMONS, \&c.

These trees will grow very irregularly, especially the Lemon, if not frequently dressed or pruned. Any time this 
month look orer them all minutely, and cut away any of the small naked wood where it is too crowded, and cut all young strong straggling shoots to the bounds of the tree, giving it a round regular head. It is sometimes necessary to cut out a small limb, but large amputations should be avoided. Cover all large wounds with clay, turpentine, or beeswax, to prevent the bad effects of the air.

\section{OF REPOTTING PLANTS.}

Any of the plants enumerated in March under this head may be now done according to directions therein given, and which apply to all sizes. This is the proper period for repotting the following:

Calla, a genus of four species. None of them in our collections, and in fact not worth cultivation, except $C$. PEthiopica, Ethiopian Lily, which is admired for the purity and singularity of its large white flowers, or rather spatha, which is cucullate, leares sagittate. It is now called Richardia Aithiopica. The roots, which are tubers, should be entirely divested of the soil they have been grown in, breaking off any small offsets, and potting them wholly in fresh earth. When growing, they cannot get too much water. The plant will grow in a pond of water, and withstand our severest winters, provided the roots are kept at the bottom of the water.

Cyclamen. There are eight species and six varieties of this genus, which consists of humble plants with very beautiful flowers. The bulbs are round, flattened and solid, and

- are peculiarly adapted for pots and the decorating of rooms. - C. còum, leares almost round; flowers light red; in bloom from January to April. C. pérsicum, with its four varieties, flower from January to April; color white, and some white and purple. C. hederæfolium, Ivy-leaved; color lilac; there is a white variety; flowers from September to December. C. Europæum, color lilac, in bloom from August to October. C. Neapolitànum, flowers red; in bloom from July to September. These are all desirable plants. When the foilage begins to decay, withhold the accustomed supplies of water, keeping them in a half dry state; and, when growing, they must not be over-watered, as thay are apt to 
rot from moisture. Keep them during the summer months in partial shade. The best time for potting either of the sorts is when the crown of the bulb begins to protrude. If the pots are becoming large, every alternate year they may be cleared from the old soil, and put in smaller pots with the crown entirely above the ground. When the flowers fade, the pedicles twist up like a screw, enclosing the germen in the centre, lying close to the ground until the seeds ripen, from which plants can be grown, and will flower the third year.

Lachencitia, a genus of about forty species of bulbs, all natives of the Cape of Good Hope, and grow well in our collections. The most common is L. tricolor. L. quadricolor and its varieties are all fine; the colors yellow, scarlet, orange and green, very pure and distinct; $L$. rùbida, $L$. punctàta, L. orchoides and L. nervòsa are all fine species. The flowers are on a stem from half to one foot high, and much in the character of a hyacinth. The end of the month is about the time of planting. Five-inch pots are large enough, and they must get very little water till they begin to grow.

Oxâlis, above one hundred species of Cape bulbs, and, like all other bulbs of that country, they do exceedingly well in our collections, in which they are only comparatively a few species, not exceeding twenty. O. liirta, branching, of a vermilion color; O. Alabilifòlia, yellow; O. elongcita, striped; and amæna, are those that require potting this month. The first of September is the most proper period for the others. (Soil No. 11.)

This genus of plants is so varied in the construction of its roots that the same treatment will not do for all. The root is commonly bulbous, and these will keep a few weeks or months out of the soil, according to their size. Several are only thick and fleshy; these ought not to be taken out of the pots, but kept in them, while dormant; and about the end of this month give them gentle waterings. When they begin to grow, take the earth from the roots, and put them in fresh soil. In a few months the bulbs are curiously produced, the original bulb near the surface striking a radical fibre downright from its base, at the extremity of which is produced a new bulb for the next year's plant, the old one perishing.

Cmithorrtum, Star of Bethlehem, about sixty species of 
bulbs, principally from the Cape of Good Hope. Many of them have but little attraction. The most beautifu] that we have seen are O. lactéum, which has a spike about one foot long, of fine white flowers, O. Peruvicina, blue-flowered, and $O$. aìreum, flowers of a golden color, in contracted racemose corymbs. These three are magnificent. O. maritimum is the officinal squill. The bulb is frequently as large as a human head, pear-shaped, and tunicated like the onion. From the eentre of the root arise several shining glaucous leaves a foot long, two inches broad at base, and narrowing to a point. They are green during winter, and decay in the spring; then the flower-stalk comes out, rising two feet, naked half way, and terminated by a pyramidal thyrse of white flowers. The bulb ought to be kept dry from the ond of June till now, or it will not flower frecly.

\section{GENERAL OBSERVATIONS.}

Watering, and other practical care of the plants, to be done as heretofore described. Frequently the weather at the end of this month becomes cool and heary. Dew falling through the night will, in part, supply the syringing operation, but it must not be suspended altogether. Once or twice a-week will suffice. Any of the plants that are plunged should be turned every week. In wet weather, observe that none are suffering from moisture.

\section{SEPTEMBER.}

DuRING this month, every part of the green-house should have a thorough cleansing, which is too frequently neglected, and many hundreds of insects left unmolested. Tio preserve the wood-work in good order, give it one coat of paint every year. Repair all broken glass, white-wash the whole interior, giving the flues two or three coats, and cover the stages with hot lime, whiterrash or oil paint; examine ropes, pulleys and weights, finishing by washing the pavement perfectly clean. 
If there have been any plants in the house during summer, be sure after this cleansing that they are clean also, before they are returned to their respective situations.

\section{OF WATERING.}

The intensity of the heat being over for the season, the heavy dews during night will prevent so much absorption among the plints. They will, in general, especially by the end of the month, require limited supplies of water compa'ratively to their wants in the summer months. Be careful among the Geraniums that were repotted in August, not to water them until the new soil about their roots is becoming dry. Syringing in this month may be suspended in time of heary dews, but in dry nights resort to it again.

The herbaceous plants and those of a succulent nature must be sparingly supplied. The large trees that were put in new earth will require a supply only once a-week, but in such quantity as will go to the bottom of the tubs.

\section{PREPARING FOR TAKING IN THE PLANTS.}

About the end of the month, all the plants should be examined and cleaned in like manner as directed for those of the hot-house, last month, which see. From the first to the eighth of October is the most proper time to take them into the green-house, except those of a half-hardy nature, which may stand out until the appearance of frost. Always endearor to have Geranium plants short and bushy, for they are unsightly otherwise, except where a few very large specimens are desired for show. All Myrtles and Oleanders that were headed down, if the young shoots are too crowded, continue to thin them out, and give regular turnings, that all the heads may grow regularly.

\section{STOCKS AND WALL-FLOWERS}

That are wanted to flower in the green-house (where they do remarkably well), and are in the ground, have them care- 
fully lifted before the end of the month, and planted in six or seven inch pots, with light loamy soil. Place them in the shade till they take fresh root, and give them frequent sprinklings of water. As soon as the foliage becomes erect, expose them to the full sun, and treat as green-house plants.

\section{CHRYSANTHEMUMS.}

These very ornamental plants blooming so late, and at a period when there are few others in flower, one of each variety (or two of some of the finest) should be lifted and put in eight-inch pots, in light loamy soil, and treated as above directed for stocks, \&c. These will flower beautifully from October to December; and, when done blooming, the pots may be plunged in the garden, or covered with any kind of litter until spring, when they can be divided, and planted out.

\section{CAPE AND HOLLAND BULBS.}

About the end of this month is the period for all of these that are intended for the green-house to be potted. We specified some of the former last month, and will here enumerate a few others.

Anemothica críenta, a sparkling little gem of a bulb, prodủcing a mass of scarlet flowers spotted with orange and brown.

Babiana, a genus of small bulbs, with pretty blue, white, red, and yellow flowers. $B$. distíca, pale blue flowers in two ranks. B. strícta, flowers blue and white. B. tubifiòra, beautiful bright blue. $B$. plicata has sweet-scented pale blue flowers. B. villosa, red; B. sulphurea, sulphur color; B. rubro-cyanea, dark purple with crimson centre. There are about twenty species of them, and they grow from six to twelve inches high. Five-inch pots are sufficient for them. (Soil No. 11.)

Gladiolus, corn-flag, a genus of above fifty species There are several very showy plants among them, and a few rery superb. $G$. floribundus, large pink and white flowers. $G$. cardinális, flowers superb scarlet, spotted with white. $G$. byzantìnus, purple. G. blándus, flowers of a blush rose color, and handsome. G. cuspidìtus, flowers white and purple. 
G. racemòsus, flowers beautiful rose and white. G. psittácinus; the flowers are striped with green, yellow, and scarlet, about four inches in diameter, in great profusion, on a stem about two feet high. G. formosissimus, beautiful bright scarlet, the three upper petals having a spot of white, a very profuse bloomer. G. Queen Victoria, G. Lafayette, and several others are of very similar character. G. gandavensis, very superb orange and yellow. G. Buistii, large bright scarlet, perhaps the finest of the whole family. They all do perfectly when kept dry all winter, and planted in the open ground early in March. The beauty of this genus is all centered in the flowers. (Soil No. 10.)

Ixia, a genus containing about twenty-five species of very free-flowering bulbs. I. monadélpha, flowers blush and green. I. leucántha, flowers large white. I. capatata, flowers in heads, of a white and almost black color. I. cònica, flowers orange and velvet. I. columelòris is a beautiful shaded rosy purple. I. Termosina, a fine vermilion color. I. squallida, shaded rosy lilac; I. viridiftòra, green; I. Tongiftòra, buff. The flower stems are from six to twenty-four inches high. (Soil No. 11.)

Lilium. The Chinese species of this emblem of purity is everywhere esteemed, and the fine Chinese sorts are very splendid, such as $L$. longifiòra, L. longiflora suavèolens, and $L$. japónicum, are all pure white; $L$. lancifòlium, white petals reflexed; L. lancifôlium punctatum, white, spotted with rose; $L$. lancifolium speciosum, rose, spotted with crimson. L. lancifölium and its varieties, are all delightfully scented with the odor of vanilla; noble specimens of the family from Japan, growing from four to six feet high; a full-grown bulb producing from ten to twenty flowers, and perfectly hardy south of Philadelphia. They should be potted in seren or eight-inch pots, and kept in a cool part of the green-house; give the pots at least one inch of drainage. (Soil No. 11.)

Oxcalis. All the varieties and species may now be potted; the whole are pretty spring flowers, requiring to be kept near the glass: among the many the following are very deserving of attention: O. luxúlus, or rosacea, bright rose. 0 . Bòwii, bright rose red, a large and profuse bloomer, and one of the finest. O. florabinda, pink; a pretty free-flowering tuberous species. O. luxula alba, blush, white; $O$. 


\section{September.] GREEN-HOUSE-HOLLAND BULBS. 279}

multifiora, profuse flowering white. 0 . versícolor, striped. O. dippii, lilac, which blooms in summer. O. caparina, yellow; there is also a double yellow variety, though not pretty; for a few others see last month. There should be three or four bulbs planted in a five-inch pot, giving very little water till they begin to grow. They will all keep in good pits, as well as in the green-house. (Soil No. 11.)

Sparáxis. We are enraptured with this beautiful genus of small bulbs, closely allied to Ixia, but more varied in color. S. grandiflora striàta is striped with purple and white. S. versicolor, colors crimson, dark purple, and yellow. S. tricolor, yellow, black, and scarlet. S. albida, large white, with black spots. S. coelestis, bluish purpie. S. sulphùrea, yellow. S. purpùrescens, purple. Treat as $O x$ ális. (Soil No. 11.)

Tritònia, a genus of about twenty-five species. Few of them deserve culture in regard to their beauty. T. croccitı is in our collections as $I$. croccita, which is among the finest, and T. zanthospila has white flowers, curiously spotted with yellow. (Soil No. 11.)

Watsònia, a genus containing several species of showy flowers, several of which are in our collections under the genus Gladiolus, but the most of the species may be distinguished from it by their flat shell-formed bulbs. W. iridifolia is the largest of the genus, and has flowers of a flesh color. W. ròsea is large growing, the flowers are pink, and on the stem in a pyramidal form. W. humilis is a pretty red-flowering species. W. fúlyita, once Antholyza fúlgens, has fine bright scarlet flowers. W. riblens is an esteemed red-flowering species, but scarce.

(Soil No. 11.)

These genera of bulbous plants are in general cultivation. There are, no doubt, some splendid species that have not come under our observation, and others which may be obtained from the Cape of Good Hope and China that are not known in any collection, all of which would be perfectly hardy in our Southern States. Bulbs generally require very little water until they begin to grow; then supply moderately, and keep them near the light. Of the Holland or Dutch bulbs, the Hyacinth is the favorite to bloom in the green-house. A few of the Tulip, Narcissus, Iris and C'rocus, may, for variety, be also planted with any other that curiosity may dictate. When these are grown in pots, the soil should 
be four-eighths loam, two-eighths leaf mould, one-eighth decomposed manure, one-eighth sand, well compounded; plant in pots from five to seven inches, keep the crown of the bulb above the surface of the soil, except of the tulip, which should be covered two inches. When these roots are potted, plunge them in the garden about three inches under ground; mark out a space sufficient to contain them; throw out the earth about four inches deep, place the pots therein, covering them with earth to the above depth, making it in the form of a bed. Leave a trench all round to carry off the rain. By so doing, the bulbs will root strongly, the soil will be kept in a congenial state about them, and they will prove far superior than if done in the common method. Lift them from this bed on the approach of frost, or not later than the second week of December; wash the pots and take them into the green-house.

\section{OCTOBER.}

\section{OF TAKING IN AND ARRANGING THE PLANTS.}

As observed in the previous month, let the housing of green-house plants now be attended to. Have all in before the eighth of the month, except a few of the half hardy sorts, which may stand until convenient. Begin by taking in all the tallest first, such as Oranges, Lemons, Myrtles, Oleanders, \&c. Limes ought to be kept in the warmest part of the house, otherwise they will throw their foliage. In arrangement, order is necessary to have a good effect; and in small houses it ought to be neat and regular, placing the tallest behind, and according to their size graduating the others down to the lowest in front. Dispose the different sorts in varied order over the house, making the contrast as striking as possible. Having the surface of the whole as even as practicable, with a few of the most conspicuous for shape and beauty protruding above the mass, which will much improve the general appearance, and greatly add to the effect. All succulents should be put together. In winter they will do 
in a dark part of the house, where other plants will not grow, studying to have the most tender kinds in the warmest part, and giving gentle waterings every three or four weeks. When all are arranged, give them a proper syringing, after which wipe clean all the stages, benches, \&c., sweeping out all litter, and wash clean the parement, which will give to all a neat and becoming appearance.

Let the waterings now be done in the mornings, as often and in such quantities as will supply their respective wants, examining the plants every day.

During the continuance of mild weather, the circulation of air must be as free as possible, opening the doors and front and top sashes regularly over the house. But observe in frosty nights to keep all closely shut. Be attentive in clearing off decayed leaves and insects.

Any plants of Lagerstrcemia, Stercùtia, Hydrangea, Pomegranate, and others equally hardy, that are deciduous, may be kept perfectly in a dry, light, airy cellar : give frequent admissions of air, and one or two waterings during winter.

\section{OF REPOTTING.}

Anemònes. Where $A$. nemoròsa flore plèno and $A$. thalictroides flòre plèno are kept in pots in the green-house, they should be turned out of the old earth, and planted in fresh soil. They are both pretty, low growing, double white flowering plants, and require a shaded situation. The latter is now called Thalictrum anemoneoídes. (Soil No. 11.)

Daphne is a genus of diminutive shrubs, mostly evergreens, of great beauty and fragrance. Very few species of them are in our collections. $D$. odora, frequently called $D$. indica, is an esteemed plant for the delightful odor of its flowers, and valuable for the period of its flowering, being from December to March, according to the situation; leares scattered, oblong, lanccolate and smooth; flowers small white in many flowered terminal heads; there is a variety equally as fine with marginated foliage. D. odora rubra, the buds are red, and the flowers rose white, of a delightful spicy fragrance. D. hylrida is a species in ligh estimation at present in Europe, but little known here, being only in a few $24 *$ 
collections, flowers rosy purple, in terminal heads, and lateral bunches in great profusion; blooms from January to May, and is of a peculiar fragrance. $D$. oleoides is what may be termed "ever-blooming :" flowers of a lilac color; leaves elliptic, lanceolate, smooth. D. laurkola, Spurge laurel; D. póntica, $D$. alpìna, and $D$. C'neòrum, are all fine species, and in Europe.are esteemed ornaments in the shrubbery, but they are not hardy in our vicinity. (Soil No. 15.)

Primula. There are a few fine species and varieties in this genus, adapted either for the green-house or rooms. All the species and rarieties will keep perfectly well in a frame, except the China sorts. Having previously observed a few of the other species and varieties, we will observe the treatment of these. $P$. sinénsis, now prcenitens, known commonly as China primrose; flowers pink, and in large proliferous umbels, flowering almost through the whole year, but most profusely from January to May. There is a double white and a double purple variety that will always be scarce, from the slow method of their propagation. Keep them in the shade, and be careful that they are not over-watered during summer. As the stems of the plant become naked, at this repotting a few inches should be taken off the bottom of the ball, and placing them in a larger pot will allow the stems to be covered up to the leaves. $P . p$. albiflora, color pure white and beautiful. P. p. dentiflora. There is also a white variety of this, both similar to the former two, only the flower indented or fringed. All these require the same treatment. As they live only a few years, many individuals, to propagate them, divide the stems, which in most cases will utterly destroy them. The best, and we may say the only method to increase them is from seed, which they produce every year. (Soil No. 2.)

Pæónia móutan: this magnificent plant and its varieties are quite hardy with us, but most of them require the greenhouse in northern latitudes. These are $P$. moutan, Tree Pæony; the flower is about five inches in diameter, of a blush color, and semi-double. $P . M$. Banksii is the common Tree Pæony, and called in our collection P. moutan; it has a very large double blush flower, and is much admired. $P$. M. papareracea is a most magnificent variety; has large single white flowers, with purple centres. $P . M$. rosea is a splendid rose-colored double variety, and is scarce; there are 
also in China several other varieties, such as purple, scarlet and crimson, which have been introduced into cultivation, and within these few years, many varieties have originated in Europe, said to be very magnificent. These plants ought not to be exposed to the sun while in flower, as the colors become degenerated, and premature decay follows.

If the Dutch bulbs intended for flowering during winter are not potted, have them all done as soon as possible, according to directions given last month.

\section{CAMELLIAS.}

These plants ought to have a thorough examination, and those that were omitted in repotting before they commenced growing, may be done in the early part of this month; but it is not advisable, except the roots are all round the ball of earth, which should be turned out entire. Examine all the pots, stir up the surface of the earth, and take it out to the roots, supplying its place with fresh soil. Destroy any worms that may be in the pots, as they are very destructive to the fibres. Look over the foliage, and, with a sponge and water, clear it of all dust, \&c. Frequently the buds are too crowded on these plants, especially the Double white and Variegated. In such case pick off the weakest, and where there are two together, be careful in cutting, so that the remaining bud may not be injured.

This is the best period of the year to make selections of these, as they now can be transported hundreds of miles without any material injury, if they are judiciously packed in close boxes. In making a choice of these, keep in view to have distinctly marked varieties, including a few of those that are esteemed as stocks for producing new kinds, which are undoubtedly indispensable, and will reward the cultivator in a few years with new sorts. Besides, it will afford unbounded gratification to behold any of these universally admired ornaments of the green-house improving by our assistance and under our immediate observation. There is nothing to prevent any individual from producing splendid varieties in a few years. Mr. Hogg correctly observes, "It is very probable in a few years we shall have as great a variety of Camellias as there are of Tulips, Hyacinths, Car- 


\section{GREEN-HOUSE-OF AIR AND WATER. [November.}

nations, Auriculas," \&c. This shrewd remark is likely to be rerified much earlier than we anticipated.

It has been often said that these plants are difficult of cultivation. This is unfounded; indeed, they are the reverse if put in a soil congenial to their nature. When highly manured soils are given, which are poisonous to the plants, sickness or death will inevitably ensue; but this cannot be attributed to the delicacy of their nature. We can unhesitatingly say there is no green-house plant more hardy or easier of cultivation, provided they are kept at an even temperature, say from $40^{\circ}$ to $45^{\circ}$ during night, and $45^{\circ}$ to $50^{\circ}$ during day, and they are equally so in the parlor, if not kept confined in a room where there is a continuance of drying fire heat, their constitution not agreeing with an arid atmosphere.

\section{SOWING CAMELLIA SEED.}

These seeds ripen generally during September and October, and must be sown as soon as ripe; plant them about one inch under ground into pots filled with leaf mould, loam, and white sand, in equal portions; if the pots after sowing can be placed in a hot-house, they will vegetate in about six weeks, and be ready to pot into single pots in February. Many of them will bloom in the second year; but if heat is not accessible, keep the pots in the warmest part of the green-house, and give an occasional watering, and the plants will appear some time in May and June: they will be ready to pot into single pots in September, and after doing so put them into a close frame, and shade them from the sun for a few weeks; use at this potting only about one-fifth of sand.

\section{NOVEMBER.}

OF AIR AND WATER.

AIRING the house should be strictly attended to. Every day that there is no frost it may be admitted largely, and 
in time of slight frosts in smaller portions, never keeping it altogether close when the sun bas any effect on the interior temperature of the house, which should not be allowed to be higher than fifty degrees.

Water must be given in a very sparing manner. None of the plants are in an active state of vegetation, consequently it will be found that looking over them thrice a-week and supplying their wants will be sufficient. Succulents will need a little once in three weeks or a month. Give very moderate supplies to the Amaryllis that are dormant, and keep all these bulbs in the warmest part of the house.

\section{OF TENDER BULBS.}

Where there are tropical bulbs in the collection, and there is not the convenience of a hot-house, they may be very well preserved by shaking them clear of the soil. Dry them properly, and place them in a box of very dry sand or moss, and put them in a situation near the furnace, where they will be free from damp. These can be potted about the first of April. Give no water till they begin to grow, then plant them in the garden about the middle of May, where they will flower during the summer season, if they are mature.

\section{GENERAL OBSERVATIONS.}

If there are any of the half-hardy plants exposed, have them taken into the house or under the requisite protection, in frames, pits, cellars, \&c. The autumn flowering Cape bulbs should be placed near the glass, and free from the shade of other plants. Cleanliness through the whole house and among the plants ought at all times to be attended to.

\section{DECEMBER.}

The weather may probably be now, severe, and it is at all times advisable to keep the temperature as steady and 
regular as possible. The thermometer should be kept in the centre of the house, and free from the effects of reflection. As noticed last month, sun heat may be as high as $50^{\circ}$ in the house, and would not be hurtful, but it should not continue so for any considerable time without admission of air. The fire heat should not exceed $45^{\circ}$, and never below $35^{\circ}$. It ought not to continue at that point $-36^{\circ}$ is the lowest for a continuation that with safety can be practiced; and where a collection of Cactii are kept, $40^{\circ}$ should be the lowest. So that no error may occur, the temperature ought to be known in the coolest and warmest parts of the house, and the variation remembered; then whatever part of the house the thermometer is placed, a true calculation of the heat of the whole interior can be made. We would recommend to the inexperienced to keep the thermometer in the coldest part of the house. A green-house compactly and closely built, and the lowest row of top sash all covered with shutters (which no house ought to be constructed without), will seldom require artificial heat; but by being long kept close, the damp will increase. In such case give a little fire heat, and admit air to purify the house. In fresh mild weather, give liberal portions of air all over the house: and though there is a little frost, while mild, and the sun shining, the plants will be benefited by a small-portion of air for the space of an hour, or even for half of that time.

Whatever state the weather may be through the winter, never keep the house long shut up. Thirty-six hours should be the longest time at once; rather give a little fire heat.

We are no advocates for keeping plants in the dark, and never think that our plants are receiving justice if kept longer in darkness than one night.

\section{BULBOUS ROOTS.}

Those that were plunged in the garden, if not lifted and brought under corer, this should now be done without delay. Clean the pots, and stir up the surface of the soil. Hyacinths grow neatest by being kept very close to the top glass; the flower stems are thereby stronger and shorter. Water moderately until they begin to grow freely. 


\section{AMERICAN FLOWER GARDEN \\ DIRECTORY.}

\section{ROOMS.}

\section{PLANTS IN ROOMS.}

To treat on the proper management of plants in windows is a subject of considerable difficulty; every genus requiring some variation both in soil, water and general treatment. Howerer, a great part of the labor will be abridged by referring to these subjects in the green-house culture, which is quite applicable to the parlor, green-room, or veranda. If the room where the plants are kept is dark and close, but few will ever thrive; if; on the contrary, it is light and airy, with the windows in a suitable aspect to receive the sun, plants will do nearly as well, and, in some instances, better, than in a green-house. This is a well-known fact, and may be observed every day. We have seen as fine plants of Cactus, Daphne, Roses, Geraniums, Callas, Laurestinus, Carnations, Azaleas and Myrtles, grown in a window from year to year as ever could be grown in a green-house. Indeed, when there is a failure, it can be traced to one of the following three causes:

1st. Want of proper light and pure air is, perhaps, the most essential point of any to be considered; for, however well all other requisites are attended to, a deficiency in either of these will cause the plants to grow weak, yellow, and 
sickly. Therefore, have them always placed as near the light as possible, and receive as much air as can be admitted, when the weather will allow, and occasionally, in fine days, carry them out of doors, and give them a sprinkling of water all over.

2 d. Injurious watering does more injury to plants in rooms that many persons imagine; and it is very often to be observed that some individuals destroy all with too much, and others kill all with too little of that nourisher of health. To prevent the soil ever having a dry appearance is an object of great importance in the estimation of many: they, therefore, water to such an excess that the soil becomes sodden, and the roots consequently perish. 'Others, as we have said, run to the opposite extreme, and do not give sufficient to sustain life, and this is a more common practice than that of too much. The best plan is, always to allow the mould in the pot to have the appearance of dryness, but never sufficient to make the plant droop before a supply of water is given, which should then be copious and thoroughly going to the bottom of the pot; but always empty it out of the saucer or pan in which the pot stands: the water used should always be of about the same temperature as that in which the plants grow; avoid using it fresh from the pump.

3d. Being over-potted in unsuituble soil. This is also a crying evil, and large pots invariably given to weak plants, with the view of causing them to grow; but such practitioners are like the unskilful physician who gluts the weakly stomach of his patient, only hastening on what they are trying to prevent. With weak plants the very reverse should be practiced, giving small pots to encourage their roots outward: whereas, the earth in a large pot to a small plant, with frequent waterings, soon becomes sour and stagnated, and utterly obnoxious to the roots of even the strongest growing plants. If the directions and table of soils, in this work, are properly followed up, unsuitable soils will rarely occur, especially when each genus is separately treated.

In fact, we have yet to be convinced why all plants, with the exception of a few tropical, and those belonging to Ericer and Epacrider, will not grow and bloom well in rooms and windows. With the following monthly instructions, and executing them properly, failure will seldom occur; but where failure should occur, we would call particular attention 
to the tribe of Cactii, which are varied, beautiful, and truly interesting, and grow admirably in dry rooms, with or without full exposure to the sun, and in any temperature from $45^{\circ}$ to $85^{\circ}$, requiring only small portions of water once a-week in winter, and twice or thrice a-week during summer : they also only require fresh soil once a-year, or even once in two years for large plants will be found sufficient. The variety now cultivatedis truly astonishing, and we doubt not but in a few years large horticultural buildings will be erected for their express culture; and, to the inexperienced amateur, there is not a family of plants that will give more satisfaction, or, when properly studied, will afford greater interest and amusement.

\section{JANUARY.}

Plants that are kept in rooms generally are such as require a medium temperature, say from $40^{\circ}$ to $60^{\circ}$. Sittingrooms or parlors, about this season, are, for the most part, heated from $60^{\circ}$ to $70^{\circ}$, and very seldom has the air any admittance into these apartments; thus keeping the temperature from $10^{\circ}$ to $15^{\circ}$ higher than the nature of the plants requires, and excluding that fresh air which is requisite to support a regetative principle. Therefore, as far as practicable, let the plants be kept in a room adjoining to one where there is fire heat, and the intervening door can be opened when desirable. They will admit sometimes of being as low as $38^{\circ}$.

If they be constantly kept where there is fire, let the window be open some inches, once a-day, for a few minutes, thereby making the air of the apartment more congenial, both for animal and vegetable nature.

WATERING, \&c.

All that is necessary is merely to keep the soil in a moist state, that is, do not let it get so dry that you can divide the particles of earth, nor so wet that they could be beat to clay. 
The frequency of watering can be best regulated by the person doing it, as it depends entirely upon the size of the pot or jar in proportion to the plant, whether it is too small or too large, and the situation it stands in, whether moist or arid. Never allow any quantity of water to stand in the flats or saucers. This is too frequently practiced with plants in general. Such as Cálla AEthiòpica, or African Lily, will do well, as water is its element (like Sagittària in this country); the Hydrángea and Hyacinths, when in a growing state, will do admirably under such treatment. Many plants may do well for some time, but it being so contrary to their nature, causes premature decay; a fetid stagnation takes place at the root, the foliage becomes yellow, the plant stunted, and death follows.

\section{OF CAMELLIA JAPONICA.}

In rooms, the buds of Camellias will be well swelled, and on the double white and double rariegated sorts perhaps they will be full-blown. While in that state the temperature should not be below $40^{\circ}$; if lower, they will not expand so well, and the expanded petals will soon become yellow and decay. If they are where there is fire heat, they must have plenty of air admitted to them every favorable opportunity, and water freely given, or the consequence will be that all the buds will turn dark brown, and fall off. It is generally the case, in the treatment of these beautiful plants in rooms, that, through too much intended care, they are entirely destroyed. They do not agree with confined air, and to sponge frequently will greatly promote the health of the plants and add to the beauty of their foliage, as it prevents the attacks of the red spider.

When the flowers are expanded, and droop, tie them up neatly, so that the flower may be shown to every advantage.

\section{OF INSEC'TS, ETC.}

Insects of various kinds will be appearing on your plants. For method of destruction, see Hot-house, January. It will not be agreeable to fumigate the ronm or rooms, or even to have the smell of tobacco near the house from this cause. 
Take a tub of soft water (if the day is frosty it had better be done in the house), invert the plant, holding the hand, or tying a piece of cloth, or anything of the kind, over the soil in the pot, put all the branches in the water, keeping the pot in the hand, drawing it to and fro a few times; take it out and shake it. If any insects remain, take a small fine brush, and brush them off, giving another dip, which will clean them for the present. As soon as they appear again, repeat the process-for nothing that we have found out, or heard of, can totally extirpate them.

\section{OF BULBOUS ROOTS IN GENERAL.}

If you have retained any of the Cape bulbs from the last planting, let them be put in in the early part of the month. For method, see September. Those that are growing must be kept very near the light, that is, close to the window, or they will not flourish to your satisfaction. The fall-flowering oxalis may be kept on the stage, or any other place, to give room to those that are to flower.

Hyacinths, Jonquils, Narcissus, Tulips, \&c., will keep very well in a room where fire heat is constantly kept, provided that they are close to the window. A succession of these, as before observed, may beautify the drawing-room from February to April, by having a reserved stock, in a cold situation, and taking a few of them every week into the warmest apartment.

Wherever any of the bulbs are growing, and in the interior of the room, remove them close to the light, observing to turn the pots or glasses frequently to prevent them from growing to one side, and giving them support as soon as the stems droop, or the head becomes pendent. The saucers under the Hyacinth and Narcissus may stand with water, and observe to change the water in the glasses once or twice a-week.

Every one that has any taste or refinement in their floral undertakings, will delight in seeing the plants in perfection; to have them so, they must be divested of every leaf that has the appearance of decaying-let this always be attended to. 


\section{FEBRUARY.}

A $\mathrm{T}$ this season, the plants call for the most assiduous attention. If the stage has been made according to our description in September, in very cold nights it should be drawn to the centre of the room, or at least withdrawn from the window, observing every night to close the window tight by shutters, or some substitute equally as good. And, if the temperature begins to fall below $40^{\circ}$, means should be adopted to prevent it from lowering, either by putting a fire in the room, or opening any adjoining apartment where fire is constantly kept. This latter method is the best, where it is practicable, and ought to be studied to be made so.

Some very injudiciously, in extreme frosts, put into the room, where there is no chimney, among the plants, a furnace of charcoal, in order to heat the room. The effect is, that the foliage becomes dark brown and hardened like, and many of the plants die, the rest not recovering until summer.

Watering may be attended to according to the directions of January, only observing that those that begin to grow will absorb a little more than those that are dormant.

Roses, especially the daily, if kept in the house, will begin to show flower. Use means to kill the green-fly that may attack them.

Hyacinths and other bulbs must have regular attendance in tying up, \&c. Take care not to tie them too tightly, leaving sufficiency of space for the stem to expand. Give those in the glasses their necessary supplies, and keep them all near the light. Never keep bulbous roots, while growing, under the shade of any other plant.

Camellias, with all their varied beauties, will, in this month, make a splendid show. Adhere to the directions given in the previous month, and so that new varieties may be obtained (see Green-house, February, under the head of ('amellia), which directions are equally applicable here. When the flowers are full-blown, and kept in a temperature between $40^{\circ}$ and $50^{\circ}$, they will be perfect for the space of four, five, and frequently six weeks, and a good selection of 
healthy plants will continue to flower from December to April.

Be sure that there is a little air admitted at all favorable opportunities.

\section{MARCH.}

IF the plants in these situations have been properly attended to by admitting air at all favorable times, and when the apartment was below $40^{\circ}$, a little fire heat applied to counteract the cold, keeping the heat above that degree, your attention will be rewarded by the healthy appearance of your plants. The weather by this time has generally become milder, so that air may be more freely admitted, especially from ten to three o'clock. They will require a more liberal supply of water, but always aroid keeping them wet. Pick off all decayed leaves, and tie up any straggling shoots; give the pots a top-dressing with fresh soil, which will greatly invigorate the plants, and will allow the fresh air to act upon the roots, which is one of the principal assistants in regetation. For those that require shifting or repotting, see Greenhouse, March; the plants enumerated there equally apply here, if they are in the collection, with this difference, that well-kept rooms are about two or three weeks earlier than the green-house. After the end of this month, where there is a convenience, plants will do better in windows that look to the east, in which the direct rays of a hot sun are prevented from falling upon them, and the morning sun is more congenial for plants in this country than the afternoon sun. Where there is any dust on the leaves of any of them, take a sponge and water, and make the whole clean; likewise divest them of all insects. The green-fly is perhaps on the roses; if there are no conreniences for fumigating, wash them off as previously directed. Where there are only a few plants, these pests could be very easily kept off by examining the plants every day. For the scaly insect, see $J a$ nuary. If they have not been cleared off, get it done di- 
rectly; for by the heat of the weather they will increase tenfold.

\section{FLOWERING PLANTS.}

Hyacinths, Tulips, Narcissus, Jonquils and Crocus, will be generally in flower. The former require plenty of water, and the saucers under the pots should be constantly full, until they are done blooming. The others need only be liberally supplied at the surface of the pot. Give them neat green-painted rods to support their flower stems, and keep them all near the light. The spring flowering Oxalis will not open except it is exposed to the full rays of the sun. The Lachenalia is greatly improved in color with exposure to the sun, though when in flower its beauties are preserved by keeping it a little in the shade.

Primulas, or Primrose, both Chinese and Fiuropean, delight in an airy exposure; but the sun destroys the beauty of their flowers by making the colors fade.

Caméllias. Many of them will be in perfection. See green-house this month for a description of the finest varie- $~$ ties. Do not let the sun shine upon the blooms. Those that are done flowering will, in small pots, require to be repotted.

The Hyacinths that are in glasses must be regularly supplied with water. The roots will be very much reduced by this method; therefore, when the bloom is over, if possible, plant them in the garden, or bury them in pots of earth, to ripen and strengthen the bulbs. They cannot satisfactorily be again flowered in glasses, and, properly, they ought not to be allowed to bloom in the garden next year. Those that are done flowering in pots can be set aside, and the usual waterings gradually withdrawn. Treat all other Dutch bulbs in a similar manner. 


\section{APRIL.}

We remarked last month that, about this season, where it is convenient, an eastern window is more congenial to plants than a southern. The sun becomes too powerful, and the morning sun is preferable to that of the afternoon. West is also preferable to south. Some keep their flowering plants in excellent order at a north window. But the weather is so mild after this that there is no difficulty in protecting and growing plants in rooms. They generally suffer most from want of air and water: the window must be up a few inches, or altogether, according to the mildness of the day. And as plants are liable to get covered with dust in these apartments, and not so convenient to be syringed or otherwise cleaned, take the first opportunity of a mild day to carry them to a shady situation, and syringe well with water such as are not in flower; or, for want of a syringe, take a watering-pot with a rose upon it; allowing them to stand until they drip, when they may be put into their respective situations; or expose them to a shower of rain, but avoid allowing them to be deluged, which would be rery injurious.

\section{DIRECTIONS FOR PLANTS BROUGHT FROM THE GREEN-HOUSE.}

Any plants that are brought from the green-house during the spring months ought to be as little exposed to the direct rays of the sun as possible. Keep them in airy situations, with plenty of light, giving frequent and liberal supplies of water. Plants may be often observed through our city during this month fully exposed in the outside of a south window, with the blaze of a mid-day sun upon them, and these, too, just come from the temperate and damp atmosphere of a well-regulated green-house. Being thus placed in an arid situation, scorched between the glass and the sun, whose heat is too powerful for them to withstand, the transition is so sudden, that, howerer great their beauties may have appeared, they in a few days become brown, the flowers tar- 
nish or decay, and the failure is generally attributed to individuals not at all concerned. From this and similar causes many have drawn the unjust conclusion, viz., that "plants from green-houses are of too delicate a nature to be exposed in rooms or windows at this early season." But every year gives more and more proof to the contrary. There are ladies in Philadelphia, and those not a few, whose rooms and windows at this period vie with the finest of our green-houses, with respect to the health, beauty and order of their plants, and we might almost say in variety. Some of them hare got abore twenty kinds of Camellias in their collections, which afford a continual beauty through the winter, with many other desirable and equally valuable plants. The plants generally are now growing pretty freely, and are not so liable to suffer from liberal supplies of water, observing never to give it until the soil in the pot is inclining to become dry, and administering it in the erenings or mornings.

\section{FLOWERING PLANTS.}

Our directions last month under this head will equally apply now. The Chinese roses and geraniums that are now coming plentifully into flower should be kept near the light, and in airy exposures, to brighten their colors, otherwise they will be very pale and sickly.

\section{BRINGING PLANTS OUT OF THE CELLAR, ETC.}

All or most of the plants that have been in the cellar during winter, such as Pomegranates, Lagerstræmias, Hydrangeas, Oleanders, Sweet-bay, \&c., may be brought out to the open air any time about the middle of the month. If any of them stand in need of larger pots or tubs, have them turned out, the balls reduced, and put them in others a little larger; or, where conrenient, they may be planted in the ground. Be sure to keep the Hydrangeas in shady situations. It will not be advisable to expose entirely the orange and lemon trees until the end of this or first of next month. Where there is any scale or foulness of any kind collected 
on the foliage or wood, have it cleaned directly before the heat increases the one, and to get clear of the disagreeable appearance of the other.

\section{MAY.}

Alu the plants will be able to withstand exposure, in the general state of the seasons, about the tenth of the month. Begin about the first to take out the hardiest, such as Laurestinus, Hydrangeas, Roses, Primroses, Polyanthus, \&c., and thus allow the others to stand more free and become hardened to exposure. The reason that plants are so often seen brown, stunted, and almost half dead during summer, is from the exposed situation they are placed in, with the direct sun upon them, and too frequently from being so sparingly watered. There are no shrubby plants cultivated in pots that are benefited by full exposure to the hot sun from this period to September. A north-eastern aspect is the best for every plant except Cactus, Aloe, Mesembryanthemum, and such as go under the name of succulents, which may be fully exposed to the sun, but not to long and continued rains. Where there are only a few plants, they should be conveniently placed, to allow water from a pot with a rose mouth to be poured frequently over them, which is the best substitute for the syringe. Daphne, Coronilla, Fúchsia, Caméllia, Primrose and Polyanthus, do not agree with bright sun through the summer. There has been a general question what is the cause of the death of so many of the Daphne odora. It may be observed that the first place that shows symptoms of decay is at the surface of the soil, and this takes place a few weeks before there are evident effects of it. The cause is from the effect of heat or sun and water, acting on the stem at least. If the soil is drawn in the form of a cone round the stem, to throw off the water to the edges of the pot, that the stem may be dry above the roots, mortification does not take place, neither do they die prematurely when thus treated. For further remarks, see Greenhouse this month. 


\section{CAPE BULBS.}

Any of these that are done flowering, such as Ixia, Oxalis, Lachencilia, \&c., as soon as the foliage begins to decay, turn the pots on their sides, which will ripen the roots, and, when perfectly dry, clear them from the soil, wrap them up in paper, with their names attached, and put them carefully aside until the time of planting.

\section{REกOTTING.}

Where it is required, repot Cactus, Aloe, Mesembryanthemums, and all other succulents, with any of the Amaryllis that are required to be kept in pots; also, Cape Jasmines. For description of the above, see Hot-house and Green-house of this month, under the same head.

\section{JUNE AND JULY.}

THE only attention requisite to these plants is in giving water, keeping them from being much exposed to either sun or high winds, and preventing the attack of insects. Water must be regularly given every evening, when there has not been rain during the day. Where they are in a growing state, they are not liable at this season of the year to suffer from too much water, except in a few instances, such as the Lemon-scented Geranium, and those kinds that are tuberoserooted, as Ardèns, Bicólor, Tristúm, \&c., which should have moderate supplies.

All the plants ought to be turned round every few weeks to prevent them from growing to one side, by the one being more dark than the other, and keep those of a straggling growth tied neatly to rods. Wherever insects of any description appear, wash them off directly. Give regular syringings or sprinklings from the rose of a watering-pot. Be par- 
ticularly attentive in this respect, to the Caméllias, which will keep the foliage in a healthy state.

If the foliage of Lilium longiflòrum, or Japónicum, has decayed, do not water them while dormant, as they are easily injured by such treatment.

\section{AUGUST.}

For the kinds of plants that require potting, we refer to the Green-house for this month. All that are therein specified are peculiarly adapted for rooms, and we would call attention to the genus Cyclamen, which has not been generally introduced into the collections of our ladies; as, from the character and beauty of the flowers, they are very attracting and highly deserving of culture. Attend to the Geraniums as there directed, and be particular in having them cut'down and repotted, as there fully described. The Oranges, Lemons, Oleanders and Myrtles that are kept in cellars or rooms, should have the same attention in this month as directed in the green-house, which to repeat here would be occupying space unnecessarily.

Réseda odorata, or Mignonette, is one of the most fragrant annuals. To have it in perfection during winter, the seed should be sown about the end of this month, or the beginning of next, into pots of fine light earth, and spriakled with water frequently. When it comes up, the plants must be thinned out or transplanted: the former method is preferable. Keep them from frost during winter, and always near the light.

This will equally apply to the green-house.

Cape bulbs, such as Sparaxis, Ixia, Oxalis and Lachenatia, should now be planted. For method and sorts, see Green-house in August and September. 


\section{SEPTEMBER.}

WHERE there is a quantity of plants to be kept in these apartments, they should be disposed of to the best effect, and, at the same time, in such a manner as will be most effectual to their preservation. A stage of some description is better than a table, and, of whaterer shape or form, it ought to be on castors, that it may, in serere nights of frost, be drawn to the centre of the room. The shape may be either concave, a half circle, or one square side. The bottom step or table should be six inches wide and five inches deep, keeping each successive step one inch farther apart, to the desired height, which may be about six feet. Allowing the first step to be about two feet from the floor, there will be five or six steps, which will hold about fifty pots of a common size. A stage in the form of half a circle will hold more, look the handsomest, and be most convenient. We have seen them circular, and, when filled, appeared like a pyramid. These do very well, but they must be turned every day, or the plants will not grow regularly. With this attention, it is decidedly the best. Green is the most suitable color to paint them.

\section{GENERAL OBSERVATIONS.}

The directions giren for the green-house this month are equally applicable here. The late blooming Chrysanthemums are particularly adapted for rooms, the colors are so raried; and many of them are dwarf-growing, and even neat in their habit, especially the new bybrid sorts.

\section{OCTOBER.}

IIATE a stage or stages, as described last month, in the situations where they are intended to remain all winter; place the plants on them from the first to the eighth of this 
month, beginning with the tallest on the top, graduating to the bottom. It is desirable to place flats or saucers under each to prevent the water from falling to the floor, and the water should be emptied from the flats of all except those of Cálla and Hydrángea. The latter while dormant should be kept only a little moist.

Previous to taking in the plants, they should be divested of every decayed leaf, insects, and all contracted dust, having their shoots neatly tied up, and every one in correct order. Every leaf of the Caméllias ought to be sponged, and the plants placed in an airy exposure, and from this period till they begin to grow have them exposed to the sun. If the flower buds are too crowded, picking off the weakest will preserve the remainder in greater perfection, and prevent them in part from falling off. Do not on any occasion keep them in a room where there is much fluctuating fire heat, as the flower buds will not expand, except they are kept in an even temperature. See Green-house, this month, more largely on this subject.

\section{OF BUEBOUS ROOTS.}

Those that are intended to flower in glasses should be placed therein this month, and kept in a cool room. After the fibres begin to push a few shoots, the glasses may be taken to the warmest apartments to cause them to flower early. Bring a few from the coldest to the warmest every two weeks, and thus a succession of bloom may be kept up from January to March. Hyacinths and other Dutch bulbs should now be planted in pots. See Green-house for full directions.

Cape Bulbs. All that are unplanted and offering to grow should be put in pots forthwith. Ample directions are given for the planting of these in the two preceding months.

Report. Riubus rosafulius, or Bramble-rose. They should have pots one size larger than those they are now in. To make them flower profusely, when done blooming in May, divide them and put only a few stems in one pot, and repot them in this month, as above directed. 


\section{GENERAL OBSERVATIONS.}

Any herbaceous plants in the collection ought to be set aside, and the water in part withheld. When the stems and foliage are decayed, the plants may be put in a cool cellar, where they will not be in danger of frost, and be permitted to remain there until they begin to grow; then bring them to the light, and treat as directed for these kinds of plants. Deciduous plants may be treated in a similar manner.

\section{NOVEMBER.}

\section{GENERAL OBSERVATIONS.}

THE remarks and instructions that are given last month for these apartments will equally answer here. Where the Dutch bulbs were omitted to be placed in glasses, they ought not to be longer delayed.

Oxalis. The autumn-flowering species will now be in bloom, and must be kept in the sun to make them expand freely. The neglect of this is the principal reason that these do not flower perfectly in rooms.

Caméllias. These plants, where there is a collection, flower from this period till April; and the general desire to be fully acquainted with the method of their culture has induced us to be liberal in our observations on every point and period through the various stages of their growth and flowering. We will here only remind the inquirer that a pure air and plenty of water, giving the plants frequent sprinklings, are the present nccessities, which only are conducive to their perfection.

Attend to the turning of Geraniums and other rapidly growing plants, that all sides of them may have an equal share of light. 


\section{DECEMBER.}

As the trying season is now approaching for all plants that are kept in rooms, especially those that are desired to have a flourishing aspect through the winter, a few general instructions (although they may have been previously advanced) will perhaps be desirable to all those who are engaged in this interesting occupation, which forms a luxury through the retired hours of a winter season, and with very little attention many are the beauties of vegetative nature that will be developed to the gratification of every reflecting mind. The following is a routine of every day-culture:-

Do not at any time admit air (except for a few moments) while the thermometer is below $35^{\circ}$, exposed in the shade.

In time of very severe frosts the plants ought to be withdrawn from the window to the centre of the room during night.

Never give water until the soil in the pots is inclining to become dry, except for Hyacinths and other Dutch bulbs that are in a growing state, which must be liberally supplied.

Destroy all insects as soon as they appear: for the means of destruction, see next month.

Give a little air every favorable opportunity (that is, when the thermometer is above $35^{\circ}$, exposed in the shade), by putting up the window one, two, or three inches, according to the state of the weather.

Clean the foliage with sponge and water frequently to remove all dust, \&c. The water thus used must not exceed $80^{\circ}$, but $60^{\circ}$ is preferable.

Turn the plants frequently to prevent them growing to one side.

Roses of the daily sort may be obtained early by having them in a warm room that has a south window, and as soon as they begin to grow admit air in small portions about noon every day that the sun has any effect. Such must be well supplied with water.

Bulbs in glasses must be supplied with fresh water at least once a-week, in which period they will inhale all the 
nutritive gas that they derive from that element, if they are in a growing state.

Caméllias, when in bud and flower, should never be allowed to becorne the least dry, neither confined from fresh air. The effects would be that the buds would become stinted, dry, and drop off. Therefore, to have these in perfection, attend strictly to watering. Give frequent airings, and wash the leaves occasionally with water. Never keep them in a room where there is a strong coal fire. The most of Caméllias will bear $3^{\circ}$ of frost without the smallest injury, so that they are easier kept than Geraniums, except when they are in bloom. In that state frost will destroy the flowers. - The air of a close cellar is also destructive to the buds.

The reason that the Camellia does not bloom perfectly in parlors or other heated rooms is owing to their being too warm and arid, destroying the vital vegetative principle of the plant, and it soon perishes. There is one way in which these plants can be kept perfect even in such dry places when the recess in the windows is of sufficient depth as to allow plants to stand within it, enclosing them from the apartment by another sash: in such a situation, water could be placed, which would keep the atmosphere between the windows perfectly moist. The verdure would be rich and the flowers brilliant; and they would be completely protected from dust - the whole would have a very pleasing effect. Attention will be requisite to give them air during the mild part of the day. There are several Camellias not proper for room culture; those which have dry brown scaly buds are to be avoided, such as anemoneflora, egertonia, cleviana, fulgens, atrorubens; also avoid woodsii, chandlerii and clorsetia, as-being difficult of expanding-they are so very full of petals. Those most proper for room culture are double white, eclipse, fimbriata, imbricata, maliflora pæoniflora, Landrethii, Sacco, Sarah Frost, Washington, Madonna, punctata, speciosa, variegata and incarnata. Such will be found to bloom freely and fully: many others might be added, but these will give an idea of those sorts that agree best with room culture. We cannot conclude our subject without giving our readers some hints on the effect of plants in household apartments. It has been proved that the leaves of plants absorb carbonic acid gas by their upper surfaces, 


\section{December.] ROOMS-CAMELLIAS. 305}

and give out oxygen by their under ones, thereby tending to purify the air, in as far as animal life is concerned, because carbonic acid gas is pernicious to animals, and oxygen is what that life requires. It is in the light, however, that these operations are carried on, for in the dark plants give out carbonic. It does not appear that any of the scentless products given out by plants are injurious to human beings, because those who live among accumulated plants are not less healthy than others, but rather enjoy more uninterrupted bealth, which, of itself, is a sufficient recommendation for all to spend their leisure moments in so healthful and rational an employment. 



\section{AMERICAN FLOWER GARDEN DIRECTORY.}

ON THE CULTURE OF THE GRAPE.

WE are not aware of any vegetable production that is more conducive to the luxurious gratifications and pleasures of man than the vine. In fact, there is no fruit so delicious, applicable to so many purposes, nor any that is so agreeable to all palates: from the remotest ages the vine has been celebrated as the emblem of plenty and the "symbol of happiness." Its quickness of growth, its great fertility, and astonishing vegetative powers, with its unknown age, has rendered it one of the most fruitful blessings bestowed by Providence; a blessing which almost every inhabitant of this Union may enjoy, and we see no occasion to doubt but that thousands of acres of our fertile uplands will be converted into vineyards, producing the finest fruits and richest wines in the world. Indeed, with very little care and attention, our unsightly post and rail-fences may be converted into grape espaliers, and fine wines produced at as little cost as spruce beer; every square foot of surface might be made to produce a pound of grapes, and every post, at least, round our gardens afford ample space for one vine, which would yearly produce from three to nine pounds of fruit, fit either for the table or the wine-press. But the small space allotted in this volume will not allow us to dilate on this fruitful subject. Our object is to give a few hints on the aspect, 
soil, propagation, and culture of the rine, so as to produce an extra crop in the smallest given space. We will then consider, first, the

\section{ASPECT.}

As our climate gives us plenty of heat for the maturation of the vine, we have, therefore, more scope in aspect than any other country. However, the most preferable is one from south to east, or west. - Shelter from high and often recurring winds is a prime consideration. Our western and south-western gusts of wind are very destructive to the vine when it is in the full vigor of growth; it dissipates all the accumulated secretions of the foliage, and closes its pores, thereby totally deranging the vital functions of the plant, which (although in the height of the growing season) has been known to be suspended for weeks. There are frequently many local circumstances affecting the shelter of walls and other buildings, which, where they exist, must determine the best aspect for training the vine. But if there. be no such local circumstances, we have no hesitation in stating that an eastern aspect is the best. On such the sun shines with full force during the morning, at which time there is something highly farorable to regetation in his rays, which seems to stimulate the energies of plants in an extraordinary degree, and to excite them to a vigorous exertion of all the functions appertaining to vegetable life.

\section{ON SOIL.}

The soil most congenial to the growth of the vine and the maturity of its fruit is a rich, sandy, turfy loam, about two feet deep, on a dry, gravelly, rocky, or sandy bottom; the roots run with avidity into such sub-soils, lying secure from the excess of moisture, which always accumulates in clayey or compact soils. The excrementitious matter discharged from the roots of a rine is very great, and if this be given out in close and retentive soils, they quickly become deleterious, and a languid and diseased vegetation ensues; this is the great reason that so many failures exist. It may hence be 
inferred that vines will not thrive in a cold wet soil, nor composed of stiff clay, which is easily accounted for from the fact that they delight only in soils easily rendered dry by evaporation, and free from excess of moisture, and are always more warm, which is so genial to the growth of this plant. To elucidate this, we can record an instance that occurred a few years ago in this vicinity: A vine border was dug out to the depth of three feet and a half, in a cold retentive clay soil ; twenty inches of stone, brick, and limerubbish were put in the bottom, and the remainder filled up with good compost for the vines, in which they were planted, and grew well for two years, and produced some fruit; finally, they languished, and almost died, and it was at once pronounced that fine foreign grapes would not do in this country. But, on examining the roots of the plants, it was discovered that they were rotten from the excess of moisture which was retained in this pit; for though it had been partially filled with a dry bottom, no provision was made to carry off the water, therefore it proved to be a complete water-pail: a drain was necessarily dug to the full depth to carry off the water, and the soil generally renewed; the vines were cut to within two feet of the ground; they now (four years after the operation) grow luxuriantly, and produce abundant crops every year. Therefore, if the subsoil is not naturally dry, it must be made so by draining, which is the basis of the work, filling up the bottom with a sufficient quainty of dry materials, such as stones broken moderately small, brickbats, lumps of lime-rubbish, oystershells, \&c., which will keep them dry and warm by the free admission of air and solar heat, and to admit of heary rains passing quickly through without being retained sufficiently long to saturate the roots or injure the tender extremities; haring thus furnished a dry bottom, cover to the desired height with turf taken about three inches deep from a rich pasture; and to every four loads of turf add one load of thoroughly decomposed manure, at least one year old, interspersing it with bones of any description, oyster-shells, or any other enriching material that undergoes slow decomposition: the whole must be repeatedly turned, and allowed to settle before the vines are planted. Wxtreme caution has to be exercised in administering bone-dust, slaughter-house offal, and other over-rich manures, especially if the vines are to be planted 
the same or even the following season. Soils glutted with instant enriching manures are destructive to the vine. The surface of the border should have a gentle descent from the wall or fence: never crop your vine borders, and be careful of treading much upon them; a board trellis should be laid for walking upon when the operation of pruning, tying, \&c., takes place, which is almost daily during summer. The border, after it has been once made, ought never to be stirred, except at intervals, to keep it from becoming hard and impervious to heat or moisture; and, when necessary, it should only be forked up about two inches deep, at all times taking care not to injure the roots.

In dry sandy soils all that is wanted for the full perfection of the grape is to take out about one foot of the poorest of the ground, and replace it by turf from a meadow, adding thereto a portion of well-decomposed manure. Sweepings from turnpike roads, where there is much travel, is an excellent article for incorporating with such soils; it is of an enriching quality, its component parts consisting chiefly of sand, pulverized stones, dung, and urine, which is of a more lasting nature than can be found in almost any other compost; it ought to be thoroughly incorporated with the other soil soon after it has been collected from the road, as all its valuable qualities will then be entirely preserved. The foregoing remarks in the preparation of soil, if followed, will insure the luxuriant growth of vines and the yearly production of fine crops of grapes, and, when circumstances will permit, should be practically adopted at all times. But it must not be supposed that vines will not grow and mature fine crops unless thus encouraged in extra prepared soils. Such is not the fact, for vines will do well in any soil that is not adhesive and has a dry bottom; but they grow finer, and bear greater crops of fruit within a given space of time, when planted in ground that has been properly prepared for their reception. For instance, if two cuttings be planted, the one in a soil fully prepared, and the other in that of the latter description, it will be found at the end of three years that the vine in the former soil is double the size of the latter ; consequently, the strong vine will produce two-thirds more fruit, and of a better quality, than the weak vine. This difference occurring every year, and even greater as the age increases, is sufficicnt to amply repay for all the 
trouble and expense incurred in making a suitable compost. However, the disadvantage of a poor soil may in part be compensated for by planting the vines closer together. If, indeed, vines could not be planted with any prospect of success, except in borders purposely prepared, only a very small quantity of grapes would be grown, compared with what this rich and fertile country is capable of producing.

Many instances occur in towns and cities, around dwellings and other descriptions of brick and stone erections, which present very favorable situations for the training of vines, but, which, nevertheless, are so situated as to admit of little or no soil being placed at their roots. In such cases, if an opening can be made, twenty inches deep, and as many wide, it will be sufficient to admit of the roots of a young vine, which will support it till its rambling roots have found their way under the pavement, or along the walls to some more distant nourishment; if a wider space can be made, it will, of course, be better: loosen the sides and bottom as much as possible, and fill up with compost, as previously directed, and therein plant the vine. The surface covering, whether of brick or stone, may be replaced after the soil has fully settled, leaving a hole about six inches square to allow the stem of the plant to swell in its future growth. The roots soon find their way under the paving or along the foundation walls, and, indeed, in every direction, in search after food, and will extract nourishment from sources apparently barren. The fact is that the roots of the vine possess an astonishing power of adapting themselves to any situation in which they may be planted, provided it be a chy one.

\section{ON THE PROPAGATION OF VINES.}

Vines are gencrally propagated in the open ground by cuttings and layers.

By cuttings. At the general pruning, provide cuttings of the preceding summer's growth; choose such as are of a medium size, well-ripened and short-jointed, cut them into lengths of about eighteen inches each, leaving at the ends not less than two inches of wood to protect the eye; place these temporary cuttings about three-fourths of their length 
in the ground, in a warm and sheltered situation, where they can be protected with a little litter from the sererity of frost during winter. The best time for planting them is about the 25 th of March in this latitude, earlier or later if more south or north : if intended to plant the cutting where the plant is to remain, which is the most preferable method, prepare them in the following manner:

By cutting them into lengths of tree-buds each, and letting the uppermost bud have an inch of blank wood remaining to protect it, the extremity of which must be cut in a slanting manner, and the slanting side opposite to the buds, to throw off the moisture: the end that is to be inserted in the ground cut transversely just urider the bud, and the cutting will be complete: the cuttings being thus prepared, plant them forthwith; if intended to remain, place trro in each space, inserting them in the ground so as the second eye may be about half an inch under the soil, which must be pressed close, when it will, most frequently, be found that the eye thus placed will grow first and strongest, when the upper eye can be displaced; if both the cuttings grow, cut off the weakest. During May, June, and July, care must be taken to keep the cuttings constantly moist; soapsuds or drainings of the dung-hill can be used for the purpose once a-week, but not oftener, using rain or river water for general waterings. If the soil should sink down, and leave the buds higher than above mentioned, more must be added to keep them as directed. To prevent the ground from becoming hard by repeated waterings, and also to retain a regular moisture about the cutting, corer the soil with shells, litter, or any such substitute, which will greatly promote the regetating powers of the scion. As soon as they have made shoots six inches long, water may be more sparingly applied, and the shoots must be carefully tied to some support, and their tendrils and lateral shoots should be cut off, the latter to within one eye of the main stem: about the first of November, cut every plant down to within two eyes of the cutting. But if the plants are intended to be remored, they should be planted in such a situation as to be shaded from the mid-day sun; from four to six hours a-day of sun is quite sufficient. A spot sheltered from severe winds is also most desirable. When transplanted, be carcful 
of their small roots, and choose a mild day (about the first of April, or earlier, is a good season), for the operation.

By layers. This is a very expeditious mode of growing young vines, provided the shoots be laid in pots; but vines raised from shoots laid down in the open ground should be avoided as the worst of all plants : they make but few roots, and, when removed, these nearly all die off from being cut at the extremities in lifting, and the second year of such a plant is not much in advance of a good cutting. To grow vines by laying the shoots in pots, the following directions, if followed, will insure success: For each intended layer procure a seven-inch pot, or a small box of a similar, or even larger size, prepare some fine rich sandy mould, containing a great portion of decayed leares, then take the shoot and run it through the hole in the bottom of the pot till you come to the last three buds; close up the aperture round the shoot with moss, cotton, or any elastic substance, and then fill up the pot or box to within half an inch of the top with the prepared soil, having previously secured it in a safe and level position; and, where it can be conveniently watered during the season; this must be attended to at least once a-day. When there is not time for this attendance, the pot or box should be plunged under ground, and the layer placed thereon, and firmly secured, so that its own force will not raise it up; then cover up the shoots at least three inches, leaving space for occasionally holding some liquid nourishment. Shoots may be thus laid any time from the first of March to the first of April. It must be clearly understood that the success of the operation depends entirely on keeping the mould in the pots moist, treating it as directed for watering-cuttings. The plant may be separated from the vine about the first of September, and instantly planted into its desired locality, or put into a larger vessel, and there remain till planting season; the following year displace the tendrils and laterals as directed for cuttings, and in pruning cut it down to within three eyes of the ground. We may safely assert that it is a species of strangling to a vine in the first three years of its growth to be sparing of the knife, allowing, at once, small weak shoots to be laid in to form in a day (comparatively) a plant that is expected to withstand the vicissitude of ages, and produce yearly its quantum of fruit; but more of this when treating of pruning. 
By eyes. This is our most favorite method of propagating plants of this most valuable fruit. Early in the month of March we cut the shoots into eyes, leaving about an inch of wood on each extremity, and plant those with their eyes uppermost into pots, and place them in a hot or cold frame, prepared for the purpose ; plants from a single eye may easily be made to grow twelve feet in -one season, by constant repotting and nourishing. The plants thus growing are decidedly the best rooted, forming more capillary fibres; "consequently more nutritious support to the vine is absorbed in the same given period of time; they also form shorter joints, and are capable of producing more fruit on a plant of the same size. We are aware that some start at this idea, and say that in a few years it is not observed. It reminds us very much of the son of the "Isle of the Ocean," when asked how old his brother was, replied he was so much, but in two years he would be "the same age." Nerertheless, this method of propagating may not be generally accessible, the former two plans being at the command of every one.

\section{ON ERECTIONS FOR THE SUPPORT AND PROTECTION OF THE VINE IN OUT-DOOR CULTURE.}

To limit the proper height for training grapes would be a preposterous idea, for they can be perfectly cultivated in this country on any height from four to forty feet: indeed, on a wall of the former, we have thirty sorts of grapes growing luxuriantly, and fruiting in the most profuse manner. Some of the vines, four years old, which have produced from six to nine bunches of fine fruit, which only occupy, after pruning, a space of about eighteen inches square.

Walls of brick are decidedly the most preferable for the perfection of the grape; and if they be built for the express purpose, the most judicious distribution of materials would be in the erection of several low walls, not more than seven feet high. For the purpose of pruning, training, \&c., walls of this height are far preferable to those of a greater; and if built to run directly south or north, the entire surface of both sides may be judiciously covered. The eastern aspect would render a sure and abundant early crop; those on the western side would not be so productive, and more liable to 
be affected by our frequent severe westerly gales. When in bloom, or when the fruit is ripening, would be the period that they would be most liable to suffer. However, as they would frequently produce a full crop, an astonishing quantity of fruit may be produced on a very small space of ground by erecting walls of this description, built parallel to, and not far distant from, each other-say, at the nearest, from twenty to twenty-five feet. If from local causes bricks cannot be had, a good substitute will be found in strong ranges of plank fencing made of well-seasoned wood, and closely jointed, having three or four good coats of oil paint. Grapes raised in this way will be nowise inferior to those produced on walls : indeed, we would prefer such to any wall of stone that could be erected, it being of a more even surface and more conrenient for training, and not giving harbor for insects, \&c. A very great advantage will be derived by having a coping on the wall or fence, projecting eight or ten inches, turning on a pivot, so as it can be used in time of heavy dashing rains while the vines are in bloom, or when the fruit is ripening, which are the only periods that it will be of actual service, for all dews and light rains are indispensable to the health and maturity of the vine; and if the fence is north and south, the light and heat excluded by it would be a serious drawback on the ripening of the fruit. We say, therefore, if it is not on a pivot, the plants will be better without it, unless it have only one or two inches of a projection, the dripping from the coping will fall on the foliage, and that will carry it entirely free from the fruit; but we urge the great utility and even necessity for movable coping. Espaliers or trellises are in common use for the training of the vine, also arbors: the former suit admirably in small gardens where it is not desirable to go to expense, but the latter should be avoided as the worst possible construction for growing grapes; the interior is always filled with a current of cold air highly prejudicial to the maturity of fine fruits; but for coarse grapes it is a matter of little consequence, as they are at best only fit for producing shade. Upright trellises in city gardens may be made eight feet high, with the spars not more than six inches apart; and these should be made of the very best materials, and supported every three feet by uprights. Strong wire makes an elegant substitute for the cross slats, which, if kept well painted, 
will not suffer by corrosion. We have seen an elegant new erection by a tasteful grape amateur, and think it will answer a very good purpose; it consists of an upright double trellis, about one foot wide at the bottom, tapering to one bar at the top, running north and south, which is about eight feet high ; from which, on each side, there is fixed a small projecting sash, at an angle of about $48^{\circ}$, which keeps the vines perfectly secure from deluging rains, and even concentrates more solar heat for their maturity. The whole has a light and rather imposing effect; its practical utility remains to be tried, as it is but lately finished; there is no apparent doubt but it will prove very beneficial in its results.

\section{ON TRANSPLANTING THE VINE.}

The best period of the year for transplanting is during the months of October or March. The longer its removal is postponed after these periods the more injurious will be the effects of transplanting. Admitting the ground has been prepared according to directions formerly given, dig a hole about twenty inches deep, and as wide as will admit of the roots, if possible, to their full extension, without crippling in any manner. If any of them are injured in lifting, they must be cut back to soundness; fill up the hole to within twelve inches of the top, set the vine in the hole thus made, with its stem about six inches from the wall or fence, and let the plant be cut even with the ground; or, where there is plenty of space, and the plant two or more feet long, plant the root at a distance from where the stem of the vine is desired, and then disbud the young shoot, except the uppermost three; lay it down its full length, bringing the terminal buds to where the plant is wanted; by this method the whole extent of the shoot will make roots, and be of infinite service for the farther growth and support of the plant. When the eyes thus left grow, displace the weakest two, leaving the strongest for the permanent plant. We have seen old vines laid down in this manner for the distance of thirty feet, and, in two years, formed plants of the most astonishing vigor and production. If the vine has been grown in a pot, shake the ball of earth from the roots, among which place, with care, new and fresh soil, taking the plant and giving it several shakes to settle it 
well about the roots, which will encourage the plant to put forth new roots for its farther support. Transplanting should always be done in dry and mild weather, and when the soil is mellow and free. During the removal the roots must be carefully kept from exposure; the atmosphere would dry up their tender extremities, and cause much injury; and, when vines are brought from a distance, this precaution ought to be carefully put in practice. Its first season's growth should be confined to one stem only, carefully cutting off all lateral shoots within one èye of the main shoot, as directed on the subject of propagation.

\section{ON PRUNING.}

The first year's growth of a transplanted vine should, in November, be cut down within four inches of the ground, and, on the appearance, cover the plant with about three inches of stable litter, allowing it to remain in this state till the middle of March. The plant will now push strongly, and two of the best shoots should be trained their full length during summer, carefully nipping off tendrils and laterals, and, at all times, securing the shoots from the effects of high winds. If walls are used for training, there should be slats fixed about one inch from the wall to tie the shoots thereto, using soft material for the purpose of tying: if the vines should show fruit, cut it off.

Having the previous season retained two well-grown shoots from near the surface of the ground, you will now, in Norember, tie these in a horizontal position, about six or eight inches above the surface, cutting them at nearly two feet distance from the main stem. In the following month, February, when the weather is mild, displace every alternate bud, observing that it is those on the under side of the shoot. If everything has been attended to in soil, planting, and pruning that we have advanced, there may be expected to arise four shoots from each of these horizontal branches, which, if any show fruit, it must be cut off: these young shoots must be trained upright during summer, being careful to displace every other as they appear. Some approve of training these young upright shoots in a serpentine form, which, in our opinion at present, is of little consequence; but top them about the end 
of August, or earlier if they are to the desired height. In November of the third summer's growth, you may now prune for fruit as above stated. Your horizontal branches will have fully matured four luxuriant upright shoots. Cut two of these alternately within one eye of the horizontal shoot, which will produce wood to be fruited the following year, and lay in the other two, in a serpentine form for fruit, to about three feet in length. The vine has now assumed the form in which it is permanently to remain, and it may be considered as the foundation of a system of alternately fruiting four shoots, and training four out their full length every year, which method may be continued every year without any alteration. After several years, if it is thought proper, the arms may be lengthened by the training in of a shoot at their extremities, and managing it in the same manner as when the arms were first formed; but it is not advisable that the branches should be far extended, which would ultimately prove injurious to those branches arising from the bosom of the vine. This system of pruning and training the vine we do not advocate as something new or original, but one which we have seen in full and successful practice twenty years ago. By procuring well-grown plants in pots, one year may be gained on the above calculation; for you can prune, and at once take two shoots to prepare for laying the foundation of your future plant; but more than this cannot be accomplished. We are aware that many of our readers are already startled at this tedious method of fruiting vines, and have almost concluded to have fruit the first year or none. Such are too frequently the conclusions of many; but, as sure as they practice it, they as invariably meet with a failure, and that in a very few years. The practice of training vines to get them up to the top of arbors, \&c., cannot be done with fine vines without risk. As we have already said, it may and will do with our native kinds, but no other. The general system of spur-pruning has many advantages in in-door culture, but does not at all agree with growing grapes in the open air. Our limits do not admit of giving in detail our reasons for so saying, but those who doubt may go on in the old way, giving the system herein advised a trial with one plant only, and we guarantee that in less than five years their old vines are headed down to the stump, to begin on a system that yearly renews itself, and can be perpetuated for ages on the same 
vine, which may be said to "renew its youth every year." In fact, it recommends itself by simplicity-by the small number of wounds annually made-by the clear and handsome appearance of the vine, and by the great ease with which it is managed-its occupying but a small space. We therefore conclude this subject with the following few general rules: Use a knife of the best description, and let it be perfectly sharp; cut always upward and in a sloping direction; always leave about an inch of blánk wood beyond a terminal bud, and let the cut be on the opposite side of the bud. In pruning out an old branch, cut it even with the parent limb, that the wound may quickly heal. Never prune in frosty weather, nor in the months of March, April, or May. Let the general fall pruning take place about the end of October or first of November; after which, stir up the ground, and let a good coating of fresh stable manure be laid thereon, which will both protect the roots that are near the surface, and also enrich the soil ; but if stable manure cannot be procured, leaves from the woods are an excellent substitute, which, after decomposition, form a vegetable manure very enriching, and one very congenial to the vine; this being done, nothing more is required till the first of March, when the roughest must be removed, and the decomposed particles forked into the borders. It may be proper to state that in more northern latitudes and greater altitudes than Philadelphia, it will be necessary to lay down the vines after pruning during winter, and give them a light covering of litter, straw, leaves, or mats, which will completely protect them from the severest frost; although it is not altogether the severity that destroys, but the alternate frost and sun acting on the plant every twenty-four hours, which overcomes the vitality of the plant; and another felldestroyer is when we have a mild February and a severe March. When such occurs, which is but rarely, the vines must all be protected by mats while there is danger.

\section{ON MANURE.}

This subject has been very recently indulged in to a destructive extent. We could record instances of soils strongly impregnated with very enriching manures being almost death to the plant; very rich soils are adhesive and retentive of 
moisture, which is destruction to the roots of the vine. The celebrated Brassin, conductor of the royal vinery of France, used to practice enriching his vine borders with exciting manures: he now finds that cleansing of ditches, grass-turf, and road sweepings, mixed well together and allowed to ferment for a year, is far preferable. He now uses it entirely as an annual dressing; but, in our opinion, this cannot be continued for any length of time unless the border is also yearly reduced; consequently, manures that are of slow decomposition are preferable, and nothing that we are acquainted with excels kones of every description; but these are not always at hand in quantity. When to be obtained, they should always be put to a good purpose; an annual winter top-dressing of manure of a few inches, and the roughest removed in the spring, digging in the remainder not over four inches deep, which will eneourage the roots to the surface, where they will be greatly benefited by solar heat and air. Liquid manures are highly valuable where immediate effect is required : they coutain all the soluble parts of manure in such a state as to admit of being taken up by the plant as soon as applied. These are urine, which may be used pure any time from the first of November to February when the ground is not frozen; but if used at any other period, must be diluted with its equal quantity of water. Drainings of manure-heaps and soap-suds can be used at all times, but not too frequently. Soot dissolved in water, in the proportion of one to twelve, is an exceedingly strong manure, and very stimulating. Guano dissolved in water at the rate of $20 \mathrm{lbs}$. to 100 gallons is a first rate manure. Where great growth is required, they may be safely watered once a-week, during the growing season, with the enriched liquid; but all these exciting manures must be cautiously applied, as excess is very injurious to the fertility of the vine; and although one of the grossest feeders in nature, even possessing the appetite of a glutton, it can be satiated and destroyed.

DESCRIPTIVE CATALOGUE OF GRAPES MOST SUITABLE FOR OPEN AIR CULTURE.

Golden Chassclas, Chasselas de Fontainbleau, D'Arboyce, or Royal Muscadine. Bunches medium size, with very small 
shoulders, berries of a moderate size, round when ripe, turning to a bright amber color, having a thin skin, a soft flesh, and a rich juice. This is an exceedingly fine grape, a free bearer, is very hardy, and ripens early; it may be considered one of the best white grapes for out-door culture.

White Chasselas or White Muscadine. Bunches medium size, shouldered, and well formed. Berries round and of a good size, juicy, rich, and well flavored; it ripens about the middle or toward the end of September, and is an excellent hardy grape and fully equal to the former. We consider this grape the same as the Mulmsey Muscadine.

White Sweet Water (early). Bunches rather large; berries of a good size, round, of a white color, and, when perfectly ripe, especially when exposed, they are shaded with a light russet color; they grow close on the bunches, and when desired to have large berries, the bunches must be well thinned, the juice very saccharine and luscious. We consider this the very best white grape for walls; it is an excellent bearer, makes good short-jointed wood, and is very early. We have had it perfectly ripe on a south wall the first day of September.

White Muscat of Alexandria, Jerusalem Muscat, Malaga. Bunches large, but short and well shouldered; berries large, oval, and, when perfectly ripe (which will not be till October), are of a pale amber color, often without stones, skin rather thick, the flesh firm, juice not plentiful, but of a sweet, highly musky, delicious and peculiar flavor. It is an extra fine grape, and requires a warm situation. It does not bear so freely as the former two.

White Frontignac or Frontignan. Bunches long and narrow, without shoulders, rather closely set, of a dull white or grecnish-yellow, and covered with a powdering bloom ; juice very sugary and rich, with a delightful spicy flavor. It ripens in September, and delights in a dry soil.

White Ilamburg, White Lisbon, White Purtugal. Bunches very large, short and loosely formed; berries large and oval, skin thick, of a greenish white color, flesh firm, juice sweet, slightly mixed with acid; one of our latest white grapes. The plant is of a strong robust habit, and an excellent bearer.

Austrian Muscat. Bunches large and tapering: berries round, of a russet white color, skin thin, juice rich and 
musky, and of excellent flavor. It ripens about the second week of September, and is an excellent bearer.

Blact Frontignac, Violet Frontignac, Muscat Noir. Bunches small and short: berries round, and grow close in bunches; skin black, corered with a fine light bloom, flesh tender and juicy, of a rich vinous spicy flavor.

Black Hamburg. Bunches tolerably large, with short compact shoulders, tapering to a point; berries large, of an oval form, skin rather thick, very nearly black, and covered with a blue bloom; flesh tender, sweet, and of a rich vinous flavor; ripens about the first of October, but will hang on the vine till frost. This is, in every respect, one of the finest black grapes that can be grown in the open air: it is also a constant bearer. The leaves in the fall are mottled with green and yellow.

Black Prince. Bunches rather long and generally shouldered: berries oval, and of a good size, skin rather thick, of a dark purple, and covered with a thick bloom : flesh white, sweet, juicy and well flavored: ripe about the first of October.

Black Lombardy, West's St. Peter's. Bunches long ànd well shouldered : berries large, round, and of a regular size; skin thin and very black, juice plentiful and of a very high flavor; is perfectly ripe about the middle of October, and will keep on the vines till frost.

Black Muscadine, Black Chasselas, Violet Chasselas. Bunches about the size and shape of the Golden Chasselas: berries perfectly round and covered with a blue bloom: flesh juicy and of a very rich flavor: ripens about the first of October.

Frankendale. Bunches large, with small shoulders, and rather longer than the Black Hamburg: berries round and closely set; skin deep purple, approaching to black, covered with a thin blue bloom; flesh tender, sweet, rich, and of a luscious flaror: it is a great bearer, and fully ripe about the end of September or first of October.

Grizzly Frontignac, Muscat Gris. Bunches of a medium size, with small shoulders: berries round, of a light brown color, intermixed with red and yellow; the juice is exceedingly rich, and possessing a high spicy flavor: it ripens about the rniddle of September. 
Hansteretto. Bunches large and well formed: berries also large and perfectly round, of a jet black color when perfectly ripe; flesh rather juicy and of a rich flavor; leaves deeply lobed and a little downy underneath. An excellent hardy grape, but inferior in quality to the Black Hamburg: ripe about the first of October. 



\section{LIST OF HARDY EVERGREEN TREES AND SHRUBS.}

THE heights given are approximations to what is supposed the plants will attain in this country, to serve as some guide in planting them out.

Abies excélsa, Norway spruce _ . . . 100

— álba, white spruce . . . . . . 50

— Canadénsis, hemlock spruce _ . . 100

—_ Douglàsii, Douglas spruce . _ . . . 150

— nigra, black spruce . • . . . 80

— rùbra, red spruce . . . . . 50

— Smithiàna . . . . . . 50

Araucària imbricàta, Chili pine . . . . 100

Aúcuba Japónica, Japan gold tree . . . 5

Bérberis dúlcis, sweet berberry . . . . 4

Bûxus arboréscens, tree box . . . . . 20

—— argéntea, silver edged do. . . . . . 15

- áurea golden do. do. . . . . 15

- latifôlia, broad leaved do. . . . . 15

Cédrus Deodìra, Deodar cedar . 100

Libini, cedar of Lebanon . . . . 100

Cotonéaster microphỳlla, small leaved . . . . 4

thymifölia, Thyme leaved . . . 3

Cratægus Pyracántha, Pyracanth . . . . 10

Cryptomèria japónica, Japan weeping cedar . 50

Cupressus torulòsa, twisted cyprus . . . 15

20

25

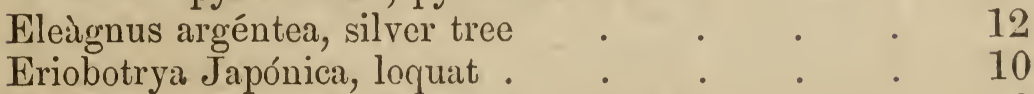

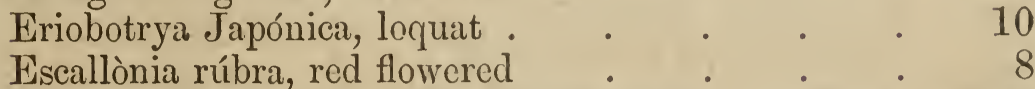

Euónymus Japónica, Japan spindle tree 10 
Euónymus argentea, silver edged do.

Feet.

10

fimbriàtus, fringed spindle tree

Hèdera hèlix creeper, Irish ivy

Ilex opàca, American holly .

- aquifólium, European do.

- variegàtum, variegated do.

Jasminum frùticans, dwarf Jasmine

- pubigerum, Japan do.

Juniperus Chinęnsis, Chinese juniper

excélsa, giant

do.

phonicea Phoenician do.

suécica, Swedish do.

Sabina, savin

do.

Virginiàna, Virginian do.

Kálmia latifòlia, broad-leaved sheep laurel

Magnòlia grandiflòra, tree laurel

Mahònia fasciculàris, evergreen berberry

- aquifòlia, holly leaved do.

Picea balsàmea, balm of Gilead fir

- pectinata, silver

Pinus Austriàca, Austrian

do.

do.

excelsa, Bhotan pine .

Larício, Corsican do.

strobus, white or Weymouth pine

- sylvestris, Scotch

- inops, Jersey

Prinos glaber, evergreen prinos

Rhododéndron Catawbiénsie, Carolina rosebay

do. máximum, mountain laurel pónticum, European rosebay

Rosmarìnus officinàlis, rosemary

Spàrtium júnceum, broom

Taxódium sempervirens, Californian spruce

Taxus baccata, English yew .

- adpréssa, appressed

- Canadénsis, Canadian jew

Chinensis, Chinese do.

do.

do.

8

30

30

30

20

6

10

15

30

10

20

8

41

10

50

10

8

60

60

60

100

80

80

60

60

6

8

10

8

8

100

20

4

16

10

10

20

pyramidàle, pyramidal

do.

4

Thùja filifórmis, weeping arhorvitæ 
LIST OF HARDY EVERGREEN 'TREES, ETC. 327

Thùja occidentilis, American arborvita Feet.

Thùja occidentalis, American arborvita •

orientilis, Chinese do. . . . 15

- plicata, tan leaved do. . . . 10

pyramidialis, pyramidale do. . . . 15

Torreya taxifolia, Florida yew tree . . . 50

Ulex Europèa, European furze or whin . . . 10

Yúcca filamentòsa, Adam's necdle . . . . 3

- gloriòsa, do. do. . . . . 4

recurvifólia recurved do. . . . . 5 


\section{LIST OF SELECT HARDY DECIDUOUS TREES AND SHRUBS.}

THE heights given are approximations to what it is supposed the plants will attain in this country in order to serve as some guide in planting them out.

Acacia Julibríssin 20 feet-Julibrissin tree, or purple Acacia; very handsome.

Acer platanoìdes, 60 feet-maple.

- campéstre, 20 feet-English maple.

— laciniatum, 20 feet-cut-leaved maple.

— sacchárinum, 60 feet-sugar maple.

- Nígrum, 50 feet-black maple.

Essculus Hippocástaneum, 60 feet-horse-chestnut.

flóre plenò-double flowered.

Amórpha fruticòsa, 10 feet-bastard indigo.

Ampelópsis quinquefòlia, Virginia creeper; very fine for covering walls or trees.

Amýgdalis nàna, 3 feet-dwarf-flowering almond.

- commùnis flore plenò, 15 feet-double-flowered peach.

Andrómeda polifòlia, 2 feet-powdered andromeda. pendùla, 10 feet-weeping peach. grandiflòra, 2 feet-large-flowered andromeda. Aràlia japónica, 12 feet-Japan aralia. Aristolòchia sipho-Dutchman's pipe, a splendid climber. Azàleas, 3 feet-hardy sorts, all beautiful. Bérberis vulgàris, 6 feet-Barberry. álba 4 feet-white fruited.

— - aristàta, 6 feet-very distinct.

- purpùreus, 4 feet-purple leaved.

Bétula álba, 50 feet-white birch.

— péndula, 20 feet-weeping birch.

- laciniàta, 40 feet-cut-leaved birch.

Búddlea Lindleyàna, 3 feet-Lindley's buddlea. 
Búddlea globòsa, 4 feet-globe-flowered.

Calycánthus flóridus, 6 feet-flowering shrub. fragràns, 4 feet-Chinese allspice.

Castànea luteà, 40 feet-yellow-flowered chestnut.

- pumila, 6 feet-dwarf chestnut.

Catálpa syringæfòlia, 30 feet-flowering catalpa.

Cérasus vulgirris fl. pl., 40 feet-double-flowering cherry. pendùla, 6 feet-weeping cherry.

Cércis Canadénsis, 20 feet-Judas tree or red-bud.

Chionánthus Virgínica, 20 feet-white fring tree.

Clèthra alnifơliæ, 5 feet-white fragrant clethra.

Córnus sanguínea, 8 feet-red dogwood.

- Flórida, 20 feet-white-flowering dogwood.

Córylus Avellàna, 10 feet-common filbert.

- purpurea, 8 feet-purple-leaved filbert.

Cratæegus edùlis, 20 feet-edible-fruited hawthorw.

- splendens, 20 feet-splendid do.

albaplèno, 15 feet-double white do.

rùbra plèno, 15 feet-double red do.

Cupréssus dísticha, 70 feet-deciduous cypress.

Cydònia Japònica, 6 feet-red pyrus.

$$
\text { álba, } 6 \text { feet-white do. }
$$

sinénsis, 10 feet-pink flowering.

Cỳtisus labúrnum, 20 feet-golden chain.

odoratus, 10 feet_-sweet-scented chain. alfinus péndulus, 10 feet-weeping labur-

num.

Delongàtus, 3 feet-dwarf do.

Deùtzia scìbra, 6 feet-garland deutzia.

stamínea, 6 feet-large white-flowered deutyia.

Eúonymus Americànus, 10 feet-spindle tree, or burning bush.

Europeus, 10 feet-European, do.

albus, 10 feet-white fruited, do.

Fàgus sylvática purpùrea, 30 feet-purple beech. - asplenifölia. 20 feet-fern-leaved beech. pendula, 16 feet-weeping do.

Forsýthia viridíssima, 4 feet-yellow flowered, large and showy.

Frìxinus excélsior péndula, 30 feet-weeping ash.

Fraxinus excélsior argéntea, 20 feet-silver-edged ash. 
Fraxinus excélsior argéntea salicifòlia-willow-leaved ash. Gymnódadus Canadénsis, 70 feet-Kentucky coffee tree. Halèsia díptera, 15 feet-silver-bell tree. tetráptera, 15 feet-snow-drop tree, beautiful.

Hibíscus syriacus, all very beautiful, 6 feet-Althæas, make very ornamental hedges.

Hypéricum kalmianum, 4 feet-St. Johns-wort. Juglans règia, 30 feet-English or Madeira walnut.

Kèrria Japónica, 6 feet-or yellow corchorus.

Kolreutéria paniculàta, 20 feet-yellow flowered, beautiful.

Làrix Americàna-American larch.

- Europæa-European do.

Lavándula spìca, 3 feet-lavender.

Ligústrum vulgàre, 8 feet-prim or privet, fine for fancy hedges.

Liriodéndron tulipífera, 80 feet-tulip tree.

Lonícera tartáricæ, 6 feet-Tartarian honeysuckle.

- rúbra, 6 feet-red flowered, do.

$\begin{array}{ll}\text { - Ledeboúrii, } 4 \text { feet-Ledebours } & \text { do. } \\ \text { - xylósteum, } 6 \text { feet-fly } & \text { do. }\end{array}$

Maclùra aurantìaca, 30 feet-Osage orange.

Magnòlia conspícua, 20 feet-Chinese, or early white magnolia.

cordàta, 60 feet-heart-leaved magnolia.

glaúca, 15 feet_-swamp laurel, or magnolia.

- macrophỳlla, 40 feet-broad-leaved do.

- purpurrea, 8 feet-purple-flowered do.

- rùbra, 8 feet-red-flowered do.

- soulangiàna, 20 feet-Chinese striped do.

- tripétala, 70 feet-cucumber tree.

Méspilus Germánica, 10 feet-Dutch medlar.

Oxycóccus macrocárpus, 10 feet-mountain cranberry.

Pæònia arbòrea fl. pl., 3 feet-tree pæonia, double ) flowered.

flowered. $\left.\begin{array}{l}\text { papaveràceæ, } 3 \text { feet-singleflower- } \\ \text { ed, white. }\end{array}\right\} \begin{aligned} & \text { Require } \\ & \text { shade. }\end{aligned}$ rósea, 3 feet-rose colored.

Paulównia imperiális, 30 feet-Chinese imperial tree, fragrant. Philadélphus coronàrius, 8 feet-mock orange.

- flòre plèno, 4 feet-double flowered. - grandiflòrus, 12 feet-large white 
Plátanus orientàlis, 80 feet-Chinese buttonwood.

Pòpulus trémula péndula, 20 feet-weeping poplar.

- alba, 30 feet-tree d'Abele, or silver poplar.

Ptèlea trifoliäta, 15 feet-hop tree.

Pyrus nivalis, 15 feet-snowy pyrus.

Americina, 20 feet-American rowan tree.

Aucupiria, 20 feet-European do.

vestita, 20 feet-waving do.

mìlus florè plèno, 15 feet-double flowering apple.

Quércus, 20 to 80 feet. The oak, though a common tree, should not be discarded in planting; it is both beautiful and valuable.

Rhús cótinus, 12 feet-mist tree.

Rìbes áurcum, 8 feet-yellow flowering currant.

sangúineum, 4 feet-red flowered, though a native, does not do well in this latitude.

Robìnia híspida, 4 fect-rose acacia. viscosa, 20 feet-white flowered.

Salisbùria adiantifòlia, 60 feet-Ginko, or maiden-hair tree. Salix babylónica, 40 feet-weeping willow.

críspa, 30 feet-ringlet willow.

Americana pendula, 15 feet-New weeping willow.

Shephérdia argéntea, 30 feet-buffalo berry.

Sophòra Japónica, 20 feet-Japan Sophora.

Spiræa-all very beautiful dwarf-growing shrubs, with white or pink flowers, exceedingly ornamental.

Syrínga vulgìris, 10 feet-purple lilac.

The red and white Persian, 6 feet-Charles the 10th and other sorts, are indispensable when planting shrubbery.

Támarix Germìnica, 10 feet-tamarisk tree, singulur.

Tilia Europaa, 40 feet-European linden.

Americina, 60 feet-American do.

Ulmus Americàna, 80 feet-American elm.

_ campéstris, 50 feet-English do.

- montina, 60 feet-mountain do.

- péndula-weeping do.

Vibúrnum òpulus, 10 feet-guelder rose.

Ví oxycóccus, 12 feet-tree cranberry.

Vitex Ágnus cástus, 8 feet-chaste tree.

Weìgelea ròsca, 4 feet-rose colored, clegant, unique.

Xanthoxylum fraxíneum, 10 feet-toothache tree. 


\section{TABLE OF SOILS.}

THE following compounds of soils are adapted to the nature of the Plants contained in this work:-

\begin{tabular}{|c|c|c|c|c|c|}
\hline$\underset{1}{\text { Number. }}$ & $\begin{array}{c}\text { Savanna. } \\
2\end{array}$ & $\begin{array}{c}\text { Loam. } \\
-\quad 1\end{array}$ & Leaf. & _ Sand. & _ Manure. \\
\hline 2 & - & $\begin{array}{l}-\quad 3 \\
-\quad 1\end{array}$ & 2 & 1 & - \\
\hline 3 & - & 4 & - & 1 & - \\
\hline 4 & - & - & 1 & - & - \\
\hline 5 & all & - & - & - & - \\
\hline 6 & 3 & - & - & - & - \\
\hline 7 & - & 3 & 1 & 1 & - \\
\hline 8 & 4 & 1 & - & - & - \\
\hline 9 & - & 2 & 2 & $\frac{2}{2}$ & - \\
\hline 10 & 1 & 1 & 1 & - & - \\
\hline 11 & - & 3 & 2 & 1 & - \\
\hline 12 & - & 3 & 1 & 1 & 1 \\
\hline 13 & 2 & 2 & 1 & $\frac{1}{2}$ & 1 \\
\hline 14 & - & 4 & - & 1 & - \\
\hline 15 & - & 4 & - & 1 & - \\
\hline 16 & 4. & - & - & - & - \\
\hline 17 & - & 5 & 1 & - & 1 \\
\hline 18 & - & 1 & 1 & 1 & 1 \\
\hline 19 & 1 & 1 & - & - & . - \\
\hline
\end{tabular}

REMARKS ON THE NATURE OF SOILS USED IN THE ABOVE TABLE.

Peat or Savanna soil is of a dark color, with a large portion of white sand incorporated with it, and is found frequently in New Jersey. A mixture of two-thirds black earth from the woods and one-third of pure white sand will be similar to it, and may be used as a substitute, but it is not exactly of the same nature.

Loam is of a light-brown color, and is that from the top of old pastures or commons, which should lie one year, and be frequently turned before using. It ought not to be from a clay bottom, and merely three inches of the turf taken.

Leaf mould is that which is to be found on the surface of the ground in woods, and is the decomposed leaves. It may be termed nearly of first rate importance in vegetation.

Sand is a substance that is generally known, and that which is found on the surface is decidedly the best. If it is from a pit, it must be spread out and frequently turned, that it may assimilate with the atmosphere before using; four months will be sufficient.

Manure.before using, must be decomposed to very fine particles. It will require two years, during which time it must be often turned, and the longer it lays it will be the finer and more congenial. 


\section{GENERAL I NDEX.}

Acacia, 147, 196, 197

Achimenes, 198

Acmadenia, 226

Aconitum, 35

Adam's needle, 46

Adenandra, 225

Adonis, 29, 34

Eschynanthus, 148

Xthiopian lily, 273

Agapanthus, 197

Agathosma, 226

Ageratum, 26

Agrostemma, 41

Air plants, 184

Allspice tree, 167

Allamanda, 148

Alligator pear, 165

Alœ, 190, 198, 267

Alonsoa, 198

Aloysia, 198

Alpinia, 142

Alstrœmeria, 199

Althœa, 19, 20, 33

A maryllis, 92, 105, 107, 144, 199

Amaranthus, 29

American cowslip, $3 \mathrm{~S}$

- sultan, 26

Ammocharis, 205

Amomum, 142

Amorpha, 19

Ampelopsis, 82

Anemone, 17, 34, 49, 87, 105, 107, 281

Aniseed tree, 236 of planting, 116

Annesleia, 147

Annuals, list of for hot-bed, 26 hardy, 29

Anomatheca, 277

Anthericum, 35

Antirrhinum, 35
Aphelandra, 148

Aphelexis, 227

Apicra, 267

Araucaria, 200

Arbor vite, 94

Arbutus, 201

Ardisia, 148

Areca, 148

A ristolochia, S0, 149

Asclepias, 35

Aster, 26, 201

Astrapea, 149

Aucuba, 201

Auricula, 17, 43, 48, 106

Azalea, 201

Azorian jasinine, 337

Babiana, 196, 277

Balsamina, 26

Bamboo cane, 149

Bambusa, 149

Banana tree, 167

Banisteria, 149

Banksia, 201

Barbadoes cherry, 166 gooseberry, 151

Barosina, 203, 226

Barringtonia, 149

Beaufortia, 203

Beaumontia, 150

Begonia, 203

Bell clematis, $\mathrm{SI}$

Belladonna, 93, 107

Bellis, 35

Benthamia, 203

Bergamotte, 221

Bignonia, S1, 150

Bindweed, 30

Birthwort, S0, 149

Bletia, 150, 203 
Bonapartea, 150

Boronia, 204

Bouvardia, 204

Brachysema, 204

Brachycome, 30

Bramble rose, 301

Brassia, 183

Brompton stock, 41

Browallia, 26

Brunsfelsia, 150

Brunsvigia, 205

Brugmansia, 204

Brunia, 204

Budding roses, 110

Buddlea, 150

Buphone, 205

Burchellia, 205

Cabbage tree, 148

Cacalia, 26

Cactus, 145, 151, 190

Calathea, 150

Calandrinia, 26

Calceolaria, 205

Calla, 264, 273

Callicoma, 206

Calliopsis, 37, 30

Calothamnus, 206, 242

Calystegia, 80

Carnellias, list of, 207

- $187,191,192,206$

Campanula, 17, 36

Camphor tree, 238

Canary-bird flower, 28

Candytuft, 30

Canna, 142, 151

Cantua, 33

Cape myrtle, 242

- jasmine, 160,268 Aster, 220

Caprifolium, 83

Carmichelia, 220

Carnation, 17, 38, 47, 88, 108, 113

-

- character of a, 108

Carolina jasmine, 233

Caryota, 155

Caryophyllus, 155

Cassava, 164

Catasetum, 183

Catalonian jasmine, 237

Catchfly, 34

Cattleya, 183
Ceanothus, 220

Celosia, 26

Centradenia, 155

Centranthus, 45

Centaurea, 26

Cerbera, 155

Cereus, 152,175

Ceropegia, 155

Cestrum, 220

Chamærops, 267

Charlwoodia, 158

Cheiranthus, 36

Chelone, 36

Chili jasmine, 167

- pine, 201

Chinese hybrid roses, 59

—- primrose, 282

- pink, 27

Chorozemia, 220

Chrysanthemum, 36, 115

Chryseis, 30

Cineraria, 220

Cinnamomum, 165, 220, 238

Cistus, 221

Citrus, 196, 221

Clarkia, 26

Clematis, 37, 80, 221

Cleome, 26

Clerodendrun, 155, 222

Clethra, 222

Clianthus, 222

Clivea, 222

Clintonia, 26

Clove tree, 155

Cobæa, 223

Coffea, 155

Coffee tree, 155

Colchicum, 107

Collinsia, 27

Colutea, 19

Combretum, 156

Commelina, 27

Convolvulus, 30

Coreopsis, 30, 37

Coral plant, 159, 230 honeysuckle, 83

Corn flag, 277

Coronilla, 223

Correa, 223

Corypha, 156

Cotyledon, 190

Cowslip, 43

Crane's bill, 233

Crassula, 190, 224 
Cratægus, 224

Crinum, 156, 224

Crocus, 107, 117

Croton, 157

Crowea, 224

Cunonia, 224

Cuphea, 224

Cupressus, 225

Curcuma, 142

Cycas, 157

Cyclamen, 273

Cydonia, 121

Cymbidium, 203

Cypripedium, 157

Cypress vine, 30

Cyrtanthus, 225

Cyrtoceras, 157

Cytisus, 19

Dahlia, history of, 96

- character of, 103

- list of, 100

- on lifting the, 122

Daisy, $17,35,48$

Dampiera, 225

Daphne, 281

Date palm, 169, 247

Daviesia, 225

Day lily, 39

Delphinium, 37

Dendrobium, 183

Dianthus, 38, 27

Dictamnus, 38

Digitalis, 33

Dillwynia, 225

Dionæa, 142

Diosma, 225

Diplacus, 226

Dodecatheon, 38

Double rocket, 17

larkspur, 116

Doryanthes, 226 wallflower, 17,106

Dracæna, 157, 226

Dracocephalum, 39

Dragon's head, 39

Dragon tree, 157, 226

Dropwort, 44

Dryandra, 226

Dutchman's pipe, 80

Dyckia, 227

Echeveria, 227

Echinocactus, 152
Edgings of various plants, 56

Edwardsia, 227

Elephant's foot, 253

Elichrysum, 227

Embothrium, 253

Enkianthus, 227

Entelea, 251

Epacris, 196, 227

Epidendrum, 183

Epiphyllum, 153, 175

Epiphytes, 184

Eranthemum, 158

Erica, 196, 228

- list of, 229

Eriobotrya, 230

Erodium, 230

Erythrina, 123, 159, 230

Erysimum, 30

Escallonia, 230

Eschscholtzia, 30

Eucalyptus, 230

Eucomis, 189

Eugenia, 158, 237

Euonymus, 95, 231

Eupatorium, 39, 231

Euphorbia, 158

Eutaxia, 231

Evergreen shrubs of planting, 84

Evening primrose, 31,42

Everlasting, 233

Fabiana, 233

Fair eye, 30

Fan palm, 164

Ferraria, 190

Ficus, 159, 231

Fig tree, 159

Flos Adonis, 29

Flax, 239

Flower-garden, on laying out a, 13

- de luce, 40, 118

Flues, on constructing, 130

Fourcroya, 190

Foxglove, 33

Franciscea, 160

Fraxinella, 38

French honeysuckle, 34

110

Fritillaria, 107, 113, 125

Fuchsia, 232

Funkia, 39, 40

Furnace, on constructing, 130 
Gardenia, 160, 267

Gardoquia, 233

Gasteria, 267

Geissomeria, 160

Gelsemium, 233

Genista, 19, 233

Gentiana, 39

Geranium, 233

Gerardia, 34

German stocks, 124

Gesneria, 142, 144

Geum, 39

Gilia, 30

Gladiolus, 92, 189, 191, 196, 277

Gloriosa, 143

Glory flower, 222

Gloxinia, 143, 144

Glycine, 81

Gnaphalium, 233

Gnidia, 233

Gongora, 183

Gomphrena, 27

Gorteria, 234

Grafting, 56

Grape vine, culture of, 307

- pruning of, 317

- manure of, 319

of, 320

Grass and other edgings, 32

Green-house, on erecting a, 185

Grevillea, 234

Grove love, 31

Guano, introduction and p. 54

Gum-elastic tree, 231

Habranthus, 234

Hawkweed, 30

Haworthia, 267

Heart's-ease, 31, 90

- culture of, 90

Heath, 196, 228 character of, 91

Hedera, 82

Hedychium, 142

Hed ysarum, 34

Helianthus, 30

Helichrysum, 234

Heliconia, 160

Heliophila, 30

Heliotropium, 161

Hemerocallis, 39

Hemimeris, 198

Hemlock spruce, 94

Heron's bill, 230
Hibbertia, 235

Hibiscus, 40, 161

Hieracium, 30

Holly, 236

Hollyhock, 33

Honeysuckle, 20, 83

Hottentot's bread, 253

Hovea, 235

Hoya, 161

Humea, 34

Hyacinth, 85, 105, 117，125, 191, 196

Hybrid roses, 59

Hydrangea, 235, 262

Hypericum, 235

Iberis, 30

Ice plant, 27

Ilex, 236

Illicium, 236

Imhofia, 205

Indig ofera, 237

Indigo tree, 237

Insects, destruction of, 136

Ipomœa, 30, 162

Ipomopsis, 33

Iris, 40, 47, 107, 118

Irish ivy, 82

Ismene, 162

Ixia, 139, 189, 191, 196, 277

Ixora, 162

Jacksonia, 237

Jacobæa lily, 92

Jambosa, 163, 237

Japan day lily, 39

Jasmine, 82, 237

Jasminum, 82, 163, 237

Jatropha, 163

Jonquil, 47, 107, 118

Juniperus, 94

Justicia, 164, 237

K̄æmpferia, 142

Kalosanthes, 224

Kennedia, 237

Lachenalia, 139, 188, 196, 274

Ladies' slipper, 26

Lagerstræmia, 262

Lantana, 164

Larkspur, 37

Lasiopetalum, 238 
Lasiandra, 164

Latania, 164

L.athyrus, 30

Laurus, 165, 238

Laurustinus, 257

Lavandula, 238

Lavender, 56, 238

Leschenaultia, 238

Lead wort, 43, 248

Leonotis, 239

Leptospermum, 239

Leptosiphon, 196

Leucadendron, 239

Leucospermum, 239

Liatris, 40

Lilium, 118, 278

Lily, 118, 278

Linum, 239

Lion's ear, 239

Liparia, 240

Loasa, 30

Lobelia, 240

London pride, 44

Lonicera, 83, 240

Lophospermum, 240, 249

Love lies bleeding, 29

Loquat, 230

Lunaria, 34

Lupinus, 30

Lychnis, 40, 240

Lysinema, 240

Lythrum, 41

Magnolia, 241

Mahernia, 241

Mahogany tree, 172

Malabar nut, 237

Malay apple, 163

Malope, 31

Malphighia, 166

Mammillaria, 151, 175

Mandevillia, 167

Manettia, 241

Manetii rose for stock, 110

Mangifera, 165

Mango tree, 165

Manihot, 164

Marica, 166

Marigold, 28

Marvel of Peru, 31

Mastich tree, 248

Matthiola, 41

Maurandia, 27

Maxillaria, 183

Meadow sweet, 44

29

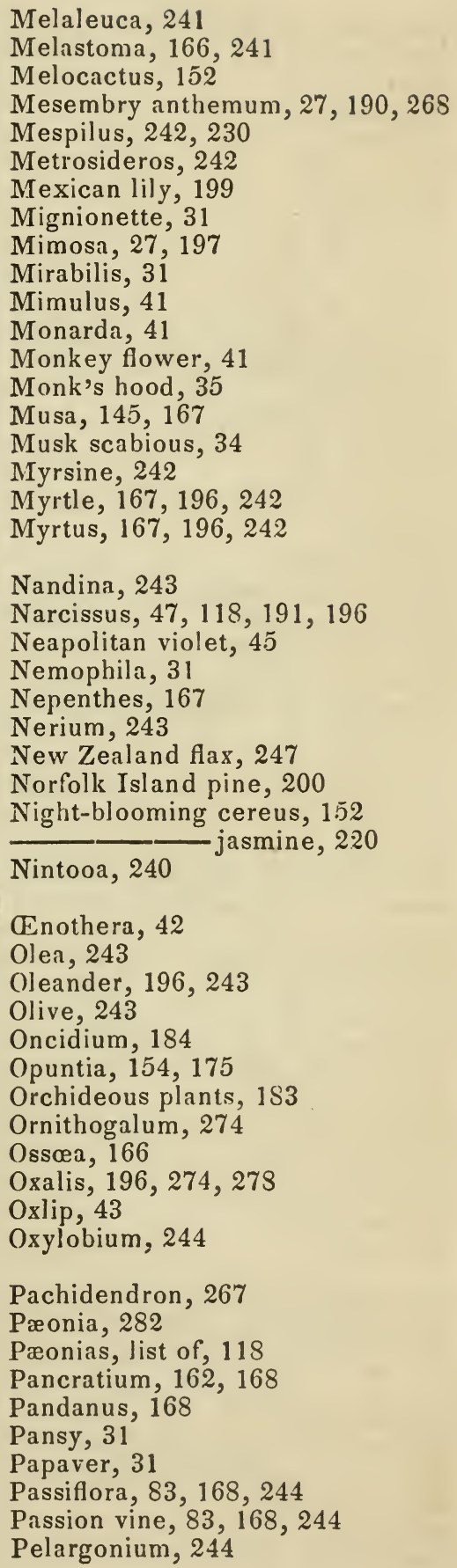

Melaleuca, 241

Melastoma, 166, 241

Melocactus, 152

Mesembry anthemum, 27, 190, 268

Mespilus, 242, 230

Metrosideros, 242

Mexican lily, 199

Mignionette, 31

Mimosa, 27, 197

Mirabilis, 31

Mimulus, 41

Monarda, 41

Monkey flower, 41

Monk's hood, 35

Musa, 145, 167

Musk scabious, 34

Myrsine, 242

Myrtle, 167, 196, 242

Myrtus, 167, 196, 242

Nandina, 243

Narcissus, 47, 118, 191, 196

Neapolitan violet, 45

Nemophila, 31

Nepenthes, 167

Nerium, 243

New Zealand flax, 247

Norfolk Island pine, 200

Night-blooming cereus, 152

Nintooa, 240

Enothera, 42

Olea, 243

Oleander, 196, 243

Olive, 243

Oncidium, 184

Opuntia, 154, 175

Orchideous plants, 183

Ornithogalum, 274

Ossœa, 166

Oxalis, 196, 274, 278

Oxlip, 43

Oxylobium, 244

Pachidendron, 267

Pæonia, 282

Pæonias, list of, 118

Pancratium, 162, 168

Pandanus, 168

Pansy, 31

Papaver, 31

Passiflora, 83, 168, 244

Passion vine, 83, 168, 244

Pelargonium, 244 
Pelargonium, list of, 246

Pentstemon, 17

Pereskia, 154

Periploca, 82

Periwinkle, 28

Persea, 165

Petunia, 27

Phaseolus, 247

Phlox, 27, 42

Phœnix, 169, 247

Phormium, 247

Photinia, 224

Phrynium, 142

Phylica, 247

Physic nut, 163

Pimelea, 247

Pimenta, 167

Pinks, 17, 38, 47, 88, 108, 109

Pinus, 94

Pistacia, 248

Pitcher plant, 167

Pittosporum, 248

Plantain tree, 167

Platylobium, 248

Plumbago, 43, 169, 248

Plumeria, 169

Podalyria, 248

Poinsettia, 170

Poivrea, 156

Polianthes tuberosa, $\delta 9$

Polyanthus, 17, 88, 106

- character of a, 89

Polyspora, 170

Pomegranate, 262

Potentilla, 43

Portulaca, 27

Primrose, 43, 48, 88, 106

Primula, 43, 282

Prince's feather, 29

Protea, 239, 248

Pruning, 18, 19

Pterospermum, 170

Pultenea, 249

Pyrus, 121

Queen Margaret, 26

Q plant, 171, 252

stock, 41

Ragged Robin, 41

Ranunculus, 17, 49, 87, 105, 107

Red cedar, 94 character of a, 87

- - spider, 137

Renanthera, 184
Reseda, 31

Rhapis, 170

Rhododendron, 249

Rhodochiton, 249

Rhus, 19

Richardia, 273

Rhipidodendron, 267

Robinia, 19

Rochea, 224

Rocket larkspur, 30

Rock rose, 221

Roella, 250

Rondeletia, 171

Rooms, treatment of plants in, 287

Rose campion, 33

- tree, 249

Roses budding, 110

- Chinese or Bengal, everblooming, 66

--, climbing, 53,75

-

- - hardy garden, list of, 49

-

- , hybrid perpetual, 63

_-, I'Isle de Bourbon, 65

--, microphylla, 78

-, musk-scented, 74

-, noisette, 72

-

- -, of grafting, 64

-, perpetual, 61

-, striped, list of, 61

Rubus, 301

Ruellia, 171

Russelia, 171

Sage, 250

Sago palm, 171

Sagus, 171

Salpiglossis, 27

Salvia, 250

Saponaria, 44

Saxifraga, 44

Scabiosa, 34

Schizanthus, 28

Scottia, 251

Screw pine, 168

Senecio, 251

Sensitive plant, 27

Shrubs, of planting, 21

Shortia, 28

Silene, 44

Silk vine, 82

Silver tree, 239

Snail flower, 247 
Snapdragon, 35

Solandra, 171

Sollya, 251

Sparaxis, 279

Sparmannia, 251

Speedwell, 45

Spherolobium, 251

Spiderwort, 173

Spiræa, 44

Spurge, 158

Spreikelia, 92

Sprengelia, 252

Stanhopea, 184

Star of Bethlehem, 274

St. Barnos lily, 35

St. Johnswort, 235

Statice, 44

Sterculia, 281

Sternbergia, 107

Stephanotis, 172

Stock gilly, 17, 41

Stork's bill, 244

Strelitzia, 171, 252

Strawberry tree, 201

Streptocarpus, 252

Stylidium, 252

Styphelia, 252

Summer heliotrope, 31

Sutherlandia, 253

Swainsonia, 253

Sweet William, 38

- bay, 124

- pea, 30

- sultan, 26

Swietenia, 172

Sword lily, 92

Tabernœmontana, 172

Tacsonia, 255

Tagetes, 28

Talauma, 241

Taliera, 156

Tea plant, 2.53

Tecoma, 82, 172, 253

Telopea, 208, 253

Testudinaria, 253

Thea, 253

Thomasia, 238

Thrift, 44, 56

Thrinax, 172
Thuja, 94

Thunbergia, 28, 172

Thyme, 56

Tiger flower, 93

Tigridia, 93

Tournefortia, 31

Tradescantia, 173

Tree primrose, 31

- pœony, 282

Tritonia, 279

Tropæolurn, 28, 255

Tuberose, 89, 105, 115

Tulip, of planting the, 119

- character of a good, 86

Tulips, 47, 86, 105, 125, 196

Turk's cap, 152

Urania, 173

Valeriana, 45

Variegated Euphorbia, 30

Vanda, 184

Venus' paint-brush, 27

- Ay-trap, 142

Verbena, 28, 256

Veronica, 45, 257

Viburnum, 19, 257

Viminaria, 257

Vinca, 28

Viola, 45, 90

Virgin's bower, 37, 80, 221

Volkameria, 222

Wachendorfia, 188

Wahlenbergia, 36

Wall flower, $36,106,124$

Warratah, 208

Watsonia, 196, 279

Wax plant, 161

Westringia, 257

Wind flower, 34

Wistaria, 81

Witsenia, 258

Wolfs'-bane, 35

Yucca, 46, 258

Zamia, 173, 258

Zebra plant, 150

Zingiber, 142

Zinnia, 28

Zygopetalum, 184 


\title{
R. B UIS T,
}

\section{NURSERYMAN AND SEED-GROWER,}

Cultivates and has for sale an extensive Stock of

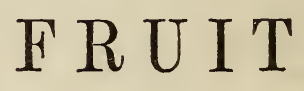

AND

O R N A MENTAL TREES,

FLOWER, SHRUBS, ROSES, \&C.

\author{
Also, an extensive grower of \\ GARDEN SEEDS. \\ WHOLESALE AND RETAIL \\ NURSERY AND SEED FARM, \\ DARBY road.

\section{SEED WAREHOUSE,} \\ 98 CIIESTNUT STREET.
}

Green-houses, to the extent of 20,000 feet of Glass, at the ROSEDALE NURSERIES, PHILADELPHIA.

Priced Catalogues on application.

N. B.-Every article warranted as represented. 


\section{INEW BOORS}

RECENTLY PUBLISHED BY

\section{A. HART, late CAREY \& HART,}

No. 126 Chestnut Street, Philadelphio.

\section{IISTORICAL AND SECRET MEHOIRS PROSE WRITERS OF GERHANY.}

OF THE

EMPRESS JOSEPHINE,

(Marie Rose Tascher de la Pageric,)

FIRST WIFE OF NAPOLEON BONAPARTE.

BY MLLE. M. A. LE NORMAND.

Transtated from the French by Jacob Howard, Esq.

In 2 vols., 700 pages, muslin extra gilt. "It possesses great intrinsic interest. It
is a chequered exhibition of the undress life of Napoleon. All the glitter and pomp and laid; and we behold not the hero, the emperor, the guide and moulder of destiny,
but a poor sickly child and creature of circumstance-affrighted by shadows and tortured by straws."-Philada. City Item.

"This is one of the most interesting works of the day, containing a multiplicity of incidents in the life of Joseph!ne and her renowned husband, which have never before been in print." -N. O. Times.

"This is a work of high and commanding interest, and derives great additional value from the fact asserted by the authoress, that the greater portion of it was written by the empress herself. It has a vast amount of information on the subject of Napoleon's ? career, with copies of original documents not to be found elsewhere, and with copious notes at the end of the work." $-N$. O. Com. Bulletin

"Affords the reader a clearer insight into the private character of Napoleon than he can obtain through any other source."Baltimore American.

"They are agreeably and well written; and it would be strange if it were not so, enjoying as Josephine did, familiar colloquial intercourse with the most distinguished men and minds of the age. The work does not, apparently, suffer by translation." - Baltimore Patriot.

"It is the history-in part the secret history, written by her own hand with rare elegance and force, and at times with surpassing pathos - of the remarkable woman who, by the greatness of her spirit was worthy to be the wife of the soaring Napoleon. it combines all the value of authentic his. ory with the absorbing interest of an autoblography or exciting romauce."-Itern.
BX FREDERICK H. HEDGE.

ILLUSTRATED WITH EIGHT PORTRAITS AND AH ENGRAVED TITLE-PAGE, FROM A DESIGX BY LEUTZE.

Complete in One Volume Octavo.

\section{Contents.}

Luther, Bœhme, Sancta Clara, Moser, Kant, Lessing, Mendelssohn, Hamann, IVieland, Musäus, Claudius, Lavater, Jacobi, Herder, Gæthe, Schiller, Fichte, Richter, A. WV. Schlegel, Schleiermacher, Hegel, Zschokke, F. Schlegel, Hardenberg, 'Tieck, Schelling, Hoffinann, Chamisso.

"The author of this work-for it is well entitled to the name of an original production, though mainly consisting of translations-Frederick H. Hedge of Bangor, is qualified, as few men are in this country, or wherever the English language is writ$\{$ ten, for the successful accomplishment of the great literary enterprise to which he has devoted his leisure for several years.

"Mr. Hedge has displayed great wisdom in the selection of the pieces to be transe lated; he has given the best specimens of the best authors, so far as was possible in his limited space.

"IV e vesture to say that the cannot be crowded into the same compass a more faithful representation of the German mind, or a richer exhibition of the profound thought, subtle speculation, massive learning and genial temper, that characterize the most eminent literary men of that nation." - Harbinger.

"What excellent matter we here have. The choicest gems of exuberant fancy, the most polished productions of scholarship, the richest flow of the heart, the deepest lessons of wisdom, all translated so well by Mr. Hedge and his friends, that they seem to have been first written by masters of the English tongue." - The City Item.

"We have read the book with rare pleasure, and have derived not less information than enjoyment."-Knickerbocker.

"The selections are judicious and tasteful, the biographies well written and compre hensive."-Inquirer 


\section{NAPOLEON}

AND

\section{THE HARSIIALS OF THE EMPIRE}

Complete in 2 vols. $12 \mathrm{mo}$.,

With 16 Steel Portraits in Military Costume.

\section{Contents.}

Napoleon, Jourdan, Serrurier, Lannes, Brune, Perignon, Oudinot, Soult, Davoust, Massena, Murat, Mortier, Ney, Poniatowski, Grouchy, Bessieres, Berthier, Souchet, St. Cyr, Victor, Moncey, Marmont, Macdonald, Bernadotte, Augereau, Lefebvre, Kellermann.

The biographies are twenty-seven in number-Napoleon and his twenty-six marshals, being all those created by himand therefore these pages have a completeness about them which no other work of a similar design possesses.

The style is clear and comprehensive, and the book may be relied upon for historical accuracy, as the materials have Deen drawn from sources the most authentic. The Conversations of Napoleon, with Montholon, Gourgaud, Las Cases and Dr. O'Meara have all been consulted as the true basis upon which the lives of Napoleon and his commanders under him should be founded.

"The article on Napoleon, which occupies the greater part of the first volume, is written in a clear and forcible style and displays marked ability in the author. Particular attention has been paid to the early portion of Napoleon's life, which other writers have hurriedly dispatched as though they were impatient to arrive at the opening glories of his great career." $-N$. Y. Mirror.

"The lives of the Marshals and their Chief, the military paladins of the gorgeous modern romance of the 'Empire,' are given with historic accuracy and without exaggeration of fact, style or language." $-B a l-$ timore Patriot.

"We have long been convinced that the character of Napole on would never receive 'even handed justice' until some impartial and intelligent American should undertake the task of weighing his merits and demerits. In the present volume this has been done with great judgment. We do not know the author of the paper on Napoleon, but whoever he may be, allow us to say to him that he has executed his duty better than any predecessor."-Evening Bulletin.

"The style of this work is worthy of commendation-plain, pleasing and narrative, the proper style of history and biography in which the reader does not seek fancy siketches, and dashing vivid pictures, but what the work professes to contain, biographies. We commend this as a valuable iibrary book worthy of preservation as a work of reference, after having been read." - Balt. Amerizan.

"This is the clearest, most concise, and most interesting life of Napoleon and his marshals which has yet been given to the public. Tne arrangement is judicious and the charm of the narrative continues un. broken to the end."-City Item

"The publishers have spared no pains or expense in its production, and the best talert in the country has been engaged on its yarious histories. The style is plain and graphic, and the reader feels that he is perusing true history rather than the ramblings of a romantic mind."-Lady's Book.

"The result of these joint labors is a series of narratives, in which the events succeed each other so rapidly, and are of so marvelous a cast, as to require only the method in arrangement and the good taste in description which they have received from the hands of their authors. The inflated and the Ossianic have been happily avoided." Colonization Herald.

"Their historical accuracy is unimpeachable, and many of them (the biographies) are stamped with originality of thought and opinion. The engravings are numerous and very fine. The book is well printed on fine white paper, and substantially bound. It deserves a place in all family and school libraries."-Bulletin.

"It abounds in graphic narratives of battles, anecdotes of the world-famed actors, and valuable historical information."-Rich mond Inquirer.

"We receive, therefore, with real pleasure, this new publication, having assurance that great pains have been taken in the preparation of each individual biography, and especially in collating the various authorities upon the early history of the Emperor. There appears to be nowhere any altempt to blind the reader by dazzling epithets, and the accuracy of construction throughout is highly creditable to the editor."-Commercial Advertiser. N. Y.

"The style is simplicity itself, wholly free from the amusing pomposity and absurd inflation that distinguish some of the works which have gone before it."

\section{BRYANT'S POEMS.} ILLUSTRATED ET TWENTY SUPERB ENGRAVINGS, From Designs by E. LEUTZE, Expressly for this Volume, ENGRAVED BY AMERICAN ARTISTS, And printed on fine Vellum paper. CONPLETE IN ONE VOLUNE OCTAVO.

\section{Sixth Edition. (Just ready.)}

Price $\$ 5.00$ bound in scarlet, gitt edges; or beautifully bound by S. Moore in calf or Turkey morocco, $\$ 7.00$.

"This is really a splendid book, and one of the most magnificent of Carey \& Hart's collection of "The Illustrated Poets." $-U .{ }^{-} S$. Gaz.

"The 'getting up' of this edition is credits able in the highest degree to the publishers and the fine arts of the country. The paper binding, and the engravings are all of the very best kind."-Inquirer and Courier. 


\section{PETER SCHIEMIET.}

\section{PETER SCHLEMIHL IN AMERICA.}

\section{Complete in One Volume, $12 \mathrm{mo}$.}

"'The object of this work is to 'catch the 'shown up, aud the morals of the book are manners living as they rise' in conllection unexceptionable. The author cannot long with the antagonisms of the present day- eseape detection, in spite of his shadowy 'novelties which disturb the peace'-as Swe- concealment, and if a new practitioner he denborgianism, Transcendentalism, Fou- will jump to the head of his profession at rierism, and other isms. The author has , once."-Godey's Lady's Book. made these pages the vehicle of valuable information on all the topics of which he has treated."

"Peter, as our readers may recol'ect, snid his shadow to a Gentleman in Black, and upon this fable the Americau adventures are founded. The author, whoever ne may be, has read much, and been at least 'a looker on in Venice,' 'f not a participator of the follies of fashiunable life.

"The theological and pnlitical criticism is inwoven with a tale of fashionable life, and the reader becomes not a little interested in the heroine, Mrs smith, who certainly must have been a remarkable woman. It is nea ily published, and will be extensively read."-Bulletin.

"We shali be greatly mistaken if this book does not kick up a whole cloud of dust." - 'I'he City Item.

"Tl.e work is characterized by much learning and sincere feeling." $-N$. Y. Mirror.

"One of the most entertaining works we have read for many a day, as well as one of the best written. Who the author is we know not; but we do know that the book will meet with a rapid sale wherever an inkling of its character leaks out. For watering places, or anywhere, during the hot weather, it is worth its weight in-gold we almost said. It is full of everything of the best, and you can scarcely open it at random without striking upon some sketch or dialogue to enchain the attention." - Germantown Telegraph.

"His stock of knowledge is large; and as his conscience is rectified by Christian principle, and his heart beats in unison with the right and the true, he uses his treasures of information only for good purposes.

"The book belongs to that class of novels which make an interesting story the medium for the communication of important ruth. In many respects it is a peculiar work, differing from all others in both design and execution, and leaving the impression that it is the product of a mind of no ordinary power.

"Those who love to think and feel, as the result of truthful thought, will read the book with interest and profit." - Reflector \& Watchman.

"A rare book. Who it the world wrote it? Here are nearly five hundred pages with gems on every one of them. The satire is equal to that of Don Quixote or Asmodeus. The hits at society in this country are admirable and well pointed. $\mathrm{T}_{L} \mathrm{e}$ humbugs of the day are skillfully

"IVe are prepared to say, that Peter schlemihl is an exccedingly clear and well-written work - that the author has displayed a considerable amount of book lore in its composition - that the story is interesting and instructive - that we have been entertained and edified by its perusal, and that it possesses merits of more than ordinary character. We cordially recommend it to the reading community, since we are sure that they will be benefitted as weli as entertained by the revelations contained in the pages of Peter.-The National Era.

"A strangely conceived and ably executcd work." N. O. Com. Times.

"The work forms a consecutive tale, all along which runs a vein of severe satire, and which at every step is illustrated by a vast deal of valuable information, and the inculcation of sound principles of morality and religion. It is a work which is adapted to do good, suited to all intelligent general readers, and a pleasant companion for the scholar's leisure hours." $-N$. Y. Recorder.

"This is a very remarkable production, and unless we are greatly deceived, it is from a new hand at the literary forge. IVe have read every page of this thick volume, and have been strongly reminded of South. ey's great book, The Doctor. The author of this work must be a man of close observa. tion, much research, and if we are accurate in our estımate, he is a layman. * * * * This same book will make a sensation in many quarters, and will unquestionably create a name and reputation for its author, who forthwith takes his place among the best and keenest writers of our country. * * We commend it to the gravest and gayest of our readers, and assure them that our own copy will not go off our table until another winter has passed away." $-N$. Y. Alliance and Visitor.

"The volume cannol fail to be read extensively and do good. 'I'he popular 'isms' of the day, their folly and injurious tendeney, are descanted upon with mingled gravity and humor, and considerable talent and truthful feeling are slown in the discussion. Whether the book have an immediate run or not, the sounduess of its views, delivered with some quaintmess of style, will insure it permanent popularity." $-N$. York Commercial Advertiser.

"Light, ssportive, graceful rallery, expressed with terse and delicate ease. ***

"It is a novel of fun, with grave notes by wav of ballast."-Christian Examiner. 


\title{
WASHITGTOM AND TE G

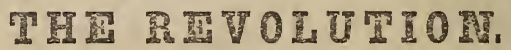

\author{
BY VARIOUS EMINENT AUTHORS.
}

\section{CONTAINING

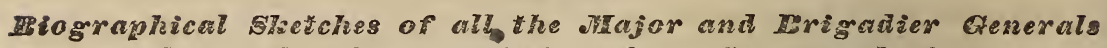 who acted azder comazisstons frome Congress dureaz \\ the Zevolutionary War.}

WE hail these beautiful volumes with name of any author, because it is the join' undisguised delight. They supply, in a dignified and comprehensive form, valuable information, which will be sought with aviby the world at large. - The want of a work of positive authority on this subject has long been felt and deplored. The enterprise and good taste of Messrs. Carey and Hart have given us two handsome and reliable volumes, betraying industry and talent, and replete with facts of the deepest interest. There is no idle romancing-no school-boy attempts at rhetorical display; on the contrary, the work is written in a clear, unaffected, business-like, yet beautiful manner. The authors had the good sense to think that the stirring events of "the times that tried men's souls," needed no embellishment. It is a complete, impartial, and well written history of the American Revolution, and, at the same time, a faithful biography of the most distinguished actors in that great struggle, whose memories are enshrined in our hearts. The typographical execution of the work is excellent, and the sixteen portraits on steel are remarkably well done. The first volume is embellished with a life-like portrait of Washington mounted on his charger, from Sully's picture, "Quelling the Whisky Riots." This is, we believe, the first engraving taken from it. There are biographies of eightyenght Generals, beginning with "the Father of his country," and closing with General Maxwell. To accomplish this task, we are assured that "the accessible published and unpublished memoirs, correspondence, and other materials relating to the period, have been carefully examined and faithfully reflected." TVe earnestl $y$ commend this work. It will be found an unerring
record of the most interesting portion of our history. - The City Item.

production of many of the most eminen? writers in the country, resident in varıous states in the Union, and having, from the circumstance, access to original materials in private hands, and to public archives not accessible to any one individual withous long journey and much consumption of time. The result, however, is a complete and authentic work, embracing biographical notices of every one of the Revolutionary Generals. The amount of fresh and original matter thus brought together in these moderate-sized volumes, is not less surprising than it is gratifying to the historical reader. This will become a standard book of reference, and will maintain its place in libraries long after the present generation shall have enjoyed the gratification of perusing its inter esting pages, exhibiting in a lively style the personal adventures and private characters of the sturdy defenders of American Independence.-Scott's Weekly Newspaper.

The author's name is not given, and from what we have read, we presume that various pens have been employed in these interesting biographies. This is no disadvantage, but, on the contrary, a decided benefit, for it insures greater accuracy than could be looked for in such a series of biographies written by one person in a few months. The volumes are published in a very hand. some style. 'The first sixty pages are oc. cupied with the biography of Washington, which is written with force and elegance, and illustrated by an original view of the character of that great man. *** * The number of the biographies in these volumes is much greater than that of Mr. Headley's work. 'There are eighty-eight distinct subjects.-N. Y. Mirror.

We have read a number of the articles,

This work differs from Mr. Headley's, having nearly the same title, in many important particulars; and as an historical book is much superior.-N. Y. Com. Advertiser.

Certainly the most comprehensive and incividualized work that has ever been piblished on the subject-each member of the great dramatis personce of the Revolutionary tragedy, standing out in bold and "sculy tured" relief, on his own glorious depds - Saturday Courier.

find them to be written with ability, and to possess a deep interest. The author has manifested excellent judgment in avoidıng all ambitious attempts at what is styled fine writing; but gives a colmected recital of the important events in the lives of his heroes. The work will be highly interesting and valuable to all readers-particularly so to youth, who are a: ways attracted by biographies. If a father wishes to pre. sent to his sons noble instances of uncorrupted and incorruptible patriotism, let him

'This work is a very different affair from 3 place this work in their hands. It should the flashy and superficial book of the Rev. have a place in every American library, J. 'I'. Headley, entitled "VVashington and 3 and is among the most valuable books of tha bis Generals." It appears without the 
FEDEPAT $\triangle$ DMINISTRATIDNS. MEMOIRS OF THE

\section{ADMLNISTRATIONS OF WASHINGTGN AND JOIN ADAMIS.}

EDITED FROM THE PAPERS OF OLIVER WOLCOTT, SECRETARY OF THE TREASURY. By GEORGE GIBBS.

"Nullius addictus jurare in verba magistri." In Two Vols. Octavo. $10 \mathrm{C0}$ Pages, Cloth Gilt, Price $\$ 5$.

"Books of this character best illustrate the history of the country. The men who have acted important parts are made to speak for themselves, and appear without any aid from the partiality of friends, or any injury from the detraction of enemies." Providence Journal.

"The materials of which these volumes ire composed are of great value. They consist of correspondence, now first given to the world, of Washington, the elder Adams, A mes, John Marshall, Rufus King, Timotliy Pickering, Wolcott, \&c. There are thirty-seven original letters from Alexander Hamilton, many of them of the highest interest; one in which the writer with keen sagacity and all the splendor of his eloquence, gives a character of Mr. Burr upon which his own fate was destined to put the seal of truth, is read now with singular emotions. Mr. Gibbs has performed his task extremely well. His preface is modest and dignified. The passages of narrative by which the letters are connected are accurate, judicious and agreeable; they illusIrate, and do not overlay the principal material of the work."-North American.

"Here we meet, illustrated in something like forty important letters, the blazing intelligence, the practical sagacity, the heroic generosity, the various genius, which have made Hamilton the name of statesmanship and greatness, rather than the name of a man. Here we have the piercing judgment of John Marshall, unsusceptible of error, whose capacity to see the truth was equalled only by his power of compelling others to receive it; in the light of whose logic opinions appeared to assume the nature of facts, and truth acquires the palpableness of a material reality; the bluntness, force and probity of Pickering; the sterling excellences of IVolcott himself, who had no artifices and no concealments, because his strength was too great to require thern, and his purposes too pure to admit them; and sounding as an understrain through the whole, the prophet tones of Ames." - U. S. Gazette.

"An important and valuable addition to the historical lore of the country." $-N$. Y. Evening Gazette.

"IV e look upon these memoirs as an excecdingly valuable contribution to our natonal records." $-N . Y$ Corn. Adtertiser.

\section{PETERS' DIGEST.}

A FULL $\triangle N D$ DRRANGED

\section{DIGEST OF THE DECISIONS}

In Common Lav, Equity, and Admiralty

OF THE COURTS OF THE UNITED STATES,

From the Organization of the Government in 1789 to 1847 :

IN THE SUPREME, CIRCUIT, DISTRICT, AND ADMIRALTY COURTS;

Reported in Dallas, Cranch, Wheaton, Peters, and Howard's Supreme Court Reports; in Gallison, Mason, Paine, Peters, Washington, Wallace, Sumner, Story, Baldwin, Brockenbrough, and McLean's Circuit Court Reports; and in Bees, Ware, Peters, and Gil. pin's District and Admiralty Reports.

\section{BY RICHARD PETERS.}

With an Appendix-containing the Rules and Orders of the Supreme Court of the United States in Proceedings in Equity, established by the Supreme Court, Complete in two large octavo volumes, law binding, raised bands, at a low price.

\section{THRILLING INCIDENTS}

$$
\text { OF THE }
$$

\section{WARS OF TIIE UNITED STATES.}

COMPRISING TIIE MOST

STRIKING AND REMARIAALE EVENTS

OF

The Revolution, the French War, the

Tripolitan War, the Indian War, the

Second War with Great Britain, and the Mexican War.

WITI TIIREE HUNDRED ENGRAVINGS.

$$
\text { BY THE AUTHOR OF }
$$

"The Army and Navy of the United States."

In Une Volume Octaro, 600 Pages, with, 300

illustrations of Battle Scenes, Portraits,

$$
\text { \&.c. \&.c. }
$$

\section{II}

$$
\text { OF TIIE }
$$

\section{QUEENS OF FRANCE.}

BY MRS. FORBES BUSH.

\section{FROM THE SECOND LONDON EDITION.}

\section{In Two Vols. 12 mo., with Portraits.}

"Mrs. Forbes Bush is a graceful writer, and in the work before us has selected the prominent features in the lives of the Queens with a great deal of judgment and discrimlnation. 'These memoirs will be found no' only peculiarly interesting, but also, structive as throwing considerable upon the manners and customs $c^{\text {r }}$ ages." - Western Continent. 


\section{MORFIT'S APPLIED CHEMTSTRY.}

\section{A TRETISR UPON CHEMISTRY,}

IN ITS APPIICATION TO THE MANUFACTURE OF

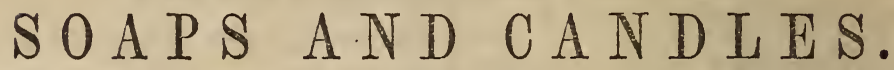

BRINA A THOROUGH EXPOSITION OF THE PRINCIPLES AND PRACTICE OF THE TRADI

IN ALI THEIR MINUTIIE, BASED UPON THE MOST RECENT DISCOVERIES IN SCIENCE.

\section{BY CAMPBELL MORFIT, \\ PRACTICAL $\triangle N D$ ANALYTICAL CHEMIST.}

With 170 Engravings on Wood.

This work is based upon the most RECENT IISCOVERIES IN SCIENCE AND IMPROVEMENT; IN ART, and presents a thorough exposition of the principles and practice of the trade in all their minutiæ. The experience and ability of the author have enabled him to produce A MORE COMPLETE AND COMPREHENSIVE BOOK upon the subject than any extant. The whole arrangement is designed with a view to the scientifie enlightenment, as well as the instrucion of the manufacturer, and its contents are such as to render it not only A STAND$\triangle R D$ GUIDR BOOK TO THE OPERATIVE, but also an authoritative work of reference for the Chrmist and the Stud ENT.

An examination of the annexed table of contents will show the invaluable usefulness of the work, the practical features of which are illustrated by upwards of ONE HUNDRED AND SIXTY ENGRAVINGS ON WOOD.

The following synopsis embraces only the main heads of each Chapter and Paragraph.

CIAP. 1. Introductory Remarks.
2. The Dignity of the Art and its Relations to Science.

6 3. Affinity and Chemical Equivalents:-Explanation of.

(6)

4. Alkalies.-Lime, Potassa, Soda, Ammonia.

6 5. Alkalimetry.

(6 6 Acids-Carbonic, Sulphuric, Hydrochloric, Nitric, Boracic. Acidimetry.

86

7. Origin and Comrposition of Fatty IMatters.

65

8. Saponifiable Fats.-Oils of Almond, Olive, MIustard, Beech, Poppy, Rapeseed, Grapeseed; Nut Oil, Linseed Oil, Castor Oil, Palm Oil, (processes for bleaching it;) Coco Butter, Nutmeg Butter, Galum Butter, A thamantine.

" 9. Adulteration of Oils.

"10. Action of Acids upon Oils.

"11. Volatile Oils.-The Properties of, and their applicability to the Manufacture of Soaps.

(12. Volatile Oils:-Their Origin and Composition; Table of their Specific Gravities.

" 13. Essential Oils:-The Adulterations of, and the modes of detecting them.

" 14. Wax:-Its Properties and Composition.

" 15. Resins:-Their Properties and Composition; Colophony and Gallipot.

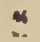

16. Animal Fats and Oils:-Lard, Mutton Suet, Beef-tallow, Beefmarrow, Bone-fat, Soap-grease, Oil-lees, Kitchen-stuff, Human-
Spermaceti, Delphinine, Neats feet Oil.

Char. 17. The Constituents of Fats, their Properties and Composition: Stearine, Stearic Acid and Salts; Margarine, Margaric Acid and Salts; Olein, Oleic Acid and Salts; Cetine, Cetylic Acid; Phocenine, Phocenic Acid and Salts; Butyrine, Butyric Acid and Salts; Caproic, Capric Acid; Hircine, Hircie Acid; Cholesterine.

18. Basic Constituents of Fats:Glycerin. Ethal.

19. Theory of Saponification.

20. Utensils:-Steam Series, Bugadiers or Ley Vats, Soap Frames, Caldrons, \&c.

21. The Systemized arrangement for a Soap Factory.

22. Remarks, - Preliminary to the Process for MIaking Soap.

23. Hard Soaps:- "Cutting Process;" Comparative Value of Oils and Fats as Soap ingredient, with Tables; IVhite, Mottled, MTarseilles, Yellow, Yankee Soaps; English Yellow and White Soap, Coco Soap, Palm Soap, Butter Soap, English Windsor Soap, French IVindsor Soap. Analyses of Soaps.

24. Process for Making Soap :-Preparation of the Leys, Empatage, Relargage, Coction, Mlottling, Cooling.

"25. Extemporaneous Soaps:-Lard, Medicinal, "Hawes," "Ma quer," and "Darcet's" Soaps

"26. Silicated Soaps:-Flint, Sand, "Dunn's," "Davis's" Soaps. 
Cuap.2\%. Patent Soaps.-Dextrine, Salinated Soaps, Soap from Hardened Fat.

"28. Anderson's Improvements.

“29. Soft Soaps:-Process for Making, Crown Soaps, "Savon Vert."

"6

“

“

“

a6

"6

40. Philosophy of Flame.
41. Raw Material for Candles:-

Modes of Rendering Fats, "WVilson's Steam Tanks.

Crap. 42. Wicks:- Their use and action. Cutting Machines.

" 43. Of the Manufacture of Candles.

" 44. Dipped Candles:-Improved Ma. chinery for facilitating thcir Manufacture.

" 45. Material of C'andles:-Process for Improving its Quality.

"46. Moulded Candles:-Improved Machinery for facilitating their Manufacture.-" Vaxeme," or Summer Candles.

“ 47. Stearic Acid Candles:-Adamantine and Star Candles.

"49. Stearin Candles:-Braconnot's and Morfit's Process.

"49. Sperm Candles.

"50. Palmine, Palm Wax, Coco Can. dles.

"51. Wax Candles:-Mode of Bleaching the WVax, with drawings of the apparatus requisite therefor; Bougies, Cierges, Flambeaux.

" 52. Patent Candles:- "Azotızed," Movable Wick and Goddard's Candles; Candles on Continuous Wick; Water and Hour Bougies, Perfumed Candles.

53. Concluding Remarks. Vocabu. lary.

Terms.-The book is handsomely printed, with large type, and on good thick paper, in an octavo volume of upwards of five hundred pages, the price of which is $\$ 5$ per copy, neatly bound in cloth gilt, or it will be forwas ded by mail free of postage in flexiblo covers, on receiving a remittance of $\$ 5$. (A limited number only printed.)

\section{$\mathrm{PER} \mathrm{E} \mathrm{UMR} \mathrm{E}$ \\ ITS MANUFACTURE AND USE:}

WITH INSTRUCTIONS IN EVERY BRANCH OF THE ART, AND RECIPES FOR ALL THE FASHIONABLE PREPARATIONS.

THE WHOLE FORIING A VALUABLE AID TO TII

Perfumer, Druggist and Soap Manufacturer.

ILLUSTRATED IVITH NUMEROUS WOOD-CUTS

From tho Erench of Celmart and other late Authorities.

WITH ADDITIONS AND IMPROVEMENTS

BY CAMPBEL MORFIT,

Practical and Analytical Chemist.

"This is a translation from the French of "A very useful work, and one which, we Celnart, and other late authorities, with think, must become immensely popular. Is additions and improvements by Campbell exposes the whole art and mystery of the Morfit. To us it is a volume of mysteries: manufacture of cosmetics, hair-dyes, poto lady readers it will doubtless be at once mades, oils, depilatories, dentifrices, soaps, intelligible and interesting, as it professes cachous, \&c., and enables every man or $20 n$. to give instructions it: every branch of the man to be his or her own beautifier, without art, and recipes for all fashionable prepara-\{ recourse to the genius or taste of the per. tions. Indeed we should scarcely imagine fumer. It is, indeed, a curious book, and that a single cosmetic has been omitted, the we have skipped over its pages with a list is so extensive."-N.Y.Com. Advertiser.? great deal of satisfaction.-Spivit of Times 


\section{The Best Illustrated Works at 50 Cents a Volume}

\section{CAREY \& HART'S}

Library of Humorous American Works,

\section{With Illustrations by Darley.}

\section{Price 50 Cents. (Complete.) THEATRICAL APPRENTICESHIP AND \\ Anecdotal Recollections \\ OF}

SOI. SHITH, Esq.

COMEDIAX, LATTER, ETC. ETC.

K/ITH॰EIGHT ORIGINAL DESIGNS,

\section{CONTENTS.}

Early Scenes- Wanderings in the WestCincinnati in Early Life- "One Man in his Time plays many Parts"-Expedient to gain a Livelihood-Early Days of Edwin ForrestThe Manager in Distress-Pittsburgh Theatricals-Philadelphia Gardens in 1824-The Old Chatham Theatre-Star-gazing in New York-Concerts in New Jersey-Getting thro' * a Winter-Strolling in Canada-The Hurderous Alleghanians-Dawning of the Drama in Lewistown-Floating down the Stream-Theatricals in Kentucky-Anecdotal Recollections since 1827-A Theatrical Dentist-The Rival Vocalists-Pettifogging in St. LouisA Friendly Game of Poker-Tom the Curtain Man-The Manager and Planter, Signor Matthieu-Letter to Rev. A. Ballard-My First and Last Sermon-Tennessee Door-keeperThe Player and the Phrenologist-Interview with an Editor, \&c. \&c.

"A very whimsical apprenticeship it is, making it impossible to preserve, while reading it, the slightest approach to gravity. Indeed, we have seldom met with a book so irresistibly provocative of a perpetual ' broad grin.' It is as good as a play, and a play of the richest comedy." - Jeffersonian.

Price 50 Cents. (Complete.)

\section{MAJOR JONES'}

\section{SEETCHES OF TRAVEL.}

COMPRISING THE SCENES, INCIDENTS AND ADVENTURES IN HIS

TOUR FROM GEORGIA TO CANADA.

With Eight Original Engravings, from Designs by Darley.

THIRD EDITION.

"Not only fun, but information is to be gained from them."-Saturday Post.

"It contains palpable and amusing hits on the people and customs of different places."-Baltimore Patriot.

"The wit is of the 'Sam Slick' sort." $-N$. I. Commercial.

\section{STREAKS OF SQUATTER LIFE AND}

FAR-WEST SCENES.

A SERIES OF HUMOROCS SKETCHES DRSCRIPTIVE OF INCIDENTS AND CHA-

RACTER IN THE WILD WEST.

$$
\text { BY "SOLITAIRE," }
$$

(JCHN S. ROBB, of St. Louis, Mo.) AUTHOR OF "STALLOWING OYSTERS ALIVE." With Eight Humorous Mlustrations by Darley. CONTENTS.

The Testern Tanderings of a Typo- "Not a Drop more, Major, unless it's sweetened"Nettle Bottom Ball-A Cat Story-A Spiritual Sister-Hoss Allen's Apology-Natural Acting-A Canal Adrenture-The Standing Candidate-An Emigrant's Perils-Fun with a "Bar"-Telegraphing an Express-The Preemption Right-Yaller Pledges-GeorgeMunday, the Hatless Prophet-Courting in French Hollow-The Second Adrent-Settlement Fun-"Doing" a Landlord-Who is Sir George Simpson?-Letters from a BabySeth Tinder's First Courtship-The Death Struggle- "Who are They ?"

"Mir. Robb is better known probably as ' Solitaire,' under which name he has written some very broad, farcical sketches of Western manners for the Reveille, of St. Louis. Some of the sketches in this rolume are spirited and cleterly written, and they are all lively and full of animal spirits; but they are too brief to contain a development of character. The best sketch is the story of 'Old Sugar,' which is illustrated by an exceedingly fine drawing by Darley. We feel, after inspecting the designs in this book, that we have heretofore unserrated the comic powers of this admirable artist; there are evidences in some of these designs of a very high order of genius." $-N$. 1. Mirror.

\section{MAJOR JONES' COURTSHIP.}

Twelfi: Edition, with Two Additional Letters,

\section{AND THIRTEEN HUNOROUS PLATES,} CONTENTS.

Major Jnnes' Courtshin detailed, with other Scenes and Adrentures, in a Series of Letters by himself.

"MIessrs. Carey \& Hart have published the drollest of the droll books of the season. It is a strange production, but so brimful of fun, that half a drop would make it run over." U. S. Gurette. 
Price 50 Cents. (Complete.)

\section{THE' DRAIKA AT POKERVILLE, The Bench and Bar of Jurytown,}

AND OTHER

\section{STORIES AND INCIDENTS.}

\section{BY "EVERPOINT,"}

( MI. FIELD, ESQ., OF THE ST. LOUIS REVEMTE.)

\section{CONTENTS.}

The Drama in Pokerville-The Great Small Affair Announcement-Feeling in Pokerville -The Great Small Affair Opening-The Great Pokerville Preliminaries-The Great Small Affair Mystery-The Great Pokerville Re-union-The Great Small Affair DinnerThe Great Pokerville "Saw"-The Great Small Affair Scandal-The Great Small Affair Chastisement-The Great Small Affair DuelWhat was built on the Great Small Affair Foundation-The Bench and Bar of Jurytown-A Sucker in a Warm Bath-An "Awful Place"-The Elk Runners-"Old Sol" in a Delicate Situation-The "Gagging Scheme," or, West's Great Picture-Establishing the Science-Ole Bull in the "Solitude"-How our Friend B-'s Hair went-A Fancy Barkeeper-"Mr. Nobble!"-"Honey Run"-A Iung Jury-Paternal Gushings-A Werry Grave Exhortation- "Your Turn next, Sir"Stopping to "Wood"-Death of Mike FinkEstablishing a Connection-A Night in a Swamp-Steamboat Miseries-A Resurrectionist and his Freight.

${ }^{6}$ When we say that it is entirely worthy of him, in design and execution, our readers 'had better believe it,' we could not pay the work a higher compliment." $-N$. Y. Spirit of the Times.

$$
\text { Price } 50 \text { Cents. (Complete.) }
$$

\section{A QUARTER RACE IN KENTUCKY AND}

\section{OTHER STORIES.}

BY W. T. PORTER, ESQ. EDITOR OF THE "BIG BEAR OF ARKANSAS," ETC.

\section{CONTENTS.}

A Quarter Race in Kentucky-A Shark Story-Lanty Oliphant in Court-Bill Morse on the City Taxes-Ance Veasy's Fight with Reub Sessions-The Fastest Funeral on Record-Going to Bed before a Young LadyA Millerite Miracle-Old Singletire- "Running a Saw" on a French Gentleman-Breaking \& Bank-Taking the Census-Dick Harlan's Tennessee Frolic-"Falling off a Log" in a Game of "Seven up"-The "Werry Fast Crab"- "Freneh without a Master"-A Rollicking Dragoon Officer-The Georgia Major in Court-Uncle Billy Brown "Glorious"Old 'Tuttle's Last Quarter Race-Bill Dean, the Texan Ranger-The Steamboat Captain who was averse to Racing-Bob IIerring the Arkansas Bear-hunter-McAlpin's Trip to Charleston-Indian Rubber Pills-A Murder Case in Mississippi-Kiclring a Yanlre-A
3 "Down-east" Original-Somebody in my Bed -A Day at Sol. Slice's-Cupping on the Starnum-A Bear Story-Playing Poker in Ar. kansas-\&c. \&c.

'It is illustrated with original engravings from designs by Darley. The 'Quarter Raco in Kentucky' is one of the best stories that was ever penned, and the volume contains a number of others, that have from time to \{ime appeared in the Spirit of the Times which are hard to beat." - N. O. Picayune.

$$
\text { Price } 50 \text { Cents. (Complete.) }
$$

\section{WAGGERIES and VAGARIES.}

\author{
BY W. E. BURTON, \\ COMTEDIAN
}

\section{WITH ILLUSTRATIONS BY DARLEY.}

\section{CONTENTS.}

The Yankee amongst the Mermaids; a Yarn by a Cape Codder, with an illustration -Leap Year; or, A Woman's Privilege-The Two Pigs, a Swinish Colloquy-Thaumaturgia; Part First, The Yankee in Hell, with an illastration; Part Second, The Resurrectionists; Part Third, The Canal-boat; Part Fourth, The Last and the Least-My First Fight, with an illustration-Immiscible Immigration, a petty Peter Pindaric-Sam Weller, a Soliloquy in Verse-The Pic-Nic Party, with two illustrations-The Poetry of Niagara-A Wet Day at a Watering Place-My First Punch, with an illustration-The Scapegrace and the Scapegoat, a Matter-of-fact Sketch-The Old Dutchman and his Long Box, with an illustration-The Man in the Big Boots-Dickey Doddicombe, with an illustration-Philadelphia in the Dog-days-\&c. \&c.

"The drollest specimen of waggery that ever emanated from that drollest of men, Burton." - The City Item. Bur $\left\{\begin{array}{c}\text { Price } 50 \text { cents. (Complete.) } \\ \text { ODD LEAVES FROM THE LIFE } \\ \text { OF A } \\ \text { LOUISIANA "SWAMP DOCTOR," }\end{array}\right.$ BY MADISON TENSAS, M.D. EX V. P. M. S. U. KY.

\section{CONTENTS.}

The City Physician versus The Swamp Doctor-My Early Life-Getting acquainted with the Medicines-A Tight Race considerin'Taking Good Advice-The Day of Judgment -A Rattlesnake on a Steamboat-Frank and the Professor-The Curious Widow-The Mississippi Patent Plan for pulling Teeth-Valerian and the Panther-Seeking a LocationCupping an Irishman-Being Examined for my Degree-Stealing a Baby-The "Swamp Doctor" to Esculapius-My First Call in the Swamp-The Man of Aristocratic Diseases-The Indefatigable Bear-hunter-Love in a Garden-How to cureFits-A Struggle forlite. 


\section{STANDARD WORKS.}

I.ORD BACON'S WORKS.

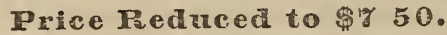

In 3 Royal 8vo. Volumes, Cloth Gilt.

\section{TIE WORES OF LORD BACON,}

FITH A IIEMTOIR, AND A TRANSLATION OF HIS LATIÑ WRITINGS,

BY BASIL MONTAGU, ESQ.

In Three Volumes, Octavo.

The American edition of the works of Lord Bacon, now offered to the public, is reprinted from the most approved English edition, that of Basil MIontagu, Esq., which has recently issued from the celebrated press of Pickering, (the modern Aldus.) in seventeen octavo volumes. It contains the complete works of the illustrious philosopher, those in Latin being translated into English. In order to render the publication cheap, and therefore attainable by all our public and social libraries, as well as by those general readers who study economy, the seventeen octavo volumes have been comprised in three volumes, imperial octavo. Being printed from the most accurate as well as complete English edition. and carefully revised, the American edition will possess greater advantages for the critical scholar as well as the general reader. In typography, paper and binding. it will be recognized as a brilliant specimen of the products of the American book trade.

"IVe may safely afirm, that, by giving the Inductive Philosophy to the world, Lord Bacon has proved one of its most signal benefactors, and has largely done his part towards promoting the final triumph of all truth, whether natural, or moral and intellectual, over all error; and towards bringing on that glorious crisis, destined, we doubt not, one day to arrive, when, according to the allegorical representation of that great poet, who was not only the Admirer of Bacon, but in some respects his kindred genius-TRUTH, though ' hewn like the mangled body of Osiris, into a thousand pieces, and scattered to the four winds, shall be gathered limb to limb, and moulded, with every joint and member, into an immortal feature of loveliness and perfec. tion." "

"We are more gratified than we can find words to express, to find a publishing house in this country, putting forth a publication like the Complete Works of Lord Bacon, in a form at once compact, elegant and economical."-Brother Jonathan.

\section{THE PROSE WRITERS OF AMERICA} AND THEIR WORKS.

PY RUFUS IVILNIOT GRISWOLD,

Author of "Poets and Poetry of America," \&c.

Ir One Volume Octaro, with nine beauti-
Price Reduced to $\$ 250$. THE WAVERLEY NOVELS. COMPLETE.

3340 Fages for Two Dollars and a Half. CAREY \& HART, have recently published A NEW EDITION OF THE WAVEREEY NOVELS, BY SIR TV ALTER SCOTT,

With all the Author's latest Notes and Additions, Complete, without the slightest Abridgment.

In Five Royal 8vo. volumes, upwards oi $\$ 50$ Pages in each volume.

\section{[CONTENTS.}

Waverley, Guy Mannering, Antiquary, Rob Roy, Black Dvarf, Old Mortality, Heart of Mid-Lothian, Bride of Lammermoor, Legend of Montrose, Ivanhoe, The Nonastery, The Abbot, Kenilworth, The Pirate, Fortunes of Nigel, Peveril of the Peak, Quentin Durward, St Ronan's WVell, Redgauntlet, 'The Betrothed, The Talisman, IVoodstock, The Highland Widow, Two Drovers, My Aunt Margaret's Mirror, Tapestried Chamber, 'The Lalrd's Jock, Fair Maid of Perth, Anne of Gierstein, Coant Robert of Paris, Castle Dangerous, The Surgeon's Daughter.

The object of the publishers in thus re. ducing the price of the Waverley Novels, is to endeavor to give them a greatly extended circulation, and they have, therefore, put them at a price which brings them within the reach of every family in the country. There is now no fireside that need be without a set of the most charming works of fiction ever issued from the press: for there is no one that can't afford two dollars and a half-TIVO DOLLARS AND A HAI,F for twenty - five of Sir IV alter Scott's Novels! ten cents for a complete Novel!! ten cents for "Ivanhoe," which was originally published at a guinea and a half!!! It seems impossible, and yer it is true. In no other way can the same amoant of amusement and instruction be obtained for ten times the money, for the WTaverley Novels alone form a Library.

The publishers wish it to be distinctly understood, that, while the price is so greatly reduced the work is in no way abridged, but is CAREFULLY PRINTED FRON, AND CONTAINS EVERY WORD IN TIIE LAST EDINBURGH EDITIoN, in foriy-eight volumes, which sells for seventy-two dollars.

Now is the time to buy $\downarrow$ Such an opportunity may never again occur. Let every one, then, who wants the Waverley Noveis for two dollars and a half, now purchase, for if the publishers do not find tlie sale greatly increased, by the immense reduction in price, they will resume the old price of twenty-five cents for each Novel, which 


\section{T H E \\ PROSE WRITERS OF NIERICA.}

WITH A SURVEY OF THE INTELLECTUAL HISTORY, CONDITION, AND PROSPECTS OE THE COUNTRY.

\section{BY RUIUS WILMOT GRISWOLD.}

SECUND EDITION, REVISED.

\section{Illustrated with Portraits from Original Pictures.}

Complete in cne volume octaro- $\$ 3.50$.

(YONTENTS.

Intellectual History, Condition, and Prospects of the Country-Edwards; Franklin, Jefferson, Madison, Dwight, Marshall, Hamilton, Ames, J. Q. A Jams, C. B. Brown, Wirt, Quincy, Allston, Story, Paulding, Flint, Channing, Wheaton, Webster, Audubon, Walsh, Irving, Buckminster, Verplanck, Norton, Sanderson, Dana, Wilde, Cooper, A. H. Everett, Hall, Schoolcraft, Dewey, Sparks, John Neal, Bryant, Edward Everett, Kennedy, Bush, Sedgwick, Wayland, Prescott, Edward Robinson, Leslie, Legare, Ware, Bancroft, Marsh, Hooker, Brownson, Child, Bird, Emerson, Fay, Cheever, Hoffman, Kirkland, Hawthorne, Willis, Longfellow, Simms, Joseph C. Neal, Poe, Tuckerman, Fuller, IIeadley, Mathews, Thorpe, Whipple.

"Mr. Griswold's book has been executed honestly, ably, and well, and is a raluabio contribution to the literature of the country." - Knickierbocker.

"We deem the book by all odds the best of its kind that has ever been issued; and we certainly know of no one who could have made it better." $-N . Y$. Courier and Inquirer.

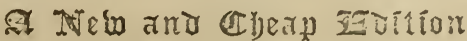
OF THE HISTORY OF

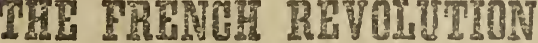
BY MI. A. THIERS,

LALE PRIME MINISTER OF FRANCE.

Translated from the French, with Notes and Additions.

The Four Volumes, complete in 'Two. Price ouly $\$$ 些 50 .

The edition of the History of the French Revolution now offered to the nublic is printed on VERY LARGE' 'I'Y 'E, oll good paper, and contains upwards of

Eighteen Hundred Large Octaro Pages, and is unquestionably the cheapest book ever published. It forms a necessary introduction to THE LIFE OF NAPOLEON, WY M. A. THIERS, NOW IN COURSE OF PUBLICATION, and the two works present a complete

\section{HISTORY OF FRANCE}

from the commencement of the French Rerolution, down to the c?eatl of Napoleon.
WASHINGTON AND THE

GENERALS OF THE AME. RICAN REVOLUTION. COMPLETE IN 'TWO VOLS. 12×IO. Illustrated by Sixteen beautiful, engraved Portraits.

Containing Biographical Sketclies of Ge. nerals IV ashington, Greene, IV ay ne, Israes Putnam, Gates, Lord Sterling, Schuyler, Sullivan, Nercer, Armstrong, Knox, Arnold, Swallwood, De Haas, St. Clair, Elbert, Irvine, Wieden, Varnum, Woodford, Williams, Moylan, McDougall, Glover, McIntosh, Thompson, Nixon, Gist, Woos. ter, Spencer, Poor, Moore, Patterson, James Reed, Pomroy, Sumner, Stark, Moultrie, Joseph Recd, Greaton, Morgan, Marion, Lee, Mifflin, Parsons, Lincoln, Montgomery, Whitcomb, Cadwalader, Heath, Thomas, Geo. Clinton, James Clinton, Larned, La Fayctte, Deborre, Pulaski, Russell. Ducoudray, La Neuville, Steuben, De Woedtke, Kosciuszko, Tufin, Duportail, De Fernoy, Conway, De Kalb, Gadsden, Hogall, Huger, Hazen, IVilkinson, Sumter, Scott, Pinckney, Howe, Frye, IVard, Rufus, Putuam, Nash, Stephen, Dayton, Hand, IIulenberg, Lewis, Huntington and Max. well.

"It is a complete, impartial and well written History of the American Revolution, and at the same time a faitliful biography of the most distinguished actors in that great struggle, whose memories are en. shrined in our hearts. Tlie typographical execution of the work is excellent, and sixteen portraits on steel are remarkably well done."-City Item.

JOHNSON'S FARMERS' CYCLOPEDIA and Dictionary of Rural Affairs, with Engravings, from the last London edi tion, with numerous additions relative to this country, by Gouverneur Ernerson, royal Evo. 1156 pp., 17 plates, full bound, raised bands, reduced to $\$ 400$.

\section{MISS LESLIE'S}

\section{LADY'S RECEIPT BOOK.}

A useful companion for large or small fa milies-being a sequel to her work on Cookcry-comprising new and improved directions for preparing Soups, Fisli, Meats, Vegetables, Poultry, Gamc, Pies, Puddings, Cakes, Confectionery, Jellies, Breakfast and Tea Cakes, Embroidery, Crotcliet work, Braiding, Needle work, Clcaning Furs, Merinos, \&c., Washing Laces, Dc. strnying Ants, Bugs and Mice, Cleaning Silver, Preparing Colors, making Artificial Flowers, \&c. \&c. Completc in one volume, 400 pages, price, bound, $\$ 100$.

\section{TISO,}

Miss Leslie's CoMplete CoOKery, bd., \$1 00 Miss I westie's House Boox, bound, . 100 MISS LESLIE's FrENCII COOKEIRY, 25 IIISS Leslie's Ixnian MEAL BooK, . 25 


\section{THE MODERN BRITISHESSAYISTS}

\section{At less than Haif Price.}

The great success that has attended the publication of THE MODERN ESSA YISTS,

Comprising the Critical and Miscellaneous IVritings of the Most Distinguished Authora of Modern Times, has induced the publishers to issue a New, Revised and very Cheap Edition, with Finely Engraved Portraits of the Authors; and while they have addel to she series the writings of several distinguished authors, they have reduced the price more than

The writings of each author will generally be comprised in a single octavo volume, well printed from new type, on fine white paper manufactured expressly for this edition.

The series will contain all the most able papers that have EVER APPEAKED.IN

\section{THE EDINBURGH REVIEW,}

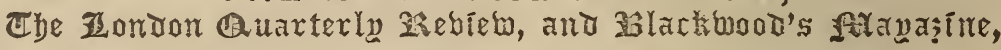

and may indeed be called the CREAM of those publications.

It is only necessary to mention the names of the authors whose writings will appear. $T$. Babington Macaulay, A rchibald Alison, Pev. Sydney Simth, Professor Wilson James Stephen, Robert Sourhey, Sir IValter Scott, Lord Jeffrey, Sir James Mack. intog, T. Noon Talfourd, J. G. Lockhart, Reg Jald Heber.

The popularity of the authors and the extreme moderaticn of the price, recommend

$$
\text { THE MODERN ESSAYISTS, }
$$

To HEADS of Families for their Children, as perfect models of style.

To MANagers of Book Societies, Book Clubs, \&c.

TO SCHOOL INSPECTORS, SCHOOLIIASTERS AND TUTORS, as suitable gifts and prizes, or adapted for School Libraries.

TraVELLERS ON A JOURNEY will find in these portable and cheap volumes something to read on the road, adapted to fill a corner in a portmanteau or carpet-bag.

To PASSENGERS ON BOARD A SHIP, here are ample materials in a narrow compass for whiling away the monotonous hours of a sea voyage.

To OfFICERS IN THE ARMY AND NAVY, and to all Eecnomists in space or pocket, who, Laving limited chambers, and small book-shelves, desire to lay up for themselves a concenrated Library, at a moderate expenditure.

To ALL who have FRIENDS IN Distant Conntries, as an acceptable present to send out to them.

THE MOD ERx EsSayists will yield to the Settler in the Backwoods of America the most r aluable and interesting writings of all the most distinguished authors of our time at less than one guarter the price they could be obtained in any other form.

THE STUDENT AND Lover of LiTERATURe at Home, who has hitherto been compelled 10 wade through volumes of Reviews for a single article, nay now become possessed of c very article worth reading for little more than the cost of the annual subscription.

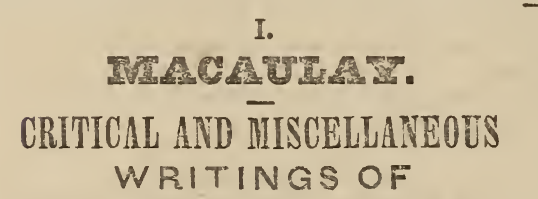

THONIAS BABINGTON MACAULAY.

In One Volume, with a finely engrared portrait, from an original picture by Henry Inman. Cloth Gilt, $\$ 200$.

\section{Contents.}

Milton, Machıavelli, Drycen, History, Hallam's Constitutional History, Southey's Colloquies on Society, Monre's Life of Byron, Southey's Bunyan's Pilgrim's Progress, Croker's Boswell's Life of Johnson, Lord Nugent's Memoirs of Hampden, Nare's Memoirs of Lord Burglley, Dumont's Recollections of Mirabeau, Lord Mahon's WVar of the Succession, Walpole's Letters to Sir $\mathrm{H}$. Mann, Thackaray's Historv of Earl Chatham. Lord Bacon, Mackintosn's History of rarv's mind by that of his book, and who colm's Life of Lord Clive, Life and Writings of Sir IV. Temple, Church and State, 3 hundred pages of octavos ind quartos.-
Ranke's Gistory of the Popes, Cowley and Milton, Mitford's History of Greece, The Athenian Orators, Comic Dramatists of the Restoration, Lord Holland, WVarren Hastings, Frederic the Great, Lays of Ancient Rome, Madame D'Arblay, Addison, Barere's Memoirs, Montgomery's Poems, Civil Disabilities of the Jews, Mill on Government. Bentham's Defence of Mill, Utilitarian 'Theory of Govermment, and Earl Chatham, second part, \&c.

"It may now be asked by some sapient critics, Why make all this coil about a mere periodica essayist? Of what possible concern is it to any body, whether Mr. Thomas Babington Nacaulay be, or be not, overrun with faults, since he is nothing more than one of the three-cay immortals who contribute flashy an ' 'taking' articles to a Quarterly Review? What great work has he written? Such questions as these might be put by the same mer who place the Spectator, Tattler and Ramb.er among the British classics, yet judge of the size of a cotemnoclassics, yet judge of the size of a cotempo-
rarv's mind by that of his book, and who can naraıy recognize amolitude of compre- 
Such men would place Bancroftabove IVeb- ' ster, and Sparks above Calhoun, Adims and Everett-deny a posterity for Eryant's Thanatopsis, and predict longevity to Pollok's Course of Time. It is singular that the sagacity which can detect thought only in a state of dilution, is not sadly graveled when it thinks of the sententious aphorisms which have survived whole libraries of folios, and the little songs which have outrun, in the race of fame, so many enormous epics.While it can easily be demonstrated that Macaulay's writings contain a hundred-fold more matter and thought, than an equal number of volumes taken from what are called, par eminence, the 'British Essayists,' it is not broaching any literary heresy to predict, that they will sail as far down the stream of time, as those eminent members of the illustrious family of British clastics."

\section{ARCIIBATD ATEOTH.}

\section{THE CRITICAL AND MIISCELLANEOUS} WRITINGS OF ARCHIBALD ALISON,

AUTHOR OF "THE HISTORY OF EUROPE," In One Volume, Svo. with a portrait. Price $\$ 125$.

\section{CON'REN'TS.}

Chateaubriand, Napoleon, Bossuet, Poland, Madame de Stael, National Monuments, Marshal Ney, Robert Bruce, Paris in 1814, The Louvre in 1814, Tyrol. France in 1833, Italy, Scott, Campbell and Byron, Schools of Design, Lamartine, The Copyright Question, Michelet's France, Military Treason and Civic Soldiers, Armold's Rome, Ślirabeau, Bulwer's Athens, The Reign of Terror, The French Revolution of 1<30, The Fall of Turkey, The Spanish Revolution of 1S20, Karamsin's Russia, Efrects of the French Revolution of 18:30, Desertion of Portugal, Wellington, Carlist Struggle in Spain, The Affghanistan Expedition, The Future, \&c. \&c.

\section{III.}

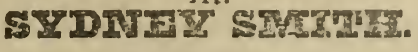

\section{THE WORKS OF THE}

REV. SYDITEY SMTIIE.

Fine Edition. In One Volume, with a portrait. Price $\$ 100$.

"Almost every thing he has written is so characteristic that it would be difficult to attribute it to any other man. 'The marked Individual features and the rare combination of power displayed in his works, give them a fascination unconnected with the subject of which he treats or the general cor. rectness of his views. He sometimes hits the mark in the white, he sometımes misses It altogether, for he by no means confines his pen to theories to which he is calculated to do justlce; but whether he hits or misses, he is always sparkling and delightful. The charm of his writings is somewhat similar to that of Montaigne or Charles Lamb" North American Revieu.

\section{REOERSSOR WIISOI.} THE RECREATIONS OF

\section{CHRISTOPHER NORTH.}

In One Volume 8vo., first American Edition with a Portrait. Price $\$ 100$.

\section{CONTEN'IS.}

Christopher in his Sporting Jacket-A Tale of Expiation-Morning MonologueThe Field of Flowers-Cottages-An Hour's Talk about Poetry-Inch Cruin-A Day $\mathbf{a}^{*}$ Windermere--The Moors-Highland Snow. Storm-The Holy Child-Our Parish-Mayday-Sacred Poetıy-Christopher in his Aviary-Dr. Kitchiner-Soliloquy on the Seasons-A Few IVords on ThomsonThe Snowball Bicker of Piedmont-Christmas Dreams-Our IVinter Quarters-Strol' to Grafsmere-L'Envoy.

Extract from Howitt's "Rural Life."

"And not less for that wonderful series of articles by IVilson, in Blackwood's Magazine-in their kind as truly amazing and as truly glorious as the romances of Scott or the poetry of Wordsworth. Far and wide and much as these papers have been admired, wherever the English language is read, I sti!l question whether any ore man has a just idea of them as a whole."

\section{Carlyle's $\overline{\text { I.iíscellanies. }}$}

\section{URITICAL AND NIISCELLANEOUS}

\section{ESSAYS OF THOMAS CARLYLE.}

In one Sio. volume, with a Portraut.

$$
\text { PRICE \$1 } 75 .
$$

C O N TENTS.

Jean Paul Friedrich Richter-State of German Literature - IVerner - Goethe's Helena-Goethe-Burns-Heyne-German Play'wrights-Voltaire--Novalis-Sigus of the Times-Jean Paul Friedrich Richter aguin-On llistory--Schiller-The Nibellungen Lied-Early German Literature'Taylor's Historic Survey of German l'octry - Characteristics-Johnson-Death of Goethe-Goethe's Works-Diderot-On History again-Count Cagliostro-Corn Law Rhymes-The Diamond Necklace-Nira beau-French Parliamentary History WValter Scott, \&c. \&c.

$$
\text { VI. }
$$

TAIEOTID \& STEPIEN, THE CRITICÁL WRITINGS OF T. NOON TALFOURD AND JAMES S'TEPHE:N

WITH A FINELY ENGRAVED PORTRAIT.

In One Volume, Svo. Price \&1 25. 
Contents of 6 Talfourd."

Essays on British Novels and Romances, introductory to a series of Criticisms on the Living Novelists-Nackenzie, The Author of Waverley, Godwin, Maturin, Rymer on Tragedy, Colley Cibber's Apology for his Life, John Dennis's Works, Modern Periodical Literature, On the Genius and Writings of Wordsworth, North's Life of Lord Guilford, Hazlitt's Lectures on the Drama, WVallace's Prospects of Mankind, Nature and Providence, On Pulpit Oratory, Recollections of Lisbon, Lioyd's Poems, Mr Oldaker on Nodern Improvements, A Chapter on Time, On the Profession of the Bar, The Wine Cellar, Destruction of the Brunswick. Theatre by Fire, First Appearance of Miss Fanny Kemble, On the Intellectual Character of the late Wm. Hazlitt.

\section{Contents of "Stephen."}

Life of Wilberforce, Life of W' hitfield and Froude, D'A ubigne's Reformation, Life and Times of Baxter, Physical Theory of Another Life, The Port Royalists, Ignatius Loyola, Taylor's Edwin the Fair.

"His ('Talfourd's) Critical writings manifest on every page a sincere, earnest and sympathizing love of intellectual excellence and moral beauty. The kindliness of temper and tenderness of sentiment with which they are animated, are continually suggesting pleasant thoughts of the author." - North American Review.

\section{VII. \\ IORD JERTERT.}

THE CRITICĀL WRITINGS

\section{FRANCIS LORD JEFFREY.}

\section{In One Volume sro., with a Portrait.}

From a very able article in the North British Review we extract the following:

"It is a book not to be read only-but siudied-it is a vast repository; or rather a system or institute, embracing the whole circle of letters-if we except the exact sciences-and contains within itself, not in a desultory form, but in a well digested scheme, more original conceptions, bold and fearless speculation and just reasoning on all kinds and varieties of subjects than are to be found in any English writer with whom we are acquainted within the present or the last generation. * * * His choice of words is unbounded and his felicity of expression, to the most impalpable shade of discrimination, almost miraculous. Playfu., lively, and full of illustration, no subject is so dull or so dry that he cannot invest it with interest, and none so trifling that it cannot acquire dignity or elegance from lis pencil. Independently lowever, of mere style, and apart from the great variety of subjects embraced by his pen, the distincuishing feature of his writings, and that in which he excels his cotempo. rary reviewers, is the deep vein of practical thought which runs throughout them all"

$\mathrm{s}$ SIP JAIRES IHACKINTOSH. SIR JAMES MACKINTOSH'S CONTRIBUTIONS TO TILE EDIN. BURGII REVIEW.

Collected and Edited by pis Son.

In One Volume $8 v o$., with a Portrait, \$1 75.

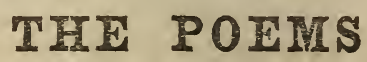

OF

\section{FRANCES SARGENT OSGOOD.}

\section{Jilustrateo bn the best artists.}

In one votume octavo, uniform with Carey de Hart's illustrated Bryant, Willis, dic.

The following exquisitely finished line engravings are from original designs, by our most celebrated painters, and are executed in the highest style of art:-Portrait of the Authoress; Hope; A Child playing with a Watch; The Reaper; Ida; Old Frieuds; The Child's Portrait; Little Red Riding Hood; The Life Boat; Twilight Hours; The Arab and his Steed ; Zuleika.

"There is nothing mechanical about her; all is buoyant, overflowing, irrepressible viracity, like the bubbling up of a natural fountain. In her almost childish playful ness, she reminds us of that exquisite crea. tion of Fouque, Undine, who knew no law but that of her own waywardness. The great charm of her poetry is its unaffected simplicity. It is the transparent simplicity of truth, reflecting the feeling of the morr. nt like a mirror."-Rev. Dr. Davidson.

"In all the poems of Mrs. Osgood, we find occasion to admire the author as well as ths works. Her spontaneous and instinctive effusions appear, in a higher degree than any others in our literature, to combine the rarest and highest capacities in art with the sincerest and deepest sentiments and the noblest aspirations. They would convince us, if the beauty of her life were otherwise-unknown, that Irs. Osgood is one of the loveliest characters in the histories of literature or society."-Pennsylvania Inquirer and Courier.

"The position of IIrs. Osgood, as a graceful and womanly poetess, is fixed, and will be enduring. To taste of faultless delicacy, a remarkable command of poetical language, great variety of cadence, and a most musical versification, she has added recently the high. est qualities of inspiration, imagination, and passion, in a degree rarely equalled in the productions of women.... The reputation which Mrs. Osgood enjoys, as one of the most amiable, true-hearted, and brilliant ladies in American society, will add to the good for. tune of a book, the intrinsic excellence and beauty of which will secure for it a place among the standard creatious of female ges sius "-Fome Journal. 


\section{THE POETS AND POETRY OF FUROPE, ENGIAND, AIMERICA, Etc.}

CAREY \& HART have just published in four splendid volumes, beautifully illustrated. and uniform in size with their new edition of "THE MODERNESSAYISTS," and forming a suitable companion to that delightful series:-

\section{THE \\ POETS AND POETRY OF AMERTCA:}

EMBRACING

Selections from the Poetical Literature of the Dnited states, from the rime of the Revolution,

WITH A

Preliminary Essay on the Progress and Condition of Poetry in this Country, and Biographical and Critical Notices of the most eminent Poets.

BY RUFUS W. GRISWOLD.

EYGHTH EDITION, REVISED AND ENLARGED. Elegantly bound in Col'd Calf and Norocco. Price $\$ 500$, or in Cloth Gilt, $\$ 300$.

" WVe think in the 500 pages of this beauiful volume, the reader will fiid nearly all that is worth reading in American Poetry." - Boston Post.

"MIr. G. has done a service to ovr literature which eminently entitles him to the regard and favor of a discerning and impartial public."-National Intelligencer.

"No better selection from the poetry of our native bards has ever been made, and no person could do better with the mate-ials than Mr. Griswold has done."-Boston Transcript.

\section{THE}

\section{POETS AND POETRY OF ELROPE}

$$
\text { WITII }
$$

\section{Riographical Notices and Translations,}

From the Earliest Period to the Present Time.

BY HENRY TV. LONGFELLOW. In One Large 8vo. Volume, 750 Pages. Morocco, elegant, $\$ 550$, or cloth gilt, $\$ 375$. Which comprises translations from the following : Anglo-Saxon, Icelandic, Swedish, Dutch, German, French, Italian, Spanish, Portuguese, \&c. \&c.

"It is the most complete work of the kind in English literature "-Boston Courier.

"A more desirable work for the scholar or man of taste has scarcely ever been issued in the United States." $-N$. Y: Tribune
ILLUSTRATED POEMS.

BY MRS. L. H. SIGOURNEY, With Designs by F. O. C. Darley, ENGRAVED BY DISTINGOISHED ARTISTS. With a Portrait of the Authoress by Cheney after Freeman.

\section{LIST OF ILLUSTRATIONS.}

The Divided Burden-A Landscape-Oriska-The Ancient Family Clock-Eve-The Scottish Weaver-The Indian SummerErin's Daughter-The Western EmigrantThe Aged Pastor-The Tomb-The Drooping Team-The Beautiful Maid.

"The volume is a most luxurious and gorgeous one, reflecting the highest credit on its 'getters up;' and we know of nothing from the American press which would form a more acceptable gift-book, or a richer ornament for the centre-table. Of the Poems themselves it is needless to speak." - Y.Blade.

"In the arts of typography the volume is unsurpassed; the illustrations are numerous and beautiful, and the binder's skill has done its best. We shall speak onily of the exter. nals of the volume. Of its contents we will not speak flippantly, nor is it needful that we should say any thing. The name of Mrs. Sigourney is familiar in every cottage in America. She has, we think, been more generally read than any poetess in the coun. try, and her pure fame is reverently cherished by all." -N. O. Picayune.

"It is illustrated in the most brilliant manner; and is throughout a gem-volume." Pa. Inquirer.

"In this production, however, they have excelled themselves. The illustrations are truly beautiful, and are exquisitely engraved. The entire exceution of the volume is a proud evidence of the growing superiority of bookmaking on the part of American publishers." -Dollar Newspaper.

"This work, so beautifully embellished, and elegantly printed, containing the select writings of one of the most celebrated female poets of America, cannot fail to be receired with approbation." - Newburyport Paper.

"The illustrations are truly beautiful, and are exquisitely engraved. They are from designs by Darley, who has risen to high eminence in his department of art. The entire execution of the volume is a proud evidence of growing superiority in book-making on the part of American publishers. And this liberality has not been displayed upon a work unworthy of it." - N.Y.CommercialAäv. 


\title{
ILEUSTRATED IMEDICAI ITBRART.
}

CAREY \& HART have recently published the following valuable Medical er.d Surgical works, superbly illustrated-10 which they beg leave to call the attentiun of the profession. This splendid series now forms SIX ROYAL QUART vOLUMES, containing FOUR HUNDRED AND EIGHTY QUARTO PLATES, beautifully executed; and the price at which they are offered is infinitely less than any similur works have heretofore been published.

\section{QUAIN'S ANATORIGA IS PIATES,}

\section{PATCOAST'S OFERATIVR SURGERY,}

MOREAU'S GREAT WORE ON MIIDWIFERT,

\author{
GODDARD ON THETEETH,
}

RICORD ON EXTREHE CASES OF VENEREAL DISEASES, AND RAYER ON DISEASES OF THE SKIN.

I.

\section{A SERIES OF}

\section{ANATOMIGAL}

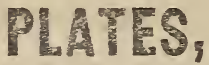

With References and Physiological Comments, illustrating the structure of the different parts of the Human Body.

\section{EDTTED BY}

JONES QUAIN, M.D., AND W. J. ERASMUS WILSON.

TWith Notes and Additions by JOSEPH PANCOAST, M. D., Professor of Anatomy in the Jefferson MIedical College of Philadelphia.

THIRD AMERICAN EDITION.

The Plates are accompanied by letterpress, containing detailed references to the various objects delineated. But with a view to render them intelligible to a greater number of persons, a running commentary on each plate is given, stating in general terms, and divested, as far as can be, of all technicality, the uses and purposes which the different objects serve in the animal economy.

THE WORK CONSISTS OF THE FOLLOWING DIVISIONS :

THE NIUSCLES OF THE HUMAN BODY, Fifty-one Plates.

THE VESSELS OF THE HUMIN BODY, Fifty Plates.

THE NERVES OF THE HUIIAN BODY, Thirty-eight Plates.

THE VISCERA OF THE HUIIAN BODY, including the Organs of Digestion, Respiration, Secretion and Excretion, Thirty-two Plates.
THE BONES AND LIGAMENTS, Thirty Plates.

Complete in One Royal Quarto Volume of nearly 500 pages, and 200 plates, compris. ing nearly 700 separate illustrations. Being the only complete system of Anatomical Plates, on a large scale, ever published in America.

Price oniy $\$ 15$, cloth gilt, or $\$ 30$ colored after nature.

II.

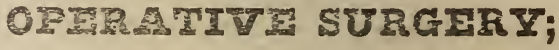
or,

A DESCRIPTION AND DEMIONSTRA-

TION OF THE VARIOUS PROCESSES OF THE ART;

INCLUDING ALL THE NEW OPERATIONS, AND EXHIBITING THE STATE OF SUR-

GICAL SCIENCE IN ITS PRESENT

ADVANCED CONDITION.

BY JOSEPH PANCOAST, M.D., Professor of General, Descriptive and Surgical Anaiomy in Jefferson Medical Co:lege, Philadelphia.

Complete in One Royal 4to. Tolume of $3 \Omega_{0}$ pages of letterpress description and eighty large 4to. plates. comprising 4 S6 Illuestra-

tions. and being the only complete work on the subject in the English

Language. Price, full bound. in cloth, only sio.

Second Edition, Improved.

"This excellent work is construcced on the model of the French Surgical Works by Velpeau and Malgaigne; and, so far as the English language is concerned, we are 


\section{A. HART'S STANDARD MEDICAL WORIS.}

proud as an American to say that, of ITS IIND IT HAS NO SUPERIOR."-New York Journal of Medicine.

"For this beautiful volume, the student and practitioner of Surgery will feel grateful to the ability and industry of Prof. Pancoast. The drawing and execution of the plates are splendid examples of American art, and do credit to Messrs. Ciclıowski and Duval, while the description is no less creditable to the author. We have examined the book with care, and feel great pleasure in declaring that, in our opinion, it is a most valuable addition to the surgical literature of the United States. It was a happy idea to illustrate this department of surgery, as it renders perfectly clear what the very best verbal description often leaves obscure, and is, to some extent, a substitute for witnessing operations. To those practitioners especially, who are called upon occasionally, only, to perform operations, we are not acquainted with any volumebetter calculated for reference prior to using the knife. There are similar works published in Europe, but they are much more expensive, without being superior in point of usefulness to the very cheap volume before us.

"All the modern operations for the cure of squinting, club-foot, and the replacing ost parts and repairing deformities from partial destruction of the nose, \&c., are very slearly explained and prettily illustrated. 't is questionable whether anyt'ing on this 'ubject can be better adapted to its purpose, han Pancoast's Operative Surgery." - Saurday Courier.

\section{III.}

\section{GODDARD ON THE TERTII.}

THE

\section{ANATOMY, PHYSIOLOGY,} AND DISEASES OF THE

\section{TEETI AND GUMV,}

WITH THE MOST APPROVED METHODS OF TREATMENT, INCLUDING OPERATIONS,

AND A GENERAL ACCOUNT OF THE METHOD OF MAKING AND SETTING

\section{Artificial Teet th.}

By PAUL BECK GODDARD, M. D., Professor of Anatomy and Histology in the Franklin College of Philadelphia.

In One 4to. Volume, illustrated by 30 beautifully executed Plates, each containing Numerous Figures,

handsomely bound in cloth.

Price Six Dollars.

Uniform with "Quain's Anatomy," "Pancoast's Surgery," and "Moreau's IIidwifery."

" We do not possess a modern work on Dental_Surgery, written by a British Au- thor, which equals tliat of Dr. Goddard. One reason for this may arise from the circumstance, that the learned author is a practical anatomist, whose knowledge is on a level with the moderu discoveries, and who has himself authenticated the latest researches into the minute anatomy of the dental structure. It is quite apparent that such knowledge must prove of immense value in enabling any one to arrive at just conclusions relative to the diseases of the teeth; and it is chiefly to be attributed to the want of such knowledge that most writers on Dental Surgery have erred so much relative to the causes and nature of these diseases. The work may confidently be recommended, as containing the best and most approved methods of performing all the operations connected with Dental Surgery.

"We cannot close our remarks without adverting to the thirty very beautiful lithographs which illustrate the text. They render it quite impossible to misunderstand the author, and afford a very favorable example of the advanced state of the Art on the American Continent." - Edinburgh Medical and Surgical Journal, 1814.

\section{IV.}

\section{MOREAU'S}

\section{Great Work on Mid wifery}

A PRACTICAL TREATISE

EXHIBITING THE PRESENT ADVANCED STATE OF THE SCIENCE.

BY F. G. MOREAU.

Translated from the French

BY T. FOREST BETTON, M. D., AND EDITED

BY PAUL BECK GODDARD, M.D. The whole illustrated by Eighty splendid Prarto Iolates, WHICH ARE EITHER

\section{The Size of Life,}

\section{OR EXACTLY HALF THE SIZE.}

Upon which the first artists have been employed, and which are fully equal,

if not superior, to the original, and the publishers can safely pronounce it

THE MOST SPLENDID WORK ON MIDWIFERY EVER PUBLISHED.

Now complete in one large 4to. volume, of the size of "Quain's Anatomy." "Pancoast's Surgery," and "Goddard on the Teeth."

Price TEN DOLLARS, full bound in cloth

"The work of Professor Moreau is a treasure of Obstetrical Science and Prac. 


\section{A. HART'S STANDARD MEDICAL WORKS.}

tice, and the American edition of it an elegant specimen of the arts." -Medical E.rominer, August, 1811.

A splendid quarto, containing cighty lithographic plates, true to the life, lias been some weeks before us-but we are groping our way through a mass of new works, with a full expectation of soon doing justice to the merits of this elaborate and truly neantiful work."-Boston Med. and Surg. Journal.

"Norean's treatise is another valuable work upon the science of Midwifery, with eighty of the most splendid lithographie plates we have ever seen. 'THESF II,LUSTRATIONS ARF FNGRAVED WVITH SO MUCH BFAUTY AND ACCURACY, AND UPON SO I.ARGE $\Lambda$ SCALF, that they cannot fail to present to the eye the precise relation of the fotus and of the parts engaged in labor, under every condition and ciremmstance, from the commencement of the state of natural parturition, to the most difficult and complicated labor. 'The profession are greatly indebted to French industry in pathological and special anatomy for the continned advance in the science of Obstetrics; and the work before us inay be regarded as the comple. tion of all that has accumulated in this department of medical science, greatly enhanced in value hy many valuable original suggestions, to the proper arrangement of which the author has devoted at great amount of labor. 'The translation is faithfully and elegamtly done, and the work will be a vuluable addition to the medical literature of our countsy." New YorkJournal of Medicine.

\section{$\mathrm{V}$. \\ A THEORETICAL AND}

\section{PRACTICAL, TREATISE} ON THE.

\section{DISFASES OP TIE STIM, B Y P. RA Y E R, M. D. \\ Physician to La Charite Hospital.}

From the second Fdition, entirely remodeled. With Notes and other Additions,

BY JOHN BELL, M. D.

Fellow of the Collere of Pliysicıans of Philadelplia, Member of the American

philosephical socicty, and of the

Gengofili siociety of Florence, and Elitor of $13 \mathrm{ell}$ and Stokes' Practice of MLdieme, de. Se

In One Royal dio. Tolume.

With Forty Beautifully Colored Plates, COMPRISING FOUR IUNDRED SEPARATE ILLUSTRATIONS,

Carefully Colored from Nature, and 450 pages of Letterpress.

Handsomely bound in Cloth Gilt. Price $\$ 15 u(1$
Opinions of the Press.

"VTe take leave of our author with the declaration that his work is a monument o. the most cxtraordimary industry. We have no hesitation in adding that it is the best book we possess in any language on the subject; and that should any of our readcrs desire to suil over the unbounded sea of letterpress formed of the history and pathology of the discases of the cutancous surface, Mr. Rayer should be his pilot."

Or tile Plates. - "Considered in this respect, but more especially in reference to the number of illustrations of the general species and varieties of such order which it contains, this Allas far surpasses any that has yctappeared. ON THE WHOLE R.A YEI'S ATLAS MAY CONSCIENTIOUSLY BE SAID TO CONTAIN THE MOST COMPLETE SERIES OF II.LUSTIATIONS OF CUTANEOUS 1)ISEASES HITIERTO PUBLISHE 1 , ANI IS, TESIDES, not only cheaper than any other, but well worth the smin for which it is offered to the profession." british and Foreign Mredical kevew.

\section{A PRACTICAL TREATISE} ON TIIE

\section{DISEASES OP THE TESTIS,}

\section{AND OF TIIE \\ SPERMATIC CORD AND SCROTUM, \\ BY J. B. CURIING. \\ Edrted ay P. B. GODDARD, M. D., With fifty-four Illustrations, engraved on Wood by Gilbert; and printed on large type and fine paper. \\ IPice $\$ 300$.}

"We have another instance of it in the work of Mr. Curliug, a diligent Inborer, who lias carefully collected every fuct within his reach, relative to the diseases of the 'l'estis and Spermatic Cord, Producing A VOLUMR TIIAT MAY FOR MANY YEARS BE TIE STANDARD WORK ON THOSE Diseases. IVe shall conclude our notice with nn extract relative to a new and promising method of treating varicose veins, and take leave of the volune by warmly recommending that it be added to the library of every sulgeon." - London Lancet, August, $1=43$.

\section{RICOR}

ON EXTREME CA SES O F

\section{VENEREAL DISEASES}

\section{Curcal at the rencreal Mospital at Furis,}

Ender the direction of Dr. Pr. Rrconn, with 276 clngantly colourel engravings, in one rolume quarto, uniforu with "Quain's Anatomical Plates," "l'anconst's Cperatire Sur Bery," de. I'rice \$ 15.00 cluth, gilt. 


\section{PRINCIPLES}

AND

\section{PRACTIEE OF MEDICINR.}

BY JOHN ELLIOTSON, M.D., F.R.S.

Complete in One Vol. of 1050 pages.

Price Three Dollars and Fifty Cents.

WITI NOTES AND ADDITIONS, ADAPTING IT TO TIIE UNITED STATES.

BY THOMAS STEWARDSON, M. D.,

Physician to the Pennsylvania Hospital.

The American Editor has introduced entirely new articles upon

\section{Remittent Fever, and Yellow Fever,}

As well as considerable additions to the article on Continued Fever.

"Unde: such circumstances we cannot but congratu'ate the profession in this country that it has now been placed within their reach, under the auspices of an editor whose ample experierce and especial study of fevers, have enan'ed him to add several chapters and notes, which matcrially enhance the usefulness of this treatise. We refer, in particular, to Dr. Stewardson's chapter on Remittent and Yellow Fevers, diseases so prevalent in many secLons of this country, and which had re?eived but very cursory notices in the original work. Dr. Stewafdson has given an account of Cholera Infantum, a disease peculiar to this country, and which, therefore, really attracts the attention of Furopean writers."-American Medical Journal, January, 1844.

"Engaged in the preparation of this work. there were four pliysicians, each one of whose names, where known, is a guarantee that the proauction is worthy the atten. tion of the whole medical public; and it is only reasonable to infer that their joint labors have furnished a PRACTICE OF MEDIcINe as complete as any other extant.Those who examine the volume will not be disappointed, for it is a very excellent book to read, to refer to, or to study as a text-book. The style is familiar, chaste and succinct; the matter is well arranged, the index (a matter of no small importance) is unexceptionable, and the etymologies of technical words are given in foot notes.In England, the volume is extensively used as a text-book, and it is fair to anticipate that it will be a favorite among students in the United States. The additions made by Dr. Stewardson, the Physician of the Pennsylvania Hospital, are very valuable; his chapters on remittent and yellow fevers, are more satisfactory than any similar treatise we, at this moment, remember to have seen. He is evidently a man who has carefully added judıcious study to no inconsiderable experience, the severe touclistone of theory in medicine, and has enjoyed full opportunity of knowing the correctness of his views." - Baltimore Palriot.

\section{COURSE OF ENGLISII READING;}

ADAPTED TO EVERY TASTE AND CAPACITY By tHe Rev JAMES PYCIROFT, B. A T'rinity College, Oxford.

Author of "Greek Grammar Practice," "Latin Grammar Practice," \& c.

Price $12 \frac{1}{2}$ Cents.

Complete in One Volume.

"A volume which we can conscientiously recommend, as marking out an accurato course of historical and general reading from which a vast acquisition of sound knowledge must result. The arrangement and system are no less admirable than the si:lection of authors pointed out for study." Literary Gazette.

" We do not know of a better index than this well-considered little book to a general course of reading. It might, as such, be safely and advantageously put into the hands of all young persolls who have finislied their education, and are about to take their place in society, or to begin the world." -Atlas.

\section{LATIN GRAMIMAR PRACTICE.}

In Three Parts: 1. Lessons of Vocabulary of all the IVords in "Valpy's Cresar," arranged according to roots, terminations, and other peculiarities; 2. Construing Lessons corresponding with Part I., exemplifying Latin Accidence and Syntax. and lilustrating Roman History ; 3. Easy English Exercises. corresponding with the Lessoris, and formea ority of the IVords of Parts I. and II.; also exemplifying Latin Accidence and Syntax.

\section{By tir REv. JA MES PYCROFT, B. A}

In One Vol. $12 \mathrm{mo}$. Price 50 Cents.

"MIr. Pycroft's plan is a good one, and well calculated to aid the pupil, and to supersede, with the utmost safety, so far as it goes, the endless labor of the Lexicon and Dictionary."-Atlas.

\section{GREEI GRAMIIIAR PRACTICE,}

\section{IN THREE PARTS}

1. Lessons of Vocabulary of more than Two Thousand IVords from Xenophon's "Anabasis," arranged accordıng to roots, terminations and other peculiarities; 2 . Construing I essons corresponding with those of Part I., exemplifying Greek Accidence and Syntax; also the greater part of the "Anabasis," Book I.; 3. Easy English Exercises, corresponding with the Lessons, and formed only of the IVords of Parts I. and II., also exemplifying both Accidence and Syntax.

By the REv. JAMES PYCROFT, B A., In One Vol.12mo. 50 Cents.

"The plan s excellent, and will tend greatly to facilitate the acquisition of the two languages. By diligent practice in these lessons and vocabularies, the pupil becomes progressively master of all the difficulties that obstruct his early progress, and gradually attains to a well-grounded knowledge, and consequent relish, of the beauties of the Greek and Latin idioms, ' John Bull. 


Deacidified using the Bookkeeper process.

Neutralizing agent: Magnesium Oxide

Treatment Date: September 2012

2)

PreservationTechnologies

A WORLD LEADER IN COLLECTIONS PRESERVATION

111 Thomson Park Drive

Cranberry Township, PA 16066

(724) $779-2111$ 



\section{LIBRARY OF CONGRESS}

|||||||||||||||||||||||||||||||||||

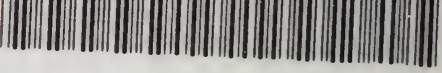

\section{6}

